UNIVERSITY OF COLORADO

\title{
Risk Perception and Effective Communication of Consequences for US Natural Hazards
}

\author{
By \\ Daniel Oliver \\ B.S., Northern Arizona University, 2008
}

\begin{abstract}
A thesis submitted to the Faculty of the Graduate School of the Civil Engineering Department of the University of Colorado in partial fulfillment of the requirement for the degree of Master of Science
\end{abstract}

Spring 2013 
This thesis entitled:

Risk Perception and Effective Communication of Consequences for US Natural Hazards

\author{
Written by Daniel Eric Oliver
}

has been approved for the Department of Civil Engineering
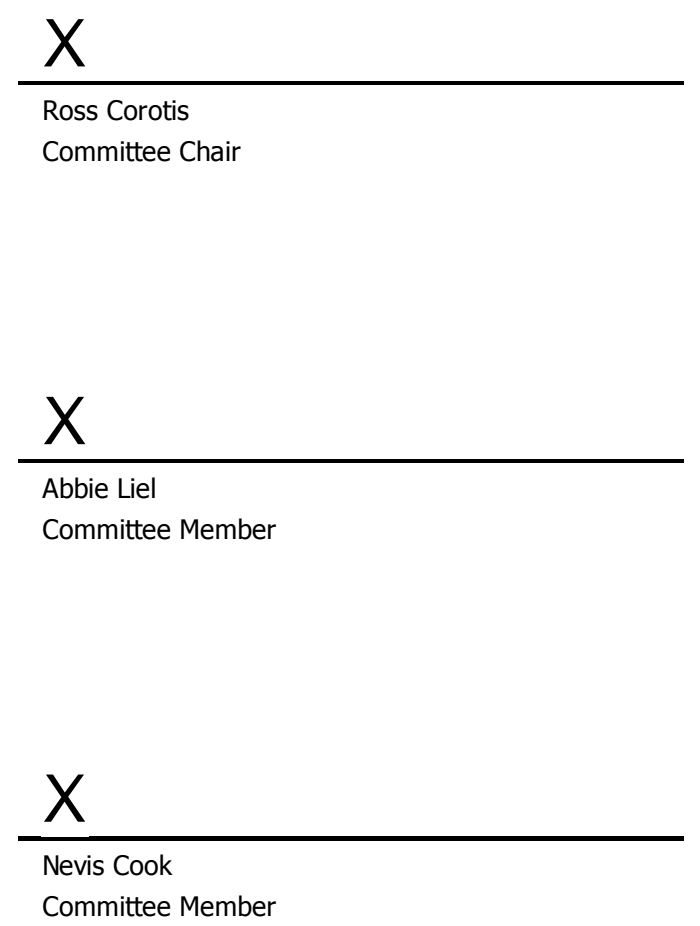

Date

The final copy of this thesis has been examined by the signatories, and we find that both the content and the form meet acceptable presentation standards of scholarly work in the above mentioned discipline. 
Oliver, Daniel Eric (M.S. Civil Engineering)

$\underline{\text { Risk Perception and Effective Communication of Consequences for US Natural Hazards }}$

Thesis directed by Professor Ross B. Corotis

The type of natural hazard, frequency of occurrence, and their range of consequences have an enormous influence in shaping a person's perceptions of risk. This research demonstrates that risk perception plays a large role in determining future mitigation decisions as well as behaviors of individuals and society. Integrating perception factors of dread and familiarity into risk communication has the potential for the development of improved mitigation plans to enhance resilience from natural hazard events. Utilizing a 50-year database of the United States, this paper identifies the consequences of the most significant natural hazards. Graphs and charts are used to convey this crucial information to stakeholders on a regional basis, enabling informed natural hazard policy decision-making. In addition, this research presents a new method of assessing natural hazard risk through the creation of 'hazard region' maps. This allows local and state governments to visualize natural hazards that result in the largest impact and helps prioritize efforts for reducing overall losses. 


\section{Table of Contents}

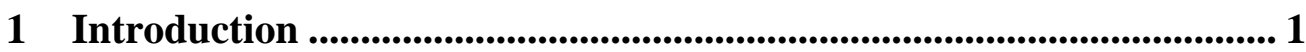

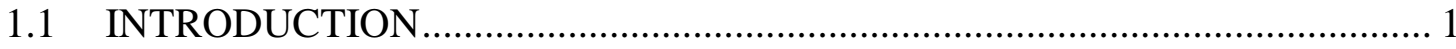

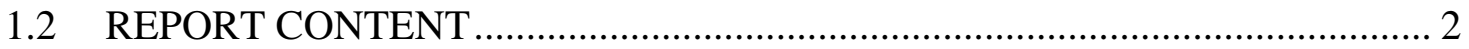

2 Natural Hazards Background ....................................................................... 4

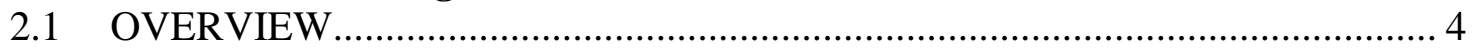

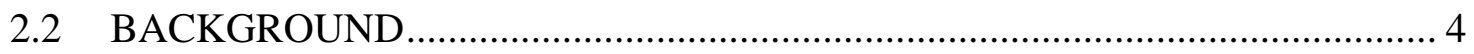

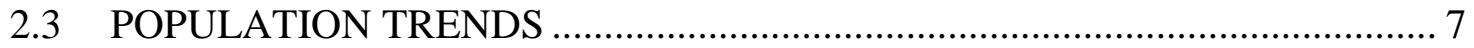

2.4 NATURAL DISASTER DECLARATIONS ................................................... 8

2.5 INADEQUATE MITIGATION PLAN IMPLEMENTATION ………................. 11

3 Perception of Risk........................................................................................... 13

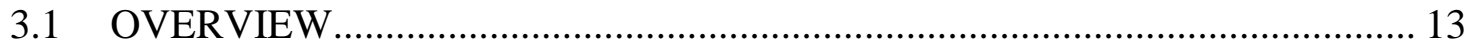

3.2 RISK PERCEPTION FACTORS .......................................................... 13

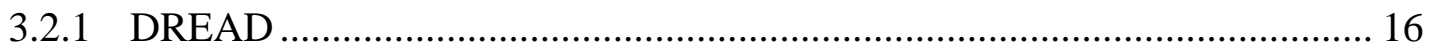

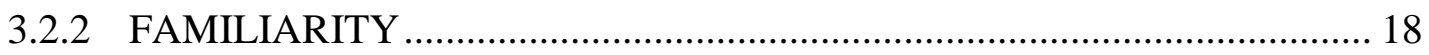

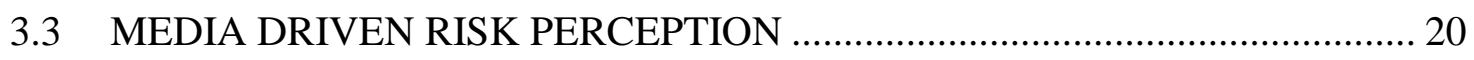

3.4 SURROGATE MEASURE OF RISK PERCEPTION ...................................... 21

4 Making Decisions Under Uncertainty......................................................... 23

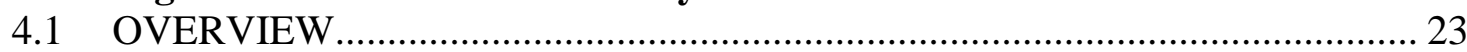

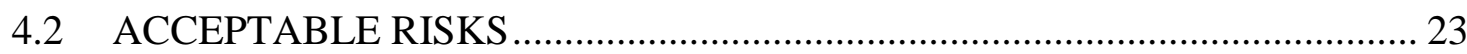

4.3 EXPECTED VALUES VERSUS EXTREME VALUES ................................. 27

5 Natural Hazard Analysis Process.................................................................... 30

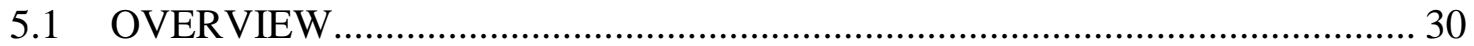

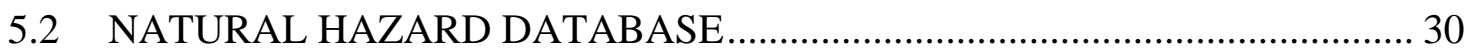

5.2.1 LOSSES DUE TO FATALITY AND INJURY ……….............................. 32

5.2.2 DIRECT ECONOMIC LOSSES............................................................. 34

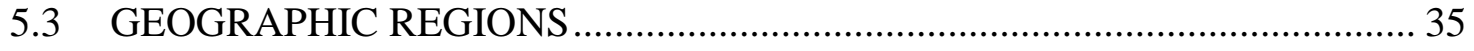

5.4 REGIONAL DATA PRESENTATION....................................................... 37

6 Pacific Regional Analysis ............................................................................... 41

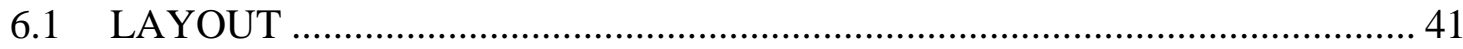

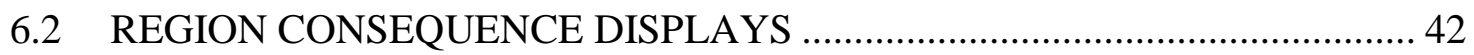

6.3 REGION CONSEQUENCE RANKINGS ................................................ 48

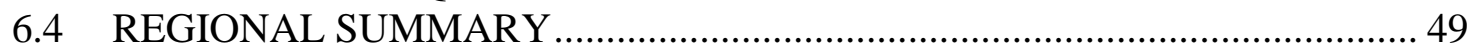

7 Mountain Regional Analysis...................................................................... 51

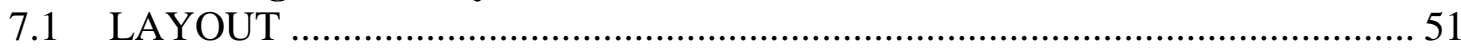

7.2 REGION CONSEQUENCE DISPLAYS ………................................... 52

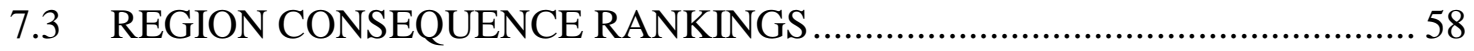

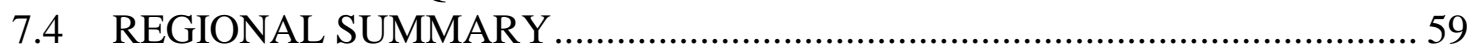

8 Southwest Regional Analysis ..........................................................................60

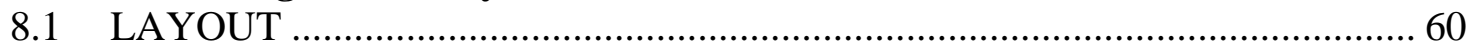

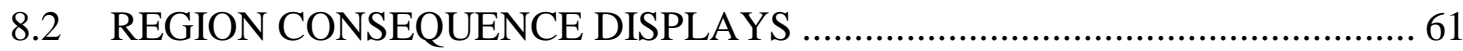

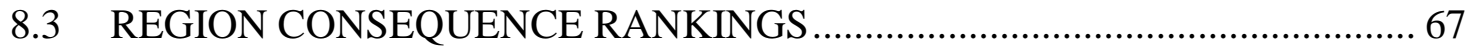

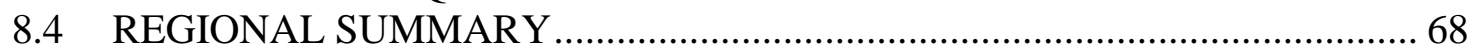

9 Plains Regional Analysis ..................................................................................... 70

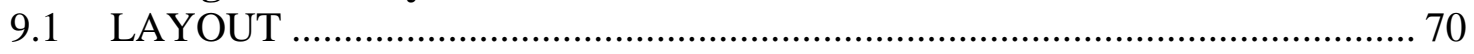

9.2 REGION CONSEQUENCE DISPLAYS ………........................................ 71 


\section{Table of Contents}

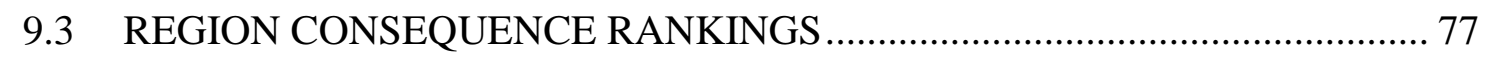

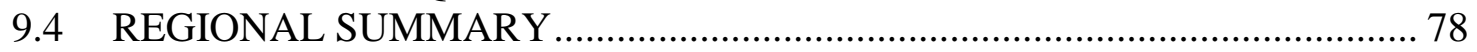

$10 \quad$ Great Lakes Regional Analysis......................................................... 79

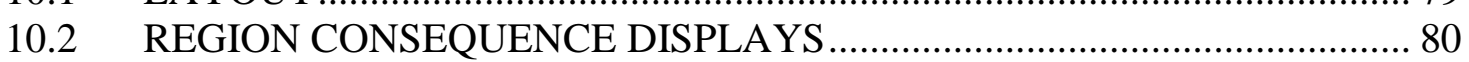

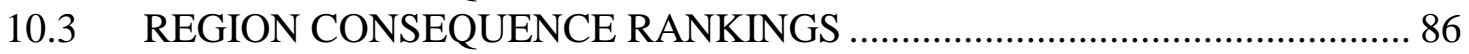

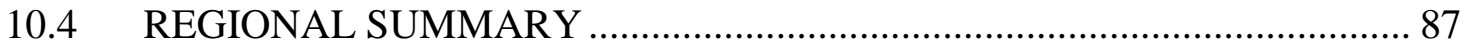

11 Southeast Regional Analysis .............................................................. 88

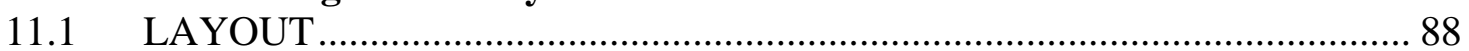

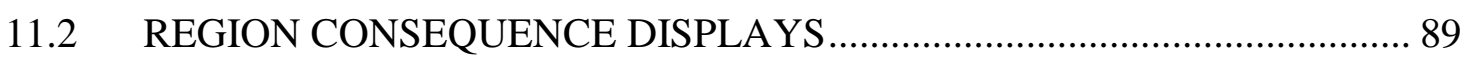

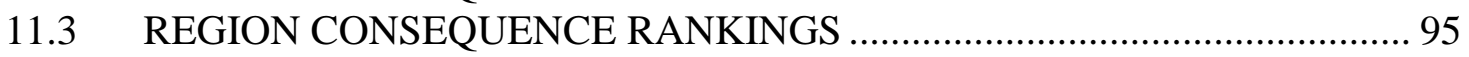

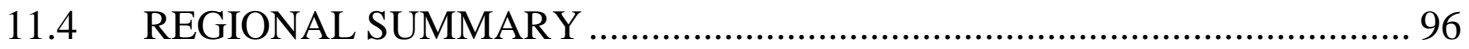

12 Mid-Atlantic Regional Analysis..................................................... 97

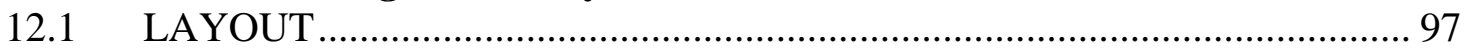

12.2 REGION CONSEQUENCE DISPLAYS ................................................... 98

12.3 REGION CONSEQUENCE RANKINGS ………...................................... 104

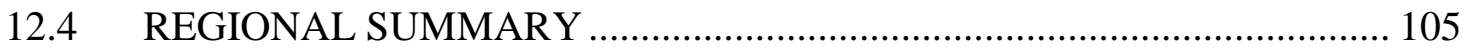

13 New England Regional Analysis .................................................. 106

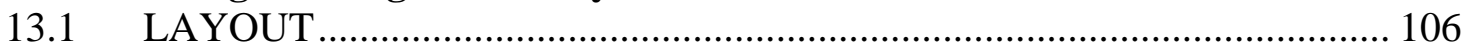

13.2 REGION CONSEQUENCE DISPLAYS .................................................... 107

13.3 REGION CONSEQUENCE RANKINGS ……...................................... 113

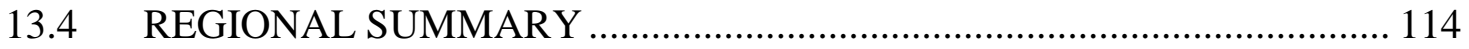

14 US Natural Hazard Conclusions ......................................................... 115

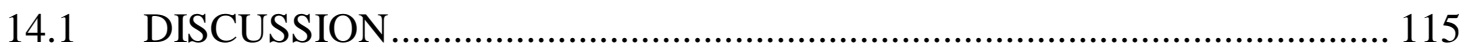

$15 \quad$ Natural Hazard Regions....................................................................... 118

15.2 DEVELOPMENT OF HAZARD REGIONS........................................ 118

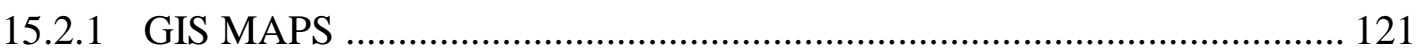

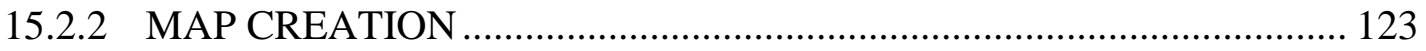

15.3 HAZARD REGION EXAMPLES …………........................................ 124

15.3.1 EARTHQUAKE HAZARD CONSEQUENCE: SAMPLE MAP ............. 124

15.3.2 HURRICANE HAZARD CONSEQUENCES: SAMPLE MAP ............... 125

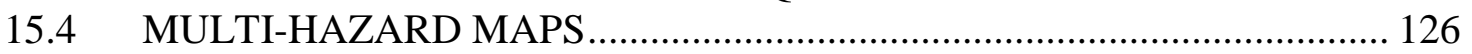

15.4.1 SOCIAL VULNERABILITY INDEX............................................... 129

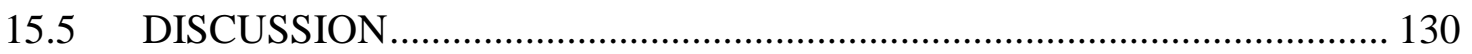

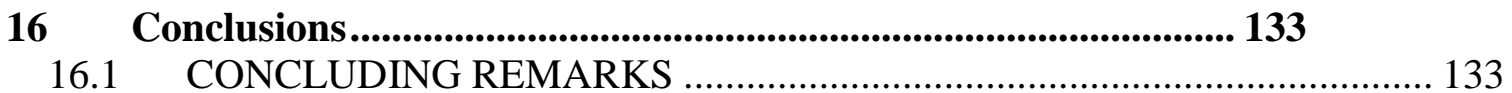

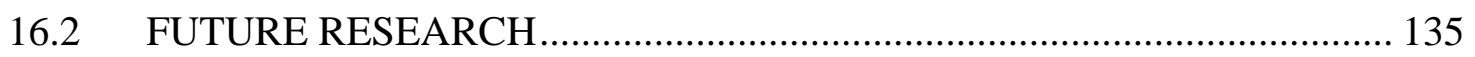

17 Bibliography ............................................................................................. 137 


\section{List of Tables}

Table 6-1: Pacific region injury consequence tables ............................................. 42

Table 6-2: Pacific region fatality consequence tables.............................................. 44

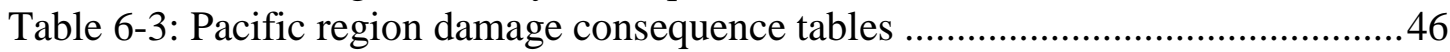

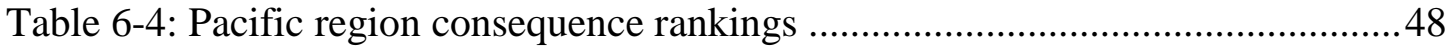

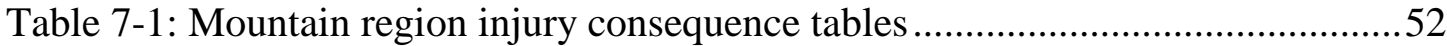

Table 7-2: Mountain region fatality consequence tables ..........................................54

Table 7-3: Mountain region damage consequence tables .........................................56

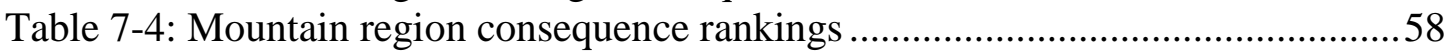

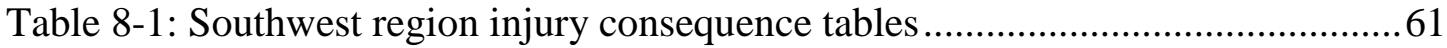

Table 8-2: Southwest region fatality consequence tables ......................................63

Table 8-3: Southwest region damage consequence tables .....................................65

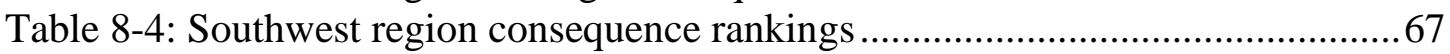

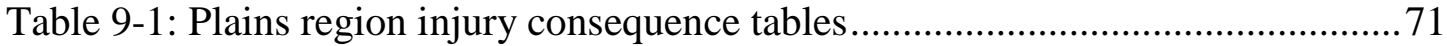

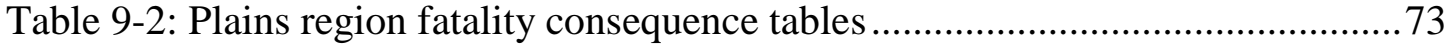

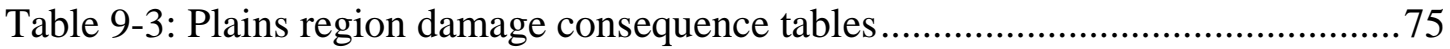

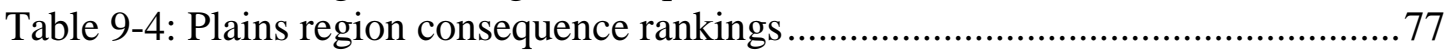

Table 10-1: Great Lakes region injury consequence tables ................................... 80

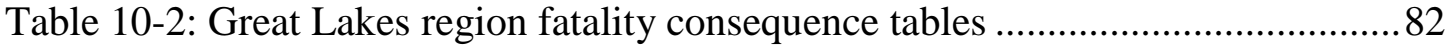

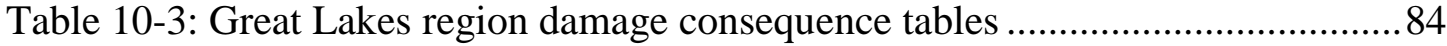

Table 10-4: Great Lakes region consequence rankings .............................................. 86

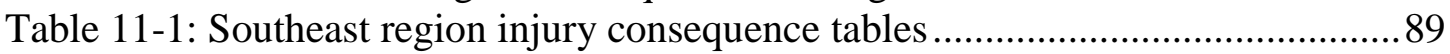

Table 11-2: Southeast region fatality consequence tables ....................................... 91

Table 11-3: Southeast region damage consequence tables .....................................93

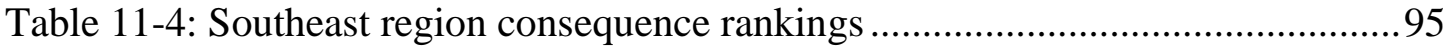

Table 12-1: Mid-Atlantic region injury consequence tables......................................98

Table 12-2: Mid-Atlantic region fatality consequence tables................................... 100

Table 12-3: Mid-Atlantic region damage consequence tables................................ 102

Table 12-4: Mid-Atlantic region consequence rankings.......................................... 104

Table 13-1: New England region injury consequence tables.................................. 107

Table 13-2: New England region fatality consequence tables................................ 109

Table 13-3: New England region damage consequence tables ............................... 111

Table 13-4: New England region consequence rankings ..................................... 113 


\section{List of Figures}

Figure 2-1 US damage costs from weather related hazards (NOAA 2011) .................5

Figure 2-2: US locations of billion dollar weather disasters (NOAA 2011) .................5

Figure 2-3 US Population 2000-2010 (US Census Bureau 2011) ............................. 8

Figure 2-4 US disaster declarations count and by hazard type (FEMA 2003) ............ 10

Figure 4-1: FN-curves that represent the maximum acceptable risk for technologies

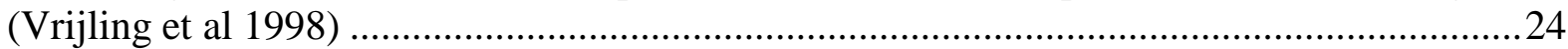

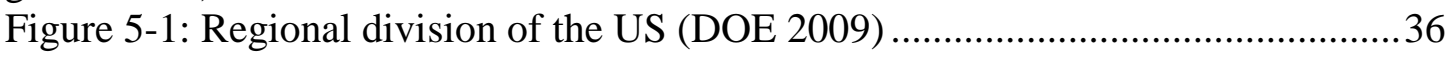

Figure 5-2: Gross Domestic Product by state in 2008 (Coakley, Reed and Taylor 2009)

Figure 5-3: Example of Pacific region total consequence graph .............................. 38

Figure 5-4: Example of Pacific region total consequence contribution chart..............39

Figure 5-5: Example of Pacific region maximum event influence on average............ 40

Figure 6-1: Pacific region injury consequence graphics ....................................... 43

Figure 6-2: Pacific region fatality consequence graphics ....................................45

Figure 6-3: Pacific region damage consequence graphics .......................................4 47

Figure 7-1: Mountain region injury consequence graphics ....................................5 53

Figure 7-2: Mountain region fatality consequence graphics....................................55

Figure 7-3: Mountain region damage consequence graphics ..................................57

Figure 8-1: Southwest region injury consequence graphics ..................................62

Figure 8-2: Southwest region fatality consequence graphics .................................64

Figure 8-3: Southwest region damage consequence graphics ..................................66

Figure 9-1: Plains region injury consequence graphics ......................................... 72

Figure 9-2: Plains region fatality consequence graphics ...................................... 74

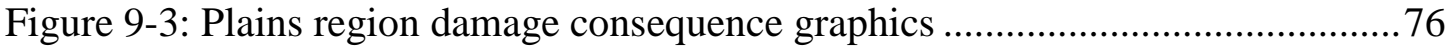

Figure 10-1: Great Lakes region injury consequence graphics .............................. 81

Figure 10-2: Great Lakes region fatality consequence graphics............................... 83

Figure 10-3: Great Lakes region damage consequence graphics............................... 85

Figure 11-1: Southeast region injury consequence graphics ................................. 90

Figure 11-2: Southeast region fatality consequence graphics.................................92

Figure 11-3: Southeast region damage consequence graphics ..................................94

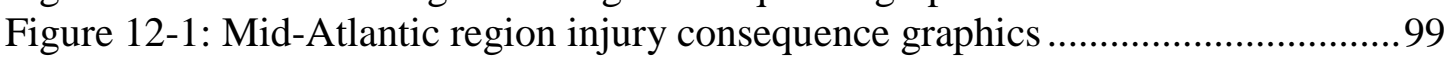

Figure 12-2: Mid-Atlantic region fatality consequence graphics ............................. 101

Figure 12-3: Mid-Atlantic region damage consequence graphics ........................... 103

Figure 13-1: New England region injury consequence graphics .............................. 108

Figure 13-2: New England region fatality consequence graphics ........................... 110

Figure 13-3: New England region damage consequence graphics .......................... 112

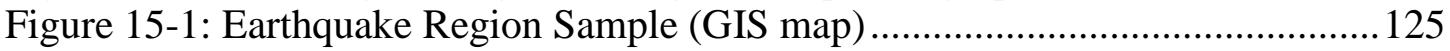

Figure 15-2: Hurricane Region Sample (GIS map) ............................................ 126 


\subsection{INTRODUCTION}

Due to increased population concentrations and uncertainties associated with climate change, natural disasters and their ramifications are a growing concern for communities and governments throughout the world. In the United States, there has been an especially significant migration toward higher risk regions, with a resulting focus on the importance of hazard mitigation. It is valuable, therefore, to examine the consequences associated with natural hazards in different regions of the country with a goal of educating the public in preparation for effective mitigation action. Successfully communicating risk factors to the public is a necessary first step in reducing the overall damage, injuries and fatalities.

This study utilizes a 50-year natural hazard database for the United States (HVRI 2009) to summarize the consequences from 13 major natural hazards in eight geographic regions of the country. Histograms of injuries, fatalities, property loss and crop loss from natural hazards on a per-event basis have been developed in a prior study (Jones and Corotis 2012). While this information from the histograms is crucial in providing guidance to state and local decisionmakers when they are preparing mitigation plans, it can be overlooked by those in decisionmaking roles because of the vast quantity. The research described in this paper transforms the basic statistical data into summary displays that are based on the factors that are central in socialpsychological studies of risk perception (Slovic 2000). The frequency of individual types of hazards and the range of consequences on a per-event basis in terms of injuries, fatalities and financial impact are metrics related to the fundamental risk perception factors of dread and 
familiarity discovered by Slovic. Integrating dread and familiarity measures into risk communication has the potential for the development of improved mitigation plans to enhance resilience from natural hazard events. Combining the perception of risk with historical data provides the means to evaluate the hazards in each region of the United States. This prioritizes efforts in reducing the overall losses from major natural hazards in each region.

In addition to analyzing risk through graphs and charts, this research suggests a new approach to assess natural hazard risk. Rather than evaluating risk by projecting natural hazard consequences into political or state borders, boundaries should be created based upon specific types of hazards. The resulting regions are defined as 'hazard regions', and used to distinguish a hazard's primary influence area in terms of consequences. This will help focus mitigation efforts in the counties that are most vulnerable to particular hazards that continue to have detrimental effects on communities. To further apply these hazard regions, this study proposes the creation of a multi-hazard GIS map by totaling hazard consequences in every county of the United States. This is a beneficial tool for passing local and state mitigation measures and is necessary to meet legislation requirements.

This study identifies the hazards that are the most significant with respect to damage costs, injuries and fatalities. Comparing the results helps determine how mitigation funding should be appropriated. This will ultimately lead to better preparation by communities and lessen the impact of hazards on quality of life.

\subsection{REPORT CONTENT}

This report examines the issue of risk analysis of hazard events in the United States. It addresses current trends of hazard events around the country, discusses the complications of 
planning and implementing hazard mitigation, provides regional risk assessments and proposes a new model for hazard mitigation analysis. First, Chapter 2 provides a background of the impact resulting from natural disasters and the need for implementing mitigation measures that reflect the changing climate and societal vulnerabilities. Then, chapters 3 and 4 address the primary risk perception factors that influence mitigation decision-making and explain why there is a need to consider the full range of hazard event possibilities from expected value to extreme values. Next, chapters 5 through 14 present, analyze, and draw conclusions of natural hazard data occurring over the last 50 years. Finally, in chapter 15, a new methodology for analyzing natural hazard risk is proposed based on establishing new regions according to a natural hazard's primary influence area. 


\section{Natural Hazards Background}

\subsection{OVERVIEW}

This chapter demonstrates the increasing impact that natural hazards have on society and recognizes some key factors that contribute to the rising damage costs in the United States. These factors include population relocation, the relationship between disaster declarations and population density, and a lack of local mitigation plan implementation. These factors explain why damages are increasing and emphasize a need for risk assessment tools for communities to create long-term mitigation strategies.

\subsection{BACKGROUND}

Natural disasters have extreme ramifications on society and quality of life. In the United States alone, data show that the frequency of disasters has tripled over the past 20 years. In 2012, there were 11 natural disasters that caused over \$1 billion in damages (NOAA 2011). In fact, according to Kellogg (2013), the combined direct losses from all natural hazards in 2012 were estimated to be $\$ 160$ billion dollars. Considering that these losses do not even take the indirect consequences into account shows that this undesirable trend has a much deeper impact than just what has been presented in current risk estimates based on long-term averages of direct costs.

In order to get a better sense of the impact that natural hazards have on society, billion dollar losses and locations in the US over the past 30 years are shown in Figure 2-1 and Figure 2-2, developed by the National Oceanic and Atmospheric Association (NOAA). 


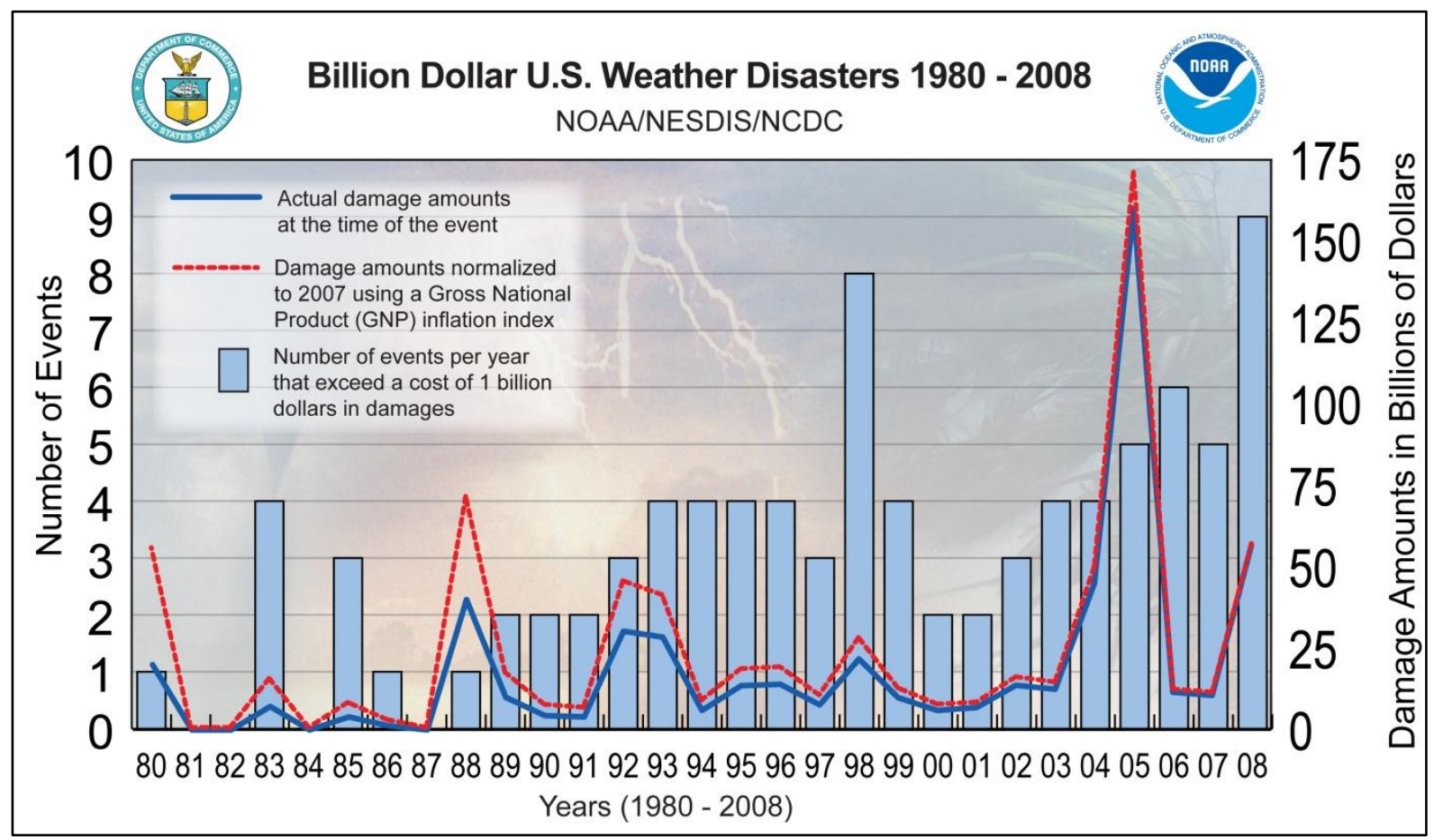

Figure 2-1 US damage costs from weather related hazards (NOAA 2011)

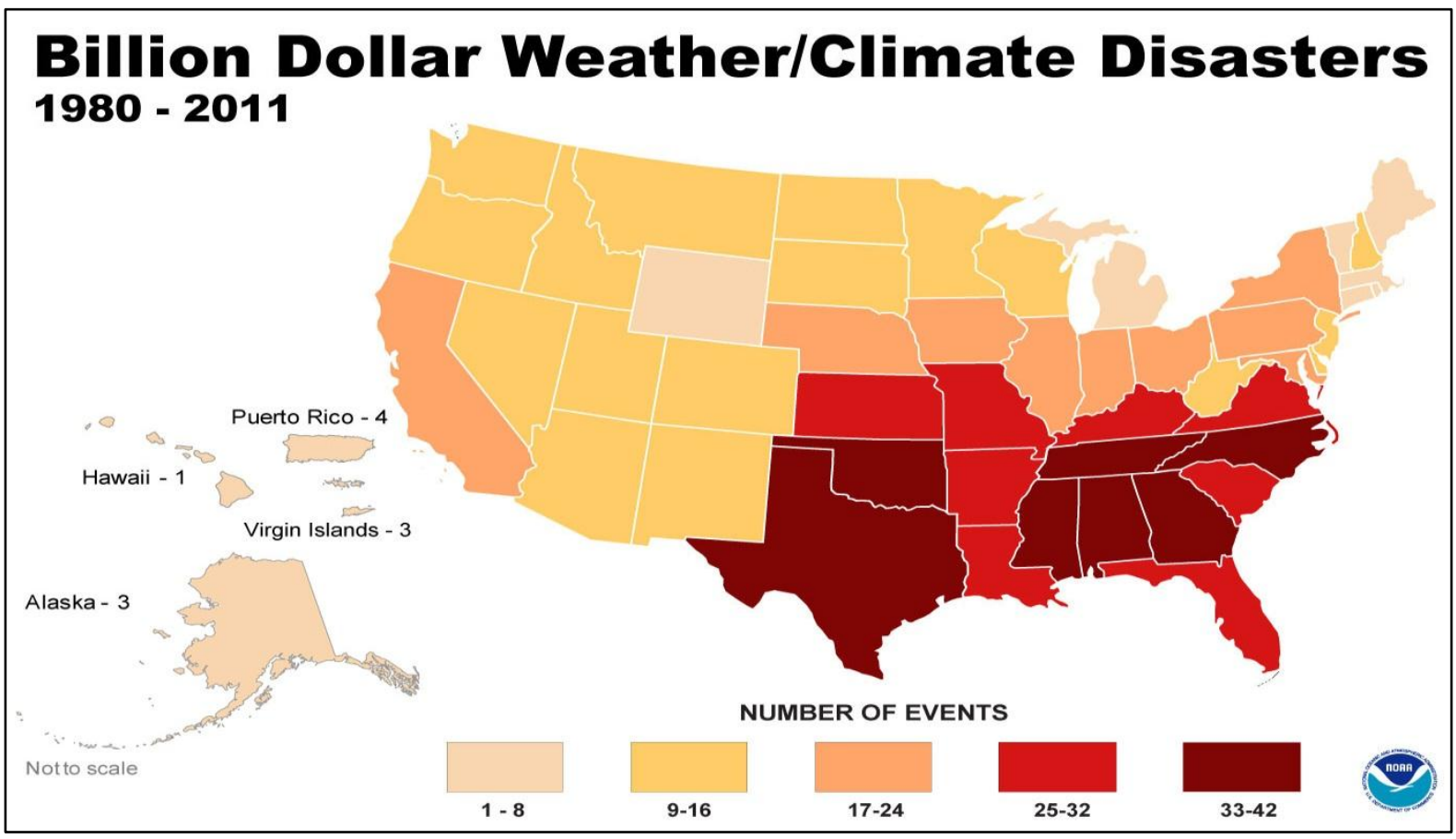

Figure 2-2: US locations of billion dollar weather disasters (NOAA 2011) 
The graph in Figure 2-1 reveals the increasing trend in both number and total direct damages from natural hazard events. It should be noted that the number of billion dollar loss events does not necessarily correlate with the amount of damages incurred from natural hazards in the same year. This is observed when looking at the years 1998 and 2005 separately. In 1998 there were 8 "billion dollar" events that contributed to $\$ 25$ billion in losses, while in 2005 , there were 5 "billion dollar" events that contributed to almost $\$ 175$ billion in losses. One of the largest contributors to the total damages in 2005 is Hurricane Katrina, which struck dense populations in and around the city of New Orleans, Louisiana. It resulted in an estimated $\$ 108$ billion of damage and affected more than 15 million people (Blake and Gibney 2011). This is one of the pivotal points in recent years that showed how vulnerable our society is to low probability, high consequence events and displayed how lack of planning and preparation led to the tremendous losses from the hurricane (Cutter, Johnson and Finch 2007).

Figure 2-2 supplements the previous graph by displaying the distribution of these billion dollar disasters on a GIS map of the United States. The central and southeast regions of the US are seen to have the largest number of billion dollar disasters, ranging between 25 and 42 events in the past 30 years. These two regions are among the highest in disaster totals due to the large populations in these regions as well as the increasing number and intensity of storms that are affecting this area (Emrich and Cutter 2011).

In the sections to follow, two explanations for the increasing losses over the past thirty years are examined. These factors are the increasing trends for population growth and migration to higher risk urban environments, and inadequate implementation of long-term mitigation planning. 


\subsection{POPULATION TRENDS}

One contributor to the increasing damages from natural hazards within the United States is the quantity of people moving to higher risk coastal regions. The counties that lie along the eastern and western seaboards of the US only account for 10 percent of the country's land mass, but are inhabited by almost 39\% of the total population, which corresponds to 124 million people (NOAA 2013). In the past forty years, these coastal developments have risen by $40 \%$ and are expected to increase by another 10 million people by the year 2020 .

Figure 2-3 created by the US Census Bureau in 2011, shows the result of this population relocation trend for every county within the US. The scale on this particular map displays counties with an upper scale of 300 or more people per square mile, but it should be noted that cities within these areas have much higher concentrations than the county average. For instance, cities such as New York and Los Angeles along the eastern and western seaboards have populations of thousands of people per square mile (US Census Bureau 2011).

This information on population is important to consider when discussing natural disasters because it shows that the large influx into cities along the coastal regions are a challenge to address when developing long-term mitigation planning. Recent disasters such as Hurricane Katrina and Super Storm Sandy demonstrate the enormous difficulties for evacuating millions of residences ahead of time and the on-going clean-up efforts that can last several months or even years afterward. While these communities have implemented measures after the fact, actions taken by all the coastal counties have been insufficient in mitigation efforts for future natural disasters, and consequently have been increasing the risk to those communities (Smith 2013). 


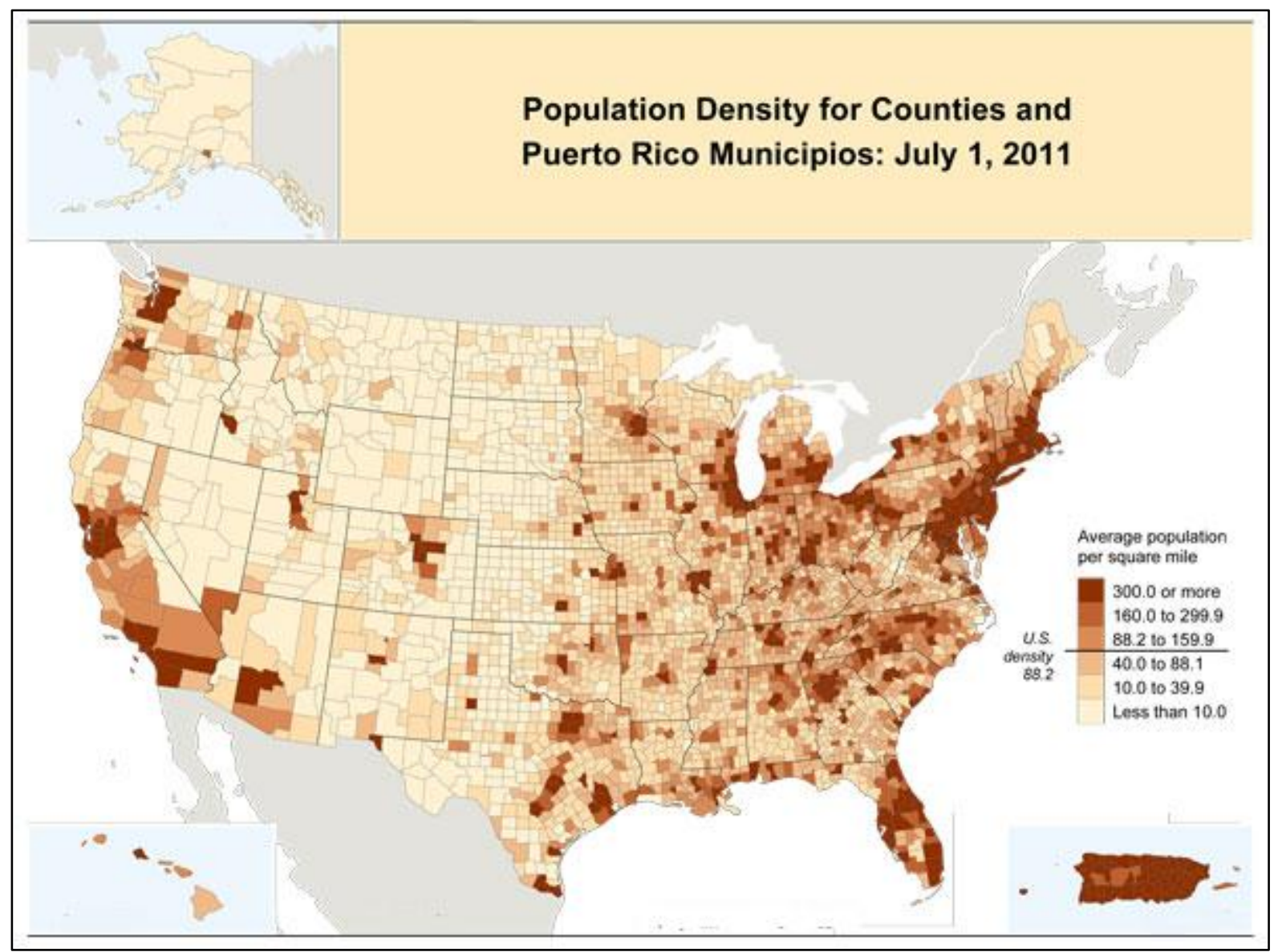

Figure 2-3 US Population 2000-2010 (US Census Bureau 2011)

\subsection{NATURAL DISASTER DECLARATIONS}

In an effort to provide monetary assistance to disaster-stricken areas after a natural hazard event, the Stafford Act was passed by the US Congress in 1988 to officially establish a process for obtaining a presidential disaster declaration (FEMA 2013). Through this act, state and local governments are able to request emergency relief aid from the federal government when a natural hazard overwhelms them. Since these disaster declarations began, FEMA has catalogued the number of disasters and the amount of aid given. Figure 2-4 shows the distribution of natural hazard declarations over a 40 year period (1965-2003), revealing a strong correlation between 
population density and frequency of presidential disaster declarations, thus suggesting that this is where risk mitigation measures need to be focused. Figure 2-4's color scale denotes counties with a high frequency of disaster declarations with darker colors and counties with low frequencies with lighter colors. Additionally, a pie chart supplements the map by providing the types of hazards that make up the declaration total over time. While the map does not indicate the amount of money dispersed to each county, it is observed that there are large amounts of disasters occurring along coastal counties where there are densely populated areas, and more than $75 \%$ percent of these are from flooding, severe storms, and hurricanes. This present study further examines the consequences associated with each type of hazard by region in order provide a way to prioritize these hazard's risks by the amount of losses. If proactive mitigation projects are implemented in these areas, then it is possible to reduce national long term natural hazard risk and spending.

An outlier to this trend is the number of counties that have a large amount of declarations granted, but do not have large populations associated with them, such as the northern plains regions around North Dakota. These outliers are primarily due to destructive flooding, severe storms, and tornado events (FEMA 2010), and may at least partially reflect political clout. The amount of funding distributed over time is still minimal compared to the disaster aid given to cities along the coasts, which often exceed $\$ 1$ billion. According to the calculations conducted in this study, the total direct damages in the Southeast region are $\$ 300$ billion over the past 50 years, whereas the Plains region encountered $\$ 60$ billion in damages, with almost half of the losses coming from crop damages. 


\section{Presidential Disaster Declarations}

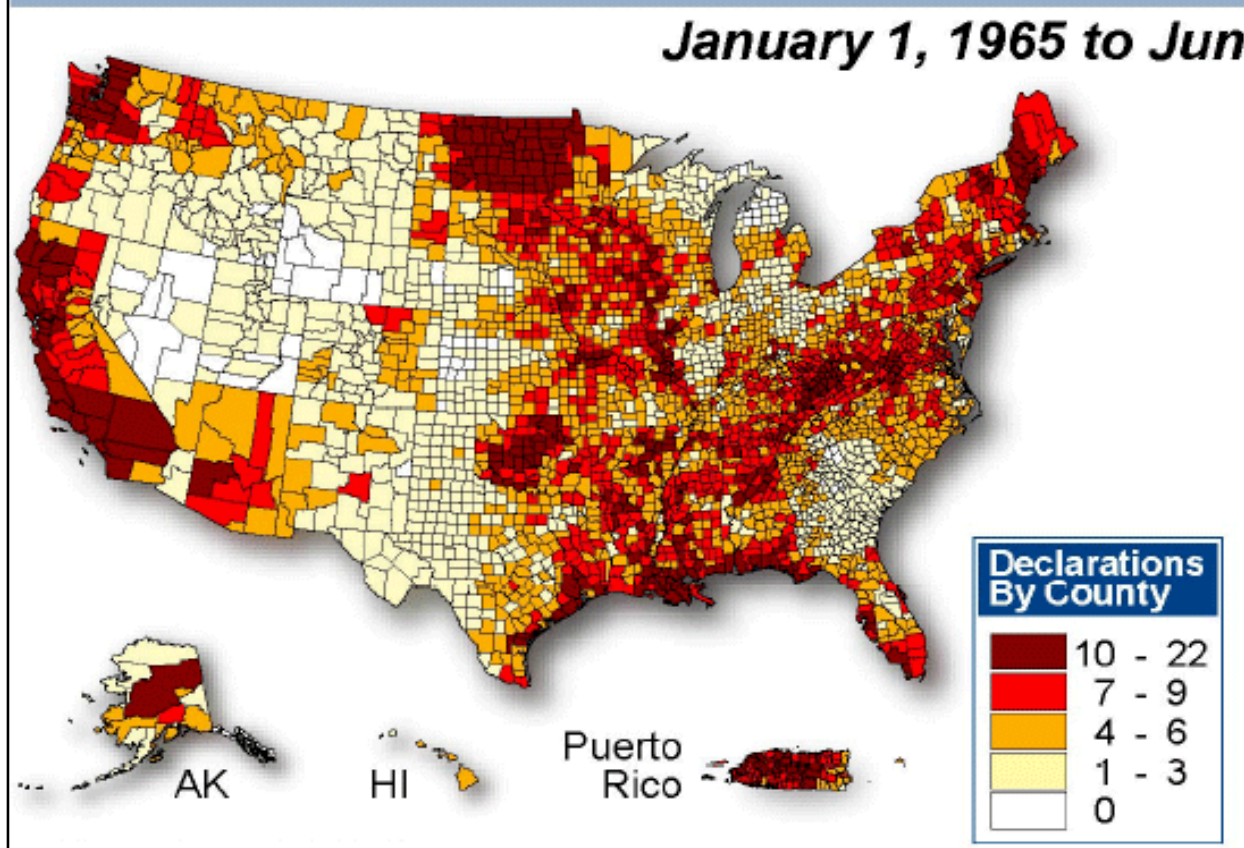

Mapped Total: $1,214^{\star}$

* Prior to January 1,1965, 185 declarations did not have county designations.

Therefore, of the total declared disasters $(1,399)$, only 1,214 are included in the Mapped Total.

\section{Disasters By Type}

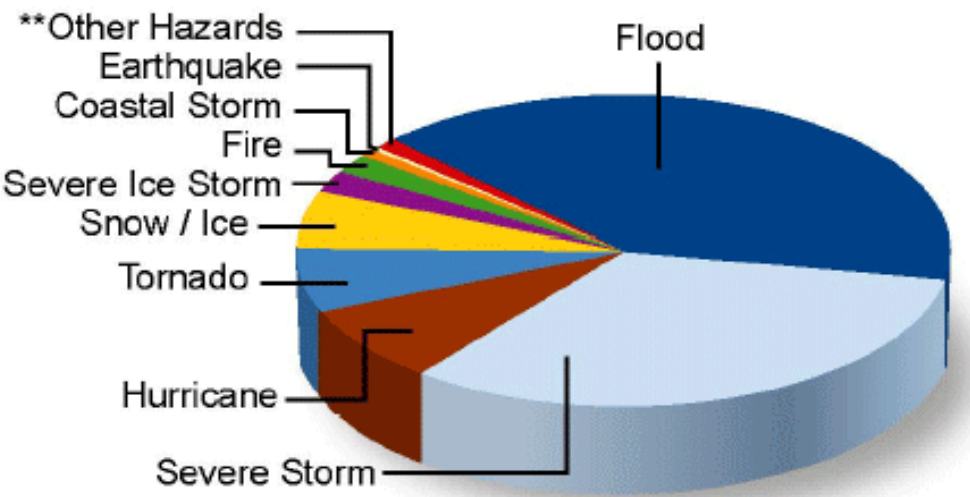

** Other Hazards include: Drought, Volcano, Other, Freezing, Mud/Landslide, Typhoon, Human Cause, Terrorist, Dam/Levee Break, Toxic Substances

Source: FEMA's National Emergency Management Information System

Figure 2-4 US disaster declarations count and by hazard type (FEMA 2003) 


\subsection{INADEQUATE MITIGATION PLAN IMPLEMENTATION}

The creation and implementation of effective mitigation plans is the primary tool that should be used to prepare for and offset losses for future natural disasters. Studies have shown that if mitigation measures are put in place prior to an event, every dollar spent yields four dollars in savings (FEMA 2007). Yet the failure to utilize these plans before a natural disaster occurs has been one of the driving forces behind the increasing amount of devastation seen by recent events along the eastern seaboard. Super Storm Sandy provides the latest example of how destructive these natural hazards can be when striking dense populations that are underprepared and where a majority of the building and land use codes are not aligned with standards that are known to reduce flooding hazards (Smith 2013). This disconnect between creating a plan and implementation will further cause increasing losses from these unlikely, catastrophic events unless society begins using the tools at its disposal to counteract them.

There is a strong need to improve mitigation plans and motivate communities to use measures to protect the public and reduce their vulnerabilities. To encourage local governments to create and adopt mitigation plans, the Disaster Mitigation Act of 2000 requires communities to have these plans in place before they can apply for and receive post-disaster aid immediately following an event (DMA 2000). In addition, once these mitigation plans are adopted by local governments, there are many incentives and grants available to begin projects to reduce their risks. Unfortunately, these funding resources have been underutilized in recent years because the plans that have been adopted lack connections between "the results of the risk assessment and the adoption of specific policies or projects designed to address identified threats" (Smith 2013). 
In the event of a disaster, communities have difficulty managing the large influx of funding and mainly focus on reconstruction of buildings to pre-event conditions rather than coordinating efforts to reduce their future risks by incorporating risk reduction measures.

Other problems identified by a previous study by the Department of Homeland Security include mitigation plans that lack land use policies to deter from building in high risk areas, and a link between risk reduction and climate change adaptation (Berke and Smith 2009). These plans are inadequate in many ways and need to incorporate defined goals and balance competing interests for the limited resources available.

The analysis completed in this study helps guide these decisions with better accuracy by showing the extent and range of losses over time for different regions in the US. By using the risk assessment summaries created, state governments are able to discern which hazards need to have the most funding allocated to them and the degree to which different types of hazards have impacted their states in the past. This research suggests that separate mitigation plans should be required to distinguish between extreme event planning and the frequent smaller events that impact communities. By doing this, local governments will be able to better coordinate actions after a natural disaster occurs and can better prepare their citizens beforehand in order to minimize losses in the future. 


\section{Perception of Risk}

\subsection{OVERVIEW}

To further understand why hazard losses are continually increasing, this chapter focuses on how societal risk perception plays a large role in our collective inability to implement longterm mitigation plans. Society's perception of risk has an enormous influence on our behaviors and decision-making processes. Incorporating these perceptions into risk communication is important so that people are able to see past their limited perspective and can begin taking steps forward to stabilize losses from natural hazards.

\subsection{RISK PERCEPTION FACTORS}

There are two fundamental ways in which people interpret risks in this world; one of which is objective and follows scientific methods, while the other is based on intuitive feelings and emotions (Slovic and Peters 2006). In the former, risk is quantified through calculation using statistical analyses, while the latter is based on subjective inference from past and imagined experience. With engineering practice, as in mathematics and science, risk is generally calculated by multiplying the likelihood of an occurrence by the consequences of that occurrence (Nafday 2009). The primary consequences that engineers consider are in terms of damage cost, fatalities, and injuries caused by hazards. This provides an unbiased and objective observation of the eventualities.

Engineers strive to reduce risks for both current and new infrastructure. Modern technology and computing power have given engineers the capability to analyze whole structures nonlinearly and design more robust structures. A study by Slovic (2000) demonstrates that 
infrastructure has one of the lowest perceived risks to society, and provides high beneficial value. Because social perceptions do not accurately reflect its importance, infrastructure is often undervalued in long-term mitigation decisions. It is important to understand the way people perceive risk so that communication of objective risk can be effective. The paradigm that people hold toward reducing risk is skewed to thinking that bigger and better technology will come along to reduce risks in the built environment (Tierney, Lindell and Perry 2001). Tierney (2001) indicates that engineers need to take a broader defined view for systems designed in society, stating, "Americans have acted as if risks can be completely overcome by massive engineered works such as the dams and levees used to control floods and the aqueducts employed to reduce drought vulnerability." This misunderstanding demonstrates the imperative to implement measures that bring perception of risk together with objective risks in order to get a holistic view of the problems that society face.

In order to synthesize actual risks with perceived risks, one needs to understand how people conceptualize risks and why they identify risks the way they do. When individuals are asked how risky a situation is without any clear reliable data on the subject, they depend on their past experiences, knowledge and emotions, reflecting how they feel about a certain activity (Slovic and Peters 2006). The event, action or technology will be deemed to have higher risks if the benefits appear low, and lower risks if the benefits are seen as being higher. There is a considerable bias in these risk estimates because they are obtained through subjective means. This is especially true if a particular hazard event has been personally experienced with resulting negative outcomes (Ripley 2008).

The formulation of higher levels of risk perception is directly linked to the biological process that occurs in an individual's brain during a traumatic event. Previous research shows 
that when experiencing a negative or unfamiliar event, neurons become activated in the temporal lobe of the brain to imprint fine details into a person's memory (Cleary 2010). Neurons called amygdalae regulate stress hormones which allow people to learn and unlearn what to fear over time. During particular catastrophic or potentially fatal scenarios, these neurons are sent into overdrive and begin to etch every detail of information into memory storage banks (Ripley 2008). This is the cause for immobility and shock that people recall experiencing during an event. It is also the reason why people are able to remember events vividly years after their occurrence. This is important to consider because it can result in an overreaction and divert limited resources to reducing risks that are perceived to be high. There needs to be a balance between these perceptions and objective reasoning to better allocate funding in order to reduce losses over time.

While personal experience is important to discuss during decision-making processes, experts need to convey the external factors that cause different risks and how influential they are. In regard to hurricane hazard mitigation, this can mean communicating to the public that land use should be limited along coastal regions because of the high risk of damage and fatalities in future storms. Once these are known, efforts can be made to reduce future consequences from potentially harmful incidents. When this information is effectively communicated to the public, they will have some background on the subjects and not have to take it on faith from the experts involved (Fischhoff and Kadvany 2011). This also builds the trust necessary for social cooperation and joint action for implementing mitigation measures and preparing for events beforehand (Cleary 2000).

Some of the most prominent studies about risk perception were conducted by Slovic and colleagues beginning in the 1970's and 1980's. (Slovic 2000). In one particular study, a factor 
analysis was completed in order to determine the primary roots of perceived risks. In this analysis, relationships between risk characteristics for a variety of hazards were summarized into three primary parameters that explained individuals' perceptions. Slovic named these parameters dread, familiarity, and voluntariness (Slovic 2000). While dread and familiarity are relevant factors in relation to risk perception of natural hazards, voluntariness will not be included since natural hazards are involuntary acts. The following sections explore how dread and familiarity contribute to misconceptions of natural hazard risk. Understanding their influence in decisionmaking is important when creating mitigation policies.

\subsubsection{DREAD}

The amount of dread that an individual feels about certain hazards is the main source in determining perception of risk. Slovic defines dread as "perceived lack of control, catastrophic potential, fatal consequences, and the inequitable distribution of risks and benefits" (Slovic 2000). The fear human beings feel is a response to prior experiences or imagined scenarios which are perceived to have negative outcomes. It has been shown in studies by Lerner et al (2003) that fear magnifies risk estimation and can distort the information that is being processed by the mind. An illustration of this point is the perceived safety of the two predominant modes of transportation: automobile and airplane.

The travel industry has been one of the most analyzed in terms of accident and fatality rates in the entire world, especially personal vehicle transportation (Fischhoff and Kadvany 2011). The comparison of vehicle and airplane travel has shown that air travel is much safer than traveling by car. Statistics from 2006 show that there were about 44,000 U.S. fatalities traveling by car in one year and there were fewer than 1,000 fatalities worldwide by commercial aircraft (Kluger 2006). Why then is there a high perceived risk of flying? Kluger (2006) explains that 
risk is underestimated by people who have control over the activity they are doing, even if that control is illusory. He also says that catastrophic events depicted in the media are more likely to sway people's perceptions towards a higher risk even though statistics demonstrate otherwise. This is exacerbated by the fact that the media tends to give extensive coverage to a single event that has a high number of fatalities, and little coverage to a high number of events with single fatalities. For instance, air travel decreased after the 9/11/2001 terrorist attacks, and people drove more, inadvertently increasing their risks (Fischhoff and Kadvany 2011).

The explanation of the higher risk perception for air travel given by Fischhoff \& Kadvany (2011) is the bias that people have when looking at different types of accidents. People normally recognize that a single trip with short distances has a small chance of an accident resulting in a fatality, and they use that as a basis for the perceived risks for a lifetime of driving (Fischhoff and Kadvany 2011). Statistics show that an individual trip has a chance of an accident fatality of one in 10 million, but a lifetime of driving as a whole increases the odds to one in a hundred (USA Today 2009). This is a drastic change, but is not reflected in the perceptions of people toward travel. For air travel integrated over a lifetime there is one chance in 7,000 of a fatal accident (USA Today 2009).

The tendency for society to exaggerate small risks and underestimate larger ones is ubiquitous. Peoples' biases, heuristics, and emotions are deeply intertwined with their notions of risks and the actions they take to avoid or attenuate them. Only when a large scale event is experienced will risk perceptions significantly increase and alter society's attention to the event for a time. Kerjan (2010) explains how low probability, high consequence events elicit an increase in dread within people, causing them to alter behavioral patterns. Since dread leads to an increased perception of risk, society tries to reduce those risks and at the same time enforce 
stringent regulations to do so (Slovic 2000). This is why the optimal time to get new codes and regulations passed for improving future infrastructure or restricting land use is within a month's period of a disaster before society's focus shifts to other issues (Drabek 2009). Once a large scale event's novelty begins to fade in the minds of society, it becomes increasingly difficult to pass the mitigation measures necessary to prevent large losses in the future.

The attention of the nation changes quickly from one subject matter to another and media shifts to cover the most recent societal risks or controversies. This can mean that funds for mitigation are diverted to causes that are not necessarily the highest actual risks, but those that are dreaded the most at the moment. According to Mileti (1999) these reasons among others are the major contributors for why society is unable to maximize utility in regard to natural hazard risks. Mileti states "The perceived benefits of hazard mitigation tend to be lower than their overall true social benefits". Mileti further explains that this consequence of mismanagement for appropriate mitigation measures come directly from the inability for people to cope rationally with unlikely catastrophic events.

\subsubsection{FAMILIARITY}

How often people are exposed to and personally experience events have a direct effect on risk attitudes towards hazards that are faced in everyday life. The term that Slovic (2000) gives this dimension in the factor analysis is familiarity. Slovic found that the more informed people are of a specific type of event, then the more likely they are going to accurately understand the frequency interval and judge the risks accordingly. Contrarily, a layperson with a lack of data will have estimates far from accurate. Fischhoff and Kadvany (2011) confirm this in a study of the differences between laypersons' judgments on annual death tolls and actual statistical figures. 
The familiarity factor also has various types of heuristics and biases that are directly linked to the term. Heuristics are mechanisms that the brain uses to learn from the past experiences through feedback loops, and store this knowledge in memory. The most predominant heuristic that forms around the familiarity of instances is the 'availability' heuristic. Kahnehman and Tversky's (2000) research on 'availability' demonstrates that people depend on observations when estimating the probability of an occurrence. Additionally, Fischhoff and Kadvany (2011) point out that "Availability is one of many heuristics that people use to judge uncertain events, providing serviceable, if imperfect, judgment when people lack needed knowledge and the resources to secure it." The more accessible the memory of the occurrence, the more people will increase their estimate of its likelihood (Keller, Siegrist and Gutscher 2006). Therefore, people will make reasonable risk approximations when they become more cognizant of a particular activity or event.

It is also argued that the factor of familiarity is associated with the emotions and feelings that an individual experiences while imagining an event. This is defined as the 'affect' heuristic (Slovic, Finucane and Peters 2004). An example is that if someone has a positive outlook toward an activity, he/she will have lower risk expectations. Similarly, a negative outlook produces higher risk expectations. The perceived benefits from either scenario also adjust in accordance with how favorable or unfavorable an activity is. Integrating both 'availability' and 'affect' heuristics together can ultimately lead to a clearer depiction of how risk is perceived by society as a whole.

It should also be noted how time plays a key role in the diminution of potent emotions. The more time that passes after an event, the more memory and emotions fade and the high levels of risk perceptions decrease (Kunreuther and Michel-Kerjan 2010). A common example of 
this is that flood insurance purchases increase dramatically after a recent natural hazard event has caused damage to homes and other infrastructure. After a few years without any flooding incidences in that same area, people begin to abandon their insurance policies because the perceived benefits of paying monthly premiums for an unlikely scenario have dwindled (Kunreuther and Michel-Kerjan 2010).

\subsection{MEDIA DRIVEN RISK PERCEPTION}

One of the largest factors driving levels of risk perception other than personal experience is through the media. The volume of sources and outlets available today makes it possible to follow news stories as they are happening 24 hours a day. This can serve as a risk amplifier because it increases the familiarity and availability of information (Slovic 2000). Additionally, a person's dread can increase through the dramatization and emotional interviews included in news reports. This can result in a consumer's change in behavior and have an impact on future decision making. The media's influence on the public's perception of risk has caused speculation as to whether or not it is more harmful than helpful in portraying natural hazards and their corresponding risks. On one hand, the media helps provide information in a timely fashion to respond to emergency situations. However, contrasting reports and exaggerations from varying news sources causes confusion and people begin to disregard the information they are given from other sources (Niedek 2003).

Another consideration is the amount of coverage extreme natural disasters get versus the frequent, low consequence events as mentioned previously. For example, flooding events are quite common in the United States, but only a few extreme events are given a large amount of exposure by news agencies. Selecting this type of event to report creates a biased view in that the 
story presented might be sensationalized to benefit the news agencies ratings (Niedek 2003).

These reports have the capacity to skew risk perception by the public. Many of the news stories report only the current event and fail to provide an in-depth analysis that addresses issues such as the previous building and land use decisions that contributed to the extreme losses occurring in the first place. According to Mileti (1999) "Sustainable hazard mitigation requires local acceptance that losses, costs, and impacts of future natural disasters will be the consequence of today's mitigation decisions and non-decisions. " If more emphasis in the media is given to looking at various mitigation strategies to reduce the impact that natural disasters have on society, then it has the potential to help stakeholders make decisions on measures in order to stabilize the consequences that these natural hazards are presently having on society.

\subsection{SURROGATE MEASURE OF RISK PERCEPTION}

In an effort to incorporate risk perception into future mitigation planning with statistical analyses, a previous study by Hurley (2013) developed and calibrated a quantitative measurement of natural hazard dread with data from SHELDUS. The hypothesized dread calculation used in the study combined elements of hazard lead time, the number of fatalities per event, and the number of people that were affected by the event. These parameters were chosen as part of the analysis because they are some of the primary characteristics that are attributed to influencing risk perception as indicated in social-psychological literature (Hurley and Corotis 2013). A factor analysis was completed for the dread measurement and then combined with familiarity - based on hazard frequency - to create a graphical depiction of risk perception. A positional coordinate was given to each natural hazard type based on the dread measurement ( $\mathrm{x}$ axis) and the familiarity element (y-axis). This created a visual representation for risk perception 
that each hazard had for eight regions of the US. These graphics can help regulators comprehend how citizens will react during certain types of events and help prepare for them. It is important to consider the risk perception during hazard events because people's behaviors and actions are guided by these perceptions. Hurley's study also provides a means to bridge the gap that has separated rational decision making with that of people's perceptions.

Currently, this hypothesized concept has not been validated through interviews or surveys. It is suggested that possible indirect quantitative or qualitative analyses be completed in order to confirm the accuracy of the postulated dread equation. Some of the possible analysis can include the amount of hazard media exposure, public awareness campaigns, or research funding provided. These can be investigated to evaluate if societal risk perception is reflected through these mediums and then compare the results with the risk perception formulation posited by Hurley's research. 


\section{Making Decisions Under Uncertainty}

\subsection{OVERVIEW}

This chapter further demonstrates how perception of risk influences decision-making and discusses the need to account for extreme values when communicating natural hazard risk.

\subsection{ACCEPTABLE RISKS}

Inherent uncertainty is an unavoidable element in long-term natural hazard mitigation decisions. The wide range of possibilities and extent of damages from natural hazards make it difficult to determine what the best course of action is to safeguard the general welfare of the public. There are a wide range of issues in society that make it challenging to determine which risks are most detrimental relative to one another. When there is insufficient information available, people rely on their emotions and intuitions in order to make these decisions (Cleary 2010). This means that the allocation of funding for reducing risk may not be optimal since it fails to reflect the actual societal risk. The level of loss from an event that is perceived to be tolerable by society, known as acceptable risk, is an important factor to consider in the mitigation planning process (Vrijling, Van Hengel and R.J. 1998). Because there are limited resources available to implement mitigation efforts, it is necessary to accurately determine the degree of protection to provide and the related societal tradeoffs.

In order to get an understanding of the relationship between the societal tradeoff of the acceptable likelihood of an occurrence with the number of fatalities per event, one could look at industries and governmental agencies that have objectively modeled acceptable risk for different technologies through the use of numerical FN-curves (Vrijling, Van Hengel and R.J. 1998). 
Three such types of FN-curves are shown in Figure 4-1 and are used only as an example to explain the concept. These linear regression lines represent the boundary for the risk tolerance that is established by the entity and characterizes a cost-benefit appraisal of the risks. This demonstrates that as the number of fatalities in an event rises, the probability of that event occurring goes down. This means that the more frequent events with little or no fatalities are easier to accept than rare events with a large amount of losses (Vrijling, Van Hengel and R.J. 1998). If the events that cause large casualties begin to occur more frequently, this is an unacceptable scenario and funding is allocated to reduce those risks. This mathematical philosophy for acceptable risk should also be put to use to determine the acceptability of natural hazard risks. This method provides a way to gauge how much risk there is versus the funding dispersed to reduce these risks.

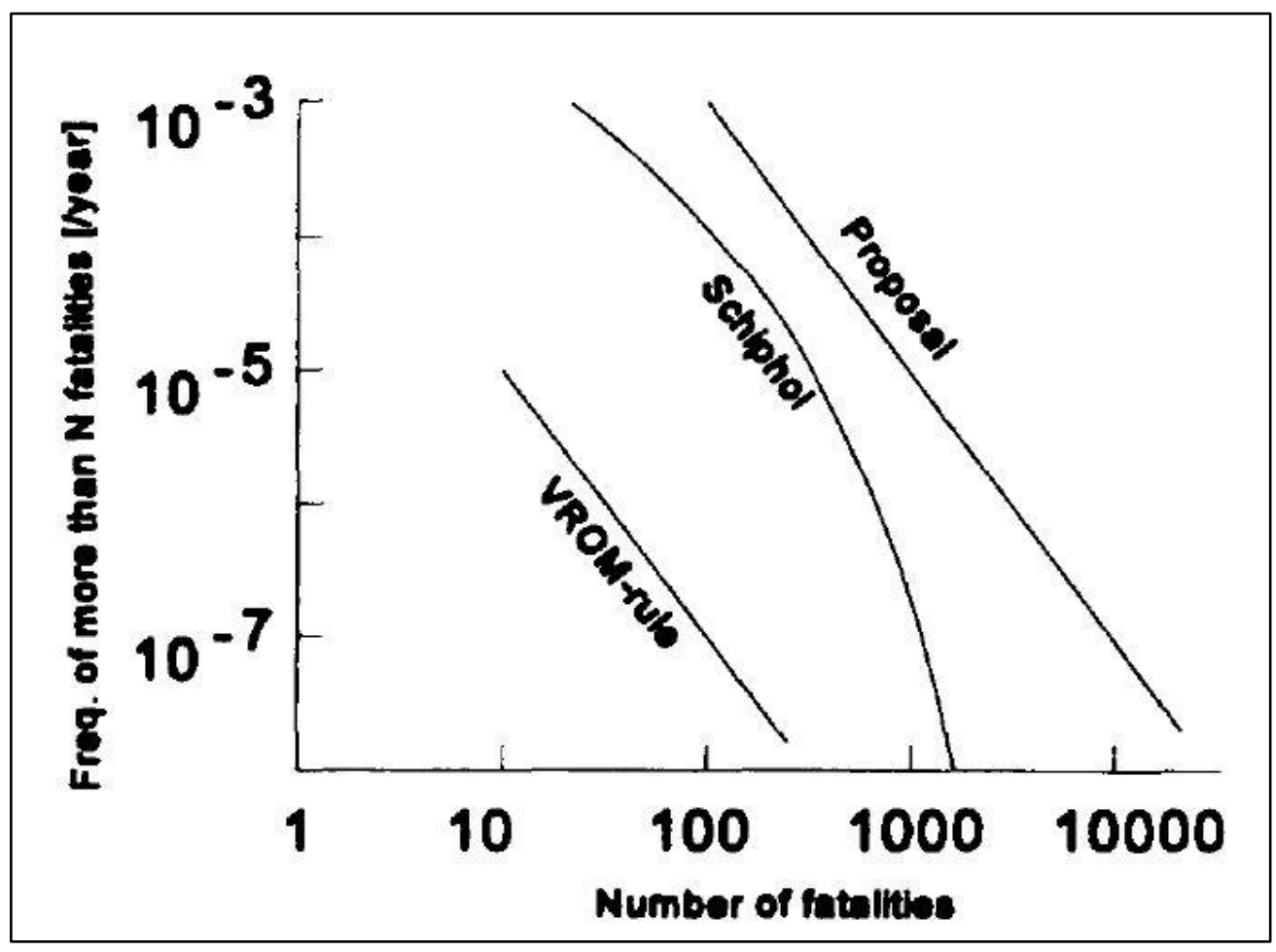

Figure 4-1: FN-curves that represent the maximum acceptable risk for technologies (Vrijling et al 1998) 
Natural hazard risks are often recognized by the public and stakeholders, but it is the perceived level of risk, distorted by biases and past experiences, that leads to disproportionate funding. This distortion of the assessment of risk hinders society's ability to create and implement long-term mitigation plans. Some additional concerns that make it difficult to adopt mitigation measures are the following. First, there is a general lack of understanding and assessment of the likelihood that a catastrophic event will occur. Second, the length of time between events means a potentially long wait for a return on mitigation investment. Finally, there are many differing opinions on what is deemed an acceptable risk and how funding should be distributed.

Behavioral science research has shown that there is a large difference between how experts and laypersons interpret low probability, high consequence events. Due to probabilistic misunderstanding, most people tend to have one of two opinions of the likelihood for these types of low probability events: they are either confident that this event will never happen in their lifetime, or they are quite sure that it will happen (Kunreuther and Useem 2009). The majority of people group around the idea that an extreme event will not occur. Consequently, there is an unwillingness to purchase insurance to protect against natural hazards and invest in infrastructure mitigation measures. This tendency to underestimate the probability of an extreme event occurring (and the amount of resulting losses) is reflected by current mitigation plans that do not align with the widespread impacts that these natural disasters have on society. A recent strategy utilized by risk managers to communicate these extreme events more effectively is to extend the timeframe for possible occurrence of an extreme event (Kunreuther and Useem 2009). For example, if a homeowner with a 30 year mortgage is considering purchasing flood insurance, they are more likely going to take the risk of a 100 year flooding event more seriously if they are 
presented with information that there is a 1-in-4 chance that flooding will occur during the 30 year period, rather than a 1-in-100 chance of occurring in any given year.

In addition to misunderstanding probabilities, a cost-benefit analysis can be difficult to achieve when there are large uncertainties involved. If local governments adopt strict building and land use requirements to lower the impacts from a potential disaster, it will increase costs of construction and living. With the unknown timeframe of the return on investment, the public might question why limited funding is being spent on low probability, high consequence projects rather than other pressing matters. The benefits from investing in extreme hazard event infrastructure could be seen a year after implementation, or it might not be seen for another 50 to 100 years. The large amount of uncertainty involved and differing public and political opinions causes focus to shift toward more urgent issues that provide more immediate feedback (Kunreuther and Michel-Kerjan 2010). However, if long-term measures are set aside for the future, this prevents the proper attention or funding needed to implement long-term mitigation plans.

To make long-term mitigation decisions effectively, a balanced approach needs to be used to minimize losses, since ignoring perceptions would be counterproductive. This involves combining people's perceptions of risks with the systematic risk-based approach offered through statistical analysis. The graphs and charts produced in this study should be used to help communicate and understand actual risks. The objective statistical data provide guidance for optimum decision-making, and subjective analyses give the data practical significance. If perceptions become aligned with objective risks, this will lead to better utilization of limited resources that are available for natural hazard mitigation projects. 


\subsection{EXPECTED VALUES VERSUS EXTREME VALUES}

Mitigation plans often use expected values to communicate natural hazard risk to the public (Haimes 1998). These values are expressed as a natural hazard's average frequency and average losses over a time frame, usually on a yearly basis. While this simplifies the collected data into a single metric generally used for optimum decision-making practices, using it to demonstrate natural hazard risk is misleading. Since it combines all event possibilities and outcomes, it disregards the level of severity from an event that happens more frequently from the extreme impacts from a low probability event. This distinction is hidden when probabilities and their corresponding consequences are combined into a single metric to represent risk. Instead of reducing the uncertainty in natural hazard decision-making, it causes ambiguity. When the metric is used as the only criterion for decision-making, it misrepresents natural hazard risks and is not reflected in mitigation planning efforts (Haimes 1998).

The degree to which the expected value can skew the data is apparent when comparing the average fatality losses with a single event loss from natural hazards. For example, this study calculated that there is an average of 6.3 fatalities for every landslide event in the Southeast region of the US. However, this average is skewed because a single extreme landslide event in this region resulted in 150 fatalities and accounts for $82 \%$ of all the fatalities from the 29 landslide events recorded from 1960 to 2009 (HVRI 2009). This extreme event has a much higher value than the rest of the events, which mostly have zero fatalities recorded. Hypothetically, if this extreme event did not occur, the calculated average would be less than one fatality per event. 
Alternatively, a hurricane hazard that is typically associated with a high amount of losses has an average of 2.1 fatalities per event in the Southeast region. This calculated expected value does not accurately demonstrate the fatality risk from hurricanes because it does not take into account the hurricane's magnitude, trajectory, intensity, or the amount of people affected by the storm. Out of 242 events recorded, the most costly and deadly event - Hurricane Katrina resulted in nearly a 1000 fatalities (HVRI 2009). When creating natural hazard policy, stakeholders need to be aware how expected value can skew the data, and they need to take extremes into consideration.

This study suggests that it is best for local and state governments to create mitigation plans that address both average losses and extreme losses. High levels of risk perception are not dominated by the expected value, but rather likely result from extreme events that are experienced (Kerjan and Slovic 2010).The extreme events have a much larger role in altering perception of risk levels and have wide-ranging, long-lasting damaging effects on society. Longterm mitigation strategies should incorporate preparation measures for low probability, high consequence events, and these time scales are such that it would be prudent to account for changing climate conditions that result in increasing environmental hazard frequency and intensities (Emrich and Cutter 2011).

In order to help facilitate effective decision making for the creation of mitigation plans, the extreme and expected values are explicitly shown in the graphs and charts produced in this study. The graphs reflect the average losses from natural hazards by placing them in a Cartesian coordinate system, while the extreme losses are seen by the size of the rings associated with the hazards. Additionally, a chart supplements each graph to show the influence that an extreme event has on the expected value calculated. If local and state governments are going to account 
for the extreme and expected values separately, they need effective methods for analyzing both types of values. 


\section{Natural Hazard Analysis Process}

\subsection{OVERVIEW}

This chapter provides a background on the natural hazard data gathered to perform risk assessments for eight regions of the US. It then explains the layout of the graphs and charts generated to be used in analyzing the data. Immediately following this chapter are the regional analyses and discussions (Chapters 6 through 13).

\subsection{NATURAL HAZARD DATABASE}

To analyze the impacts that natural hazards have on the United States, data were gathered from documented events over the past 50 years (1960-2009) by the Hazards and Vulnerability Research Institute (HVRI) at the University of South Carolina. These data were made accessible through the Spatial Hazards Events and Losses Database for the United States (SHELDUS) to summarize the consequences for 13 major types of natural hazards in eight geographic regions of the country (HVRI 2009). SHELDUS is continually updated and made up of a consolidation of several main natural hazard databases from governmental agencies such as the National Climatic Data Center (NCDC) and the US Geological Survey (USGS). Since the data contained within SHELDUS total more than 600,000 entries, it serves as a comprehensive data set for calculating natural hazard risk throughout the United States.

The typical risk assessment factors that are represented within SHELDUS for each natural hazard event are fatalities, injuries, property damage, and crop damage for each county of the United States. The information acquired for each event is comprised of a hazard I.D. number, the date of occurrence, type of hazard, county and state name, brief remarks describing the event 
and total loss amounts for each of the counties that were affected by a single hazard event. It is beneficial to receive hazard data by county because emergency management decisions and functions begin at the county level (Emrich and Cutter 2011). Additionally, county level analysis extends itself well to state-wide administration decisions for hazard mitigation funding opportunities. Since SHELDUS reports losses at a county level, the distribution of the losses within the hazard zone cannot be narrowed down to exact locations. The distribution of impacts is important when implementing mitigation strategies and will be investigated further in this study by combining natural hazard consequences with the social vulnerability index (SoVI) in a GIS map format. SoVI is discretized at a US census block level and incorporates many demographic factors that contribute to losses and the ability for people to resist and cope with natural hazard events (Cutter, Mitchell and Scott 2000). Further discussion of this topic will be seen later in Chapter 15 on the development of specific hazard regions and multi-hazard mapping.

Although SHELDUS is a comprehensive public database, it has disadvantages of which a user needs to be aware during analysis. Currently, information from the database only accounts for the direct losses from a hazard event and lacks indirect losses and corresponding long-term impacts that hazards have on society. These long-term impacts almost always outweigh the initial direct damages from a hazard event (Gall, Borden and Emrich 2011). This is important to consider when communicating risk to decision makers and the public because it shows that total risks are larger than have been estimated.

There are additional considerations when using SHELDUS data to communicate risk to stakeholders. During the five year period between 1990 and 1995, the NCDC changed its reporting methodology from providing exact damage figures to classifying damages on a 
logarithmic scale and incorporated the lowest estimates of hazard consequences. Furthermore, SHELDUS catalogued hazard events only if they surpassed the threshold of at least $\$ 50,000$ or had involved one fatality. For example, if the NCDC reported losses given in a range of $\$ 50,000$ to $\$ 500,000$ encompassing two separate counties, SHELDUS reported $\$ 25,000$ in losses for each of the counties (Gall, Borden and Emrich 2011). Additionally, if the hazard was declared a statewide event, the database divides the loss amount by the number of counties in the state and then assigns each county with a fraction of the total. This can undervalue the overall economic impacts of the various natural hazards. Hence, the methodology was reformed back by the NCDC to provide accurate loss figures reported back to the specific counties where the natural hazard losses occurred. All losses from this previous period are continually updated to SHELDUS to account for the inaccuracies between the 1990 and 1995 period.

Despite these shortcomings, SHELDUS is the most reliable database to use for a study of this paper's scope because it is the most extensive public database available for analytical purposes. Therefore, it will be used as the source of data in creating graphical summaries to disseminate knowledge about natural hazard frequency and consequences to stakeholders and governmental agencies. These will provide a powerful tool in making decisions on natural hazard policies by illustrating the risks that different types of hazards have on a region.

\subsubsection{LOSSES DUE TO FATALITY AND INJURY}

This study analyzes levels of fatality, injury, and damage risk caused by different types of hazards in distinct geographic regions. In addition, these three factors are combined into an equivalent dollar figure that represents the total consequence related to each of the 13 types of hazards considered. Including all hazard consequences from an economic standpoint can help increase the outlook on safety measures and funding for mitigation causes (Vrijling, Van Hengel 
and R.J. 1998). Another reason the data are converted and combined into a monetary sum is so that risk can be visually interpreted in a concise manner by stakeholders and act as a tool for distributing knowledge to the public. Furthermore, the 13 types of hazards and corresponding risk levels can be compared together by observing the scale in which each hazard relates to one another in a region. It should be noted that separate information about the total fatalities and injuries is still preserved and displayed in the figures. To maintain transparency, these factors are explicitly expressed in tables for all eight regions of the US and are supplemented by bar charts that display percentage contributions for each of the separate assessment factors.

While associating a value to life and injury is beneficial in making mitigation decisions, the sensitive moral nature of the subject makes it challenging in assigning a dollar figure. Various governmental entities in the US have produced differing values and weighting factors assigned to a life (Applebaum 2011). When creating mitigation measures it is important to consider the differences between these life estimates and their varying applications. The value chosen can impact the way that risk is interpreted and alter decisions that are made. In this study, both fatalities and injuries will be displayed by actual totals and by monetary values, so as to not to lose important information.

The number of fatalities is perhaps the most important assessment factor to determine the severity of natural hazard events, after overall direct damages. A previous study by Rose et al (2006) analyzed estimates for the value of life from varying agencies and determined that it ranges from $\$ 1$ million to $\$ 10$ million with some agencies providing weighting systems for lives that are deemed more valuable than others. For instance, occupations that are more dangerous, such as working on construction sites, are given a lower life value than those unlikely to result in a fatality on the job (Viscusi 2007). A study by Hurley (2013) performed a comprehensive 
analysis in order to determine the dollar value that would be assigned to each fatality due to natural hazard events. This investigation concluded that a life value of $\$ 4$ million was reasonable for applications that deal with investment and regulatory decisions. This fatality estimate is used in this study and is conveyed in the generated consequence graphs.

Similar to monetizing life, assigning a dollar value to injury is a difficult task. First, the severity of injuries is not factored into SHELDUS records and is only given as the total amount resulting from a hazard event. Second, the indirect losses from injuries outweigh the direct losses depending on the severity. For example, a sustained injury can result in a person's inability to return to work and earn an income for a substantial amount of time (Jones 2012). Hence, these indirect losses create larger financial burdens in the long-term. The study completed by Hurley (2013) compared various injury severity levels to that of the probability of severity level occurrence in a natural hazard event and determined a range between $6 \%$ and $12 \%$ of total life value. This figure is a reasonable estimation because it was derived from previous natural hazard event data. These results can vary widely depending on the type and magnitude of a hazard as well as the number of people affected. For this study a conservative value of $15 \%$ of the total life value is used in analysis to account for uncertainties in the mentioned analysis and unknown long-term effects.

\subsubsection{DIRECT ECONOMIC LOSSES}

As previously stated, SHELDUS differentiates damage totals into two categories: property loss and crop loss. These losses represent the direct economic impacts from each hazard event, with an inflation adjustment to 2009 dollars. The property damage totals from natural hazards include all public infrastructure and personal property damage that result from a hazard event. In this study, these losses are combined into a single metric termed "total damage" when reporting 
values in consequence graphs for each of the 13 types of hazards. As with fatality and injury values, percentage contributions for property and crop loss are shown in supplemental bar charts so that totals are not misleading.

\subsection{GEOGRAPHIC REGIONS}

In 2007, FEMA produced legislation that requires all communities to develop action and mitigation plans for hazards in their area (FEMA 592). Since there are significant differences in the natural hazards that impact communities across the US, consequences of natural hazards are evaluated separately in this study by dividing the country into the same eight geographical regions used by the Bureau of Economic Analysis (BEA). This is also consistent with previous natural hazard studies completed by Jones and Hurley $(2012,2013)$. These regions are Pacific, Mountain, Southwest, Plains, Great Lakes, Southeast, Mid-Atlantic, and New England (Figure 5-1). Although not incorporated into this study, it would be advantageous to evaluate the impacts caused by hazard events in a region in conjunction with its gross domestic product (GDP) or some other measure to adjust for the differences in potential damages resulting from similar events in areas with considerably different levels of population and development. The map shown in Figure 5-2 displays the GDP by state in 2008 and could be used to assess the financial impacts that natural hazards have on each of the regions separately. 


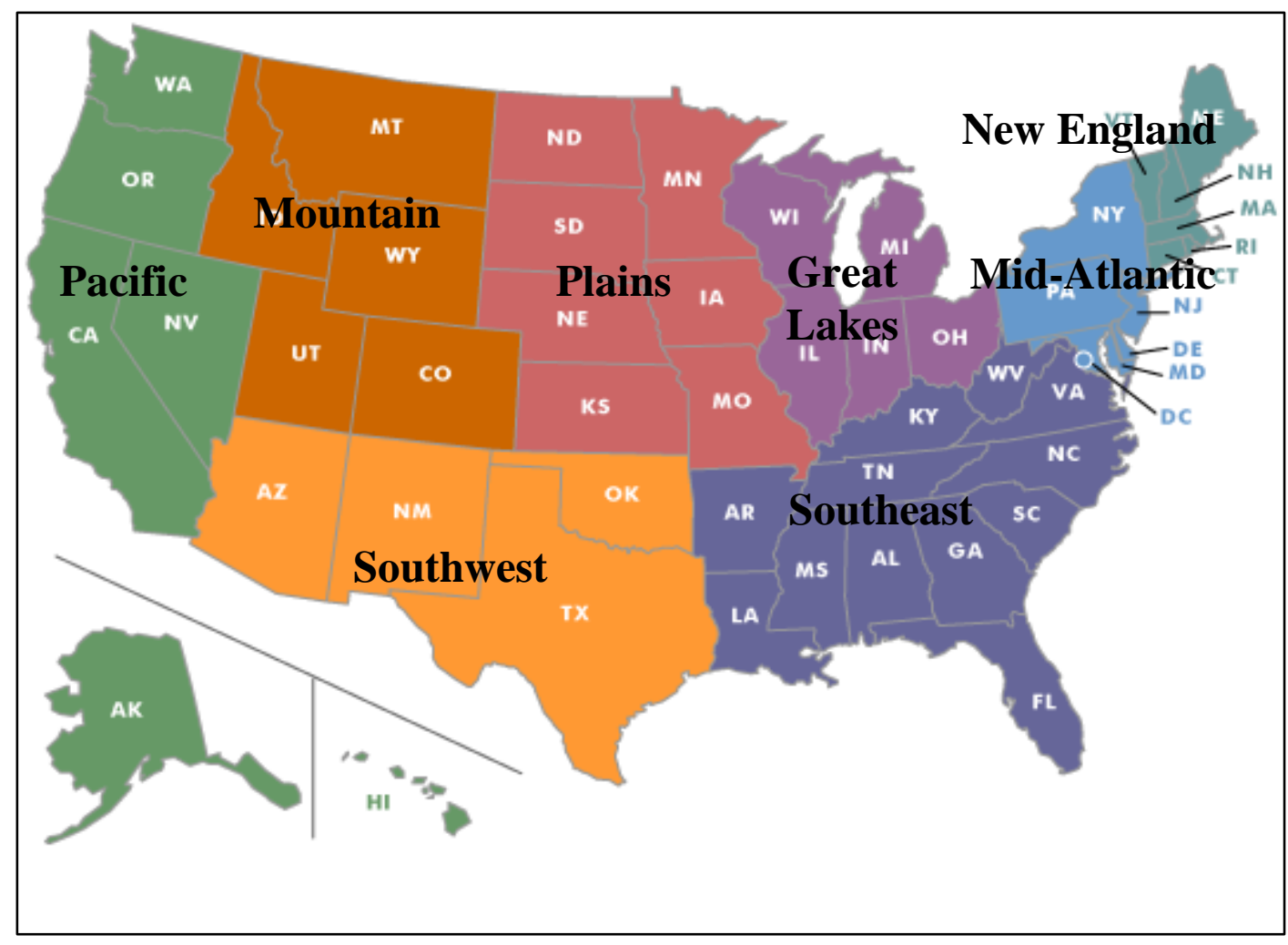

Figure 5-1: Regional division of the US (DOE 2009)

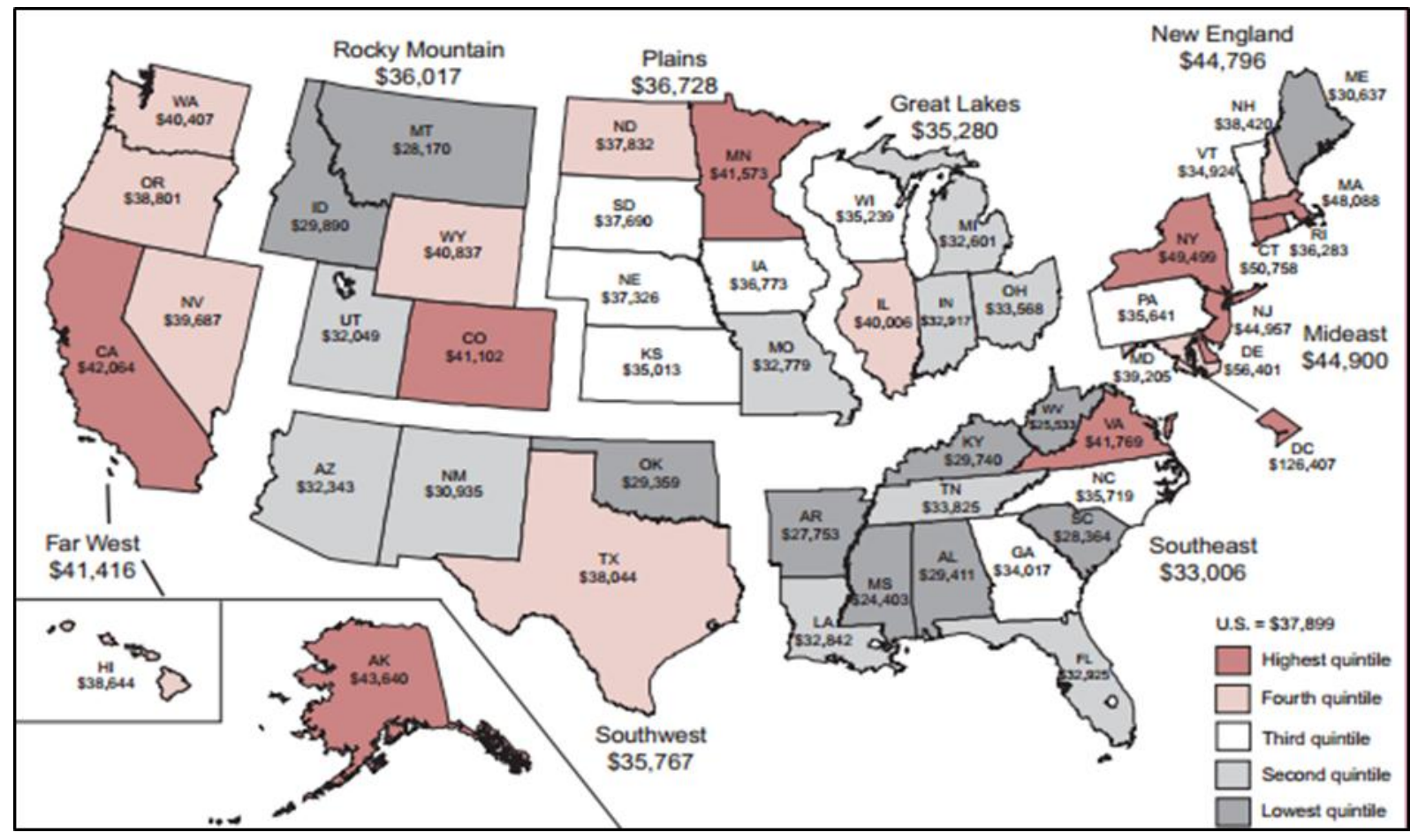

Figure 5-2: Gross Domestic Product by state in 2008 (Coakley, Reed and Taylor 2009) 


\subsection{REGIONAL DATA PRESENTATION}

Analyzing regional data helps stakeholders make decisions on natural hazard policy particular to specific areas of the country. By using graphs and charts as a tool to concisely present data, this study shows a practical way to aid in risk assessment and mitigation decisionmaking. For each of the eight regions there are three graphs of total consequences graphed along axes for damages, fatalities and injuries, along with two bar charts for each graph. In addition, each graph and chart has a corresponding table that display the statistics related to the information shown. An example of the graph and charts is provided following each of the following paragraphs of this section. These represent the fatality assessment in the Pacific region, and are shown in Figure 5-3, Figure 5-4, and Figure 5-5.

The graphs in this study represent the total consequences from 13 types of natural hazards. An example of the Pacific total consequence graph is shown in Figure 5-3. The graph of total consequences shows three rings for each of the hazards where the size is proportional to the amount of consequences. The outermost ring size (in area, not in diameter) totals the sum of consequences from every event in 50 years. The middle ring represents the consequences from the largest five percent of events. Finally, the inner ring represents the single hazard event that has caused the maximum consequence. The positional coordinates of each hazard ring are related to both the average losses and the number of events in the dataset. Note that the areas of rings are relative to each other within each region only, and sizes cannot be compared between regions.

The location of the hazard ring coupled with the overall sizes of the nested consequence rings need to be considered during the mitigation planning process. This distinguishes this approach from the use of expected values typically communicated to the public. For example, the 
earthquake hazard analysis completed in this research shows an average of nine fatalities per event in the Pacific region. However, in reality this figure has the potential to be in the thousands. The public need to be educated about these risks in order to properly prepare for and advocate for long-term mitigation policy.

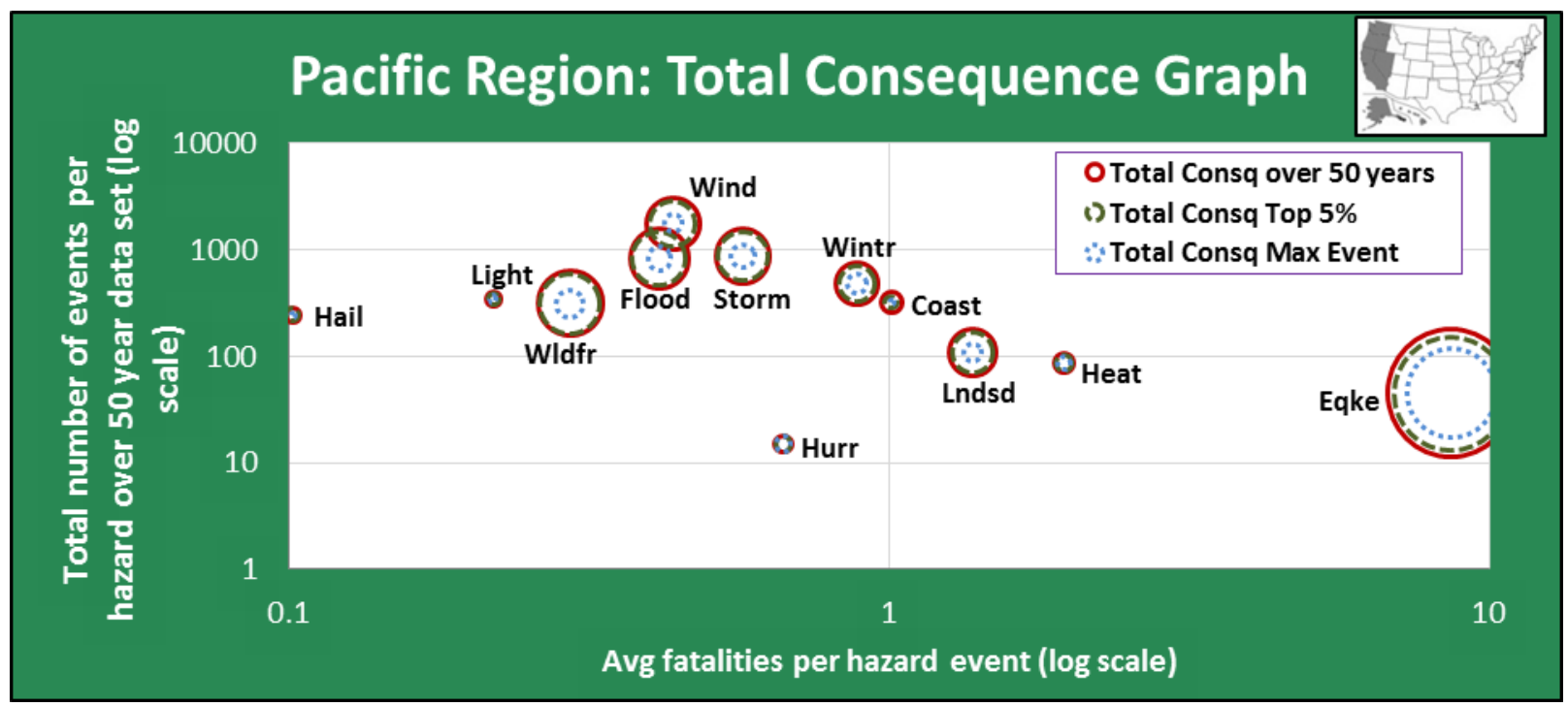

Figure 5-3: Example of Pacific region total consequence graph

Two bar charts were generated to provide supplemental data that are needed to make mitigation investment decisions. The first, in Figure 5-4, shows the percentage contribution of each of the four assessment factors: property loss, crop loss, fatalities and injuries. The total consequence amount shown in the outermost ring is made up of varying proportions of all four of these factors. From this chart, it is clear which factors affect the total consequences the most. 


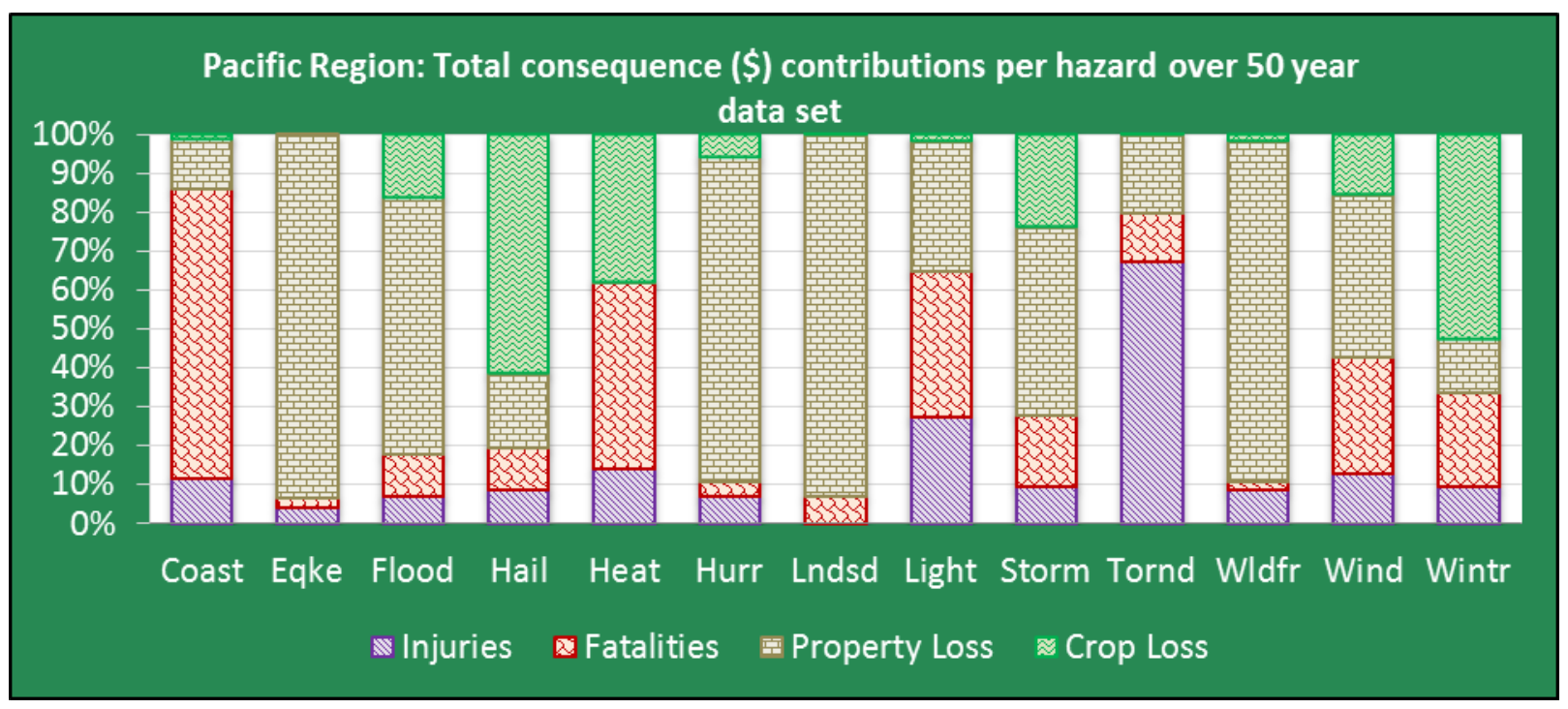

Figure 5-4: Example of Pacific region total consequence contribution chart

The second bar chart, in Figure 5-5, illustrates the influence that one event's losses can have on the average loss that determines the $\mathrm{x}$-axis coordinate for the hazard rings (fatalities for the example shown in Figure 5-3). For instance, if a hazard in a region has relatively few occurrences, but has one event with a significantly high loss compared to the others, then this can distort the average shown on the total consequence graph. Displaying this aspect explicitly is important when gauging the degree of risk of a hazard. 


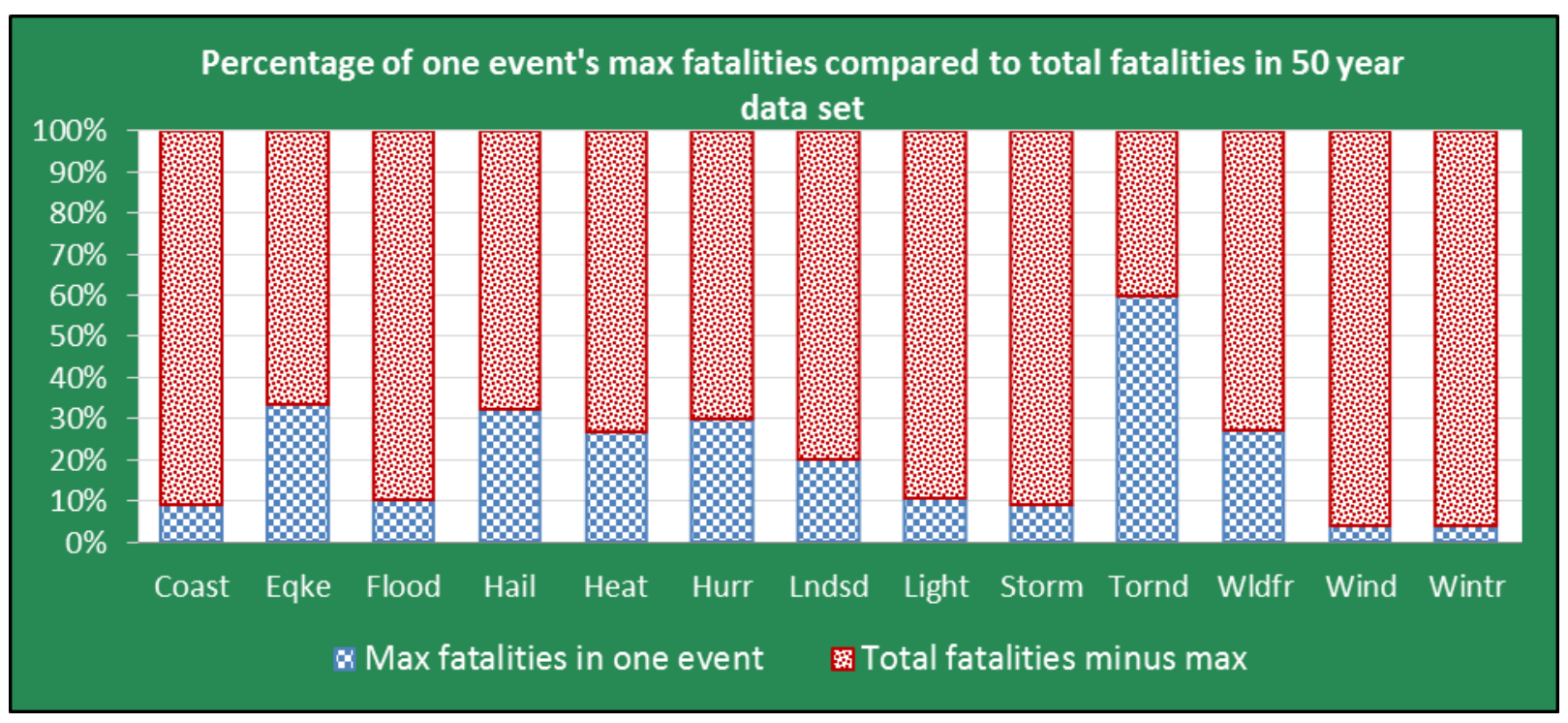

Figure 5-5: Example of Pacific region maximum event influence on average

Immediately following the graphs and charts generated for each region, natural hazard ranking tables are shown for total consequences, injuries, fatalities, and damages. Each of these tables shows a ranked list of the total losses over the 50-year data set and the average losses per event. This allows mitigation planners to see which hazards affect their region the most and can help in the allocation of funding based on the amounts. 


\section{Pacific Regional Analysis}

\subsection{LAYOUT}

Chapter 6 contains the natural hazard risk assessment and analysis for the Pacific region, which consists of the following six states: California, Nevada, Oregon, Washington, Alaska and Hawaii. Figures included in this chapter are:

- Pacific region consequence tables for injuries, fatalities, and damages

Table 6-1, Table 6-2, and Table 6-3, respectively

- Pacific region consequence graphics for injuries, fatalities, and damages

$>$ Figure 6-1, Figure 6-2, and Figure 6-3, respectively

- Pacific region consequence rankings (Table 6-4)

$>$ Total consequence and overall percentage

Average loss per event: injuries, fatalities, damages

Total losses: injuries, fatalities, damages

All 13 natural hazards are represented in the consequence displays and rankings for the Pacific region. 


\subsection{REGION CONSEQUENCE DISPLAYS}

\begin{tabular}{|c|c|c|c|c|c|}
\hline INJURIES & $\mathrm{Y}$-axis & $X$-axis & Outside Circle Size & Inner Circle Size & Middle Circle Size \\
\hline Hazard & $\#$ of events & $\begin{array}{c}\text { Avg injuries per } \\
\text { event }\end{array}$ & Total Consequence & Total Consq Max & Total Consq Top 5\% \\
\hline Coast & 322 & 1.07 & $\$ 1,757,606,390$ & $\$ 133,125,000$ & $\$ 608,596,589$ \\
\hline Eqke & 45 & 90.69 & $\$ 60,435,874,500$ & $\$ 29,640,000,000$ & $\$ 47,954,224,000$ \\
\hline Flood & 826 & 1.83 & $\$ 12,914,088,153$ & $\$ 2,025,000,000$ & $\$ 11,029,964,947$ \\
\hline Hail & 244 & 0.54 & $\$ 907,830,007$ & $\$ 113,011,300$ & $\$ 632,547,440$ \\
\hline Heat & 87 & 3.80 & $\$ 1,422,082,656$ & $\$ 726,729,600$ & $\$ 983,955,600$ \\
\hline Hurr & 15 & 8.60 & $\$ 1,074,827,612$ & $\$ 854,750,000$ & $\$ 854,750,000$ \\
\hline Lndsd & 108 & 0.29 & $\$ 8,568,092,071$ & $\$ 1,270,080,000$ & $\$ 6,465,295,437$ \\
\hline Light & 343 & 1.07 & $\$ 803,356,011$ & $\$ 189,156,000$ & $\$ 528,198,822$ \\
\hline Storm & 875 & 2.05 & $\$ 11,101,329,706$ & $\$ 2,025,000,000$ & $\$ 9,084,341,109$ \\
\hline Tornd & 208 & 3.42 & $\$ 635,647,327$ & $\$ 461,142,171$ & $\$ 591,439,646$ \\
\hline Wldfr & 313 & 7.16 & $\$ 15,665,022,221$ & $\$ 2,910,000,000$ & $\$ 13,691,568,000$ \\
\hline Wind & 1775 & 1.25 & $\$ 10,360,441,221$ & $\$ 1,123,694,000$ & $\$ 7,669,195,178$ \\
\hline Wintr & 481 & 2.29 & $\$ 7,057,893,293$ & $\$ 1,563,753,400$ & $\$ 4,894,389,745$ \\
\hline & & \multicolumn{4}{|c|}{ Contributions to the Total Consequence amount } \\
\hline Hazard & Total Consequence & Injuries & Fatalities & Property Loss & Crop Loss \\
\hline Coast & $\$ 1,757,606,390$ & $\$ 206,412,000$ & $\$ 1,299,840,000$ & $\$ 229,853,688$ & $\$ 21,500,703$ \\
\hline Eqke & $\$ 60,435,874,500$ & $\$ 2,448,624,000$ & $\$ 1,556,000,000$ & $\$ 56,431,250,500$ & $\$ 0$ \\
\hline Flood & $\$ 12,914,088,153$ & $\$ 908,382,000$ & $\$ 1,366,720,000$ & $\$ 8,548,745,295$ & $\$ 2,090,240,859$ \\
\hline Hail & $\$ 907,830,007$ & $\$ 78,684,000$ & $\$ 98,960,000$ & $\$ 173,924,324$ & $\$ 556,261,683$ \\
\hline Heat & $\$ 1,422,082,656$ & $\$ 198,432,000$ & $\$ 680,560,000$ & $\$ 1,941,777$ & $\$ 541,148,880$ \\
\hline Hurr & $\$ 1,074,827,612$ & $\$ 77,400,000$ & $\$ 40,000,000$ & $\$ 895,107,612$ & $\$ 62,320,000$ \\
\hline Lndsd & $\$ 8,568,092,071$ & $\$ 19,050,000$ & $\$ 595,640,000$ & $\$ 7,928,556,220$ & $\$ 24,845,851$ \\
\hline Light & $\$ 803,356,011$ & $\$ 219,228,000$ & $\$ 300,200,000$ & $\$ 270,928,289$ & $\$ 12,999,722$ \\
\hline Storm & $\$ 11,101,329,706$ & $\$ 1,076,748,000$ & $\$ 1,998,320,000$ & $\$ 5,363,002,942$ & $\$ 2,663,258,764$ \\
\hline Tornd & $\$ 635,647,327$ & $\$ 427,200,000$ & $\$ 80,000,000$ & $\$ 127,423,030$ & $\$ 1,024,297$ \\
\hline Wldfr & $\$ 15,665,022,221$ & $\$ 1,344,612,000$ & $\$ 368,080,000$ & $\$ 13,649,146,901$ & $\$ 303,183,319$ \\
\hline Wind & $\$ 10,360,441,221$ & $\$ 1,328,010,000$ & $\$ 3,097,960,000$ & $\$ 4,309,960,351$ & $\$ 1,624,510,870$ \\
\hline Wintr & $\$ 7,057,893,293$ & $\$ 659,484,000$ & $\$ 1,699,920,000$ & $\$ 1,000,618,496$ & $\$ 3,697,870,797$ \\
\hline \multicolumn{6}{|l|}{ INJURIES } \\
\hline Hazard & Total injuries & \# of events & Max injuries in one & Total minus max & $\%$ of total \\
\hline Coast & 344 & 322 & 27 & 317 & $8 \%$ \\
\hline Eqke & 4081 & 45 & 3757 & 324 & $92 \%$ \\
\hline Flood & 1514 & 826 & 1078 & 436 & $71 \%$ \\
\hline Hail & 131 & 244 & 31 & 100 & $24 \%$ \\
\hline Heat & 331 & 87 & 102 & 229 & $31 \%$ \\
\hline Hurr & 129 & 15 & 100 & 29 & $78 \%$ \\
\hline Lndsd & 32 & 108 & 10 & 22 & $31 \%$ \\
\hline Light & 365 & 343 & 102 & 263 & $28 \%$ \\
\hline Storm & 1795 & 875 & 1078 & 717 & $60 \%$ \\
\hline Tornd & 712 & 208 & 601 & 111 & $84 \%$ \\
\hline Wldfr & 2241 & 313 & 750 & 1491 & $33 \%$ \\
\hline Wind & 2213 & 1775 & 318 & 1895 & $14 \%$ \\
\hline Wintr & 1099 & 481 & 150 & 949 & $14 \%$ \\
\hline
\end{tabular}

Table 6-1: Pacific region injury consequence tables 

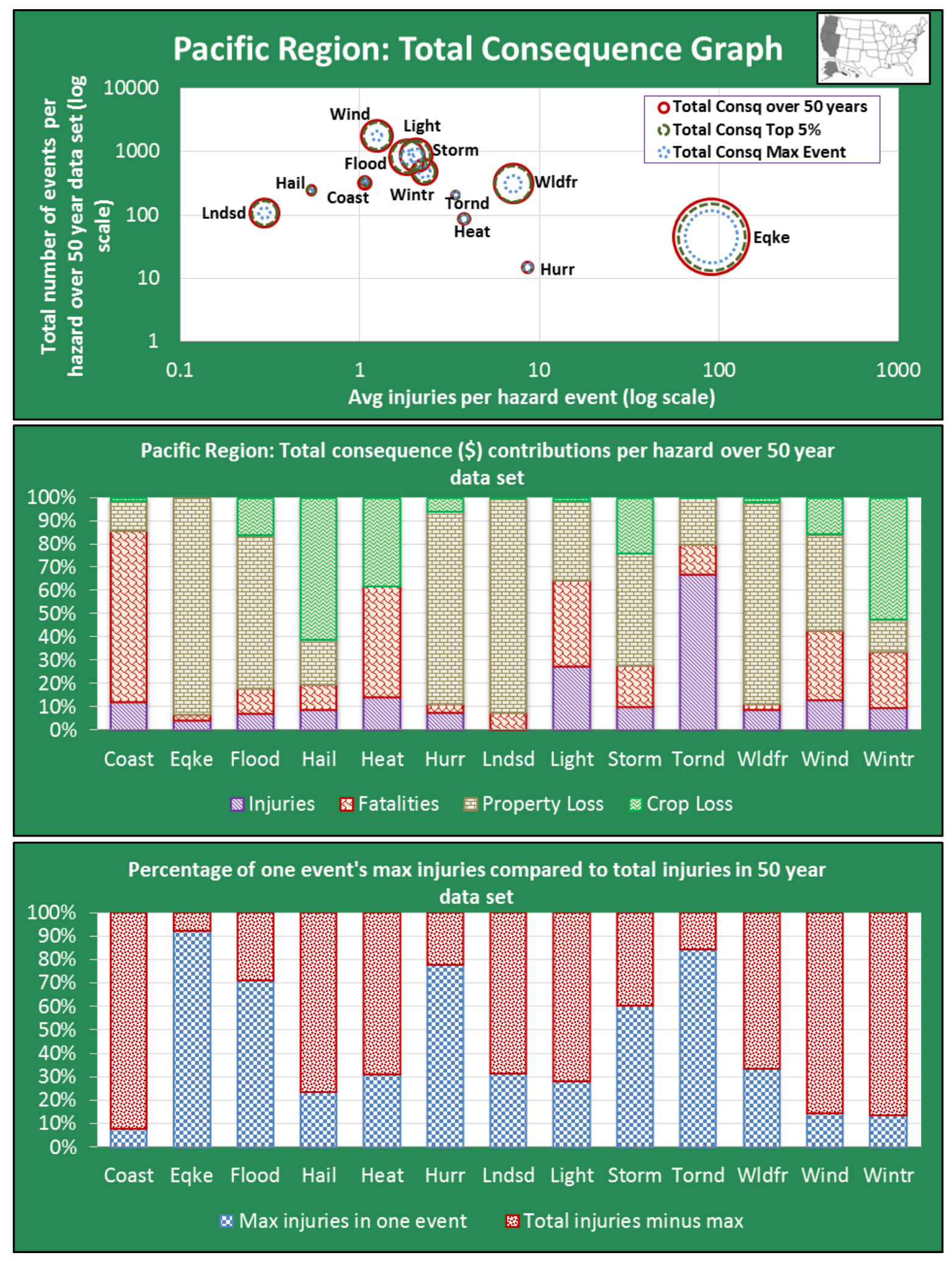

Figure 6-1: Pacific region injury consequence graphics 


\begin{tabular}{|c|c|c|r|r|r|}
\hline FATALITIES & Y-axis & \multicolumn{1}{|c|}{ X-axis } & Outside Circle Size & \multicolumn{1}{|c|}{ Inner Circle Size } & \multicolumn{1}{c|}{ Middle Circle Size } \\
\hline Hazard & \# of events & $\begin{array}{c}\text { Avg fatalities per } \\
\text { event }\end{array}$ & Total Consequence & Total Consq Max & Total Consq Top 5\% \\
\hline Coast & 322 & 1.01 & $\$ 1,757,606,390$ & $\$ 133,125,000$ & $\$ 608,596,589$ \\
\hline Eqke & 45 & 8.64 & $\$ 60,435,874,500$ & $\$ 29,640,000,000$ & $\$ 47,954,224,000$ \\
\hline Flood & 826 & 0.41 & $\$ 12,914,088,153$ & $\$ 2,025,000,000$ & $\$ 11,029,964,947$ \\
\hline Hail & 244 & 0.10 & $\$ 907,830,007$ & $\$ 113,011,300$ & $\$ 632,547,440$ \\
\hline Heat & 87 & 1.96 & $\$ 1,422,082,656$ & $\$ 726,729,600$ & $\$ 983,955,600$ \\
\hline Hurr & 15 & 0.67 & $\$ 1,074,827,612$ & $\$ 854,750,000$ & $\$ 854,750,000$ \\
\hline Lndsd & 108 & 1.38 & $\$ 8,568,092,071$ & $\$ 1,270,080,000$ & $\$ 6,465,295,437$ \\
\hline Light & 343 & 0.22 & $\$ 803,356,011$ & $\$ 189,156,000$ & $\$ 528,198,822$ \\
\hline Storm & 875 & 0.57 & $\$ 11,101,329,706$ & $\$ 2,025,000,000$ & $\$ 9,084,341,109$ \\
\hline Tornd & 208 & 0.10 & $\$ 635,647,327$ & $\$ 461,142,171$ & $\$ 591,439,646$ \\
\hline Wldfr & 313 & 0.29 & $\$ 15,665,022,221$ & $\$ 2,910,000,000$ & $\$ 13,691,568,000$ \\
\hline Wind & 1775 & 0.44 & $\$ 10,360,441,221$ & $\$ 1,123,694,000$ & $\$ 7,669,195,178$ \\
\hline Wintr & 481 & 0.88 & $\$ 7,057,893,293$ & $\$ 1,563,753,400$ & $\$ 4,894,389,745$ \\
\hline
\end{tabular}

\begin{tabular}{|c|r|r|r|r|r|}
\cline { 3 - 6 } \multicolumn{2}{c|}{} & \multicolumn{4}{c|}{ Contributions to the Total Consequence amount } \\
\hline Hazard & Total Consequence & \multicolumn{1}{c|}{ Injuries } & \multicolumn{1}{c|}{ Fatalities } & \multicolumn{1}{c|}{ Property Loss } & \multicolumn{1}{c|}{ Crop Loss } \\
\hline Coast & $\mathbf{\$ 1 , 7 5 7 , 6 0 6 , 3 9 0}$ & $\$ 206,412,000$ & $\$ 1,299,840,000$ & $\$ 229,853,688$ & $\$ 21,500,703$ \\
\hline Eqke & $\mathbf{\$ 6 0 , 4 3 5 , 8 7 4 , 5 0 0}$ & $\$ 2,448,624,000$ & $\$ 1,556,000,000$ & $\$ 56,431,250,500$ & $\$ 0$ \\
\hline Flood & $\mathbf{\$ 1 2 , 9 1 4 , 0 8 8 , 1 5 3}$ & $\$ 908,382,000$ & $\$ 1,366,720,000$ & $\$ 8,548,745,295$ & $\$ 2,090,240,859$ \\
\hline Hail & $\mathbf{\$ 9 0 7 , 8 3 0 , 0 0 7}$ & $\$ 78,684,000$ & $\$ 98,960,000$ & $\$ 173,924,324$ & $\$ 556,261,683$ \\
\hline Heat & $\mathbf{\$ 1 , 4 2 2 , 0 8 2 , 6 5 6}$ & $\$ 198,432,000$ & $\$ 680,560,000$ & $\$ 1,941,777$ & $\$ 541,148,880$ \\
\hline Hurr & $\mathbf{\$ 1 , 0 7 4 , 8 2 7 , 6 1 2}$ & $\$ 77,400,000$ & $\$ 40,000,000$ & $\$ 895,107,612$ & $\$ 62,320,000$ \\
\hline Lndsd & $\mathbf{\$ 8 , 5 6 8 , 0 9 2 , 0 7 1}$ & $\$ 19,050,000$ & $\$ 595,640,000$ & $\$ 7,928,556,220$ & $\$ 24,845,851$ \\
\hline Light & $\mathbf{\$ 8 0 3 , 3 5 6 , 0 1 1}$ & $\$ 219,228,000$ & $\$ 300,200,000$ & $\$ 270,928,289$ & $\$ 12,999,722$ \\
\hline Storm & $\mathbf{\$ 1 1 , 1 0 1 , 3 2 9 , 7 0 6}$ & $\$ 1,076,748,000$ & $\$ 1,998,320,000$ & $\$ 5,363,002,942$ & $\$ 2,663,258,764$ \\
\hline Tornd & $\mathbf{\$ 6 3 5 , 6 4 7 , 3 2 7}$ & $\$ 427,200,000$ & $\$ 80,000,000$ & $\$ 127,423,030$ & $\$ 1,024,297$ \\
\hline Wldfr & $\mathbf{\$ 1 5 , 6 6 5 , 0 2 2 , 2 2 1}$ & $\$ 1,344,612,000$ & $\$ 368,080,000$ & $\$ 13,649,146,901$ & $\$ 303,183,319$ \\
\hline Wind & $\mathbf{\$ 1 0 , 3 6 0 , 4 4 1 , 2 2 1}$ & $\$ 1,328,010,000$ & $\$ 3,097,960,000$ & $\$ 4,309,960,351$ & $\$ 1,624,510,870$ \\
\hline Wintr & $\mathbf{\$ 7 , 0 5 7 , 8 9 3 , 2 9 3}$ & $\$ 659,484,000$ & $\$ 1,699,920,000$ & $\$ 1,000,618,496$ & $\$ 3,697,870,797$ \\
\hline
\end{tabular}

\begin{tabular}{|c|c|c|c|c|c|}
\hline FATALITIES & & & & & \\
\hline Hazard & Total fatalities & \# of events & Max fatalities in one & Total minus max & $\%$ of total \\
\hline Coast & 325 & 322 & 30 & 295 & $9 \%$ \\
\hline Eqke & 389 & 45 & 131 & 258 & $34 \%$ \\
\hline Flood & 342 & 826 & 36 & 306 & $10 \%$ \\
\hline Hail & 25 & 244 & 8 & 17 & $32 \%$ \\
\hline Heat & 170 & 87 & 46 & 124 & $27 \%$ \\
\hline Hurr & 10 & 15 & 3 & 7 & $30 \%$ \\
\hline Lndsd & 149 & 108 & 30 & 119 & $20 \%$ \\
\hline Light & 75 & 343 & 8 & 67 & $11 \%$ \\
\hline Storm & 500 & 875 & 45 & 454 & $9 \%$ \\
\hline Tornd & 20 & 208 & 12 & 8 & $60 \%$ \\
\hline Wldfr & 92 & 313 & 25 & 67 & $27 \%$ \\
\hline Wind & 774 & 1775 & 31 & 743 & $4 \%$ \\
\hline Wintr & 425 & 481 & 17 & 408 & $4 \%$ \\
\hline
\end{tabular}

Table 6-2: Pacific region fatality consequence tables 

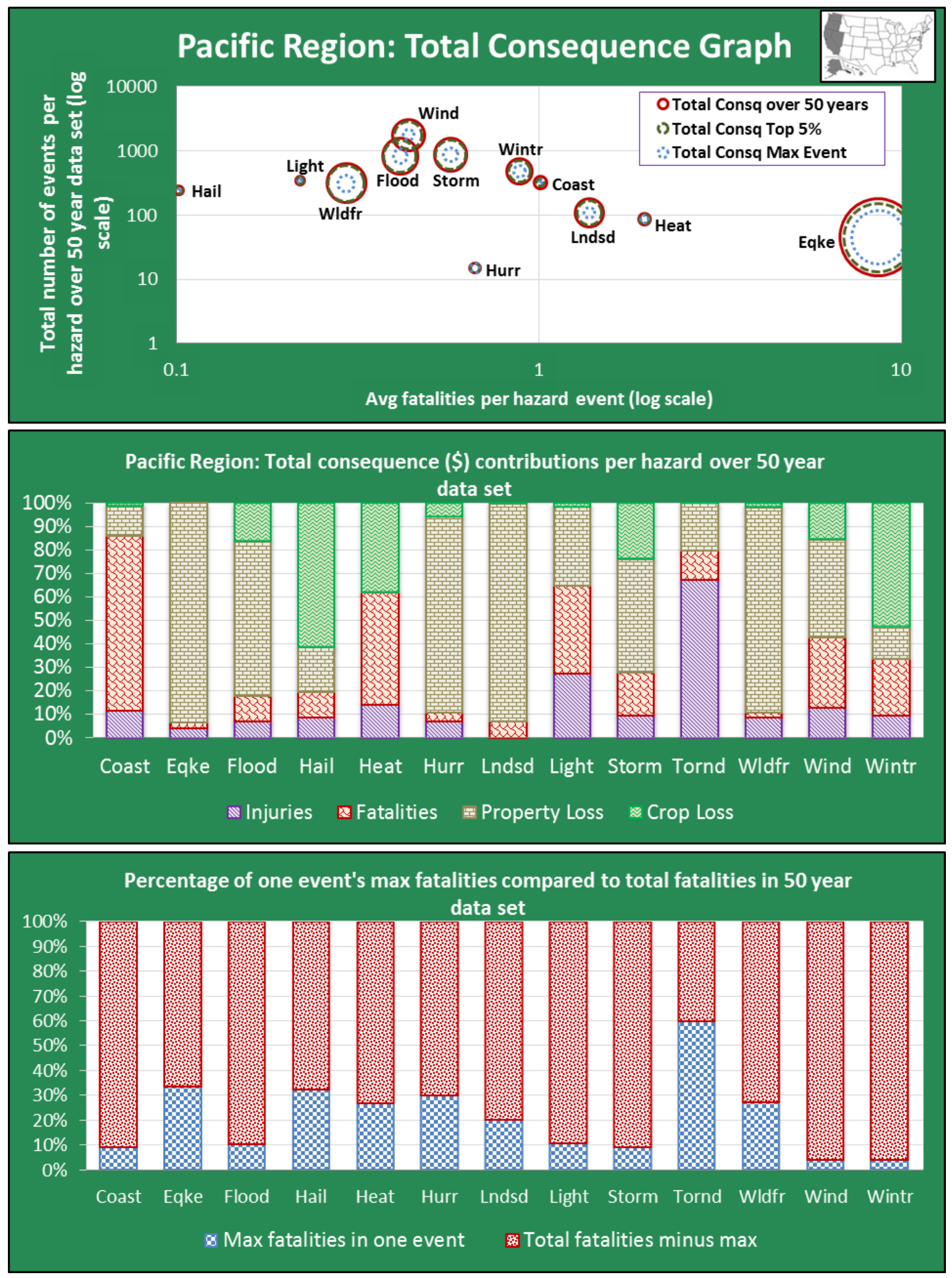

Figure 6-2: Pacific region fatality consequence graphics 


\begin{tabular}{|c|c|r|r|r|r|}
\hline DAMAGES & Y-axis & \multicolumn{1}{c|}{ X-axis } & Outside Circle Size & Inner Circle Size & \multicolumn{1}{c|}{ Middle Circle Size } \\
\hline Hazard & \# of events & $\begin{array}{c}\text { Avg damages per } \\
\text { event }\end{array}$ & Total Consequence & Total Consq Max & Total Consq Top 5\% \\
\hline Coast & 322 & $\$ 780,604$ & $\$ 1,757,606,390$ & $\$ 133,125,000$ & $\$ 608,596,589$ \\
\hline Eqke & 45 & $\$ 1,254,027,789$ & $\$ 60,435,874,500$ & $\$ 29,640,000,000$ & $\$ 47,954,224,000$ \\
\hline Flood & 826 & $\$ 12,880,129$ & $\$ 12,914,088,153$ & $\$ 2,025,000,000$ & $\$ 11,029,964,947$ \\
\hline Hail & 244 & $\$ 2,992,566$ & $\$ 907,830,007$ & $\$ 113,011,300$ & $\$ 632,547,440$ \\
\hline Heat & 87 & $\$ 6,242,421$ & $\$ 1,422,082,656$ & $\$ 726,729,600$ & $\$ 983,955,600$ \\
\hline Hurr & 15 & $\$ 63,828,507$ & $\$ 1,074,827,612$ & $\$ 854,750,000$ & $\$ 854,750,000$ \\
\hline Lndsd & 108 & $\$ 73,642,612$ & $\$ 8,568,092,071$ & $\$ 1,270,080,000$ & $\$ 6,465,295,437$ \\
\hline Light & 343 & $\$ 827,778$ & $\$ 803,356,011$ & $\$ 189,156,000$ & $\$ 528,198,822$ \\
\hline Storm & 875 & $\$ 9,172,871$ & $\$ 11,101,329,706$ & $\$ 2,025,000,000$ & $\$ 9,084,341,109$ \\
\hline Tornd & 208 & $\$ 617,535$ & $\$ 635,647,327$ & $\$ 461,142,171$ & $\$ 591,439,646$ \\
\hline Wldfr & 313 & $\$ 44,576,135$ & $\$ 15,665,022,221$ & $\$ 2,910,000,000$ & $\$ 13,691,568,000$ \\
\hline Wind & 1775 & $\$ 3,343,364$ & $\$ 10,360,441,221$ & $\$ 1,123,694,000$ & $\$ 7,669,195,178$ \\
\hline Wintr & 481 & $\$ 9,768,169$ & $\$ 7,057,893,293$ & $\$ 1,563,753,400$ & $\$ 4,894,389,745$ \\
\hline
\end{tabular}

\begin{tabular}{|c|r|r|r|r|r|}
\cline { 3 - 6 } \multicolumn{2}{c|}{} & \multicolumn{3}{c|}{ Contributions to the Total Consequence amount } \\
\hline Hazard & Total Consequence & \multicolumn{1}{c|}{ Injuries } & \multicolumn{1}{c|}{ Fatalities } & \multicolumn{1}{c|}{ Property Loss } & \multicolumn{1}{c|}{ Crop Loss } \\
\hline Coast & $\mathbf{\$ 1 , 7 5 7 , 6 0 6 , 3 9 0}$ & $\$ 206,412,000$ & $\$ 1,299,840,000$ & $\$ 229,853,688$ & $\$ 21,500,703$ \\
\hline Eqke & $\mathbf{\$ 6 0 , 4 3 5 , 8 7 4 , 5 0 0}$ & $\$ 2,448,624,000$ & $\$ 1,556,000,000$ & $\$ 56,431,250,500$ & $\$ 0$ \\
\hline Flood & $\mathbf{\$ 1 2 , 9 1 4 , 0 8 8 , 1 5 3}$ & $\$ 908,382,000$ & $\$ 1,366,720,000$ & $\$ 8,548,745,295$ & $\$ 2,090,240,859$ \\
\hline Hail & $\mathbf{\$ 9 0 7 , 8 3 0 , 0 0 7}$ & $\$ 78,684,000$ & $\$ 98,960,000$ & $\$ 173,924,324$ & $\$ 556,261,683$ \\
\hline Heat & $\mathbf{\$ 1 , 4 2 2 , 0 8 2 , 6 5 6}$ & $\$ 198,432,000$ & $\$ 680,560,000$ & $\$ 1,941,777$ & $\$ 541,148,880$ \\
\hline Hurr & $\mathbf{\$ 1 , 0 7 4 , 8 2 7 , 6 1 2}$ & $\$ 77,400,000$ & $\$ 40,000,000$ & $\$ 895,107,612$ & $\$ 62,320,000$ \\
\hline Lndsd & $\mathbf{\$ 8 , 5 6 8 , 0 9 2 , 0 7 1}$ & $\$ 19,050,000$ & $\$ 595,640,000$ & $\$ 7,928,556,220$ & $\$ 24,845,851$ \\
\hline Light & $\mathbf{\$ 8 0 3 , 3 5 6 , 0 1 1}$ & $\$ 219,228,000$ & $\$ 300,200,000$ & $\$ 270,928,289$ & $\$ 12,999,722$ \\
\hline Storm & $\mathbf{\$ 1 1 , 1 0 1 , 3 2 9 , 7 0 6}$ & $\$ 1,076,748,000$ & $\$ 1,998,320,000$ & $\$ 5,363,002,942$ & $\$ 2,663,258,764$ \\
\hline Tornd & $\mathbf{\$ 6 3 5 , 6 4 7 , 3 2 7}$ & $\$ 427,200,000$ & $\$ 80,000,000$ & $\$ 127,423,030$ & $\$ 1,024,297$ \\
\hline Wldfr & $\mathbf{\$ 1 5 , 6 6 5 , 0 2 2 , 2 2 1}$ & $\$ 1,344,612,000$ & $\$ 368,080,000$ & $\$ 13,649,146,901$ & $\$ 303,183,319$ \\
\hline Wind & $\mathbf{\$ 1 0 , 3 6 0 , 4 4 1 , 2 2 1}$ & $\$ 1,328,010,000$ & $\$ 3,097,960,000$ & $\$ 4,309,960,351$ & $\$ 1,624,510,870$ \\
\hline Wintr & $\mathbf{\$ 7 , 0 5 7 , 8 9 3 , 2 9 3}$ & $\$ 659,484,000$ & $\$ 1,699,920,000$ & $\$ 1,000,618,496$ & $\$ 3,697,870,797$ \\
\hline
\end{tabular}

\begin{tabular}{|c|r|c|r|r|r|}
\hline DAMAGES & & & & & \\
\hline Hazard & \multicolumn{1}{|c|}{ Total damages } & \# of events & Max damages in one & \multicolumn{1}{c|}{ Total minus max } & $\%$ of total \\
\hline Coast & $\$ 251,354,390$ & 322 & $\$ 24,614,100$ & $\$ 226,740,290$ & $10 \%$ \\
\hline Eqke & $\$ 56,431,250,500$ & 45 & $\$ 29,400,000,000$ & $\$ 27,031,250,500$ & $52 \%$ \\
\hline Flood & $\$ 10,638,986,153$ & 826 & $\$ 2,025,000,000$ & $\$ 8,613,986,153$ & $19 \%$ \\
\hline Hail & $\$ 730,186,007$ & 244 & $\$ 113,011,300$ & $\$ 617,174,707$ & $15 \%$ \\
\hline Heat & $\$ 543,090,656$ & 87 & $\$ 531,975,600$ & $\$ 11,115,057$ & $98 \%$ \\
\hline Hurr & $\$ 957,427,612$ & 15 & $\$ 782,750,000$ & $\$ 174,677,612$ & $82 \%$ \\
\hline Lndsd & $\$ 7,953,402,071$ & 108 & $\$ 1,270,080,000$ & $\$ 6,683,322,071$ & $16 \%$ \\
\hline Light & $\$ 283,928,011$ & 343 & $\$ 96,000,000$ & $\$ 187,928,011$ & $34 \%$ \\
\hline Storm & $\$ 8,026,261,706$ & 875 & $\$ 2,025,000,000$ & $\$ 6,001,261,706$ & $25 \%$ \\
\hline Tornd & $\$ 128,447,327$ & 208 & $\$ 52,542,171$ & $\$ 75,905,156$ & $41 \%$ \\
\hline Wldfr & $\$ 13,952,330,221$ & 313 & $\$ 2,720,000,000$ & $\$ 11,232,330,221$ & $19 \%$ \\
\hline Wind & $\$ 5,934,471,221$ & 1775 & $\$ 1,123,694,000$ & $\$ 4,810,777,221$ & $19 \%$ \\
\hline Wintr & $\$ 4,698,489,293$ & 481 & $\$ 1,555,753,400$ & $\$ 3,142,735,893$ & $33 \%$ \\
\hline
\end{tabular}

Table 6-3: Pacific region damage consequence tables 

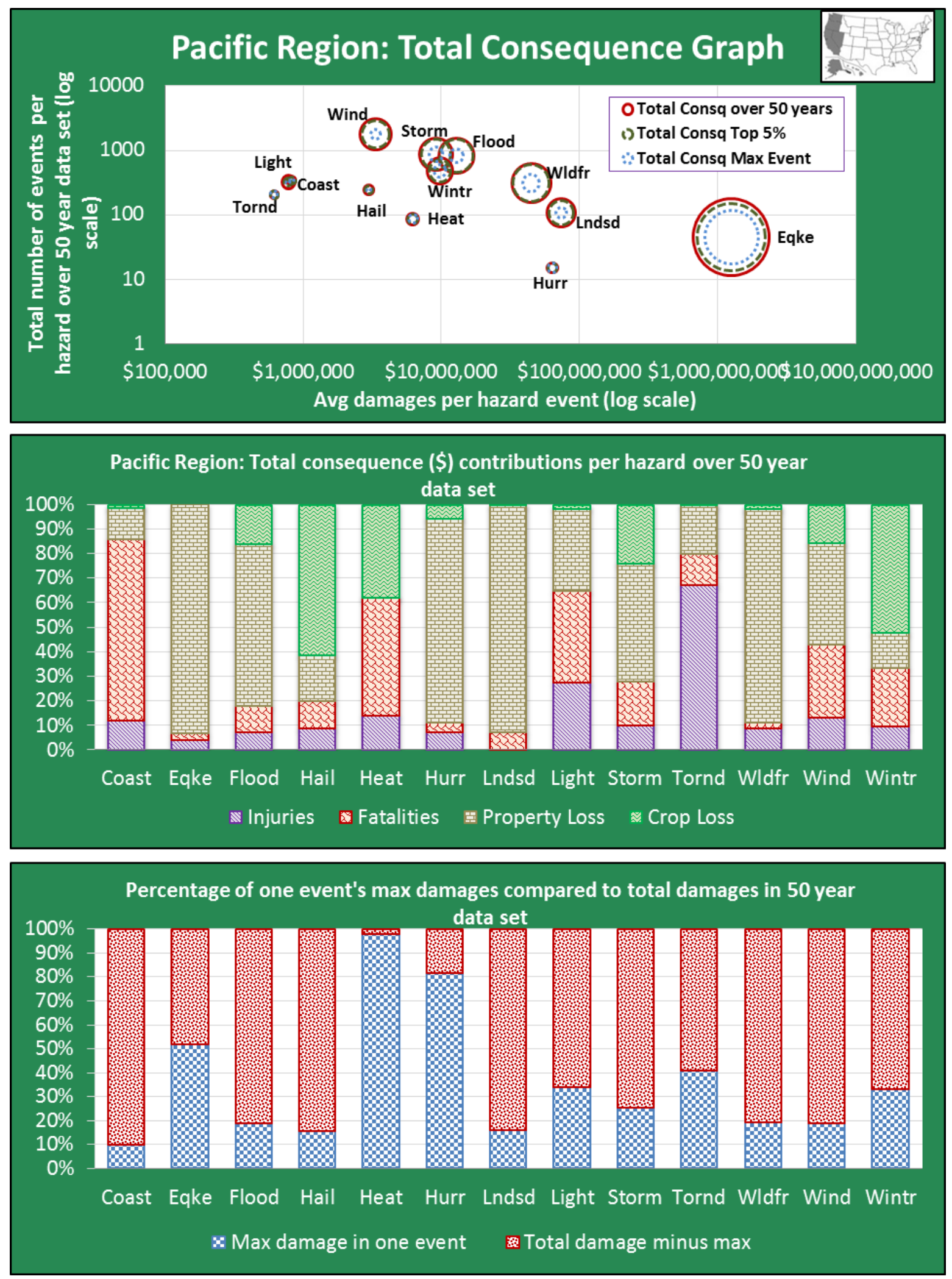

Figure 6-3: Pacific region damage consequence graphics 


\subsection{REGION CONSEQUENCE RANKINGS}

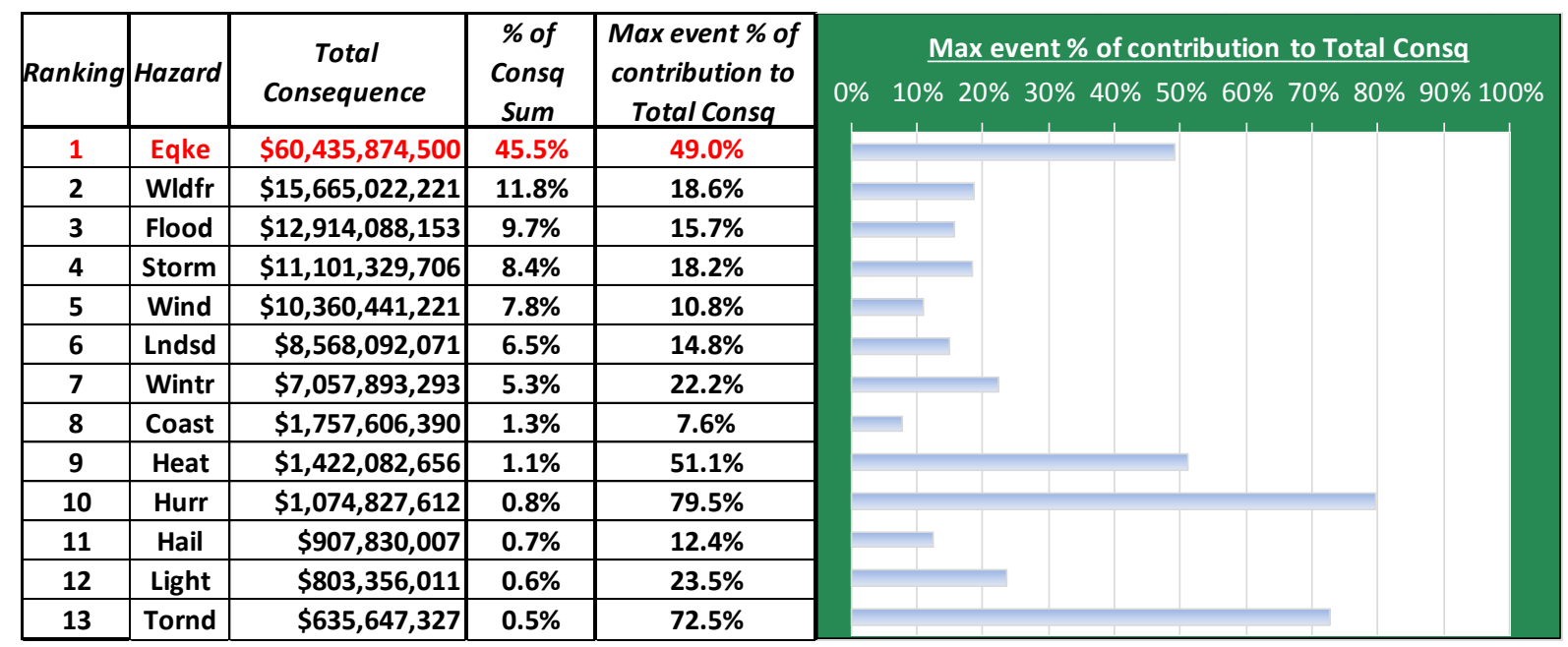

INJURIES

\begin{tabular}{|c|c|}
\hline Hazard & Avg injuries/event \\
\hline Eqke & 90.69 \\
\hline Hurr & 8.60 \\
\hline Wldfr & 7.16 \\
\hline Heat & 3.80 \\
\hline Tornd & 3.42 \\
\hline Wintr & 2.29 \\
\hline Storm & 2.05 \\
\hline Flood & 1.83 \\
\hline Wind & 1.25 \\
\hline Coast & 1.07 \\
\hline Light & 1.07 \\
\hline Hail & 0.54 \\
\hline Lndsd & 0.29 \\
\hline Hazard & Total injuries \\
\hline Eqke & 4081 \\
\hline Wldfr & 2241 \\
\hline Wind & 2213 \\
\hline Storm & 1795 \\
\hline Flood & 1514 \\
\hline Wintr & 1099 \\
\hline Tornd & 712 \\
\hline Light & 365 \\
\hline Coast & 344 \\
\hline Heat & 331 \\
\hline Hail & 131 \\
\hline Hurr & 129 \\
\hline Lndsd & 32 \\
\hline
\end{tabular}

FATALITIES

\begin{tabular}{|c|c|}
\hline Hazard & Avg fatalities/event \\
\hline Eqke & 8.64 \\
\hline Heat & 1.96 \\
\hline Lndsd & 1.38 \\
\hline Coast & 1.01 \\
\hline Wintr & 0.88 \\
\hline Hurr & 0.67 \\
\hline Storm & 0.57 \\
\hline Wind & 0.44 \\
\hline Flood & 0.41 \\
\hline Wldfr & 0.29 \\
\hline Light & 0.22 \\
\hline Hail & 0.10 \\
\hline Tornd & 0.10 \\
\hline \hline
\end{tabular}

\begin{tabular}{|c|c|}
\hline \hline Hazard & Total fatalities \\
\hline Wind & 774 \\
\hline Storm & 500 \\
\hline Wintr & 425 \\
\hline Eqke & 389 \\
\hline Flood & 342 \\
\hline Coast & 325 \\
\hline Heat & 170 \\
\hline Lndsd & 149 \\
\hline Wldfr & 92 \\
\hline Light & 75 \\
\hline Hail & 25 \\
\hline Tornd & 20 \\
\hline Hurr & 10 \\
\hline
\end{tabular}

DAMAGES

\begin{tabular}{|c|c|}
\hline Hazard & Avg damage/event \\
\hline Eqke & $\$ 1,254,027,789$ \\
\hline Lndsd & $\$ 73,642,612$ \\
\hline Hurr & $\$ 63,828,507$ \\
\hline Wldfr & $\$ 44,576,135$ \\
\hline Flood & $\$ 12,880,129$ \\
\hline Wintr & $\$ 9,768,169$ \\
\hline Storm & $\$ 9,172,871$ \\
\hline Heat & $\$ 6,242,421$ \\
\hline Wind & $\$ 3,343,364$ \\
\hline Hail & $\$ 2,992,566$ \\
\hline Light & $\$ 827,778$ \\
\hline Coast & $\$ 780,604$ \\
\hline Tornd & $\$ 617,535$ \\
\hline Hazard & Total damage \\
\hline Eqke & $\$ 56,431,250,500$ \\
\hline Wldfr & $\$ 13,952,330,221$ \\
\hline Flood & $\$ 10,638,986,153$ \\
\hline Storm & $\$ 8,026,261,706$ \\
\hline Lndsd & $\$ 7,953,402,071$ \\
\hline Wind & $\$ 5,934,471,221$ \\
\hline Wintr & $\$ 4,698,489,293$ \\
\hline Hurr & $\$ 957,427,612$ \\
\hline Hail & $\$ 730,186,007$ \\
\hline Heat & $\$ 543,090,656$ \\
\hline Light & $\$ 283,928,011$ \\
\hline Coast & $\$ 251,354,390$ \\
\hline Tornd & $\$ 128,447,327$ \\
\hline
\end{tabular}

Table 6-4: Pacific region consequence rankings 


\subsection{REGIONAL SUMMARY}

The Pacific region was among the lowest in terms of the number of hazardous events, but accounts for $20 \%$ of property losses in the US since 1960 . All 13 natural hazards in this study are represented and some of the largest catastrophes that the United States has ever experienced have occurred in this region. Notably, there is a significant difference in the size of hazard rings in the total consequence graphs (Figures 6-1, 6-2, 6-3). It is evident from the graphs that the earthquake hazard is the largest and accounts for $\$ 60$ billion in consequences to date. Although earthquakes had the fewest number of events at 45 , it amounts to nearly half of all the consequences combined.

Additionally, earthquakes are ranked the highest in average losses for all three categories. When comparing these averages of the earthquake hazard to the second contribution bar chart, it can be seen that an event has caused half of all damages, a third of all fatalities, and more than ninety percent of all injuries. It should be noted that losses from these three categories are represented by three separate earthquake occurrences. When the largest figure is removed from each category, the averages reduce drastically. This demonstrates how much one significant loss can influence the average.

Furthermore, an evaluation of the earthquake hazard's contributions reveals that nearly $93 \%$ of the consequences are due to property damage. Out of the property damage amounts, there is a $75 \%$ chance that damage value will range from $\$ 1$ million to $\$ 1$ billion in the next occurrence. Even though relatively few, when earthquakes occur, they have destructive longterm effects. A larger sample size over a greater amount of time will give a better depiction of how severe these events can be. According to engineering estimates, in the California shake-out 
exercise, one earthquake can cause damages of over two hundred billion dollars and tens of thousands of injuries and thousands fatalities if it occurs in a highly populated area (CalShakeOut 2008). This exemplifies how extreme low probability events require special scrutiny in mitigation practices. 


\section{Mountain Regional Analysis}

\subsection{LAYOUT}

Chapter 7 contains the natural hazard risk assessment and analysis for the Mountain region, which consists of the following five states: Idaho, Montana, Wyoming, Utah, and Colorado. Figures included in this chapter are:

- Mountain region consequence tables for injuries, fatalities, and damages

\section{Table 7-1, Table 7-2, and Table 7-3, respectively}

- Mountain region consequence graphics for injuries, fatalities, and damages

$$
\text { Figure 7-1, Figure 7-2, and Figure 7-3, respectively }
$$

- Mountain region consequence rankings (Table 7-4)

Total consequence and overall percentage

Average loss per event: injuries, fatalities, damages

Total losses: injuries, fatalities, damages

The following hazard events have not been recorded by SHELDUS and will not appear in the graphical or chart displays for this region.

- Coastal

- Hurricane 


\subsection{REGION CONSEQUENCE DISPLAYS}

\begin{tabular}{|c|c|c|c|c|c|}
\hline INJURIES & Y-axis & $\mathrm{X}$-axis & Outside Circle Size & Inner Circle Size & Middle Circle Size \\
\hline Hazard & \# of events & $\begin{array}{c}\text { Avg injuries per } \\
\text { event }\end{array}$ & Total Consequence & Total Consq Max & Total Consq Top 5\% \\
\hline Coast & 0 & 0.00 & $\$ 0$ & $\$ 0$ & $\$ 0$ \\
\hline Eqke & 5 & 1.80 & $\$ 57,994,150$ & $\$ 37,175,000$ & $\$ 37,175,000$ \\
\hline Flood & 630 & 0.70 & $\$ 3,357,130,954$ & $\$ 793,399,142$ & $\$ 2,946,960,220$ \\
\hline Hail & 1161 & 0.41 & $\$ 7,324,025,576$ & $\$ 3,610,000,000$ & $\$ 6,634,487,272$ \\
\hline Heat & 12 & 0.67 & $\$ 18,181,750$ & $\$ 6,757,500$ & $\$ 6,757,500$ \\
\hline Hurr & 0 & 0.00 & $\$ 0$ & $\$ 0$ & $\$ 0$ \\
\hline Lndsd & 37 & 0.43 & $\$ 1,143,019,196$ & $\$ 984,418,861$ & $\$ 1,074,018,410$ \\
\hline Light & 859 & 0.77 & $\$ 1,558,906,692$ & $\$ 17,600,000$ & $\$ 404,661,181$ \\
\hline Storm & 1109 & 0.66 & $\$ 3,068,472,503$ & $\$ 793,150,000$ & $\$ 2,423,606,630$ \\
\hline Tornd & 416 & 0.90 & $\$ 696,227,624$ & $\$ 275,365,480$ & $\$ 562,055,780$ \\
\hline Wldfr & 81 & 0.64 & $\$ 502,156,631$ & $\$ 147,281,181$ & $\$ 295,826,681$ \\
\hline Wind & 1897 & 0.87 & $\$ 6,788,879,625$ & $\$ 3,610,000,000$ & $\$ 5,594,568,666$ \\
\hline Wintr & 715 & 2.40 & $\$ 3,657,157,109$ & $\$ 151,330,030$ & $\$ 1,756,933,958$ \\
\hline
\end{tabular}

\begin{tabular}{|c|c|c|c|c|c|}
\hline \multirow[b]{2}{*}{ Hazard } & \multirow[b]{2}{*}{ Total Consequence } & \multicolumn{4}{|c|}{ Contributions to the Total Consequence amount } \\
\hline & & Injuries & Fatalities & Property Loss & Crop Loss \\
\hline Coast & \$0 & $\$ 0$ & $\$ 0$ & $\$ 0$ & $\$ 0$ \\
\hline Eqke & $\$ 57,994,150$ & $\$ 5,400,000$ & $\$ 20,000,000$ & $\$ 32,594,150$ & $\$ 0$ \\
\hline Flood & $\$ 3,357,130,954$ & $\$ 265,620,000$ & $\$ 965,560,000$ & $\$ 1,966,864,090$ & $\$ 159,086,864$ \\
\hline Hail & $\$ 7,324,025,576$ & $\$ 282,246,000$ & $\$ 176,360,000$ & $\$ 2,708,475,356$ & $\$ 4,156,944,219$ \\
\hline Heat & $\$ 18,181,750$ & $\$ 4,794,000$ & $\$ 3,960,000$ & $\$ 6,402,750$ & $\$ 3,025,000$ \\
\hline Hurr & $\$ 0$ & $\$ 0$ & $\$ 0$ & $\$ 0$ & $\$ 0$ \\
\hline Lndsd & $\$ 1,143,019,196$ & $\$ 9,600,000$ & $\$ 40,000,000$ & $\$ 1,093,419,196$ & $\$ 0$ \\
\hline Light & $\$ 1,558,906,692$ & $\$ 396,078,000$ & $\$ 1,031,920,000$ & $\$ 74,985,853$ & $\$ 55,922,839$ \\
\hline Storm & $\$ 3,068,472,503$ & $\$ 438,822,000$ & $\$ 1,227,080,000$ & $\$ 1,138,615,457$ & $\$ 263,955,046$ \\
\hline Tornd & $\$ 696,227,624$ & $\$ 225,000,000$ & $\$ 44,000,000$ & $\$ 386,460,051$ & $\$ 40,767,573$ \\
\hline Wldfr & $\$ 502,156,631$ & $\$ 31,200,000$ & $\$ 59,920,000$ & $\$ 331,727,897$ & $\$ 79,308,735$ \\
\hline Wind & $\$ 6,788,879,625$ & $\$ 984,732,000$ & $\$ 924,120,000$ & $\$ 999,023,013$ & $\$ 3,881,004,612$ \\
\hline Wintr & $\$ 3,657,157,109$ & $\$ 1,031,430,000$ & $\$ 1,558,480,000$ & $\$ 802,737,507$ & $\$ 264,509,602$ \\
\hline
\end{tabular}

\begin{tabular}{|c|c|c|c|c|c|}
\hline INJURIES & & & & & \\
\hline Hazard & Total injuries & \# of events & Max injuries in one & Total minus max & $\%$ of total \\
\hline Coast & 0 & 0 & 0 & 0 & $0 \%$ \\
\hline Eqke & 9 & 5 & 6 & 3 & $67 \%$ \\
\hline Flood & 443 & 630 & 250 & 193 & $56 \%$ \\
\hline Hail & 470 & 1161 & 70 & 400 & $15 \%$ \\
\hline Heat & 8 & 12 & 7 & 1 & $88 \%$ \\
\hline Hurr & 0 & 0 & 0 & 0 & $0 \%$ \\
\hline Lndsd & 16 & 37 & 6 & 10 & $38 \%$ \\
\hline Light & 660 & 859 & 19 & 641 & $3 \%$ \\
\hline Storm & 731 & 1109 & 250 & 481 & $\mathbf{3 4 \%}$ \\
\hline Tornd & 375 & 416 & 80 & 295 & $\mathbf{2 1 \%}$ \\
\hline Wldfr & 52 & 81 & 9 & 43 & $17 \%$ \\
\hline Wind & 1641 & 1897 & 140 & 1501 & $9 \%$ \\
\hline Wintr & 1719 & 715 & 200 & 1519 & $12 \%$ \\
\hline
\end{tabular}

Table 7-1: Mountain region injury consequence tables 


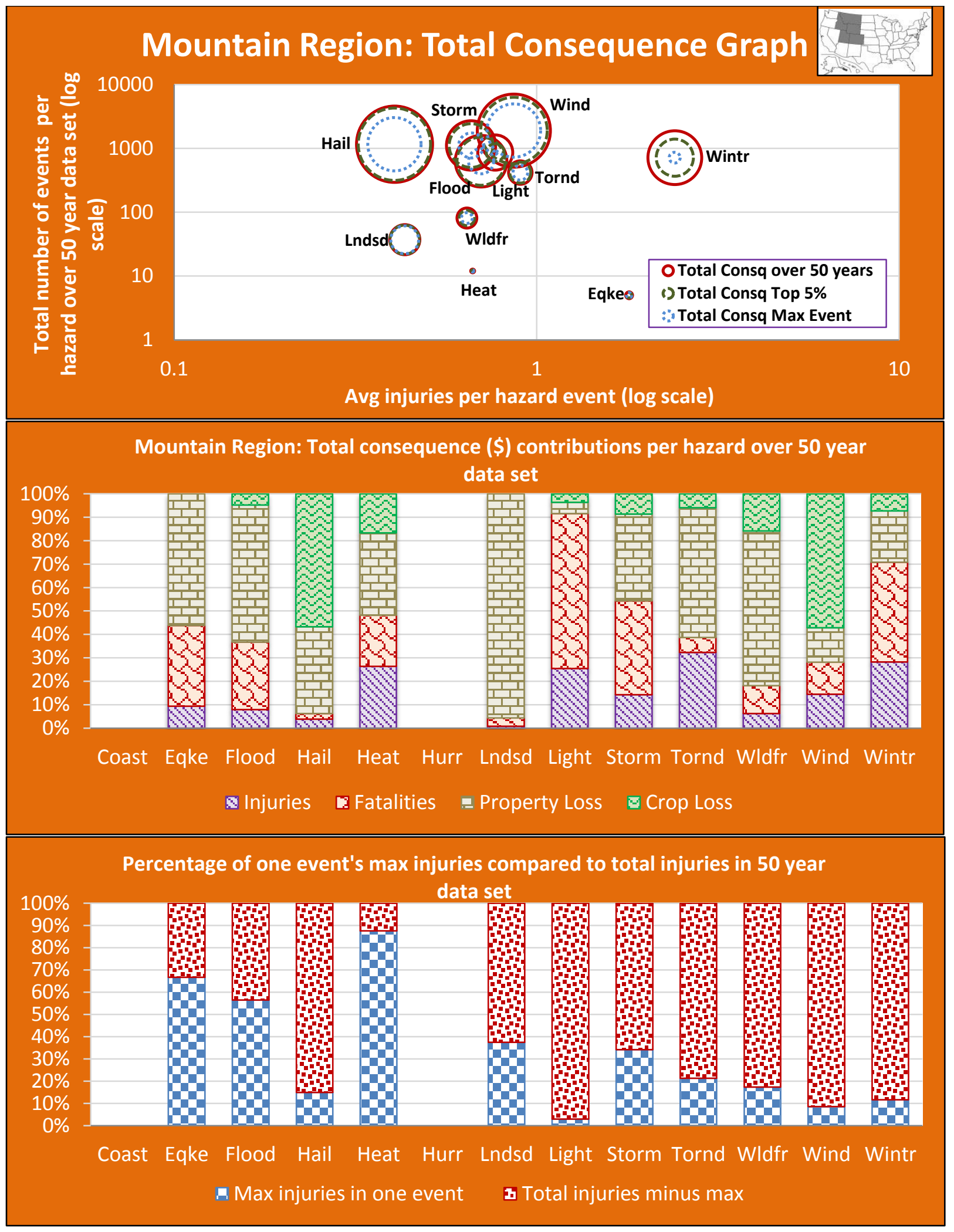

Figure 7-1: Mountain region injury consequence graphics 


\begin{tabular}{|c|c|c|c|c|c|}
\hline FATALITIES & $\mathrm{Y}$-axis & $\mathrm{X}$-axis & Outside Circle Size & Inner Circle Size & Middle Circle Size \\
\hline Hazard & \# of events & $\begin{array}{c}\text { Avg fatalities per } \\
\text { event }\end{array}$ & Total Consequence & Total Consq Max & Total Consq Top 5\% \\
\hline Coast & 0 & 0.00 & $\$ 0$ & $\$ 0$ & $\$ 0$ \\
\hline Eqke & 5 & 1.00 & $\$ 57,994,150$ & $\$ 37,175,000$ & $\$ 37,175,000$ \\
\hline Flood & 630 & 0.38 & $\$ 3,357,130,954$ & $\$ 793,399,142$ & $\$ 2,946,960,220$ \\
\hline Hail & 1161 & 0.04 & $\$ 7,324,025,576$ & $\$ 3,610,000,000$ & $\$ 6,634,487,272$ \\
\hline Heat & 12 & 0.08 & $\$ 18,181,750$ & $\$ 6,757,500$ & $\$ 6,757,500$ \\
\hline Hurr & 0 & 0.00 & $\$ 0$ & $\$ 0$ & $\$ 0$ \\
\hline Lndsd & 37 & 0.27 & $\$ 1,143,019,196$ & $\$ 984,418,861$ & $\$ 1,074,018,410$ \\
\hline Light & 859 & 0.30 & $\$ 1,558,906,692$ & $\$ 17,600,000$ & $\$ 404,661,181$ \\
\hline Storm & 1109 & 0.28 & $\$ 3,068,472,503$ & $\$ 793,150,000$ & $\$ 2,423,606,630$ \\
\hline Tornd & 416 & 0.03 & $\$ 696,227,624$ & $\$ 275,365,480$ & $\$ 562,055,780$ \\
\hline Wldfr & 81 & 0.18 & $\$ 502,156,631$ & $\$ 147,281,181$ & $\$ 295,826,681$ \\
\hline Wind & 1897 & 0.12 & $\$ 6,788,879,625$ & $\$ 3,610,000,000$ & $\$ 5,594,568,666$ \\
\hline Wintr & 715 & 0.54 & $\$ 3,657,157,109$ & $\$ 151,330,030$ & $\$ 1,756,933,958$ \\
\hline
\end{tabular}

\begin{tabular}{|c|r|r|r|r|r|}
\cline { 3 - 6 } \multicolumn{2}{c|}{} & \multicolumn{3}{c|}{ Contributions to the Total Consequence amount } \\
\hline Hazard & Total Consequence & \multicolumn{1}{c|}{ Injuries } & \multicolumn{1}{c|}{ Fatalities } & \multicolumn{1}{c|}{ Property Loss } & \multicolumn{1}{c|}{ Crop Loss } \\
\hline Coast & $\mathbf{\$ 0}$ & $\$ 0$ & $\$ 0$ & $\$ 0$ & $\$ 0$ \\
\hline Eqke & $\mathbf{\$ 5 7 , 9 9 4 , \mathbf { 1 5 0 }}$ & $\$ 5,400,000$ & $\$ 20,000,000$ & $\$ 32,594,150$ & $\$ 0$ \\
\hline Flood & $\mathbf{\$ 3 , 3 5 7 , 1 3 0 , 9 5 4}$ & $\$ 265,620,000$ & $\$ 965,560,000$ & $\$ 1,966,864,090$ & $\$ 159,086,864$ \\
\hline Hail & $\mathbf{\$ 7 , 3 2 4 , 0 2 5 , 5 7 6}$ & $\$ 282,246,000$ & $\$ 176,360,000$ & $\$ 2,708,475,356$ & $\$ 4,156,944,219$ \\
\hline Heat & $\mathbf{\$ 1 8 , 1 8 1 , 7 5 0}$ & $\$ 4,794,000$ & $\$ 3,960,000$ & $\$ 6,402,750$ & $\$ 3,025,000$ \\
\hline Hurr & $\mathbf{\$ 0}$ & $\$ 0$ & $\$ 0$ & $\$ 0$ & $\$ 0$ \\
\hline Lndsd & $\mathbf{\$ 1 , 1 4 3 , 0 1 9 , 1 9 6}$ & $\$ 9,600,000$ & $\$ 40,000,000$ & $\$ 1,093,419,196$ & $\$ 0$ \\
\hline Light & $\mathbf{\$ 1 , 5 5 8 , 9 0 6 , 6 9 2}$ & $\$ 396,078,000$ & $\$ 1,031,920,000$ & $\$ 74,985,853$ & $\$ 55,922,839$ \\
\hline Storm & $\mathbf{\$ 3 , 0 6 8 , 4 7 2 , 5 0 3}$ & $\$ 438,822,000$ & $\$ 1,227,080,000$ & $\$ 1,138,615,457$ & $\$ 263,955,046$ \\
\hline Tornd & $\mathbf{\$ 6 9 6 , 2 2 7 , 6 2 4}$ & $\$ 225,000,000$ & $\$ 44,000,000$ & $\$ 386,460,051$ & $\$ 40,767,573$ \\
\hline Wldfr & $\mathbf{\$ 5 0 2 , 1 5 6 , 6 3 1}$ & $\$ 31,200,000$ & $\$ 59,920,000$ & $\$ 331,727,897$ & $\$ 79,308,735$ \\
\hline Wind & $\mathbf{\$ 6 , 7 8 8 , 8 7 9 , 6 2 5}$ & $\$ 984,732,000$ & $\$ 924,120,000$ & $\$ 999,023,013$ & $\$ 3,881,004,612$ \\
\hline Wintr & $\mathbf{\$ 3 , 6 5 7 , 1 5 7 , 1 0 9}$ & $\$ 1,031,430,000$ & $\$ 1,558,480,000$ & $\$ 802,737,507$ & $\$ 264,509,602$ \\
\hline
\end{tabular}

\begin{tabular}{|c|c|c|c|c|c|}
\hline FATALITIES & & & & & \\
\hline Hazard & Total fatalities & \# of events & Max fatalities in one & Total minus max & $\%$ of total \\
\hline Coast & 0 & 0 & 0 & 0 & $0 \%$ \\
\hline Eqke & 5 & 5 & 3 & 2 & $60 \%$ \\
\hline Flood & 241 & 630 & 156 & 85 & $65 \%$ \\
\hline Hail & 44 & 1161 & 12 & 32 & $27 \%$ \\
\hline Heat & 1 & 12 & 1 & 0 & $100 \%$ \\
\hline Hurr & 0 & 0 & 0 & 0 & $0 \%$ \\
\hline Lndsd & 10 & 37 & 2 & 8 & $20 \%$ \\
\hline Light & 258 & 859 & 3 & 255 & $1 \%$ \\
\hline Storm & 307 & 1109 & 156 & 151 & $51 \%$ \\
\hline Tornd & 11 & 416 & 2 & 9 & $18 \%$ \\
\hline Wldfr & 15 & 81 & 6 & 9 & $40 \%$ \\
\hline Wind & 231 & 1897 & 25 & 206 & $11 \%$ \\
\hline Wintr & 390 & 715 & 25 & 365 & $6 \%$ \\
\hline
\end{tabular}

Table 7-2: Mountain region fatality consequence tables 

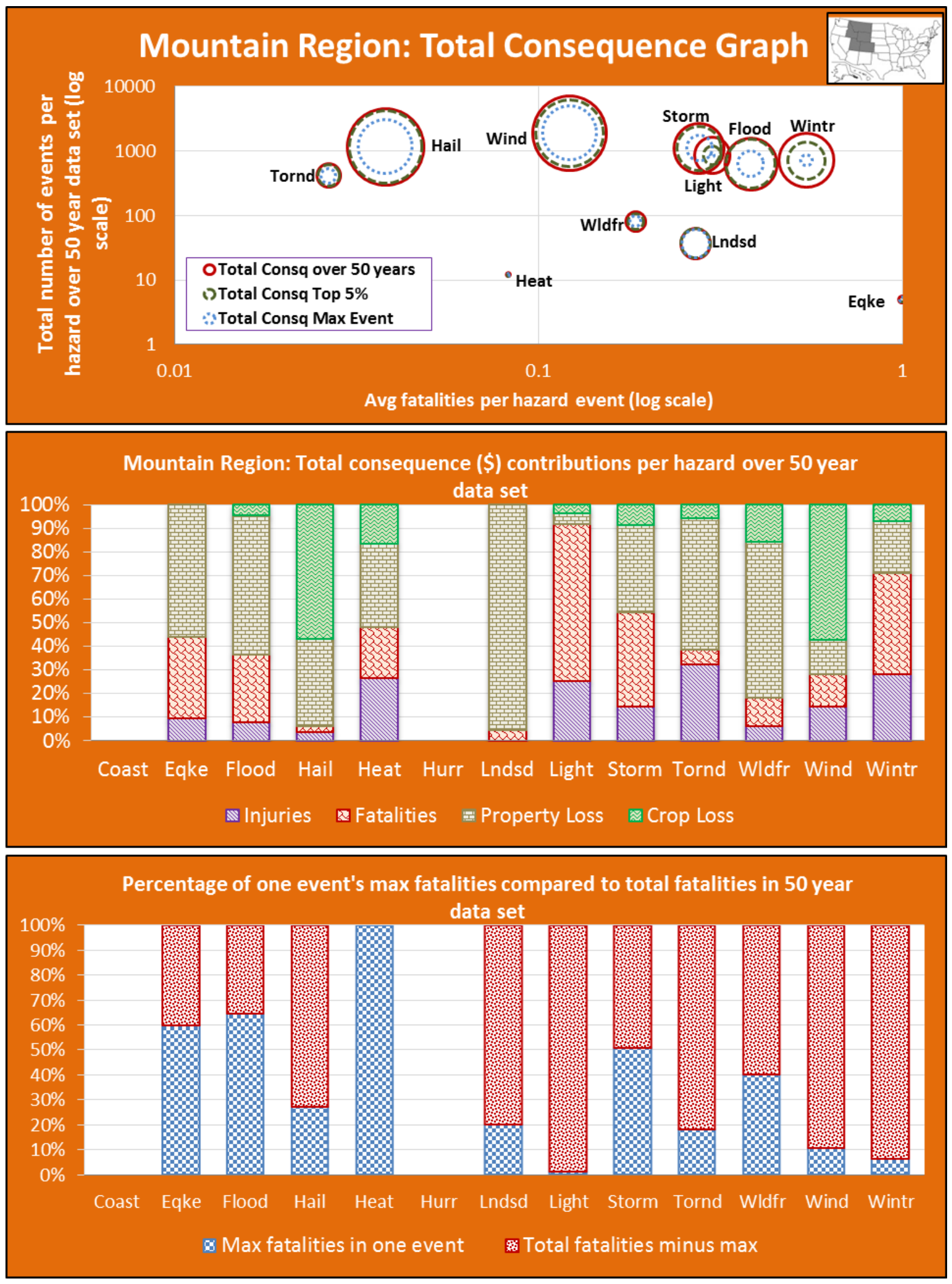

Figure 7-2: Mountain region fatality consequence graphics 


\begin{tabular}{|c|c|c|c|c|c|}
\hline DAMAGES & Y-axis & $\mathrm{X}$-axis & Outside Circle Size & Inner Circle Size & Middle Circle Size \\
\hline Hazard & \# of events & $\begin{array}{c}\text { Avg damages per } \\
\text { event }\end{array}$ & Total Consequence & Total Consq Max & Total Consq Top 5\% \\
\hline Coast & 0 & $\$ 0$ & $\$ 0$ & $\$ 0$ & $\$ 0$ \\
\hline Eqke & 5 & $\$ 6,518,830$ & $\$ 57,994,150$ & $\$ 37,175,000$ & $\$ 37,175,000$ \\
\hline Flood & 630 & $\$ 3,374,525$ & $\$ 3,357,130,954$ & $\$ 793,399,142$ & $\$ 2,946,960,220$ \\
\hline Hail & 1161 & $\$ 5,913,367$ & $\$ 7,324,025,576$ & $\$ 3,610,000,000$ & $\$ 6,634,487,272$ \\
\hline Heat & 12 & $\$ 785,646$ & $\$ 18,181,750$ & $\$ 6,757,500$ & $\$ 6,757,500$ \\
\hline Hurr & 0 & $\$ 0$ & $\$ 0$ & $\$ 0$ & $\$ 0$ \\
\hline Lndsd & 37 & $\$ 29,551,870$ & $\$ 1,143,019,196$ & $\$ 984,418,861$ & $\$ 1,074,018,410$ \\
\hline Light & 859 & $\$ 152,397$ & $\$ 1,558,906,692$ & $\$ 17,600,000$ & $\$ 404,661,181$ \\
\hline Storm & 1109 & $\$ 1,264,716$ & $\$ 3,068,472,503$ & $\$ 793,150,000$ & $\$ 2,423,606,630$ \\
\hline Tornd & 416 & $\$ 1,026,989$ & $\$ 696,227,624$ & $\$ 275,365,480$ & $\$ 562,055,780$ \\
\hline Wldfr & 81 & $\$ 5,074,526$ & $\$ 502,156,631$ & $\$ 147,281,181$ & $\$ 295,826,681$ \\
\hline Wind & 1897 & $\$ 2,572,497$ & $\$ 6,788,879,625$ & $\$ 3,610,000,000$ & $\$ 5,594,568,666$ \\
\hline Wintr & 715 & $\$ 1,492,653$ & $\$ 3,657,157,109$ & $\$ 151,330,030$ & $\$ 1,756,933,958$ \\
\hline
\end{tabular}

\begin{tabular}{|c|c|c|c|c|c|}
\hline \multirow[b]{2}{*}{ Hazard } & \multirow[b]{2}{*}{ Total Consequence } & \multicolumn{4}{|c|}{ Contributions to the Total Consequence amount } \\
\hline & & Injuries & Fatalities & Property Loss & Crop Loss \\
\hline Coast & $\$ 0$ & $\$ 0$ & $\$ 0$ & $\$ 0$ & $\$ 0$ \\
\hline Eqke & $\$ 57,994,150$ & $\$ 5,400,000$ & $\$ 20,000,000$ & $\$ 32,594,150$ & $\$ 0$ \\
\hline Flood & $\$ 3,357,130,954$ & $\$ 265,620,000$ & $\$ 965,560,000$ & $\$ 1,966,864,090$ & $\$ 159,086,864$ \\
\hline Hail & $\$ 7,324,025,576$ & $\$ 282,246,000$ & $\$ 176,360,000$ & $\$ 2,708,475,356$ & $\$ 4,156,944,219$ \\
\hline Heat & $\$ 18,181,750$ & $\$ 4,794,000$ & $\$ 3,960,000$ & $\$ 6,402,750$ & $\$ 3,025,000$ \\
\hline Hurr & $\$ 0$ & $\$ 0$ & $\$ 0$ & $\$ 0$ & $\$ 0$ \\
\hline Lndsd & $\$ 1,143,019,196$ & $\$ 9,600,000$ & $\$ 40,000,000$ & $\$ 1,093,419,196$ & $\$ 0$ \\
\hline Light & $\$ 1,558,906,692$ & $\$ 396,078,000$ & $\$ 1,031,920,000$ & $\$ 74,985,853$ & $\$ 55,922,839$ \\
\hline Storm & $\$ 3,068,472,503$ & $\$ 438,822,000$ & $\$ 1,227,080,000$ & $\$ 1,138,615,457$ & $\$ 263,955,046$ \\
\hline Tornd & $\$ 696,227,624$ & $\$ 225,000,000$ & $\$ 44,000,000$ & $\$ 386,460,051$ & $\$ 40,767,573$ \\
\hline Wldfr & $\$ 502,156,631$ & $\$ 31,200,000$ & $\$ 59,920,000$ & $\$ 331,727,897$ & $\$ 79,308,735$ \\
\hline Wind & $\$ 6,788,879,625$ & $\$ 984,732,000$ & $\$ 924,120,000$ & $\$ 999,023,013$ & $\$ 3,881,004,612$ \\
\hline Wintr & $\$ 3,657,157,109$ & $\$ 1,031,430,000$ & $\$ 1,558,480,000$ & $\$ 802,737,507$ & $\$ 264,509,602$ \\
\hline
\end{tabular}

\begin{tabular}{|c|r|c|r|r|c|}
\hline DAMAGES & & & & & \\
\hline Hazard & \multicolumn{1}{|l|}{ Total damages } & \# of events & Max damages in one & \multicolumn{1}{|c|}{ Total minus max } & $\%$ of total \\
\hline Coast & $\$ 0$ & 0 & $\$ 0$ & $\$ 0$ & $0 \%$ \\
\hline Eqke & $\$ 32,594,150$ & 5 & $\$ 27,375,000$ & $\$ 5,219,150$ & $84 \%$ \\
\hline Flood & $\$ 2,125,950,954$ & 630 & $\$ 346,346,000$ & $\$ 1,779,604,953$ & $16 \%$ \\
\hline Hail & $\$ 6,865,419,576$ & 1161 & $\$ 3,610,000,000$ & $\$ 3,255,419,576$ & $53 \%$ \\
\hline Heat & $\$ 9,427,750$ & 12 & $\$ 2,557,500$ & $\$ 6,870,250$ & $27 \%$ \\
\hline Hurr & $\$ 0$ & 0 & $\$ 0$ & $\$ 0$ & $0 \%$ \\
\hline Lndsd & $\$ 1,093,419,196$ & 37 & $\$ 984,418,861$ & $\$ 109,000,336$ & $90 \%$ \\
\hline Light & $\$ 130,908,692$ & 859 & $\$ 17,600,000$ & $\$ 113,308,692$ & $13 \%$ \\
\hline Storm & $\$ 1,402,570,503$ & 1109 & $\$ 346,384,060$ & $\$ 1,056,186,443$ & $25 \%$ \\
\hline Tornd & $\$ 427,227,624$ & 416 & $\$ 223,365,480$ & $\$ 203,862,144$ & $52 \%$ \\
\hline Wldfr & $\$ 411,036,631$ & 81 & $\$ 147,281,181$ & $\$ 263,755,450$ & $36 \%$ \\
\hline Wind & $\$ 4,880,027,625$ & 1897 & $\$ 3,610,000,000$ & $\$ 1,270,027,625$ & $74 \%$ \\
\hline Wintr & $\$ 1,067,247,109$ & 715 & $\$ 114,130,030$ & $\$ 953,117,079$ & $11 \%$ \\
\hline
\end{tabular}

Table 7-3: Mountain region damage consequence tables 

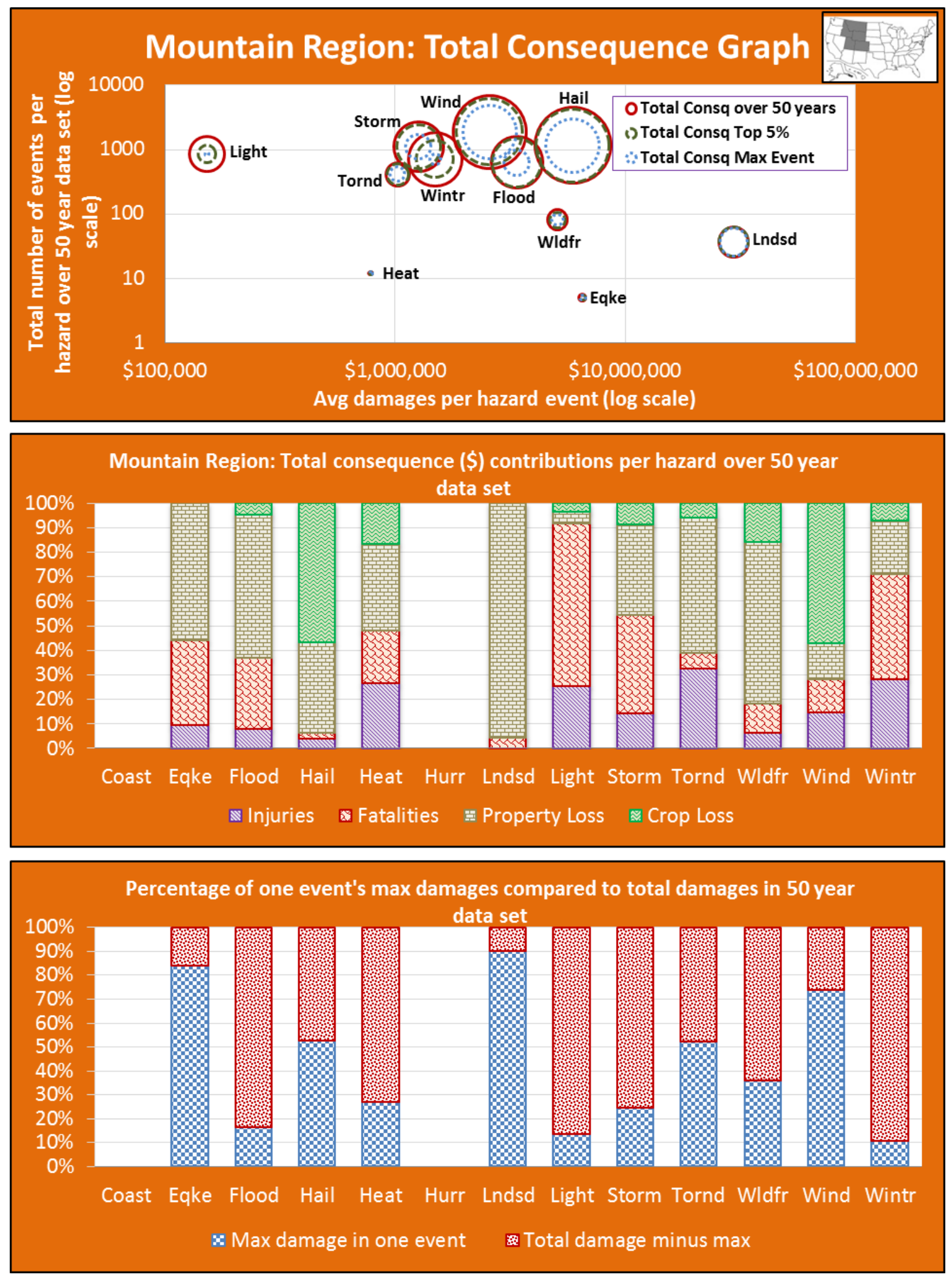

Figure 7-3: Mountain region damage consequence graphics 


\subsection{REGION CONSEQUENCE RANKINGS}

\begin{tabular}{|c|c|c|c|c|c|c|c|c|c|c|c|}
\hline Ranking & Hazard & $\begin{array}{c}\text { Total } \\
\text { Consequence }\end{array}$ & $\begin{array}{c}\text { \% of } \\
\text { Consq } \\
\text { Sum }\end{array}$ & $\begin{array}{c}\text { Max event \% of } \\
\text { contribution to } \\
\text { Total Consq }\end{array}$ & \multicolumn{7}{|c|}{$\begin{array}{l}\text { Max event } \% \text { of contribution to Total Consq } \\
\% 20 \% 30 \% 40 \% 50 \% 60 \% 70 \% \quad 80 \% 90 \%\end{array}$} \\
\hline 1 & Hail & $\$ 7,324,025,576$ & $26.0 \%$ & $49.3 \%$ & & & 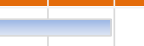 & & & & \\
\hline 2 & Wind & $\$ 6,788,879,625$ & $24.1 \%$ & $53.2 \%$ & & & & & & & \\
\hline 3 & Wintr & $\$ 3,657,157,109$ & $13.0 \%$ & $4.1 \%$ & & & & & & & \\
\hline 4 & Flood & $\$ 3,357,130,954$ & $11.9 \%$ & $23.6 \%$ & & & & & & & \\
\hline 5 & Storm & $\$ 3,068,472,503$ & $10.9 \%$ & $25.8 \%$ & & & & & & & \\
\hline 6 & Light & $\$ 1,558,906,692$ & $5.5 \%$ & $1.1 \%$ & & & & & & & \\
\hline 7 & Lndsd & $\$ 1,143,019,196$ & $4.1 \%$ & $86.1 \%$ & & & & & & & \\
\hline 8 & Tornd & $\$ 696,227,624$ & $2.5 \%$ & $0.0 \%$ & & & & & & & \\
\hline 9 & Wldfr & $\$ 502,156,631$ & $1.8 \%$ & $29.3 \%$ & & & & & & & \\
\hline 10 & Eqke & $\$ 57,994,150$ & $0.2 \%$ & $0.0 \%$ & & & & & & & \\
\hline 11 & Heat & $\$ 18,181,750$ & $0.1 \%$ & $37.2 \%$ & & & & & & & \\
\hline 12 & Coast & $\$ 0$ & $0.0 \%$ & $0.0 \%$ & & & & & & & \\
\hline 13 & Hurr & $\$ 0$ & $0.0 \%$ & $0.0 \%$ & & & & & & & \\
\hline
\end{tabular}

INJURIES

\begin{tabular}{|c|c|}
\hline Hazard & Avg injuries/event \\
\hline Wintr & 2.40 \\
\hline Eqke & 1.80 \\
\hline Tornd & 0.90 \\
\hline Wind & 0.87 \\
\hline Light & 0.77 \\
\hline Flood & 0.70 \\
\hline Heat & 0.67 \\
\hline Storm & 0.66 \\
\hline Wldfr & 0.64 \\
\hline Lndsd & 0.43 \\
\hline Hail & 0.41 \\
\hline Hurr & 0.00 \\
\hline Coast & 0.00 \\
\hline Hazard & Total injuries \\
\hline Wintr & 1719 \\
\hline Wind & 1641 \\
\hline Storm & 731 \\
\hline Light & 660 \\
\hline Hail & 470 \\
\hline Flood & 443 \\
\hline Tornd & 375 \\
\hline Wldfr & 52 \\
\hline Lndsd & 16 \\
\hline Eqke & 9 \\
\hline Heat & 8 \\
\hline Coast & 0 \\
\hline Hurr & 0 \\
\hline
\end{tabular}

FATALITIES

\begin{tabular}{|c|c|}
\hline Hazard & Avg fatalities/event \\
\hline Eqke & 1.00 \\
\hline Wintr & 0.54 \\
\hline Flood & 0.38 \\
\hline Light & 0.30 \\
\hline Storm & 0.28 \\
\hline Lndsd & 0.27 \\
\hline Wldfr & 0.18 \\
\hline Wind & 0.12 \\
\hline Heat & 0.08 \\
\hline Hail & 0.04 \\
\hline Tornd & 0.03 \\
\hline Coast & 0.00 \\
\hline Hurr & 0.00 \\
\hline Harard & \\
\hline
\end{tabular}

\begin{tabular}{|c|c|}
\hline \hline Hazard & Total fatalities \\
\hline Wintr & 390 \\
\hline Storm & 307 \\
\hline Light & 258 \\
\hline Flood & 241 \\
\hline Wind & 231 \\
\hline Hail & 44 \\
\hline Wldfr & 15 \\
\hline Tornd & 11 \\
\hline Lndsd & 10 \\
\hline Eqke & 5 \\
\hline Heat & 1 \\
\hline Coast & 0 \\
\hline Hurr & 0 \\
\hline
\end{tabular}

DAMAGES

\begin{tabular}{|c|r|}
\hline Hazard & Avg damage/event \\
\hline Lndsd & $\$ \mathbf{\$ 2 9 , 5 5 1 , 8 7 0}$ \\
\hline Eqke & $\$ 6,518,830$ \\
\hline Hail & $\$ 5,913,367$ \\
\hline Wldfr & $\$ 5,074,526$ \\
\hline Flood & $\$ 3,374,525$ \\
\hline Wind & $\$ 2,572,497$ \\
\hline Wintr & $\$ 1,492,653$ \\
\hline Storm & $\$ 1,264,716$ \\
\hline Tornd & $\$ 1,026,989$ \\
\hline Heat & $\$ \mathbf{\$ 1 8 5 , 6 4 6}$ \\
\hline Light & $\$ 152,397$ \\
\hline Coast & $\$ \mathbf{\$}$ \\
\hline Hurr & $\$ \mathbf{0}$ \\
\hline \hline
\end{tabular}

\begin{tabular}{|c|c|}
\hline Hazard & Total damage \\
\hline Hail & $\$ 6,865,419,576$ \\
\hline Wind & $\$ 4,880,027,625$ \\
\hline Flood & $\$ 2,125,950,954$ \\
\hline Storm & $\$ 1,402,570,503$ \\
\hline Lndsd & $\$ 1,093,419,196$ \\
\hline Wintr & $\$ 1,067,247,109$ \\
\hline Tornd & $\$ 427,227,624$ \\
\hline Wldfr & $\$ 411,036,631$ \\
\hline Light & $\$ 130,908,692$ \\
\hline Eqke & $\$ 32,594,150$ \\
\hline Heat & $\$ 9,427,750$ \\
\hline Hurr & $\$ 0$ \\
\hline & \\
\hline
\end{tabular}

Table 7-4: Mountain region consequence rankings 


\subsection{REGIONAL SUMMARY}

Compared to the other seven regions, the Mountain region was among the lowest in terms of the number of hazard events ( $7 \%$ of the total) and total consequences (3\%) over the 50 year period. This can be attributed to the population size and density. These factors need to be accounted for when looking at these figures. The combined population of all five states amounts to three percent of the US population according to the 2010 Census (US Census Bureau 2011). Also, few population concentrated counties are spread throughout the region and the density is less than 10 persons per square mile for a vast amount of the area.

There are a few natural hazards that have high consequences for this region. The top five; hail, wind, winter, flooding, and storm hazard, account for almost ninety percent of all of the consequences. Hail hazards amount to a quarter of the total. It can be observed from previous figures that almost fifty percent of the hail value comes from one single event with nearly all of the damage stemming from crop loss of that event. This becomes clear when taking both the chart tables and maximum consequence into consideration.

Additionally these top five region hazards can be compared in other ways to each of their impacts on the region. While hail has the highest total consequence rank, the hazard appears lower in the charts when it comes to injuries and fatalities. Winter storms are among the largest values when it comes to these two factors. When mitigation plans address the difference between the hazards, they can be broken down from a whole and separated into individualized parts to evaluate the most important steps to be taken when combatting future hazard losses. 


\section{Southwest Regional Analysis}

\subsection{LAYOUT}

Chapter 8 contains the natural hazard risk assessment and analysis for the Southwest region, which consists of the following four states: Arizona, New Mexico, Oklahoma, and Texas. Figures included in this chapter are:

- Southwest region consequence tables for injuries, fatalities, and damages

Table 8-1, Table 8-2, and Table 8-3, respectively

- Southwest region consequence graphics for injuries, fatalities, and damages

Figure 8-1, Figure 8-2, and Figure 8-3, respectively

- Southwest region consequence rankings (Table 8-4)

Total consequence and overall percentage

Average loss per event: injuries, fatalities, damages

$>$ Total losses: injuries, fatalities, damages

The following hazard events have not been recorded by SHELDUS and will not appear in the graphical or chart displays for this region.

- Earthquake 


\subsection{REGION CONSEQUENCE DISPLAYS}

\begin{tabular}{|c|c|c|c|c|c|}
\hline INJURIES & $\mathrm{Y}$-axis & $X$-axis & Outside Circle Size & Inner Circle Size & Middle Circle Size \\
\hline Hazard & $\#$ of events & $\begin{array}{l}\text { Avg injuries per } \\
\text { event }\end{array}$ & Total Consequence & Total Consq Max & Total Consq Top 5\% \\
\hline Coast & 17 & 0.06 & $\$ 1,032,485,954$ & $\$ 864,080,005$ & $\$ 864,080,005$ \\
\hline Eqke & 0 & 0.00 & $\$ 0$ & $\$ 0$ & $\$ 0$ \\
\hline Flood & 1836 & 4.36 & $\$ 16,728,893,723$ & $\$ 3,587,247,100$ & $\$ 12,858,711,352$ \\
\hline Hail & 2292 & 1.02 & $\$ 9,806,532,559$ & $\$ 685,000,000$ & $\$ 7,464,590,779$ \\
\hline Heat & 166 & 3.64 & $\$ 2,486,153,465$ & $\$ 509,949,027$ & $\$ 1,220,081,027$ \\
\hline Hurr & 42 & 69.24 & $\$ 21,500,830,221$ & $\$ 6,361,200,000$ & $\$ 12,231,428,000$ \\
\hline Lndsd & 4 & 0.00 & $\$ 28,991,300$ & $\$ 20,800,000$ & $\$ 20,800,000$ \\
\hline Light & 1705 & 0.63 & $\$ 2,825,948,747$ & $\$ 39,353,135$ & $\$ 917,831,935$ \\
\hline Storm & 3047 & 0.65 & $\$ 11,141,513,462$ & $\$ 1,737,097,640$ & $\$ 9,277,610,243$ \\
\hline Tornd & 1848 & 6.38 & $\$ 17,104,338,185$ & $\$ 2,005,713,241$ & $\$ 14,297,527,342$ \\
\hline Wldfr & 113 & 0.66 & $\$ 2,541,557,178$ & $\$ 1,905,000,000$ & $\$ 2,348,197,480$ \\
\hline Wind & 4034 & 1.10 & $\$ 11,636,397,508$ & $\$ 1,716,497,640$ & $\$ 8,860,306,111$ \\
\hline Wintr & 315 & 8.08 & $\$ 4,882,713,613$ & $\$ 1,220,604,001$ & $\$ 2,888,034,050$ \\
\hline & & \multicolumn{4}{|c|}{ Contributions to the Total Consequence amount } \\
\hline Hazard & Total Consequence & Injuries & Fatalities & Property Loss & Crop Loss \\
\hline Coast & $\$ 1,032,485,954$ & $\$ 600,000$ & $\$ 163,360,000$ & $\$ 868,525,954$ & $\$ 0$ \\
\hline Eqke & $\$ 0$ & $\$ 0$ & $\$ 0$ & $\$ 0$ & $\$ 0$ \\
\hline Flood & $\$ 16,728,893,723$ & $\$ 4,807,782,000$ & $\$ 3,884,400,000$ & $\$ 5,991,258,774$ & $\$ 2,045,452,949$ \\
\hline Hail & $\$ 9,806,532,559$ & $\$ 1,407,960,000$ & $\$ 601,280,000$ & $\$ 6,160,552,873$ & $\$ 1,636,739,686$ \\
\hline Heat & $\$ 2,486,153,465$ & $\$ 362,454,000$ & $\$ 1,857,080,000$ & $\$ 1,531,800$ & $\$ 265,087,665$ \\
\hline Hurr & $\$ 21,500,830,221$ & $\$ 1,744,746,000$ & $\$ 582,160,000$ & $\$ 16,812,159,151$ & $\$ 2,361,765,070$ \\
\hline Lndsd & $\$ 28,991,300$ & $\$ 0$ & $\$ 20,000,000$ & $\$ 8,991,300$ & $\$ 0$ \\
\hline Light & $\$ 2,825,948,747$ & $\$ 643,800,000$ & $\$ 1,888,000,000$ & $\$ 278,477,771$ & $\$ 15,670,975$ \\
\hline Storm & $\$ 11,141,513,462$ & $\$ 1,190,400,000$ & $\$ 1,519,840,000$ & $\$ 7,641,717,041$ & $\$ 789,556,421$ \\
\hline Tornd & $\$ 17,104,338,185$ & $\$ 7,076,442,000$ & $\$ 3,298,360,000$ & $\$ 6,175,721,277$ & $\$ 553,814,908$ \\
\hline WIdfr & $\$ 2,541,557,178$ & $\$ 44,982,000$ & $\$ 83,960,000$ & $\$ 2,244,409,186$ & $\$ 168,205,992$ \\
\hline Wind & $\$ 11,636,397,508$ & $\$ 2,656,140,000$ & $\$ 1,547,600,000$ & $\$ 6,747,489,129$ & $\$ 685,168,379$ \\
\hline Wintr & $\$ 4,882,713,613$ & $\$ 1,526,358,000$ & $\$ 1,452,000,000$ & $\$ 1,339,734,454$ & $\$ 564,621,158$ \\
\hline \multicolumn{6}{|l|}{ INJURIES } \\
\hline Hazard & Total injuries & \# of events & Max injuries in one & Total minus max & $\%$ of total \\
\hline Coast & 1 & 17 & 1 & 0 & $100 \%$ \\
\hline Eqke & 0 & 0 & 0 & 0 & $0 \%$ \\
\hline Flood & 8013 & 1836 & 4570 & 3443 & $57 \%$ \\
\hline Hail & 2347 & 2292 & 500 & 1847 & $21 \%$ \\
\hline Heat & 604 & 166 & 200 & 404 & $33 \%$ \\
\hline Hurr & 2908 & 42 & 1800 & 1108 & $62 \%$ \\
\hline Lndsd & 0 & 4 & 0 & 0 & $0 \%$ \\
\hline Light & 1073 & 1705 & 40 & 1033 & $4 \%$ \\
\hline Storm & 1984 & 3047 & 150 & 1834 & $8 \%$ \\
\hline Tornd & 11794 & 1848 & 1920 & 9874 & $16 \%$ \\
\hline Wldfr & 75 & 113 & 13 & 62 & $17 \%$ \\
\hline Wind & 4427 & 4034 & 500 & 3927 & $11 \%$ \\
\hline Wintr & 2544 & 315 & 2000 & 544 & $79 \%$ \\
\hline
\end{tabular}

Table 8-1: Southwest region injury consequence tables 

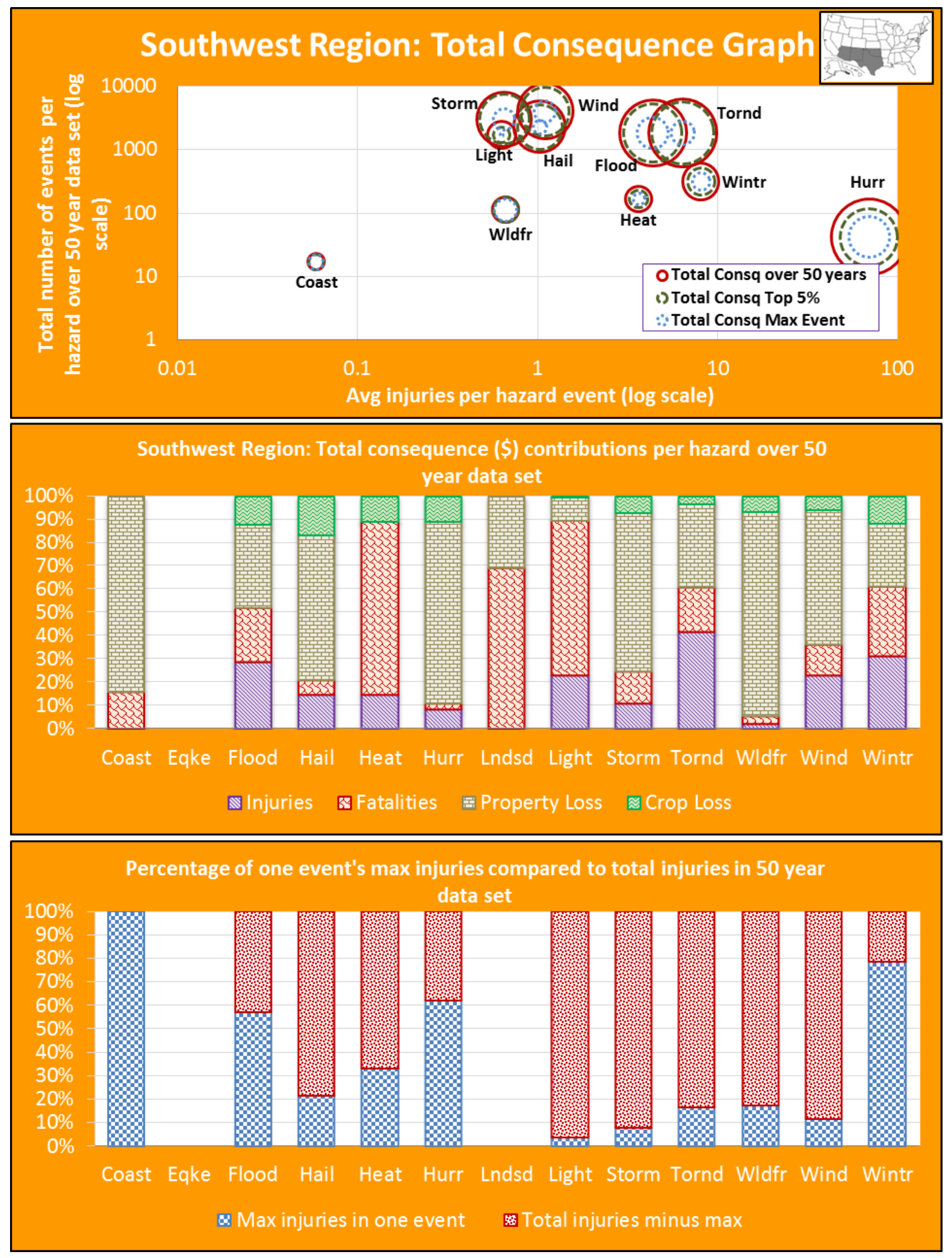

Figure 8-1: Southwest region injury consequence graphics 


\begin{tabular}{|c|c|c|r|r|r|}
\hline FATALITIES & Y-axis & X-axis & Outside Circle Size & Inner Circle Size & Middle Circle Size \\
\hline Hazard & \# of events & $\begin{array}{c}\text { Avg fatalities per } \\
\text { event }\end{array}$ & Total Consequence & Total Consq Max & Total Consq Top 5\% \\
\hline Coast & 17 & 2.40 & $\$ 1,032,485,954$ & $\$ 864,080,005$ & $\$ 864,080,005$ \\
\hline Eqke & 0 & 0.00 & $\$ 0$ & $\$ 0$ & $\$ 0$ \\
\hline Flood & 1836 & 0.53 & $\$ 16,728,893,723$ & $\$ 3,587,247,100$ & $\$ 12,858,711,352$ \\
\hline Hail & 2292 & 0.07 & $\$ 9,806,532,559$ & $\$ 685,000,000$ & $\$ 7,464,590,779$ \\
\hline Heat & 166 & 2.80 & $\$ 2,486,153,465$ & $\$ 509,949,027$ & $\$ 1,220,081,027$ \\
\hline Hurr & 42 & 3.47 & $\$ 21,500,830,221$ & $\$ 6,361,200,000$ & $\$ 12,231,428,000$ \\
\hline Lndsd & 4 & 1.25 & $\$ 28,991,300$ & $\$ 20,800,000$ & $\$ 20,800,000$ \\
\hline Light & 1705 & 0.28 & $\$ 2,825,948,747$ & $\$ 39,353,135$ & $\$ 917,831,935$ \\
\hline Storm & 3047 & 0.12 & $\$ 11,141,513,462$ & $\$ 1,737,097,640$ & $\$ 9,277,610,243$ \\
\hline Tornd & 1848 & 0.45 & $\$ 17,104,338,185$ & $\$ 2,005,713,241$ & $\$ 14,297,527,342$ \\
\hline Wldfr & 113 & 0.19 & $\$ 2,541,557,178$ & $\$ 1,905,000,000$ & $\$ 2,348,197,480$ \\
\hline Wind & 4034 & 0.10 & $\$ 11,636,397,508$ & $\$ 1,716,497,640$ & $\$ 8,860,306,111$ \\
\hline Wintr & 315 & 1.15 & $\$ 4,882,713,613$ & $\$ 1,220,604,001$ & $\$ 2,888,034,050$ \\
\hline
\end{tabular}

\begin{tabular}{|c|r|r|r|r|r|}
\cline { 3 - 6 } \multicolumn{2}{c|}{} & \multicolumn{3}{c|}{ Contributions to the Total Consequence amount } \\
\hline Hazard & Total Consequence & \multicolumn{1}{c|}{ Injuries } & Fatalities & Property Loss & \multicolumn{1}{c|}{ Crop Loss } \\
\hline Coast & $\mathbf{\$ 1 , 0 3 2 , 4 8 5 , 9 5 4}$ & $\$ 600,000$ & $\$ 163,360,000$ & $\$ 868,525,954$ & $\$ 0$ \\
\hline Eqke & $\mathbf{\$ 0}$ & $\$ 0$ & $\$ 0$ & $\$ 0$ & $\$ 0$ \\
\hline Flood & $\mathbf{\$ 1 6 , 7 2 8 , 8 9 3 , 7 2 3}$ & $\$ 4,807,782,000$ & $\$ 3,884,400,000$ & $\$ 5,991,258,774$ & $\$ 2,045,452,949$ \\
\hline Hail & $\mathbf{\$ 9 , 8 0 6 , 5 3 2 , 5 5 9}$ & $\$ 1,407,960,000$ & $\$ 601,280,000$ & $\$ 6,160,552,873$ & $\$ 1,636,739,686$ \\
\hline Heat & $\mathbf{\$ 2 , 4 8 6 , 1 5 3 , 4 6 5}$ & $\$ 362,454,000$ & $\$ 1,857,080,000$ & $\$ 1,531,800$ & $\$ 265,087,665$ \\
\hline Hurr & $\mathbf{\$ 2 1 , 5 0 0 , 8 3 0 , 2 2 1}$ & $\$ 1,744,746,000$ & $\$ 582,160,000$ & $\$ 16,812,159,151$ & $\$ 2,361,765,070$ \\
\hline Lndsd & $\mathbf{\$ 2 8 , 9 9 1 , 3 0 0}$ & $\$ 0$ & $\$ 20,000,000$ & $\$ 8,991,300$ & $\$ 0$ \\
\hline Light & $\mathbf{\$ 2 , 8 2 5 , 9 4 8 , 7 4 7}$ & $\$ 643,800,000$ & $\$ 1,888,000,000$ & $\$ 278,477,771$ & $\$ 15,670,975$ \\
\hline Storm & $\mathbf{\$ 1 1 , 1 4 1 , 5 1 3 , 4 6 2}$ & $\$ 1,190,400,000$ & $\$ 1,519,840,000$ & $\$ 7,641,717,041$ & $\$ 789,556,421$ \\
\hline Tornd & $\mathbf{\$ 1 7 , 1 0 4 , 3 3 8 , 1 8 5}$ & $\$ 7,076,442,000$ & $\$ 3,298,360,000$ & $\$ 6,175,721,277$ & $\$ 553,814,908$ \\
\hline Wldfr & $\mathbf{\$ 2 , 5 4 1 , 5 5 7 , 1 7 8}$ & $\$ 44,982,000$ & $\$ 83,960,000$ & $\$ 2,244,409,186$ & $\$ 168,205,992$ \\
\hline Wind & $\mathbf{\$ 1 1 , 6 3 6 , 3 9 7 , 5 0 8}$ & $\$ 2,656,140,000$ & $\$ 1,547,600,000$ & $\$ 6,747,489,129$ & $\$ 685,168,379$ \\
\hline Wintr & $\mathbf{\$ 4 , 8 8 2 , 7 1 3 , 6 1 3}$ & $\$ 1,526,358,000$ & $\$ 1,452,000,000$ & $\$ 1,339,734,454$ & $\$ 564,621,158$ \\
\hline
\end{tabular}

\begin{tabular}{|c|c|c|c|c|c|}
\hline FATALITIES & & & & & \\
\hline Hazard & Total fatalities & \# of events & Max fatalities in one & Total minus max & $\%$ of total \\
\hline Coast & 41 & 17 & 13 & 28 & $32 \%$ \\
\hline Eqke & 0 & 0 & 0 & 0 & $0 \%$ \\
\hline Flood & 971 & 1836 & 33 & 938 & $3 \%$ \\
\hline Hail & 150 & 2292 & 26 & 124 & $17 \%$ \\
\hline Heat & 464 & 166 & 46 & 418 & $10 \%$ \\
\hline Hurr & 146 & 42 & 34 & 111 & $24 \%$ \\
\hline Lndsd & 5 & 4 & 3 & 2 & $60 \%$ \\
\hline Light & 472 & 1705 & 4 & 468 & $1 \%$ \\
\hline Storm & 380 & 3047 & 25 & 355 & $7 \%$ \\
\hline Tornd & 825 & 1848 & 114 & 711 & $14 \%$ \\
\hline Wldfr & 21 & 113 & 12 & 9 & $57 \%$ \\
\hline Wind & 387 & 4034 & 26 & 361 & $7 \%$ \\
\hline Wintr & 363 & 315 & 14 & 349 & $4 \%$ \\
\hline
\end{tabular}

Table 8-2: Southwest region fatality consequence tables 

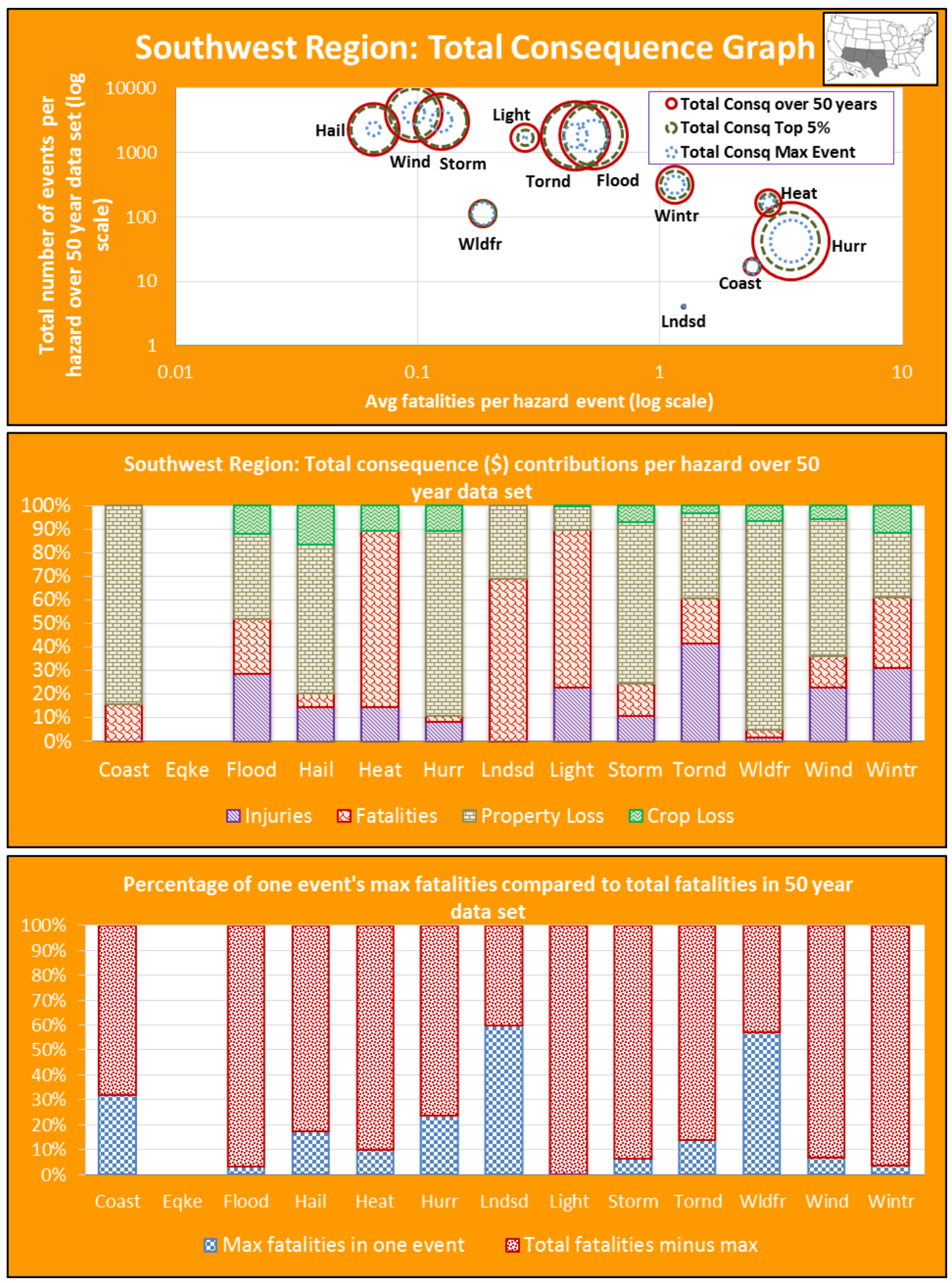

Figure 8-2: Southwest region fatality consequence graphics 


\begin{tabular}{|c|c|r|r|r|r|}
\hline DAMAGES & Y-axis & \multicolumn{1}{|c|}{ X-axis } & Outside Circle Size & Inner Circle Size & Middle Circle Size \\
\hline Hazard & \# of events & $\begin{array}{c}\text { Avg damages per } \\
\text { event }\end{array}$ & Total Consequence & Total Consq Max & Total Consq Top 5\% \\
\hline Coast & 17 & $\$ 51,089,762$ & $\$ 1,032,485,954$ & $\$ 864,080,005$ & $\$ 864,080,005$ \\
\hline Eqke & 0 & $\$ 0$ & $\$ 0$ & $\$ 0$ & $\$ 0$ \\
\hline Flood & 1836 & $\$ 4,377,294$ & $\$ 16,728,893,723$ & $\$ 3,587,247,100$ & $\$ 12,858,711,352$ \\
\hline Hail & 2292 & $\$ 3,401,960$ & $\$ 9,806,532,559$ & $\$ 685,000,000$ & $\$ 7,464,590,779$ \\
\hline Heat & 166 & $\$ 1,606,141$ & $\$ 2,486,153,465$ & $\$ 509,949,027$ & $\$ 1,220,081,027$ \\
\hline Hurr & 42 & $\$ 456,522,005$ & $\$ 21,500,830,221$ & $\$ 6,361,200,000$ & $\$ 12,231,428,000$ \\
\hline Lndsd & 4 & $\$ 2,247,825$ & $\$ 28,991,300$ & $\$ 20,800,000$ & $\$ 20,800,000$ \\
\hline Light & 1705 & $\$ 172,521$ & $\$ 2,825,948,747$ & $\$ 39,353,135$ & $\$ 917,831,935$ \\
\hline Storm & 3047 & $\$ 2,767,074$ & $\$ 11,141,513,462$ & $\$ 1,737,097,640$ & $\$ 9,277,610,243$ \\
\hline Tornd & 1848 & $\$ 3,641,524$ & $\$ 17,104,338,185$ & $\$ 2,005,713,241$ & $\$ 14,297,527,342$ \\
\hline Wldfr & 113 & $\$ 21,350,577$ & $\$ 2,541,557,178$ & $\$ 1,905,000,000$ & $\$ 2,348,197,480$ \\
\hline Wind & 4034 & $\$ 1,842,503$ & $\$ 11,636,397,508$ & $\$ 1,716,497,640$ & $\$ 8,860,306,111$ \\
\hline Wintr & 315 & $\$ 6,045,573$ & $\$ 4,882,713,613$ & $\$ 1,220,604,001$ & $\$ 2,888,034,050$ \\
\hline
\end{tabular}

\begin{tabular}{|c|c|c|c|c|c|}
\hline \multirow[b]{2}{*}{ Hazard } & \multirow[b]{2}{*}{ Total Consequence } & \multicolumn{4}{|c|}{ Contributions to the Total Consequence amount } \\
\hline & & Injuries & Fatalities & Property Loss & Crop Loss \\
\hline Coast & $\$ 1,032,485,954$ & $\$ 600,000$ & $\$ 163,360,000$ & $\$ 868,525,954$ & $\$ 0$ \\
\hline Eqke & $\$ 0$ & $\$ 0$ & $\$ 0$ & $\$ 0$ & $\$ 0$ \\
\hline Flood & $\$ 16,728,893,723$ & $\$ 4,807,782,000$ & $\$ 3,884,400,000$ & $\$ 5,991,258,774$ & $\$ 2,045,452,949$ \\
\hline Hail & $\$ 9,806,532,559$ & $\$ 1,407,960,000$ & $\$ 601,280,000$ & $\$ 6,160,552,873$ & $\$ 1,636,739,686$ \\
\hline Heat & $\$ 2,486,153,465$ & $\$ 362,454,000$ & $\$ 1,857,080,000$ & $\$ 1,531,800$ & $\$ 265,087,665$ \\
\hline Hurr & $\$ 21,500,830,221$ & $\$ 1,744,746,000$ & $\$ 582,160,000$ & $\$ 16,812,159,151$ & $\$ 2,361,765,070$ \\
\hline Lndsd & $\$ 28,991,300$ & $\$ 0$ & $\$ 20,000,000$ & $\$ 8,991,300$ & $\$ 0$ \\
\hline Light & $\$ 2,825,948,747$ & $\$ 643,800,000$ & $\$ 1,888,000,000$ & $\$ 278,477,771$ & $\$ 15,670,975$ \\
\hline Storm & $\$ 11,141,513,462$ & $\$ 1,190,400,000$ & $\$ 1,519,840,000$ & $\$ 7,641,717,041$ & $\$ 789,556,421$ \\
\hline Tornd & $\$ 17,104,338,185$ & $\$ 7,076,442,000$ & $\$ 3,298,360,000$ & $\$ 6,175,721,277$ & $\$ 553,814,908$ \\
\hline Wldfr & $\$ 2,541,557,178$ & $\$ 44,982,000$ & $\$ 83,960,000$ & $\$ 2,244,409,186$ & $\$ 168,205,992$ \\
\hline Wind & $\$ 11,636,397,508$ & $\$ 2,656,140,000$ & $\$ 1,547,600,000$ & $\$ 6,747,489,129$ & $\$ 685,168,379$ \\
\hline Wintr & $\$ 4,882,713,613$ & $\$ 1,526,358,000$ & $\$ 1,452,000,000$ & $\$ 1,339,734,454$ & $\$ 564,621,158$ \\
\hline \multicolumn{6}{|c|}{ DAMAGES } \\
\hline Hazard & Total damages & \# of events & Max damages in one & Total minus max & $\%$ of total \\
\hline Coast & $\$ 868,525,954$ & 17 & $\$ 816,080,005$ & $\$ 52,445,949$ & $94 \%$ \\
\hline Eqke & $\$ 0$ & 0 & $\$ 0$ & $\$ 0$ & $0 \%$ \\
\hline Flood & $\$ 8,036,711,723$ & 1836 & $\$ 969,599,612$ & $\$ 7,067,112,111$ & $12 \%$ \\
\hline Hail & $\$ 7,797,292,559$ & 2292 & $\$ 344,630,000$ & $\$ 7,452,662,559$ & $4 \%$ \\
\hline Heat & $\$ 266,619,465$ & 166 & $\$ 266,325,027$ & $\$ 294,438$ & $100 \%$ \\
\hline Hurr & $\$ 19,173,924,221$ & 42 & $\$ 6,273,000,000$ & $\$ 12,900,924,221$ & $33 \%$ \\
\hline Lndsd & $\$ 8,991,300$ & 4 & $\$ 8,800,000$ & $\$ 191,300$ & $98 \%$ \\
\hline Light & $\$ 294,148,747$ & 1705 & $\$ 31,353,135$ & $\$ 262,795,612$ & $11 \%$ \\
\hline Storm & $\$ 8,431,273,462$ & 3047 & $\$ 1,716,497,640$ & $\$ 6,714,775,822$ & $20 \%$ \\
\hline Tornd & $\$ 6,729,536,185$ & 1848 & $\$ 1,440,713,241$ & $\$ 5,288,822,944$ & $21 \%$ \\
\hline Wldfr & $\$ 2,412,615,178$ & 113 & $\$ 1,905,000,000$ & $\$ 507,615,178$ & $79 \%$ \\
\hline Wind & $\$ 7,432,657,508$ & 4034 & $\$ 1,716,497,640$ & $\$ 5,716,159,868$ & $23 \%$ \\
\hline Wintr & $\$ 1,904,355,613$ & 315 & $\$ 363,018,150$ & $\$ 1,541,337,463$ & $19 \%$ \\
\hline
\end{tabular}

Table 8-3: Southwest region damage consequence tables 

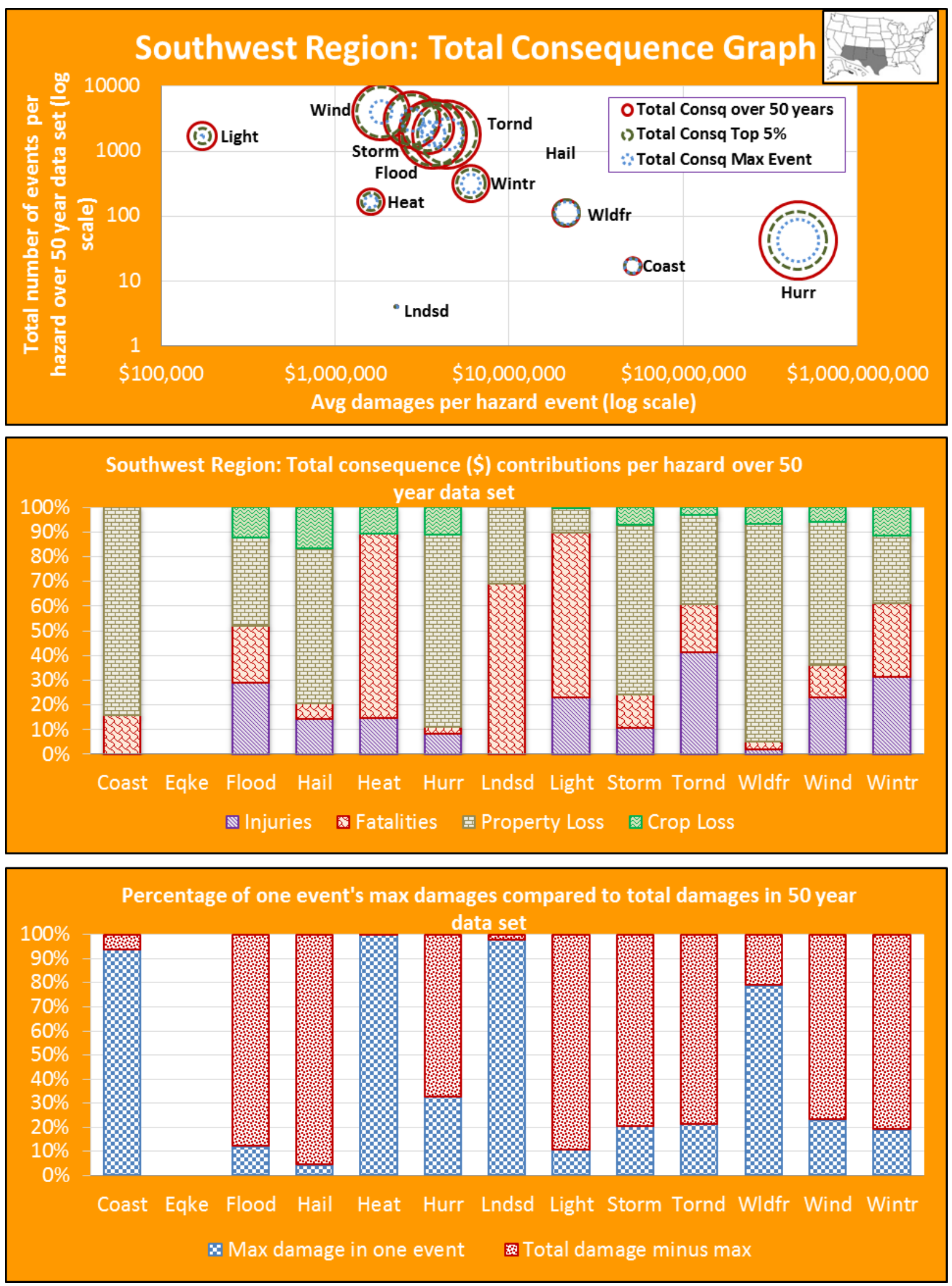

Figure 8-3: Southwest region damage consequence graphics 


\subsection{REGION CONSEQUENCE RANKINGS}

$\left.\begin{array}{|c|c|c|c|c|}\hline \text { Ranking } & \text { Hazard } & \begin{array}{c}\text { Total } \\
\text { Consequence }\end{array} & \begin{array}{c}\text { \% of } \\
\text { Consq } \\
\text { Sum }\end{array} & \begin{array}{c}\text { Max event \% of } \\
\text { contribution to } \\
\text { Total Consq }\end{array}\end{array}\right)$\begin{tabular}{c} 
Max event \% of contribution to Total Consq \\
\hline 1
\end{tabular}

INJURIES

\begin{tabular}{|c|c|}
\hline Hazard & Avg injuries/event \\
\hline Hurr & 69.24 \\
\hline Wintr & 8.08 \\
\hline Tornd & 6.38 \\
\hline Flood & 4.36 \\
\hline Heat & 3.64 \\
\hline Wind & 1.10 \\
\hline Hail & 1.02 \\
\hline Wldfr & 0.66 \\
\hline Storm & 0.65 \\
\hline Light & 0.63 \\
\hline Coast & 0.06 \\
\hline Eqke & 0.00 \\
\hline Lndsd & 0.00 \\
\hline Hazard & Total injuries \\
\hline Tornd & 11794 \\
\hline Flood & 8013 \\
\hline Wind & 4427 \\
\hline Hurr & 2908 \\
\hline Wintr & 2544 \\
\hline Hail & 2347 \\
\hline Storm & 1984 \\
\hline Light & 1073 \\
\hline Heat & 604 \\
\hline Wldfr & 75 \\
\hline Coast & 1 \\
\hline Eqke & 0 \\
\hline Lndsd & 0 \\
\hline
\end{tabular}

FATALITIES

\begin{tabular}{|c|c|}
\hline Hazard & Avg fatalities/event \\
\hline Hurr & 3.47 \\
\hline Heat & 2.80 \\
\hline Coast & 2.40 \\
\hline Lndsd & 1.25 \\
\hline Wintr & 1.15 \\
\hline Flood & 0.53 \\
\hline Tornd & 0.45 \\
\hline Light & 0.28 \\
\hline Wldfr & 0.19 \\
\hline Storm & 0.12 \\
\hline Wind & 0.10 \\
\hline Hail & 0.07 \\
\hline Eqke & 0.00 \\
\hline
\end{tabular}

\begin{tabular}{|c|c|}
\hline \hline Hazard & Total fatalities \\
\hline Flood & 971 \\
\hline Tornd & 825 \\
\hline Light & 472 \\
\hline Heat & 464 \\
\hline Wind & 387 \\
\hline Storm & 380 \\
\hline Wintr & 363 \\
\hline Hail & 150 \\
\hline Hurr & 146 \\
\hline Coast & 41 \\
\hline Wldfr & 21 \\
\hline Lndsd & 5 \\
\hline Eqke & 0 \\
\hline
\end{tabular}

DAMAGES

\begin{tabular}{|c|r|}
\hline Hazard & Avg damage/event \\
\hline Hurr & $\mathbf{\$ 4 5 6 , 5 2 2 , 0 0 5}$ \\
\hline Coast & $\mathbf{\$ 5 1 , 0 8 9 , 7 6 2}$ \\
\hline Wldfr & $\mathbf{\$ 2 1 , 3 5 0 , 5 7 7}$ \\
\hline Wintr & $\mathbf{\$ 6 , 0 4 5 , 5 7 3}$ \\
\hline Flood & $\mathbf{\$ 4 , 3 7 7 , 2 9 4}$ \\
\hline Tornd & $\mathbf{\$ 3 , 6 4 1 , 5 2 4}$ \\
\hline Hail & $\mathbf{\$ 3 , 4 0 1 , 9 6 0}$ \\
\hline Storm & $\mathbf{\$ 2 , 7 6 7 , 0 7 4}$ \\
\hline Lndsd & $\mathbf{\$ 2 , 2 4 7 , 8 2 5}$ \\
\hline Wind & $\mathbf{\$ 1 , 8 4 2 , 5 0 3}$ \\
\hline Heat & $\mathbf{\$ 1 , 6 0 6 , 1 4 1}$ \\
\hline Light & $\mathbf{\$ 1 7 2 , 5 2 1}$ \\
\hline Eqke & $\mathbf{\$} 0$ \\
\hline \hline Hazard & Total damage \\
\hline Hurr & $\mathbf{\$ 1 9 , 1 7 3 , 9 2 4 , 2 2 1}$ \\
\hline Storm & $\mathbf{\$ 8 , 4 3 1 , 2 7 3 , 4 6 2}$ \\
\hline Flood & $\mathbf{\$ 8 , 0 3 6 , 7 1 1 , 7 2 3}$ \\
\hline Hail & $\mathbf{\$ 7 , 7 9 7 , 2 9 2 , 5 5 9}$ \\
\hline Wind & $\mathbf{\$ 7 , 4 3 2 , 6 5 7 , 5 0 8}$ \\
\hline Tornd & $\mathbf{\$ 6 , 7 2 9 , 5 3 6 , 1 8 5}$ \\
\hline Wldfr & $\mathbf{\$ 2 , 4 1 2 , 6 1 5 , 1 7 8}$ \\
\hline Wintr & $\mathbf{\$ 1 , 9 0 4 , 3 5 5 , 6 1 3}$ \\
\hline Coast & $\mathbf{\$ 8 6 8 , 5 2 5 , 9 5 4}$ \\
\hline Light & $\mathbf{\$ 2 9 4 , 1 4 8 , 7 4 7}$ \\
\hline Heat & $\mathbf{\$ 2 6 6 , 6 1 9 , 4 6 5}$ \\
\hline Lndsd & $\mathbf{\$ 8 , 9 9 1 , 3 0 0}$ \\
\hline Eqke & $\mathbf{\$} 0$ \\
\hline
\end{tabular}

Table 8-4: Southwest region consequence rankings 


\subsection{REGIONAL SUMMARY}

This region's total consequences from natural hazards are dominated by the state of Texas. Its population totals 25 million residents and accounts for $70 \%$ of the Southwest region population as of 2010 (US Census Bureau 2011). High concentrations are located near the central to eastern coastlines of the state and are the primary reason why the largest consequences from this region come from hurricane hazards. An overwhelming contributor to this consequence value comes from property damage, which accounts for $80 \%$ of all losses since 1950 , as seen in the first bar chart. Nearly 30\% of these losses came from a single event (Tropical Storm Allison 2001) and demonstrates the extent of destruction of an unlikely hurricane hazard.

Along with this hazard, the other major risks to consider are tornadoes, flooding, wind, and storm hazards. Together, these make up three quarters of all the consequences in the region. When comparing the consequences, the majority of fatality and injury losses are due to flooding and tornadoes. The largest hazard categories can be attributed to the states of Texas and Oklahoma. Emphasis should not only be on the hazard that causes the greatest average losses, but also need to be compared to frequent hazard events that have smaller averages, but higher cumulative effects.

Comparing these hazard events and losses to the states of Arizona and New Mexico show great differences from those observed in eastern Texas. The contributions from these states are small in comparison and contribute little to the overall total consequences of the region. Similar to other regions in the US, further exploration is needed to break down these hazard events on a state by state basis so that allocation of funding and mitigation plans can be tailored to the state's 
needs. This study proposes an additional measure to better categorize losses by developing specific 'hazard' regions. This concept will be explained in detail later in chapter 15. 


\section{Plains Regional Analysis}

\subsection{LAYOUT}

Chapter 9 contains the natural hazard risk assessment and analysis for the Plains region, which consists of the following seven states: North Dakota, South Dakota, Nebraska, Kansas, Minnesota, Iowa, and Missouri. Figures included in this chapter are:

- Plains region consequence tables for injuries, fatalities, and damages

Table 9-1, Table 9-2, and Table 9-3, respectively

- Plains region consequence graphics for injuries, fatalities, and damages

$>$ Figure 9-1, Figure 9-2, and Figure 9-3, respectively

- Plains region consequence rankings (Table 9-4)

$>$ Total consequence and overall percentage

Average loss per event: injuries, fatalities, damages

$>$ Total losses: injuries, fatalities, damages

The following hazard events have not been recorded by SHELDUS and will not appear in the graphical or chart displays for this region.

- Coastal 


\subsection{REGION CONSEQUENCE DISPLAYS}

\begin{tabular}{|c|c|c|r|r|r|}
\hline INJURIES & Y-axis & \multicolumn{1}{|c|}{ X-axis } & Outside Circle Size & Inner Circle Size & \multicolumn{1}{c|}{ Middle Circle Size } \\
\hline Hazard & \# of events & $\begin{array}{c}\text { Avg injuries per } \\
\text { event }\end{array}$ & Total Consequence & Total Consq Max & Total Consq Top 5\% \\
\hline Coast & 0 & 0.00 & $\$ 0$ & $\$ 0$ & $\$ 0$ \\
\hline Eqke & 1 & 0.00 & $\$ 2,025$ & $\$ 2,025$ & $\$ 0$ \\
\hline Flood & 1459 & 2.81 & $\$ 31,697,672,031$ & $\$ 8,121,435,250$ & $\$ 28,447,427,116$ \\
\hline Hail & 3245 & 1.01 & $\$ 13,828,100,870$ & $\$ 1,663,080,810$ & $\$ 9,919,789,302$ \\
\hline Heat & 122 & 28.97 & $\$ 3,300,306,369$ & $\$ 502,140,000$ & $\$ 1,591,640,250$ \\
\hline Hurr & 1 & 2.00 & $\$ 1,503,000$ & $\$ 1,503,000$ & $\$ 0$ \\
\hline Lndsd & 1 & 0.00 & $\$ 109,450$ & $\$ 109,450$ & $\$ 0$ \\
\hline Light & 2044 & 0.44 & $\$ 2,519,283,990$ & $\$ 69,589,935$ & $\$ 1,097,923,428$ \\
\hline Storm & 3039 & 0.65 & $\$ 13,733,480,469$ & $\$ 1,822,702,500$ & $\$ 11,093,865,038$ \\
\hline Tornd & 2004 & 5.41 & $\$ 16,527,113,889$ & $\$ 683,068,800$ & $\$ 12,665,244,585$ \\
\hline Wldfr & 20 & 0.85 & $\$ 26,193,487$ & $\$ 4,669,850$ & $\$ 4,669,850$ \\
\hline Wind & 3940 & 1.14 & $\$ 13,917,665,794$ & $\$ 760,076,000$ & $\$ 9,456,279,821$ \\
\hline Wintr & 909 & 2.21 & $\$ 10,195,367,607$ & $\$ 410,410,000$ & $\$ 6,525,955,906$ \\
\hline
\end{tabular}

\begin{tabular}{|c|r|r|r|r|r|}
\cline { 3 - 7 } \multicolumn{2}{c|}{} & \multicolumn{4}{c|}{ Contributions to the Total Consequence amount } \\
\hline Hazard & Total Consequence & \multicolumn{1}{|c|}{ Injuries } & \multicolumn{1}{c|}{ Fatalities } & \multicolumn{1}{c|}{ Property Loss } & \multicolumn{1}{|c|}{ Crop Loss } \\
\hline Coast & $\mathbf{\$ 0}$ & $\$ 0$ & $\$ 0$ & $\$ 0$ & $\$ 0$ \\
\hline Eqke & $\mathbf{\$ 2 , 0 2 5}$ & $\$ 0$ & $\$ 0$ & $\$ 2,025$ & $\$ 0$ \\
\hline Flood & $\mathbf{\$ 1 , 6 9 7 , 6 7 2 , 0 3 1}$ & $\$ 2,463,510,000$ & $\$ 2,303,600,000$ & $\$ 21,097,518,888$ & $\$ 5,833,043,143$ \\
\hline Hail & $\mathbf{\$ 1 3 , 8 2 8 , 1 0 0 , 8 7 0}$ & $\$ 1,970,076,000$ & $\$ 310,960,000$ & $\$ 6,308,768,167$ & $\$ 5,238,296,703$ \\
\hline Heat & $\mathbf{\$ 3 , 3 0 0 , 3 0 6 , 3 6 9}$ & $\$ 2,120,742,000$ & $\$ 1,127,760,000$ & $\$ 41,202,769$ & $\$ 10,601,600$ \\
\hline Hurr & $\mathbf{\$ 1 , 5 0 3 , 0 0 0}$ & $\$ 1,200,000$ & $\$ 0$ & $\$ 303,000$ & $\$ 0$ \\
\hline Lndsd & $\mathbf{\$ 1 0 9 , 4 5 0}$ & $\$ 0$ & $\$ 0$ & $\$ 99,500$ & $\$ 9,950$ \\
\hline Light & $\mathbf{\$ 2 , 5 1 9 , 2 8 3 , 9 9 0}$ & $\$ 534,180,000$ & $\$ 1,416,080,000$ & $\$ 409,197,040$ & $\$ 159,826,950$ \\
\hline Storm & $\mathbf{\$ 1 3 , 7 3 3 , 4 8 0 , 4 6 9}$ & $\$ 1,185,510,000$ & $\$ 833,800,000$ & $\$ 4,838,747,584$ & $\$ 6,875,422,884$ \\
\hline Tornd & $\mathbf{\$ 1 6 , 5 2 7 , 1 1 3 , 8 8 9}$ & $\$ 6,510,318,000$ & $\$ 2,287,680,000$ & $\$ 7,146,901,599$ & $\$ 582,214,290$ \\
\hline Wldfr & $\mathbf{\$ 2 6 , 1 9 3 , 4 8 7}$ & $\$ 10,200,000$ & $\$ 4,000,000$ & $\$ 11,814,087$ & $\$ 179,400$ \\
\hline Wind & $\mathbf{\$ 1 3 , 9 1 7 , 6 6 5 , 7 9 4}$ & $\$ 2,706,726,000$ & $\$ 1,375,960,000$ & $\$ 5,356,234,185$ & $\$ 4,478,745,609$ \\
\hline Wintr & $\mathbf{\$ 1 0 , 1 9 5 , 3 6 7 , 6 0 7}$ & $\$ 1,205,046,000$ & $\$ 2,697,880,000$ & $\$ 3,651,769,001$ & $\$ 2,640,672,606$ \\
\hline
\end{tabular}

\begin{tabular}{|c|c|c|c|c|c|}
\hline INJURIES & & & & & \\
\hline Hazard & Total injuries & \# of events & Max injuries in one & Total minus max & \% of total \\
\hline Coast & 0 & 0 & 0 & 0 & $0 \%$ \\
\hline Eqke & 0 & 1 & 0 & 0 & $0 \%$ \\
\hline Flood & 4106 & 1459 & 2932 & 1174 & $71 \%$ \\
\hline Hail & 3283 & 3245 & 1000 & 2283 & $30 \%$ \\
\hline Heat & 3535 & 122 & 437 & 3098 & $12 \%$ \\
\hline Hurr & 2 & 1 & 2 & 0 & $100 \%$ \\
\hline Lndsd & 0 & 1 & 0 & 0 & $0 \%$ \\
\hline Light & 890 & 2044 & 58 & 832 & $7 \%$ \\
\hline Storm & 1976 & 3039 & 150 & 1826 & $8 \%$ \\
\hline Tornd & 10851 & 2004 & 683 & 10168 & $6 \%$ \\
\hline Wldfr & 17 & 20 & 4 & 13 & $24 \%$ \\
\hline Wind & 4511 & 3940 & 685 & 3826 & $15 \%$ \\
\hline Wintr & 2008 & 909 & 250 & 1758 & $12 \%$ \\
\hline
\end{tabular}

Table 9-1: Plains region injury consequence tables 

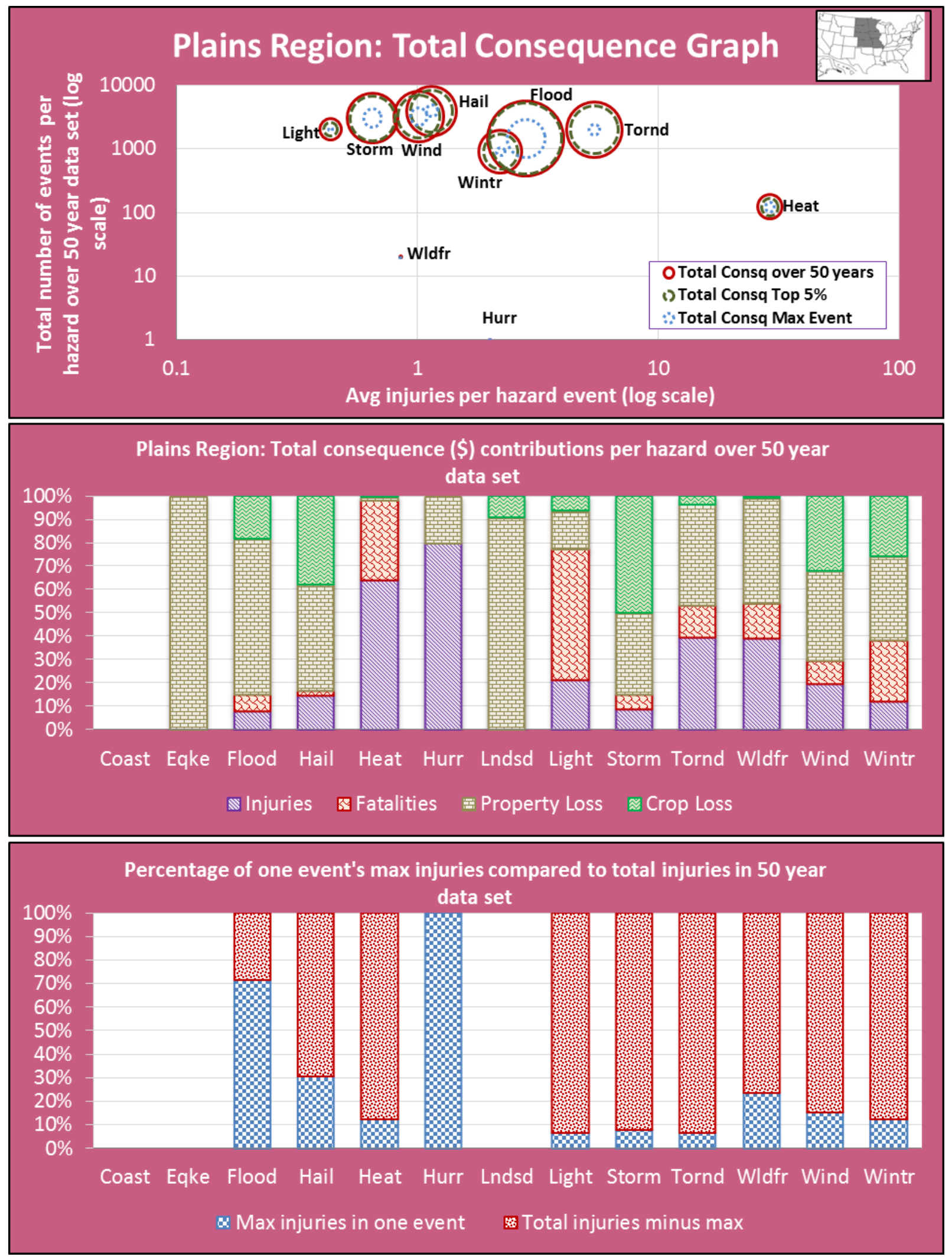

Figure 9-1: Plains region injury consequence graphics 


\begin{tabular}{|c|c|c|r|r|r|}
\hline FATALITIES & Y-axis & \multicolumn{1}{|c|}{ X-axis } & Outside Circle Size & Inner Circle Size & Middle Circle Size \\
\hline Hazard & \# of events & $\begin{array}{c}\text { Avg fatalities per } \\
\text { event }\end{array}$ & Total Consequence & Total Consq Max & Total Consq Top 5\% \\
\hline Coast & 0 & 0.00 & $\$ 0$ & $\$ 0$ & $\$ 0$ \\
\hline Eqke & 1 & 0.00 & $\$ 2,025$ & $\$ 2,025$ & $\$ 0$ \\
\hline Flood & 1459 & 0.39 & $\$ 31,697,672,031$ & $\$ 8,121,435,250$ & $\$ 28,447,427,116$ \\
\hline Hail & 3245 & 0.02 & $\$ 13,828,100,870$ & $\$ 1,663,080,810$ & $\$ 9,919,789,302$ \\
\hline Heat & 122 & 2.31 & $\$ 3,300,306,369$ & $\$ 502,140,000$ & $\$ 1,591,640,250$ \\
\hline Hurr & 1 & 0.00 & $\$ 1,503,000$ & $\$ 1,503,000$ & $\$ 0$ \\
\hline Lndsd & 1 & 0.00 & $\$ 109,450$ & $\$ 109,450$ & $\$ 0$ \\
\hline Light & 2044 & 0.17 & $\$ 2,519,283,990$ & $\$ 69,589,935$ & $\$ 1,097,923,428$ \\
\hline Storm & 3039 & 0.07 & $\$ 13,733,480,469$ & $\$ 1,822,702,500$ & $\$ 11,093,865,038$ \\
\hline Tornd & 2004 & 0.29 & $\$ 16,527,113,889$ & $\$ 683,068,800$ & $\$ 12,665,244,585$ \\
\hline Wldfr & 20 & 0.05 & $\$ 26,193,487$ & $\$ 4,669,850$ & $\$ 4,669,850$ \\
\hline Wind & 3940 & 0.09 & $\$ 13,917,665,794$ & $\$ 760,076,000$ & $\$ 9,456,279,821$ \\
\hline Wintr & 909 & 0.74 & $\$ 10,195,367,607$ & $\$ 410,410,000$ & $\$ 6,525,955,906$ \\
\hline
\end{tabular}

\begin{tabular}{|c|r|r|r|r|r|}
\cline { 3 - 6 } \multicolumn{2}{c|}{} & \multicolumn{3}{c|}{ Contributions to the Total Consequence amount } \\
\hline Hazard & Total Consequence & \multicolumn{1}{c|}{ Injuries } & \multicolumn{1}{c|}{ Fatalities } & \multicolumn{1}{c|}{ Property Loss } & \multicolumn{1}{c|}{ Crop Loss } \\
\hline Coast & $\mathbf{\$ 0}$ & $\$ 0$ & $\$ 0$ & $\$ 0$ & $\$ 0$ \\
\hline Eqke & $\mathbf{\$ 2 , 0 2 5}$ & $\$ 0$ & $\$ 0$ & $\$ 2,025$ & $\$ 0$ \\
\hline Flood & $\mathbf{\$ 1 , 6 9 7 , 6 7 2 , 0 3 1}$ & $\$ 2,463,510,000$ & $\$ 2,303,600,000$ & $\$ 21,097,518,888$ & $\$ 5,833,043,143$ \\
\hline Hail & $\mathbf{\$ 1 3 , 8 2 8 , 1 0 0 , 8 7 0}$ & $\$ 1,970,076,000$ & $\$ 310,960,000$ & $\$ 6,308,768,167$ & $\$ 5,238,296,703$ \\
\hline Heat & $\mathbf{\$ 3 , 3 0 0 , 3 0 6 , 3 6 9}$ & $\$ 2,120,742,000$ & $\$ 1,127,760,000$ & $\$ 41,202,769$ & $\$ 10,601,600$ \\
\hline Hurr & $\mathbf{\$ 1 , 5 0 3 , 0 0 0}$ & $\$ 1,200,000$ & $\$ 0$ & $\$ 303,000$ & $\$ 0$ \\
\hline Lndsd & $\mathbf{\$ 1 0 9 , 4 5 0}$ & $\$ 0$ & $\$ 0$ & $\$ 99,500$ & $\$ 9,950$ \\
\hline Light & $\mathbf{\$ 2 , 5 1 9 , 2 8 3 , 9 9 0}$ & $\$ 534,180,000$ & $\$ 1,416,080,000$ & $\$ 409,197,040$ & $\$ 159,826,950$ \\
\hline Storm & $\mathbf{\$ 1 3 , 7 3 3 , 4 8 0 , 4 6 9}$ & $\$ 1,185,510,000$ & $\$ 833,800,000$ & $\$ 4,838,747,584$ & $\$ 6,875,422,884$ \\
\hline Tornd & $\mathbf{\$ 1 6 , 5 2 7 , 1 1 3 , 8 8 9}$ & $\$ 6,510,318,000$ & $\$ 2,287,680,000$ & $\$ 7,146,901,599$ & $\$ 582,214,290$ \\
\hline Wldfr & $\mathbf{\$ 2 6 , 1 9 3 , 4 8 7}$ & $\$ 10,200,000$ & $\$ 4,000,000$ & $\$ 11,814,087$ & $\$ 179,400$ \\
\hline Wind & $\mathbf{\$ 1 3 , 9 1 7 , 6 6 5 , 7 9 4}$ & $\$ 2,706,726,000$ & $\$ 1,375,960,000$ & $\$ 5,356,234,185$ & $\$ 4,478,745,609$ \\
\hline Wintr & $\mathbf{\$ 1 0 , 1 9 5 , 3 6 7 , 6 0 7}$ & $\$ 1,205,046,000$ & $\$ 2,697,880,000$ & $\$ 3,651,769,001$ & $\$ 2,640,672,606$ \\
\hline
\end{tabular}

\begin{tabular}{|c|c|c|c|c|c|}
\hline FATALITIES & & & & & \\
\hline Hazard & Total fatalities & \# of events & Max fatalities in one & Total minus max & $\%$ of total \\
\hline Coast & 0 & 0 & 0 & 0 & $0 \%$ \\
\hline Eqke & 0 & 1 & 0 & 0 & $0 \%$ \\
\hline Flood & 576 & 1459 & 237 & 339 & $41 \%$ \\
\hline Hail & 78 & 3245 & 14 & 64 & $18 \%$ \\
\hline Heat & 282 & 122 & 66 & 216 & $23 \%$ \\
\hline Hurr & 0 & 1 & 0 & 0 & $0 \%$ \\
\hline Lndsd & 0 & 1 & 0 & 0 & $0 \%$ \\
\hline Light & 354 & 2044 & 6 & 348 & $2 \%$ \\
\hline Storm & 208 & 3039 & 5 & 203 & $2 \%$ \\
\hline Tornd & 572 & 2004 & 37 & 535 & $6 \%$ \\
\hline Wldfr & 1 & 20 & 1 & 0 & $100 \%$ \\
\hline Wind & 344 & 3940 & 14 & 330 & $4 \%$ \\
\hline Wintr & 674 & 909 & 57 & 618 & $8 \%$ \\
\hline
\end{tabular}

Table 9-2: Plains region fatality consequence tables 

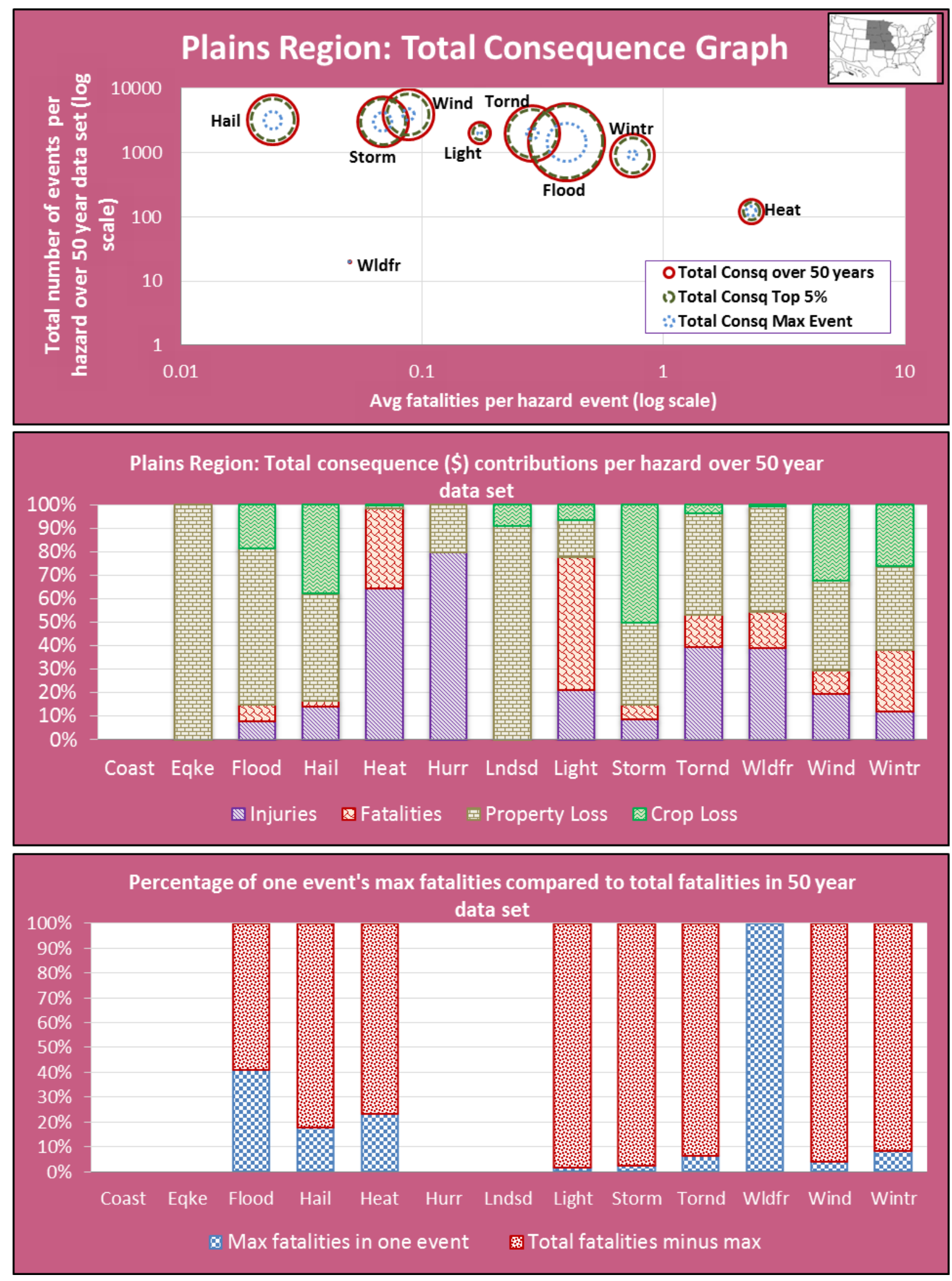

Figure 9-2: Plains region fatality consequence graphics 


\begin{tabular}{|c|c|r|r|r|r|}
\hline DAMAGES & Y-axis & \multicolumn{1}{|c|}{ X-axis } & Outside Circle Size & Inner Circle Size & Middle Circle Size \\
\hline Hazard & \# of events & $\begin{array}{c}\text { Avg damages per } \\
\text { event }\end{array}$ & Total Consequence & Total Consq Max & Total Consq Top 5\% \\
\hline Coast & 0 & $\$ 0$ & $\$ 0$ & $\$ 0$ & $\$ 0$ \\
\hline Eqke & 1 & $\$ 2,025$ & $\$ 2,025$ & $\$ 2,025$ & $\$ 0$ \\
\hline Flood & 1459 & $\$ 18,458,233$ & $\$ 31,697,672,031$ & $\$ 8,121,435,250$ & $\$ 28,447,427,116$ \\
\hline Hail & 3245 & $\$ 3,558,418$ & $\$ 13,828,100,870$ & $\$ 1,663,080,810$ & $\$ 9,919,789,302$ \\
\hline Heat & 122 & $\$ 424,626$ & $\$ 3,300,306,369$ & $\$ 502,140,000$ & $\$ 1,591,640,250$ \\
\hline Hurr & 1 & $\$ 303,000$ & $\$ 1,503,000$ & $\$ 1,503,000$ & $\$ 0$ \\
\hline Lndsd & 1 & $\$ 109,450$ & $\$ 109,450$ & $\$ 109,450$ & $\$ 0$ \\
\hline Light & 2044 & $\$ 278,387$ & $\$ 2,519,283,990$ & $\$ 69,589,935$ & $\$ 1,097,923,428$ \\
\hline Storm & 3039 & $\$ 3,854,614$ & $\$ 13,733,480,469$ & $\$ 1,822,702,500$ & $\$ 11,093,865,038$ \\
\hline Tornd & 2004 & $\$ 3,856,844$ & $\$ 16,527,113,889$ & $\$ 683,068,800$ & $\$ 12,665,244,585$ \\
\hline Wldfr & 20 & $\$ 599,674$ & $\$ 26,193,487$ & $\$ 4,669,850$ & $\$ 4,669,850$ \\
\hline Wind & 3940 & $\$ 2,496,188$ & $\$ 13,917,665,794$ & $\$ 760,076,000$ & $\$ 9,456,279,821$ \\
\hline Wintr & 909 & $\$ 6,922,378$ & $\$ 10,195,367,607$ & $\$ 410,410,000$ & $\$ 6,525,955,906$ \\
\hline
\end{tabular}

\begin{tabular}{|c|r|r|r|r|r|}
\cline { 3 - 7 } \multicolumn{2}{c|}{} & \multicolumn{4}{c|}{ Contributions to the Total Consequence amount } \\
\hline Hazard & Total Consequence & \multicolumn{1}{|c|}{ Injuries } & \multicolumn{1}{c|}{ Fatalities } & \multicolumn{1}{c|}{ Property Loss } & \multicolumn{1}{c|}{ Crop Loss } \\
\hline Coast & $\mathbf{\$ 0}$ & $\$ 0$ & $\$ 0$ & $\$ 0$ & $\$ 0$ \\
\hline Eqke & $\mathbf{\$ 2 , 0 2 5}$ & $\$ 0$ & $\$ 0$ & $\$ 2,025$ & $\$ 0$ \\
\hline Flood & $\mathbf{\$ 1 , 6 9 7 , 6 7 2 , 0 3 1}$ & $\$ 2,463,510,000$ & $\$ 2,303,600,000$ & $\$ 21,097,518,888$ & $\$ 5,833,043,143$ \\
\hline Hail & $\mathbf{\$ 1 3 , 8 2 8 , 1 0 0 , 8 7 0}$ & $\$ 1,970,076,000$ & $\$ 310,960,000$ & $\$ 6,308,768,167$ & $\$ 5,238,296,703$ \\
\hline Heat & $\mathbf{\$ 3 , 3 0 0 , 3 0 6 , 3 6 9}$ & $\$ 2,120,742,000$ & $\$ 1,127,760,000$ & $\$ 41,202,769$ & $\$ 10,601,600$ \\
\hline Hurr & $\mathbf{\$ 1 , 5 0 3 , 0 0 0}$ & $\$ 1,200,000$ & $\$ 0$ & $\$ 303,000$ & $\$ 0$ \\
\hline Lndsd & $\mathbf{\$ 1 0 9 , 4 5 0}$ & $\$ 0$ & $\$ 0$ & $\$ 99,500$ & $\$ 9,950$ \\
\hline Light & $\mathbf{\$ 2 , 5 1 9 , 2 8 3 , 9 9 0}$ & $\$ 534,180,000$ & $\$ 1,416,080,000$ & $\$ 409,197,040$ & $\$ 159,826,950$ \\
\hline Storm & $\mathbf{\$ 1 3 , 7 3 3 , 4 8 0 , 4 6 9}$ & $\$ 1,185,510,000$ & $\$ 833,800,000$ & $\$ 4,838,747,584$ & $\$ 6,875,422,884$ \\
\hline Tornd & $\mathbf{\$ 1 6 , 5 2 7 , 1 1 3 , 8 8 9}$ & $\$ 6,510,318,000$ & $\$ 2,287,680,000$ & $\$ 7,146,901,599$ & $\$ 582,214,290$ \\
\hline Wldfr & $\mathbf{\$ 2 6 , 1 9 3 , 4 8 7}$ & $\$ 10,200,000$ & $\$ 4,000,000$ & $\$ 11,814,087$ & $\$ 179,400$ \\
\hline Wind & $\mathbf{\$ 1 3 , 9 1 7 , 6 6 5 , 7 9 4}$ & $\$ 2,706,726,000$ & $\$ 1,375,960,000$ & $\$ 5,356,234,185$ & $\$ 4,478,745,609$ \\
\hline Wintr & $\mathbf{\$ 1 0 , 1 9 5 , 3 6 7 , 6 0 7}$ & $\$ 1,205,046,000$ & $\$ 2,697,880,000$ & $\$ 3,651,769,001$ & $\$ 2,640,672,606$ \\
\hline
\end{tabular}

\begin{tabular}{|c|r|c|r|r|c|}
\hline DAMAGES & & & & & \\
\hline Hazard & \multicolumn{1}{|c|}{ Total damages } & \# of events & Max damages in one & \multicolumn{1}{l|}{ Total minus max } & $\%$ of total \\
\hline Coast & $\$ 0$ & 0 & $\$ 0$ & $\$ 0$ & $0 \%$ \\
\hline Eqke & $\$ 2,025$ & 1 & $\$ 2,025$ & $\$ 0$ & $100 \%$ \\
\hline Flood & $\$ 26,930,562,031$ & 1459 & $\$ 8,121,435,250$ & $\$ 18,809,126,781$ & $30 \%$ \\
\hline Hail & $\$ 11,547,064,870$ & 3245 & $\$ 1,660,680,810$ & $\$ 9,886,384,060$ & $14 \%$ \\
\hline Heat & $\$ 51,804,369$ & 122 & $\$ 18,399,999$ & $\$ 33,404,369$ & $36 \%$ \\
\hline Hurr & $\$ 303,000$ & 1 & $\$ 303,000$ & $\$ 0$ & $100 \%$ \\
\hline Lndsd & $\$ 109,450$ & 1 & $\$ 109,450$ & $\$ 0$ & $100 \%$ \\
\hline Light & $\$ 569,023,990$ & 2044 & $\$ 65,299,935$ & $\$ 503,724,055$ & $11 \%$ \\
\hline Storm & $\$ 11,714,170,469$ & 3039 & $\$ 1,822,702,500$ & $\$ 9,891,467,969$ & $16 \%$ \\
\hline Tornd & $\$ 7,729,115,889$ & 2004 & $\$ 427,968,030$ & $\$ 7,301,147,859$ & $6 \%$ \\
\hline Wldfr & $\$ 11,993,487$ & 20 & $\$ 4,200,000$ & $\$ 7,793,487$ & $35 \%$ \\
\hline Wind & $\$ 9,834,979,794$ & 3940 & $\$ 760,076,000$ & $\$ 9,074,903,794$ & $8 \%$ \\
\hline Wintr & $\$ 6,292,441,607$ & 909 & $\$ 410,410,000$ & $\$ 5,882,031,606$ & $7 \%$ \\
\hline
\end{tabular}

Table 9-3: Plains region damage consequence tables 

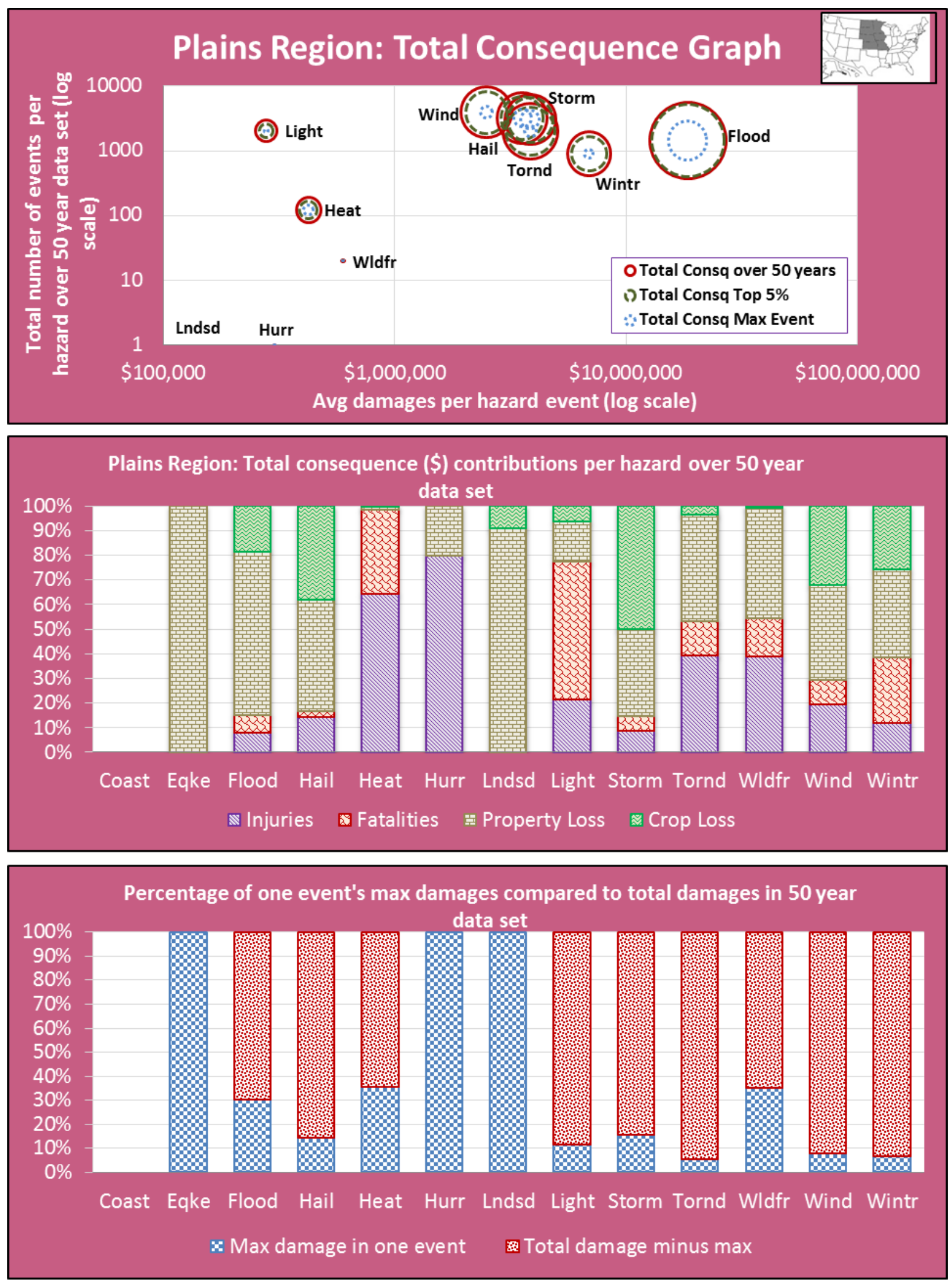

Figure 9-3: Plains region damage consequence graphics 


\subsection{REGION CONSEQUENCE RANKINGS}

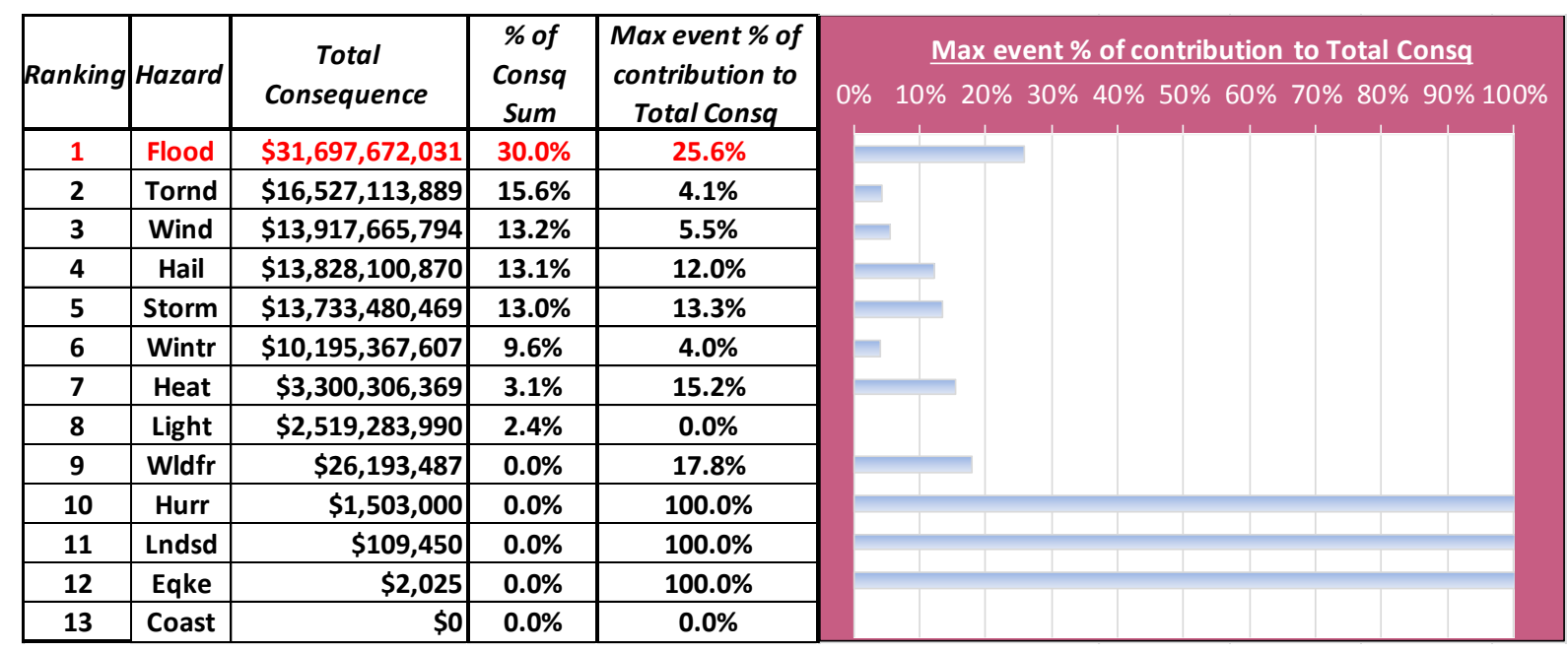

INJURIES

\begin{tabular}{|c|c|}
\hline Hazard & Avg injuries/event \\
\hline Heat & 28.97 \\
\hline Tornd & 5.41 \\
\hline Flood & 2.81 \\
\hline Wintr & 2.21 \\
\hline Hurr & 2.00 \\
\hline Wind & 1.14 \\
\hline Hail & 1.01 \\
\hline Wldfr & 0.85 \\
\hline Storm & 0.65 \\
\hline Light & 0.44 \\
\hline Eqke & 0.00 \\
\hline Coast & 0.00 \\
\hline Lndsd & 0.00 \\
\hline Hazard & Total injuries \\
\hline Tornd & 10851 \\
\hline Wind & 4511 \\
\hline Flood & 4106 \\
\hline Heat & 3535 \\
\hline Hail & 3283 \\
\hline Wintr & 2008 \\
\hline Storm & 1976 \\
\hline Light & 890 \\
\hline Wldfr & 17 \\
\hline Hurr & 2 \\
\hline Eqke & 0 \\
\hline Coast & 0 \\
\hline Lndsd & 0 \\
\hline
\end{tabular}

FATALITIES

\begin{tabular}{|c|c|}
\hline Hazard & Avg fatalities/event \\
\hline Heat & 2.31 \\
\hline Wintr & 0.74 \\
\hline Flood & 0.39 \\
\hline Tornd & 0.29 \\
\hline Light & 0.17 \\
\hline Wind & 0.09 \\
\hline Storm & 0.07 \\
\hline Wldfr & 0.05 \\
\hline Hail & 0.02 \\
\hline Eqke & 0.00 \\
\hline Lndsd & 0.00 \\
\hline Coast & 0.00 \\
\hline Hurr & 0.00 \\
\hline Hard & \\
\hline
\end{tabular}

\begin{tabular}{|c|c|}
\hline \hline Hazard & Total fatalities \\
\hline Wintr & 674 \\
\hline Flood & 576 \\
\hline Tornd & 572 \\
\hline Light & 354 \\
\hline Wind & 344 \\
\hline Heat & 282 \\
\hline Storm & 208 \\
\hline Hail & 78 \\
\hline Wldfr & 1 \\
\hline Eqke & 0 \\
\hline Coast & 0 \\
\hline Lndsd & 0 \\
\hline Hurr & 0 \\
\hline
\end{tabular}

DAMAGES

\begin{tabular}{|c|c|}
\hline Hazard & Avg damage/event \\
\hline Flood & $\$ 18,458,233$ \\
\hline Wintr & $\$ 6,922,378$ \\
\hline Tornd & $\$ 3,856,844$ \\
\hline Storm & $\$ 3,854,614$ \\
\hline Hail & $\$ 3,558,418$ \\
\hline Wind & $\$ 2,496,188$ \\
\hline Wldfr & $\$ 599,674$ \\
\hline Heat & $\$ 424,626$ \\
\hline Hurr & $\$ 303,000$ \\
\hline Light & $\$ 278,387$ \\
\hline Lndsd & $\$ 109,450$ \\
\hline Eqke & $\$ 2,025$ \\
\hline Coast & $\$$ \\
\hline Hazard & Total damage \\
\hline Flood & $\$ 26,930,562,031$ \\
\hline Storm & $\$ 11,714,170,469$ \\
\hline Hail & $\$ 11,547,064,870$ \\
\hline Wind & $\$ 9,834,979,794$ \\
\hline Tornd & $\$ 7,729,115,889$ \\
\hline Wintr & $\$ 6,292,441,607$ \\
\hline Light & $\$ 569,023,990$ \\
\hline Heat & $\$ 51,804,369$ \\
\hline Wldfr & $\$ 11,993,487$ \\
\hline Hurr & $\$ 303,000$ \\
\hline Lndsd & $\$ 109,450$ \\
\hline Eqke & $\$ 2,025$ \\
\hline Coast & $\$ 0$ \\
\hline
\end{tabular}

Table 9-4: Plains region consequence rankings 


\subsection{REGIONAL SUMMARY}

Nearly $20 \%$ of the documented hazard events in the US have occurred in the Plains region in the past 50 years. With only a small percentage of the nation's overall population, this region's natural hazards make up 12\% of the total consequences for the US. Eighty-five percent comes from five primary hazards: flooding, tornadoes, wind, hail, and severe storms. The major influence in this region are flooding hazards, which make up a third of the consequences totaling $\$ 32$ billion, and comprise of $70 \%$ property losses. When looking at the presidential declaration map in Figure 2-4, the majority of flooding borders the Missouri and Mississippi Rivers. A few urban cities are spread out along the river fronts but there are also heavy populations that lie along the entire river waterfront. The US density map (Figure 2-3) shows that the density ranges from 40 to 300 people per square mile in the counties bordering these rivers. One recommendation for this region to decrease the impacts would be to limit the development along the banks after flooding occurrences have caused significant losses among them. This can be difficult to interpret by observing calculations, but by combining the graphs/charts with GIS maps, a method is developed for providing a straightforward way to make better decisions about future growth and reducing risk.

While flooding is the largest hazard in terms of property loss, tornadoes and winter storms have caused the most injuries and fatalities in the region. The tornado hazard has the largest amount of injuries with almost 11,000 totals, and has 5.4 injuries per event. Taking the average and the totals into consideration separately can help mitigation planners see if implementing new measures have reduced the losses caused by hazards as well as convey to the public that these measures have helped lessen the societal impacts. 


\section{Great Lakes Regional Analysis}

\subsection{LAYOUT}

Chapter 10 contains the natural hazard risk assessment and analysis for the Great Lakes region, which consists of the following five states: Wisconsin, Illinois, Michigan, Indiana, and Ohio. Figures included in this chapter are:

- Great Lakes region consequence tables for injuries, fatalities, and damages

$>$ Table 10-1, Table 10-2, and Table 10-3, respectively

- Great Lakes region consequence graphics for injuries, fatalities, and damages

$>$ Figure 10-1, Figure 10-2, and Figure 10-3, respectively

- Great Lakes region consequence rankings (Table 10-4)

$>$ Total consequence and overall percentage

$>$ Average loss per event: injuries, fatalities, damages

$>$ Total losses: injuries, fatalities, damages

The following hazard events have not been recorded by SHELDUS and will not appear in the graphical or chart displays for this region.

- Hurricane 


\subsection{REGION CONSEQUENCE DISPLAYS}

\begin{tabular}{|c|c|c|r|r|r|}
\hline INJURIES & Y-axis & X-axis & Outside Circle Size & Inner Circle Size & Middle Circle Size \\
\hline Hazard & \# of events & $\begin{array}{c}\text { Avg injuries per } \\
\text { event }\end{array}$ & Total Consequence & Total Consq Max & Total Consq Top 5\% \\
\hline Coast & 58 & 0.17 & $\$ 191,631,931$ & $\$ 27,203,855$ & $\$ 51,203,988$ \\
\hline Eqke & 1 & 0.00 & $\$ 311$ & $\$ 311$ & $\$ 0$ \\
\hline Flood & 1280 & 0.65 & $\$ 17,684,189,897$ & $\$ 1,778,592,725$ & $\$ 14,775,181,110$ \\
\hline Hail & 1290 & 2.40 & $\$ 7,620,285,149$ & $\$ 1,016,915,459$ & $\$ 6,218,991,203$ \\
\hline Heat & 102 & 14.15 & $\$ 5,852,715,901$ & $\$ 2,388,058,000$ & $\$ 4,004,135,501$ \\
\hline Hurr & 0 & 0.00 & $\$ 0$ & $\$ 0$ & $\$ 0$ \\
\hline Lndsd & 4 & 0.50 & $\$ 26,580,696$ & $\$ 14,188,196$ & $\$ 14,188,196$ \\
\hline Light & 1835 & 1.43 & $\$ 6,608,787,347$ & $\$ 1,663,974,701$ & $\$ 3,870,490,264$ \\
\hline Storm & 2316 & 1.51 & $\$ 8,748,303,353$ & $\$ 558,075,348$ & $\$ 5,732,026,188$ \\
\hline Tornd & 1383 & 12.34 & $\$ 24,572,038,146$ & $\$ 7,366,998,800$ & $\$ 21,278,264,621$ \\
\hline Wldfr & 19 & 0.26 & $\$ 13,370,149$ & $\$ 4,967,600$ & $\$ 4,967,600$ \\
\hline Wind & 2957 & 1.98 & $\$ 15,794,382,128$ & $\$ 1,714,160,000$ & $\$ 11,250,616,052$ \\
\hline Wintr & 651 & 6.05 & $\$ 10,732,805,921$ & $\$ 2,078,277,999$ & $\$ 8,005,015,345$ \\
\hline
\end{tabular}

\begin{tabular}{|c|r|r|r|r|r|}
\cline { 3 - 6 } \multicolumn{2}{c|}{} & \multicolumn{4}{c|}{ Contributions to the Total Consequence amount } \\
\hline Hazard & Total Consequence & \multicolumn{1}{c|}{ Injuries } & \multicolumn{1}{c|}{ Fatalities } & Property Loss & \multicolumn{1}{c|}{ Crop Loss } \\
\hline Coast & $\mathbf{\$ 1 9 1 , 6 3 1 , 9 3 1}$ & $\$ 6,000,000$ & $\$ 124,000,000$ & $\$ 61,308,081$ & $\$ 323,850$ \\
\hline Eqke & $\mathbf{\$ 3 1 1}$ & $\$ 0$ & $\$ 0$ & $\$ 311$ & $\$ 0$ \\
\hline Flood & $\mathbf{\$ 1 7 , 6 8 4 , \mathbf { 1 8 9 , 8 9 7 }}$ & $\$ 498,576,000$ & $\$ 1,322,480,000$ & $\$ 10,636,821,783$ & $\$ 5,226,312,114$ \\
\hline Hail & $\mathbf{\$ 7 , 6 2 0 , 2 8 5 , 1 4 9}$ & $\$ 1,858,062,000$ & $\$ 785,760,000$ & $\$ 4,586,753,369$ & $\$ 389,709,780$ \\
\hline Heat & $\mathbf{\$ 5 , 8 5 2 , 7 1 5 , 9 0 1}$ & $\$ 865,686,000$ & $\$ 4,869,680,000$ & $\$ 4,172,101$ & $\$ 113,177,800$ \\
\hline Hurr & $\mathbf{\$ 0}$ & $\$ 0$ & $\$ 0$ & $\$ 0$ & $\$ 0$ \\
\hline Lndsd & $\mathbf{\$ 2 6 , 5 8 0 , 6 9 6}$ & $\$ 1,200,000$ & $\$ 0$ & $\$ 25,380,696$ & $\$ 0$ \\
\hline Light & $\mathbf{\$ 6 , 6 0 8 , 7 8 7 , 3 4 7}$ & $\$ 1,578,324,000$ & $\$ 2,423,520,000$ & $\$ 1,322,837,781$ & $\$ 1,284,105,566$ \\
\hline Storm & $\mathbf{\$ 8 , 7 4 8 , 3 0 3 , 3 5 3}$ & $\$ 2,104,722,000$ & $\$ 1,640,320,000$ & $\$ 4,267,940,196$ & $\$ 735,321,156$ \\
\hline Tornd & $\mathbf{\$ 2 4 , 5 7 2 , 0 3 8 , 1 4 6}$ & $\$ 10,236,006,000$ & $\$ 3,839,840,000$ & $\$ 10,353,550,909$ & $\$ 142,641,238$ \\
\hline Wldfr & $\mathbf{\$ 1 3 , 3 7 0 , 1 4 9}$ & $\$ 3,000,000$ & $\$ 0$ & $\$ 8,984,650$ & $\$ 1,385,500$ \\
\hline Wind & $\mathbf{\$ 1 5 , 7 9 4 , 3 8 2 , 1 2 8}$ & $\$ 3,519,582,000$ & $\$ 3,359,080,000$ & $\$ 7,209,951,073$ & $\$ 1,705,769,055$ \\
\hline Wintr & $\mathbf{\$ 1 0 , 7 3 2 , 8 0 5 , 9 2 1}$ & $\$ 2,361,360,000$ & $\$ 2,349,360,000$ & $\$ 5,205,324,281$ & $\$ 816,761,639$ \\
\hline
\end{tabular}

\begin{tabular}{|c|c|c|c|c|c|}
\hline INJURIES & & & & & \\
\hline Hazard & Total injuries & \# of events & Max injuries in one & Total minus max & $\%$ of total \\
\hline Coast & 10 & 58 & 4 & 6 & $40 \%$ \\
\hline Eqke & 0 & 1 & 0 & 0 & $0 \%$ \\
\hline Flood & 831 & 1280 & 559 & 272 & $67 \%$ \\
\hline Hail & 3097 & 1290 & 937 & 2160 & $30 \%$ \\
\hline Heat & 1443 & 102 & 215 & 1228 & $15 \%$ \\
\hline Hurr & 0 & 0 & 0 & 0 & $0 \%$ \\
\hline Lndsd & 2 & 4 & 2 & 0 & $100 \%$ \\
\hline Light & 2631 & 1835 & 562 & 2069 & $21 \%$ \\
\hline Storm & 3508 & 2316 & 247 & 3261 & $7 \%$ \\
\hline Tornd & 17060 & 1383 & 3339 & 13721 & $20 \%$ \\
\hline Wldfr & 5 & 19 & 4 & 1 & $80 \%$ \\
\hline Wind & 5866 & 2957 & 562 & 5304 & $10 \%$ \\
\hline Wintr & 3936 & 651 & 1574 & 2362 & $40 \%$ \\
\hline
\end{tabular}

Table 10-1: Great Lakes region injury consequence tables 

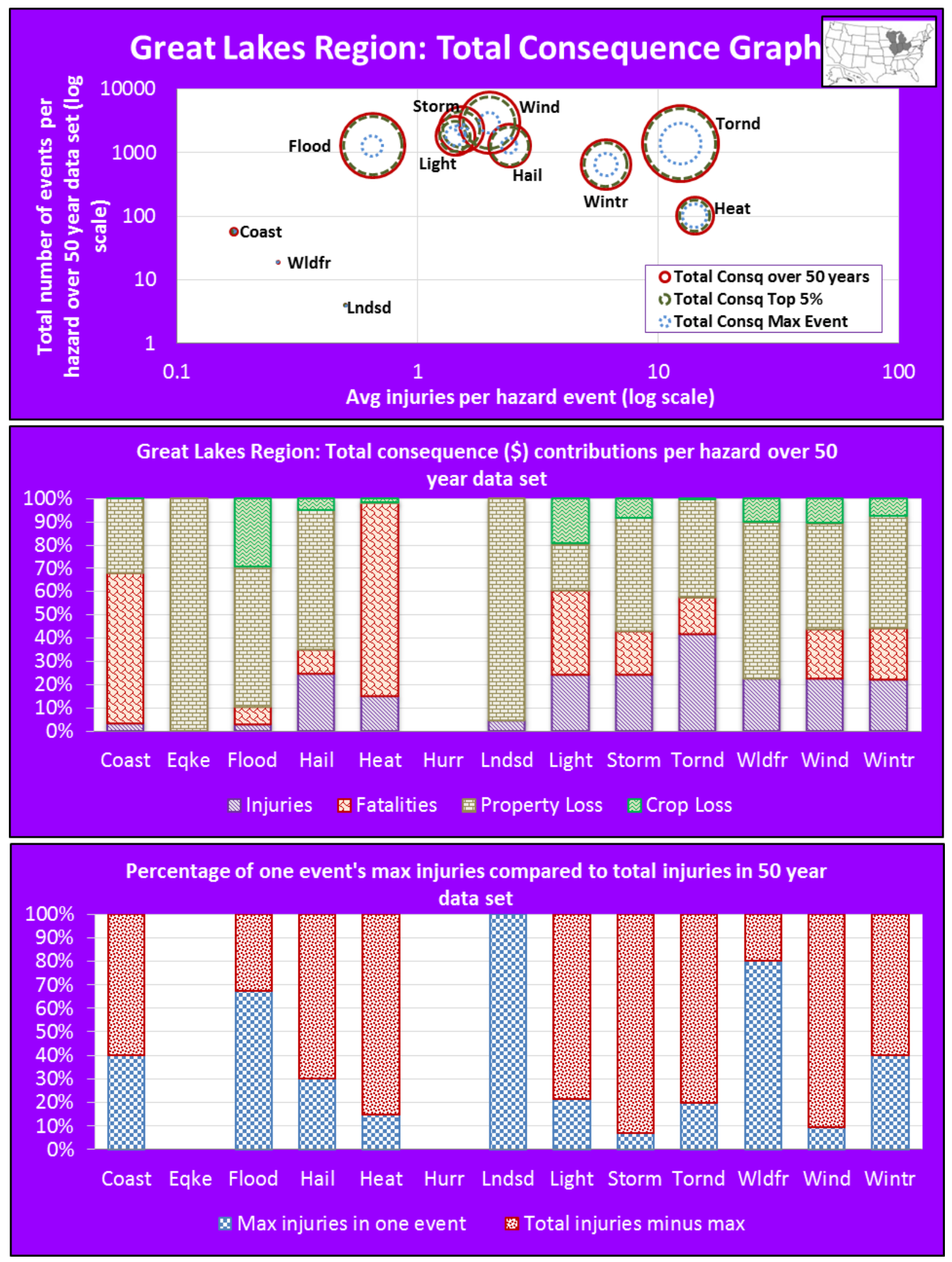

Figure 10-1: Great Lakes region injury consequence graphics 


\begin{tabular}{|c|c|c|c|c|c|}
\hline FATALITIES & Y-axis & $\mathrm{X}$-axis & Outside Circle Size & Inner Circle Size & Middle Circle Size \\
\hline Hazard & \# of events & $\begin{array}{c}\text { Avg fatalities per } \\
\text { event }\end{array}$ & Total Consequence & Total Consq Max & Total Consq Top 5\% \\
\hline Coast & 58 & 0.53 & $\$ 191,631,931$ & $\$ 27,203,855$ & $\$ 51,203,988$ \\
\hline Eqke & 1 & 0.00 & $\$ 311$ & $\$ 311$ & $\$ 0$ \\
\hline Flood & 1280 & 0.26 & $\$ 17,684,189,897$ & $\$ 1,778,592,725$ & $\$ 14,775,181,110$ \\
\hline Hail & 1290 & 0.15 & $\$ 7,620,285,149$ & $\$ 1,016,915,459$ & $\$ 6,218,991,203$ \\
\hline Heat & 102 & 11.94 & $\$ 5,852,715,901$ & $\$ 2,388,058,000$ & $\$ 4,004,135,501$ \\
\hline Hurr & 0 & 0.00 & $\$ 0$ & $\$ 0$ & $\$ 0$ \\
\hline Lndsd & 4 & 0.00 & $\$ 26,580,696$ & $\$ 14,188,196$ & $\$ 14,188,196$ \\
\hline Light & 1835 & 0.33 & $\$ 6,608,787,347$ & $\$ 1,663,974,701$ & $\$ 3,870,490,264$ \\
\hline Storm & 2316 & 0.18 & $\$ 8,748,303,353$ & $\$ 558,075,348$ & $\$ 5,732,026,188$ \\
\hline Tornd & 1383 & 0.69 & $\$ 24,572,038,146$ & $\$ 7,366,998,800$ & $\$ 21,278,264,621$ \\
\hline Wldfr & 19 & 0.00 & $\$ 13,370,149$ & $\$ 4,967,600$ & $\$ 4,967,600$ \\
\hline Wind & 2957 & 0.28 & $\$ 15,794,382,128$ & $\$ 1,714,160,000$ & $\$ 11,250,616,052$ \\
\hline Wintr & 651 & 0.90 & $\$ 10,732,805,921$ & $\$ 2,078,277,999$ & $\$ 8,005,015,345$ \\
\hline
\end{tabular}

\begin{tabular}{|c|c|c|c|c|c|}
\hline \multirow[b]{2}{*}{ Hazard } & \multirow[b]{2}{*}{ Total Consequence } & \multicolumn{4}{|c|}{ Contributions to the Total Consequence amount } \\
\hline & & Injuries & Fatalities & Property Loss & Crop Loss \\
\hline Coast & $\$ 191,631,931$ & $\$ 6,000,000$ & $\$ 124,000,000$ & $\$ 61,308,081$ & $\$ 323,850$ \\
\hline Eqke & $\$ 311$ & $\$ 0$ & $\$ 0$ & $\$ 311$ & $\$ 0$ \\
\hline Flood & $\$ 17,684,189,897$ & $\$ 498,576,000$ & $\$ 1,322,480,000$ & $\$ 10,636,821,783$ & $\$ 5,226,312,114$ \\
\hline Hail & $\$ 7,620,285,149$ & $\$ 1,858,062,000$ & $\$ 785,760,000$ & $\$ 4,586,753,369$ & $\$ 389,709,780$ \\
\hline Heat & $\$ 5,852,715,901$ & $\$ 865,686,000$ & $\$ 4,869,680,000$ & $\$ 4,172,101$ & $\$ 113,177,800$ \\
\hline Hurr & $\$ 0$ & $\$ 0$ & \$O & $\$ 0$ & $\$ 0$ \\
\hline Lndsd & $\$ 26,580,696$ & $\$ 1,200,000$ & $\$ 0$ & $\$ 25,380,696$ & $\$ 0$ \\
\hline Light & $\$ 6,608,787,347$ & $\$ 1,578,324,000$ & $\$ 2,423,520,000$ & $\$ 1,322,837,781$ & $\$ 1,284,105,566$ \\
\hline Storm & $\$ 8,748,303,353$ & $\$ 2,104,722,000$ & $\$ 1,640,320,000$ & $\$ 4,267,940,196$ & $\$ 735,321,156$ \\
\hline Tornd & $\$ 24,572,038,146$ & $\$ 10,236,006,000$ & $\$ 3,839,840,000$ & $\$ 10,353,550,909$ & $\$ 142,641,238$ \\
\hline Wldfr & $\$ 13,370,149$ & $\$ 3,000,000$ & $\$ 0$ & $\$ 8,984,650$ & $\$ 1,385,500$ \\
\hline Wind & $\$ 15,794,382,128$ & $\$ 3,519,582,000$ & $\$ 3,359,080,000$ & $\$ 7,209,951,073$ & $\$ 1,705,769,055$ \\
\hline Wintr & $\$ 10,732,805,921$ & $\$ 2,361,360,000$ & $\$ 2,349,360,000$ & $\$ 5,205,324,281$ & $\$ 816,761,639$ \\
\hline
\end{tabular}

\begin{tabular}{|c|c|c|c|c|c|}
\hline FATALITIES & & & & & \\
\hline Hazard & Total fatalities & \# of events & Max fatalities in one & Total minus max & $\%$ of total \\
\hline Coast & 31 & 58 & 3 & 28 & $10 \%$ \\
\hline Eqke & 0 & 1 & 0 & 0 & $0 \%$ \\
\hline Flood & 331 & 1280 & 41 & 290 & $12 \%$ \\
\hline Hail & 196 & 1290 & 27 & 169 & $14 \%$ \\
\hline Heat & 1217 & 102 & 583 & 634 & $48 \%$ \\
\hline Hurr & 0 & 0 & 0 & 0 & $0 \%$ \\
\hline Lndsd & 0 & 4 & 0 & 52 & $0 \%$ \\
\hline Light & 606 & 1835 & 8 & 402 & $7 \%$ \\
\hline Storm & 410 & 1383 & 260 & 700 & $2 \%$ \\
\hline Tornd & 960 & 19 & 0 & 0 & $0 \%$ \\
\hline Wldfr & 0 & 2957 & 42 & 798 & $5 \%$ \\
\hline Wind & 840 & 651 & 56 & 531 & $10 \%$ \\
\hline Wintr & 587 & & & & 0 \\
\hline
\end{tabular}

Table 10-2: Great Lakes region fatality consequence tables 

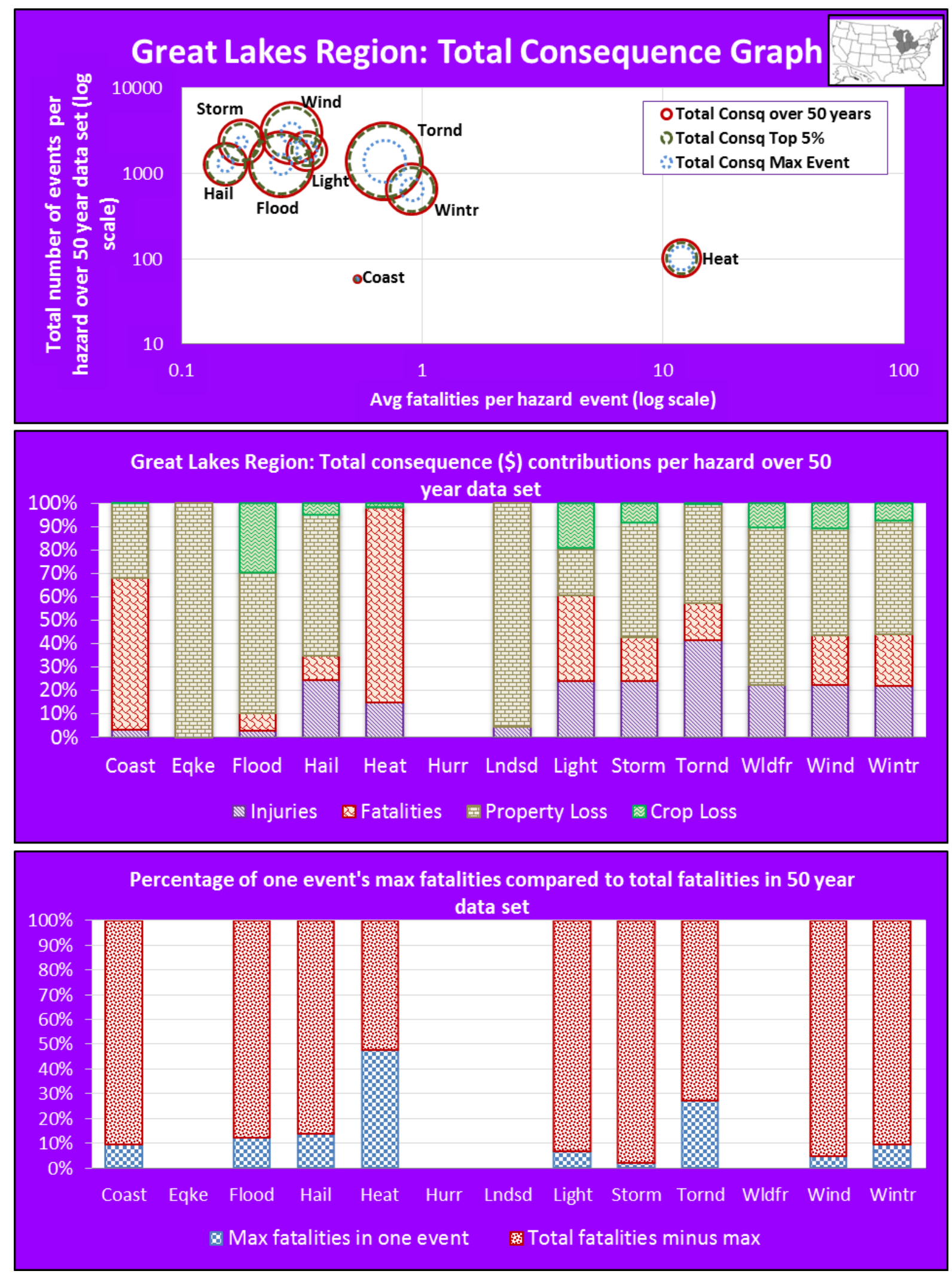

Figure 10-2: Great Lakes region fatality consequence graphics 


\begin{tabular}{|c|c|r|r|r|r|}
\hline DAMAGES & Y-axis & \multicolumn{1}{|c|}{ X-axis } & Outside Circle Size & Inner Circle Size & Middle Circle Size \\
\hline Hazard & \# of events & $\begin{array}{c}\text { Avg damages per } \\
\text { event }\end{array}$ & Total Consequence & Total Consq Max & Total Consq Top 5\% \\
\hline Coast & 58 & $\$ 1,062,620$ & $\$ 191,631,931$ & $\$ 27,203,855$ & $\$ 51,203,988$ \\
\hline Eqke & 1 & $\$ 311$ & $\$ 311$ & $\$ 311$ & $\$ 0$ \\
\hline Flood & 1280 & $\$ 12,393,073$ & $\$ 17,684,189,897$ & $\$ 1,778,592,725$ & $\$ 14,775,181,110$ \\
\hline Hail & 1290 & $\$ 3,857,723$ & $\$ 7,620,285,149$ & $\$ 1,016,915,459$ & $\$ 6,218,991,203$ \\
\hline Heat & 102 & $\$ 1,150,489$ & $\$ 5,852,715,901$ & $\$ 2,388,058,000$ & $\$ 4,004,135,501$ \\
\hline Hurr & 0 & $\$ 0$ & $\$ 0$ & $\$ 0$ & $\$ 0$ \\
\hline Lndsd & 4 & $\$ 6,345,174$ & $\$ 26,580,696$ & $\$ 14,188,196$ & $\$ 14,188,196$ \\
\hline Light & 1835 & $\$ 1,420,678$ & $\$ 6,608,787,347$ & $\$ 1,663,974,701$ & $\$ 3,870,490,264$ \\
\hline Storm & 2316 & $\$ 2,160,303$ & $\$ 8,748,303,353$ & $\$ 558,075,348$ & $\$ 5,732,026,188$ \\
\hline Tornd & 1383 & $\$ 7,589,438$ & $\$ 24,572,038,146$ & $\$ 7,366,998,800$ & $\$ 21,278,264,621$ \\
\hline Wldfr & 19 & $\$ 545,797$ & $\$ 13,370,149$ & $\$ 4,967,600$ & $\$ 4,967,600$ \\
\hline Wind & 2957 & $\$ 3,015,123$ & $\$ 15,794,382,128$ & $\$ 1,714,160,000$ & $\$ 11,250,616,052$ \\
\hline Wintr & 651 & $\$ 9,250,516$ & $\$ 10,732,805,921$ & $\$ 2,078,277,999$ & $\$ 8,005,015,345$ \\
\hline
\end{tabular}

\begin{tabular}{|c|c|c|c|c|c|}
\hline \multirow[b]{2}{*}{ Hazard } & \multirow[b]{2}{*}{ Total Consequence } & \multicolumn{4}{|c|}{ Contributions to the Total Consequence amount } \\
\hline & & Injuries & Fatalities & Property Loss & Crop Loss \\
\hline Coast & $\$ 191,631,931$ & $\$ 6,000,000$ & $\$ 124,000,000$ & $\$ 61,308,081$ & $\$ 323,850$ \\
\hline Eqke & $\$ 311$ & \$O & $\$ 0$ & $\$ 311$ & $\$ 0$ \\
\hline Flood & $\$ 17,684,189,897$ & $\$ 498,576,000$ & $\$ 1,322,480,000$ & $\$ 10,636,821,783$ & $\$ 5,226,312,114$ \\
\hline Hail & $\$ 7,620,285,149$ & $\$ 1,858,062,000$ & $\$ 785,760,000$ & $\$ 4,586,753,369$ & $\$ 389,709,780$ \\
\hline Heat & $\$ 5,852,715,901$ & $\$ 865,686,000$ & $\$ 4,869,680,000$ & $\$ 4,172,101$ & $\$ 113,177,800$ \\
\hline Hurr & $\$ 0$ & $\$ 0$ & $\$ 0$ & $\$ 0$ & $\$ 0$ \\
\hline Lndsd & $\$ 26,580,696$ & $\$ 1,200,000$ & $\$ 0$ & $\$ 25,380,696$ & $\$ 0$ \\
\hline Light & $\$ 6,608,787,347$ & $\$ 1,578,324,000$ & $\$ 2,423,520,000$ & $\$ 1,322,837,781$ & $\$ 1,284,105,566$ \\
\hline Storm & $\$ 8,748,303,353$ & $\$ 2,104,722,000$ & $\$ 1,640,320,000$ & $\$ 4,267,940,196$ & $\$ 735,321,156$ \\
\hline Tornd & $\$ 24,572,038,146$ & $\$ 10,236,006,000$ & $\$ 3,839,840,000$ & $\$ 10,353,550,909$ & $\$ 142,641,238$ \\
\hline Wldfr & $\$ 13,370,149$ & $\$ 3,000,000$ & $\$ 0$ & $\$ 8,984,650$ & $\$ 1,385,500$ \\
\hline Wind & $\$ 15,794,382,128$ & $\$ 3,519,582,000$ & $\$ 3,359,080,000$ & $\$ 7,209,951,073$ & $\$ 1,705,769,055$ \\
\hline Wintr & $\$ 10,732,805,921$ & $\$ 2,361,360,000$ & $\$ 2,349,360,000$ & $\$ 5,205,324,281$ & $\$ 816,761,639$ \\
\hline
\end{tabular}

\begin{tabular}{|c|r|c|r|r|r|}
\hline DAMAGES & & & & & \\
\hline Hazard & Total damages & \# of events & Max damages in one & \multicolumn{1}{c|}{ Total minus max } & $\%$ of total \\
\hline Coast & $\$ 61,631,931$ & 58 & $\$ 27,203,855$ & $\$ 34,428,076$ & $44 \%$ \\
\hline Eqke & $\$ 311$ & 1 & $\$ 311$ & $\$ 0$ & $100 \%$ \\
\hline Flood & $\$ 15,863,133,897$ & 1280 & $\$ 1,774,592,725$ & $\$ 14,088,541,172$ & $11 \%$ \\
\hline Hail & $\$ 4,976,463,149$ & 1290 & $\$ 546,057,750$ & $\$ 4,430,405,399$ & $11 \%$ \\
\hline Heat & $\$ 117,349,901$ & 102 & $\$ 109,500,000$ & $\$ 7,849,901$ & $93 \%$ \\
\hline Hurr & $\$ 0$ & 0 & $\$ 0$ & $\$ 0$ & $0 \%$ \\
\hline Lndsd & $\$ 25,380,696$ & 4 & $\$ 14,188,196$ & $\$ 11,192,500$ & $56 \%$ \\
\hline Light & $\$ 2,606,943,347$ & 1835 & $\$ 1,158,626,701$ & $\$ 1,448,316,647$ & $44 \%$ \\
\hline Storm & $\$ 5,003,261,353$ & 2316 & $\$ 427,275,348$ & $\$ 4,575,986,005$ & $9 \%$ \\
\hline Tornd & $\$ 10,496,192,146$ & 1383 & $\$ 4,323,546,800$ & $\$ 6,172,645,346$ & $41 \%$ \\
\hline Wldfr & $\$ 10,370,149$ & 19 & $\$ 4,050,000$ & $\$ 6,320,149$ & $39 \%$ \\
\hline Wind & $\$ 8,915,720,128$ & 2957 & $\$ 1,670,000,000$ & $\$ 7,245,720,128$ & $19 \%$ \\
\hline Wintr & $\$ 6,022,085,921$ & 651 & $\$ 1,853,699,999$ & $\$ 4,168,385,922$ & $31 \%$ \\
\hline
\end{tabular}

Table 10-3: Great Lakes region damage consequence tables 

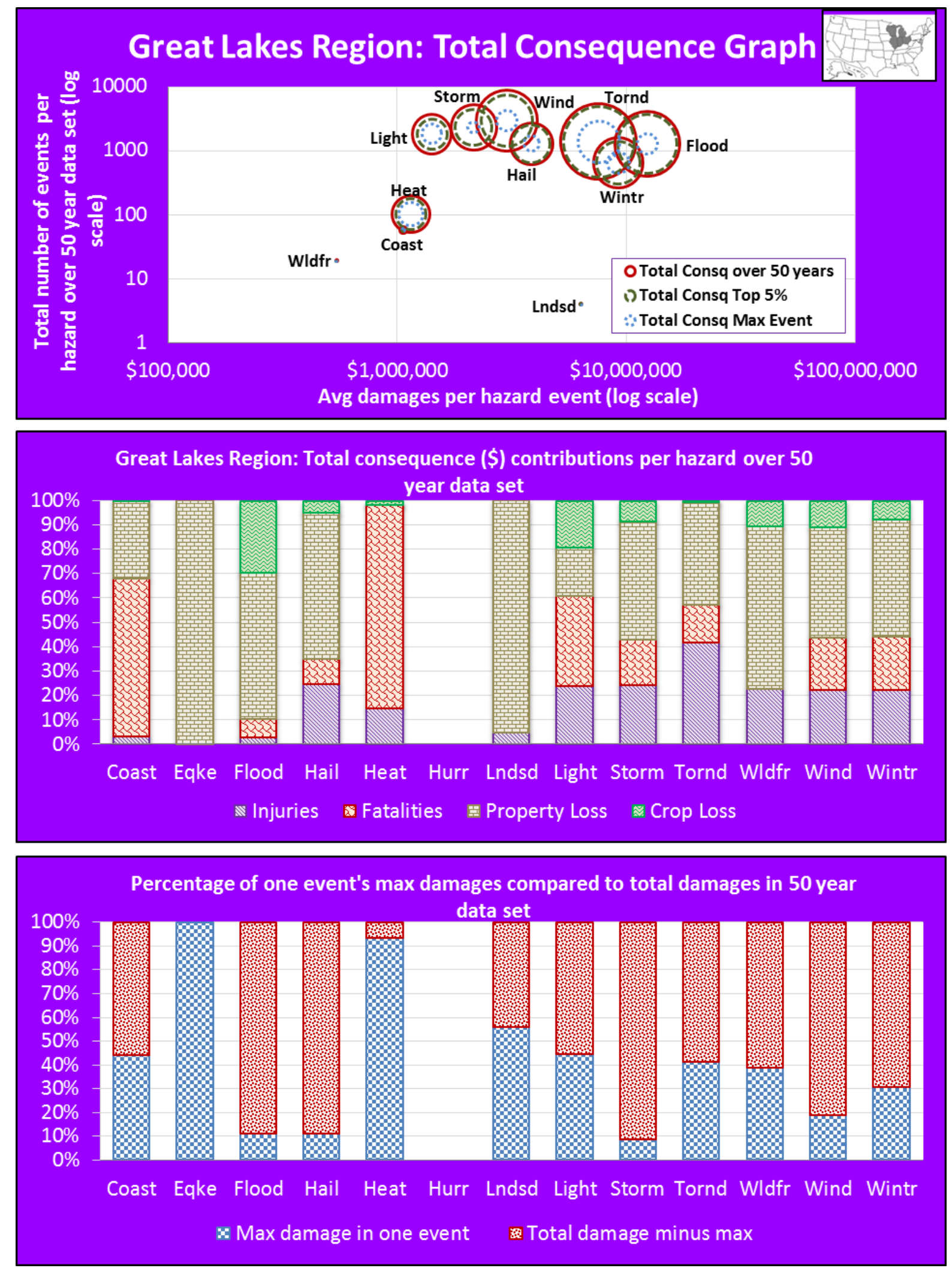

Figure 10-3: Great Lakes region damage consequence graphics 


\subsection{REGION CONSEQUENCE RANKINGS}

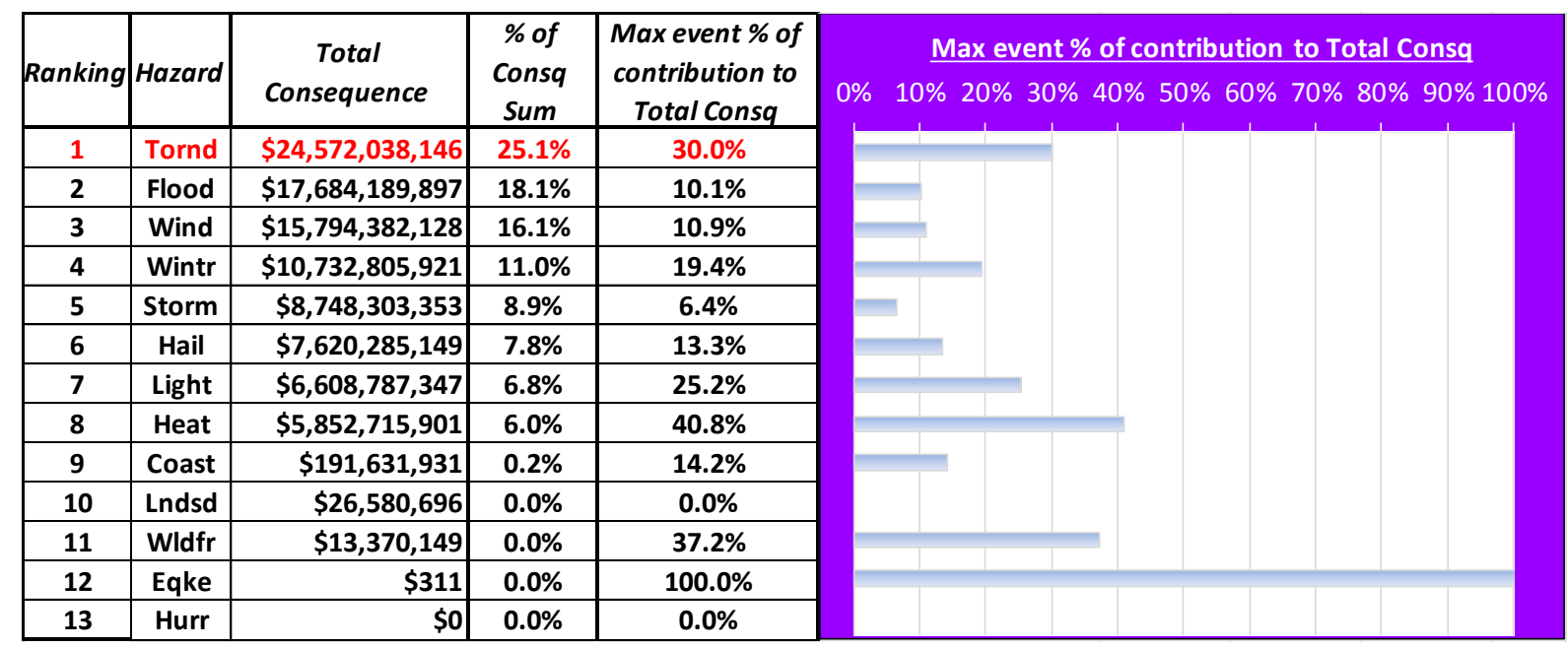

INJURIES

\begin{tabular}{|c|c|}
\hline Hazard & Avg injuries/event \\
\hline Heat & 14.15 \\
\hline Tornd & 12.34 \\
\hline Wintr & 6.05 \\
\hline Hail & 2.40 \\
\hline Wind & 1.98 \\
\hline Storm & 1.51 \\
\hline Light & 1.43 \\
\hline Flood & 0.65 \\
\hline Lndsd & 0.50 \\
\hline Wldfr & 0.26 \\
\hline Coast & 0.17 \\
\hline Hurr & 0.00 \\
\hline Eqke & 0.00 \\
\hline \hline Hazard & Total injuries \\
\hline Tornd & 17060 \\
\hline Wind & 5866 \\
\hline Wintr & 3936 \\
\hline Storm & 3508 \\
\hline Hail & 3097 \\
\hline Light & 2631 \\
\hline Heat & 1443 \\
\hline Flood & 831 \\
\hline Coast & 10 \\
\hline Wldfr & 5 \\
\hline Lndsd & 2 \\
\hline Eqke & 0 \\
\hline Hurr & 0 \\
\hline & \\
\hline
\end{tabular}

\section{FATALITIES}

\begin{tabular}{|c|c|}
\hline Hazard & Avg fatalities/event \\
\hline Heat & 11.94 \\
\hline Wintr & 0.90 \\
\hline Tornd & 0.69 \\
\hline Coast & 0.53 \\
\hline Light & 0.33 \\
\hline Wind & 0.28 \\
\hline Flood & 0.26 \\
\hline Storm & 0.18 \\
\hline Hail & 0.15 \\
\hline Eqke & 0.00 \\
\hline Lndsd & 0.00 \\
\hline Hurr & 0.00 \\
\hline Wldfr & 0.00 \\
\hline \hline
\end{tabular}

\begin{tabular}{|c|c|}
\hline Hazard & Total fatalities \\
\hline Heat & 1217 \\
\hline Tornd & 960 \\
\hline Wind & 840 \\
\hline Light & 606 \\
\hline Wintr & 587 \\
\hline Storm & 410 \\
\hline Flood & 331 \\
\hline Hail & 196 \\
\hline Coast & 31 \\
\hline Eqke & 0 \\
\hline Lndsd & 0 \\
\hline Wldfr & 0 \\
\hline Hurr & 0 \\
\hline
\end{tabular}

DAMAGES

\begin{tabular}{|c|r|}
\hline Hazard & Avg damage/event \\
\hline Flood & $\mathbf{\$ 1 2 , 3 9 3 , 0 7 3}$ \\
\hline Wintr & $\mathbf{\$ 9 , 2 5 0 , 5 1 6}$ \\
\hline Tornd & $\mathbf{\$ 1 , 5 8 9 , 4 3 8}$ \\
\hline Lndsd & $\mathbf{\$ 6 , 3 4 5 , 1 7 4}$ \\
\hline Hail & $\mathbf{\$ 3 , 8 5 7 , 7 2 3}$ \\
\hline Wind & $\mathbf{\$ 3 , 0 1 5 , 1 2 3}$ \\
\hline Storm & $\mathbf{\$ 2 , 1 6 0 , 3 0 3}$ \\
\hline Light & $\mathbf{\$ 1 , 4 2 0 , 6 7 8}$ \\
\hline Heat & $\mathbf{\$ 1 , 1 5 0 , 4 8 9}$ \\
\hline Coast & $\mathbf{\$ 1 , 0 6 2 , 6 2 0}$ \\
\hline Wldfr & $\mathbf{\$ 5 4 5 , 7 9 7}$ \\
\hline Eqke & $\mathbf{\$ 3 1 1}$ \\
\hline Hurr & $\mathbf{\$} 0$ \\
\hline \hline Hazard & Total damage \\
\hline Flood & $\mathbf{\$ 1 5 , 8 6 3 , 1 3 3 , 8 9 7}$ \\
\hline Tornd & $\mathbf{\$ 1 0 , 4 9 6 , 1 9 2 , 1 4 6}$ \\
\hline Wind & $\mathbf{\$ 8 , 9 1 5 , 7 2 0 , 1 2 8}$ \\
\hline Wintr & $\mathbf{\$ 6 , 0 2 2 , 0 8 5 , 9 2 1}$ \\
\hline Storm & $\mathbf{\$ 5 , 0 0 3 , 2 6 1 , 3 5 3}$ \\
\hline Hail & $\mathbf{\$ 4 , 9 7 6 , 4 6 3 , 1 4 9}$ \\
\hline Light & $\mathbf{\$ 2 , 6 0 6 , 9 4 3 , 3 4 7}$ \\
\hline Heat & $\mathbf{\$ 1 1 7 , 3 4 9 , 9 0 1}$ \\
\hline Coast & $\mathbf{\$ 6 1 , 6 3 1 , 9 3 1}$ \\
\hline Lndsd & $\mathbf{\$ 2 5 , 3 8 0 , 6 9 6}$ \\
\hline Wldfr & $\mathbf{\$ 1 0 , 3 7 0 , 1 4 9}$ \\
\hline Eqke & $\mathbf{\$ 3 1 1}$ \\
\hline Hurr & $\mathbf{\$} 0$ \\
\hline
\end{tabular}

Table 10-4: Great Lakes region consequence rankings 


\subsection{REGIONAL SUMMARY}

Tornado and flooding have caused nearly half of all the consequences in the Great Lakes region and total $\$ 42$ billion in losses. Taking a closer look into the tornado hazard reveals that one event in the past 60 years has caused a third of its consequence value of $\$ 25$ billion. The damages from the event are primarily due to property losses. As with the Plains region, tornadoes have caused over 10,000 injuries and almost 1,000 fatalities. The documented tornado hazards happen 23 times per year on average and have detrimental impacts on communities. To lessen these losses, stakeholders can look at building codes and construction materials that would better withstand these extreme winds upon redevelopment of an area.

When focusing on the average losses for events, the heat hazard is most significant. This hazard has over 10 injuries and fatalities for every single event occurrence in the region. Only a small portion of this hazard's overall consequences can be related to crop loss, otherwise the rest is from injuries and fatalities. To observe how much one event influences the average fatality rate, the second chart in Figure 10-2 is utilized. Upon examining the table and chart, 583 fatalities were a result by a single extreme heat event and it makes up nearly half of the total over the 50 year time frame. Hypothetically, if this single event figure is taken out of the data set, the average fatality rate drops to half of the original amount. This demonstrates how one large event affects the average fatality rate substantially. Does this mean that this hazard should be of less concern to the communities in this region? Whether measures are to be taken by local officials to increase public awareness of this issue can be determined by considering these charts and tables. It is ultimately up to the citizens and the local governments to decide the best course of action. 


\section{Southeast Regional Analysis}

\subsection{LAYOUT}

Chapter 11 contains the natural hazard risk assessment and analysis for the Southeast region, which consists of the following twelve states: Arkansas, Louisiana, Mississippi, Alabama, Georgia, Florida, Tennessee, Kentucky, West Virginia, Virginia, North Carolina, and South Carolina. Figures included in this chapter are:

- Southeast region consequence tables for injuries, fatalities, and damages

$$
\text { Table 11-1, Table 11-2, and Table 11-3, respectively }
$$

- Southeast region consequence graphics for injuries, fatalities, and damages

$$
\text { Figure 11-1, Figure 11-2, and Figure 11-3, respectively }
$$

- Southeast region consequence rankings (Table 11-4)

Total consequence and overall percentage

Average loss per event: injuries, fatalities, damages

Total losses: injuries, fatalities, damages

All 13 natural hazards are represented in the consequence displays and rankings for the Southeast region. 


\subsection{REGION CONSEQUENCE DISPLAYS}

\begin{tabular}{|c|c|c|r|r|r|}
\hline INJURIES & Y-axis & \multicolumn{1}{|c|}{ X-axis } & Outside Circle Size & \multicolumn{1}{|c|}{ Inner Circle Size } & \multicolumn{1}{c|}{ Middle Circle Size } \\
\hline Hazard & \# of events & $\begin{array}{c}\text { Avg injuries per } \\
\text { event }\end{array}$ & Total Consequence & Total Consq Max & \multicolumn{1}{|c|}{ Total Consq Top 5\% } \\
\hline Coast & 417 & 0.90 & $\$ 52,733,193,430$ & $\$ 47,712,000,000$ & $\$ 51,025,207,881$ \\
\hline Eqke & 2 & 0.00 & $\$ 2,650,261$ & $\$ 2,650,000$ & $\$ 2,650,000$ \\
\hline Flood & 2518 & 0.66 & $\$ 28,750,107,823$ & $\$ 2,252,970,095$ & $\$ 23,817,374,479$ \\
\hline Hail & 2512 & 1.02 & $\$ 6,316,010,461$ & $\$ 683,588,243$ & $\$ 4,957,600,864$ \\
\hline Heat & 253 & 3.04 & $\$ 8,547,841,166$ & $\$ 2,000,500,001$ & $\$ 6,710,715,393$ \\
\hline Hurr & 242 & 138.03 & $\$ 149,929,385,734$ & $\$ 27,105,904,000$ & $\$ 113,740,820,097$ \\
\hline Lndsd & 29 & 3.62 & $\$ 1,039,396,389$ & $\$ 599,840,000$ & $\$ 794,059,470$ \\
\hline Light & 4295 & 1.14 & $\$ 10,513,852,852$ & $\$ 300,104,250$ & $\$ 3,326,700,989$ \\
\hline Storm & 4930 & 0.94 & $\$ 20,473,142,065$ & $\$ 3,576,585,870$ & $\$ 16,207,144,059$ \\
\hline Tornd & 3195 & 10.55 & $\$ 39,615,609,830$ & $\$ 3,693,959,087$ & $\$ 30,571,014,557$ \\
\hline Wldfr & 114 & 2.45 & $\$ 1,080,680,279$ & $\$ 548,200,000$ & $\$ 985,548,654$ \\
\hline Wind & 5756 & 1.49 & $\$ 21,891,561,180$ & $\$ 2,214,315,610$ & $\$ 16,628,084,552$ \\
\hline Wintr & 686 & 5.25 & $\$ 15,677,868,954$ & $\$ 1,093,316,001$ & $\$ 10,144,843,014$ \\
\hline
\end{tabular}

\begin{tabular}{|c|r|r|r|r|r|}
\cline { 3 - 6 } \multicolumn{2}{c|}{} & \multicolumn{4}{c|}{ Contributions to the Total Consequence amount } \\
\hline Hazard & Total Consequence & \multicolumn{1}{|c|}{ Injuries } & \multicolumn{1}{c|}{ Fatalities } & \multicolumn{1}{c|}{ Property Loss } & \multicolumn{1}{c|}{ Crop Loss } \\
\hline Coast & $\mathbf{\$ 2 , 7 3 3 , 1 9 3 , 4 3 0}$ & $\$ 225,084,000$ & $\$ 1,763,280,000$ & $\$ 50,703,409,749$ & $\$ 41,419,681$ \\
\hline Eqke & $\mathbf{\$ 2 , 6 5 0 , 2 6 1}$ & $\$ 0$ & $\$ 0$ & $\$ 2,650,261$ & $\$ 0$ \\
\hline Flood & $\mathbf{\$ 2 8 , 7 5 0 , 1 0 7 , 8 2 3}$ & $\$ 1,001,112,000$ & $\$ 4,440,600,000$ & $\$ 19,399,582,928$ & $\$ 3,908,812,895$ \\
\hline Hail & $\mathbf{\$ 6 , 3 1 6 , 0 1 0 , 4 6 1}$ & $\$ 1,535,592,000$ & $\$ 976,000,000$ & $\$ 2,571,245,522$ & $\$ 1,233,172,939$ \\
\hline Heat & $\mathbf{\$ 8 , 5 4 7 , 8 4 1 , 1 6 6}$ & $\$ 461,052,000$ & $\$ 4,161,120,000$ & $\$ 1,066,103,161$ & $\$ 2,859,566,006$ \\
\hline Hurr & $\mathbf{\$ 1 4 9 , 9 2 9 , 3 8 5 , 7 3 4}$ & $\$ 20,042,160,000$ & $\$ 2,021,240,000$ & $\$ 114,524,504,667$ & $\$ 13,341,481,067$ \\
\hline Lndsd & $\mathbf{\$ 1 , 0 3 9 , 3 9 6 , 3 8 9}$ & $\$ 63,000,000$ & $\$ 731,040,000$ & $\$ 227,356,389$ & $\$ 18,000,000$ \\
\hline Light & $\mathbf{\$ 1 0 , 5 1 3 , 8 5 2 , 8 5 2}$ & $\$ 2,932,752,000$ & $\$ 6,605,120,000$ & $\$ 807,988,027$ & $\$ 167,992,826$ \\
\hline Storm & $\mathbf{\$ 2 0 , 4 7 3 , 1 4 2 , 0 6 5}$ & $\$ 2,790,348,000$ & $\$ 3,688,400,000$ & $\$ 11,861,271,120$ & $\$ 2,133,122,945$ \\
\hline Tornd & $\mathbf{\$ 3 9 , 6 1 5 , 6 0 9 , 8 3 0}$ & $\$ 20,216,442,000$ & $\$ 8,667,160,000$ & $\$ 10,567,447,166$ & $\$ 164,560,664$ \\
\hline Wldfr & $\mathbf{\$ 1 , 0 8 0 , 6 8 0 , 2 7 9}$ & $\$ 167,268,000$ & $\$ 8,000,000$ & $\$ 868,528,778$ & $\$ 36,883,501$ \\
\hline Wind & $\mathbf{\$ 2 1 , 8 9 1 , 5 6 1 , 1 8 0}$ & $\$ 5,144,208,000$ & $\$ 4,445,360,000$ & $\$ 10,290,406,217$ & $\$ 2,011,586,963$ \\
\hline Wintr & $\mathbf{\$ 1 5 , 6 7 7 , 8 6 8 , 9 5 4}$ & $\$ 2,161,140,000$ & $\$ 4,560,040,000$ & $\$ 5,563,551,758$ & $\$ 3,393,137,196$ \\
\hline
\end{tabular}

\begin{tabular}{|c|c|c|c|c|c|}
\hline INJURIES & & & & & \\
\hline Hazard & Total injuries & \# of events & Max injuries in one & Total minus max & \% of total \\
\hline Coast & 375 & 417 & 75 & 300 & $\mathbf{2 0 \%}$ \\
\hline Eqke & 0 & 2 & 0 & 0 & $0 \%$ \\
\hline Flood & 1669 & 2518 & 545 & 1124 & $33 \%$ \\
\hline Hail & 2559 & 2512 & 500 & 2059 & $20 \%$ \\
\hline Heat & 768 & 253 & 296 & 473 & $38 \%$ \\
\hline Hurr & 33404 & 242 & 17500 & 15903 & $52 \%$ \\
\hline Lndsd & 105 & 29 & 70 & 35 & $67 \%$ \\
\hline Light & 4888 & 4295 & 500 & 4388 & $10 \%$ \\
\hline Storm & 4651 & 4930 & 183 & 4468 & $4 \%$ \\
\hline Tornd & 33694 & 3195 & 3815 & 29879 & $11 \%$ \\
\hline Wldfr & 279 & 114 & 150 & 129 & $54 \%$ \\
\hline Wind & 8574 & 5756 & 1501 & 7073 & $18 \%$ \\
\hline Wintr & 3602 & 686 & 407 & 3195 & $11 \%$ \\
\hline
\end{tabular}

Table 11-1: Southeast region injury consequence tables 

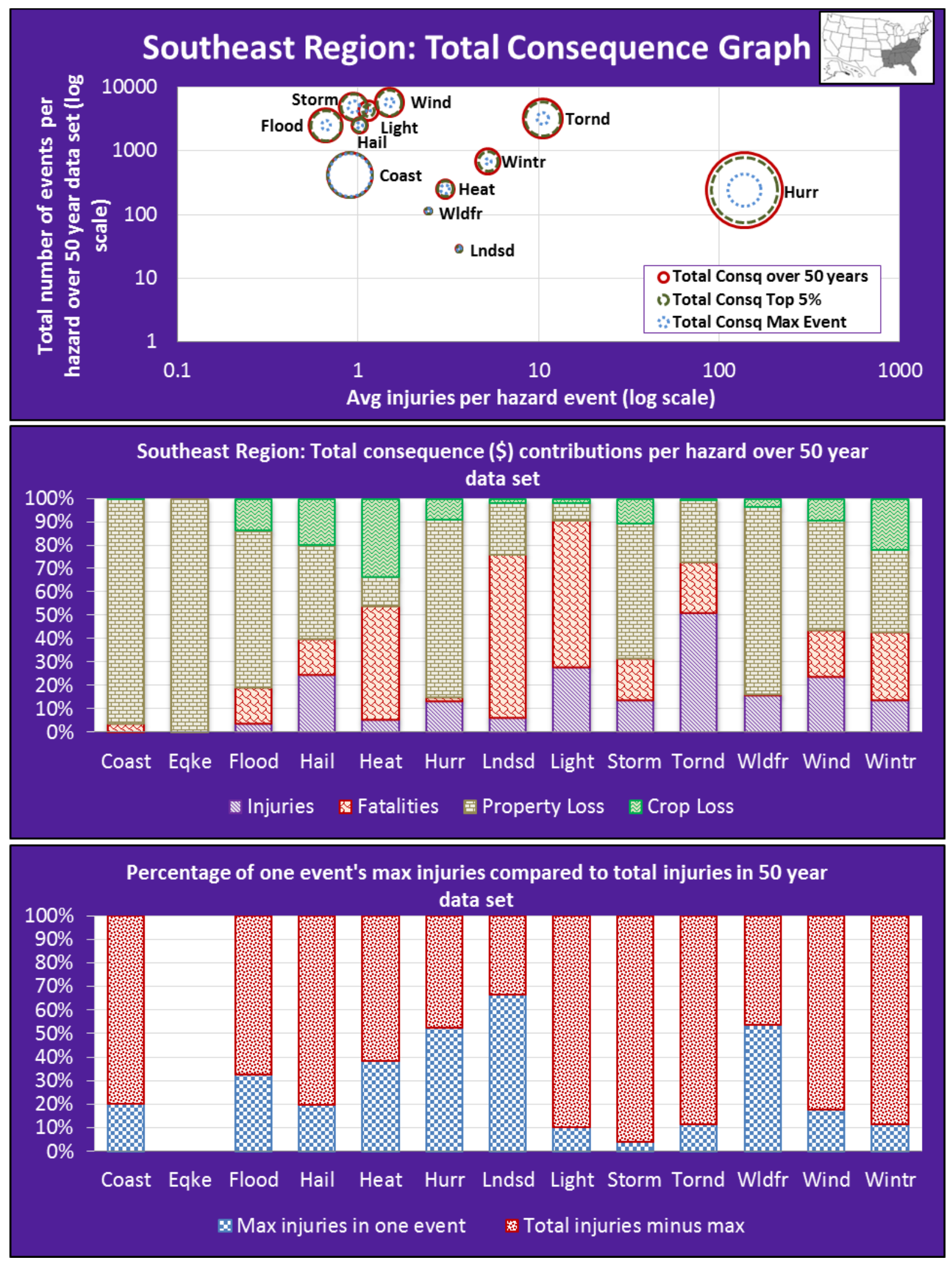

Figure 11-1: Southeast region injury consequence graphics 


\begin{tabular}{|c|c|c|r|r|r|}
\hline FATALITIES & Y-axis & \multicolumn{1}{|c|}{ X-axis } & Outside Circle Size & \multicolumn{1}{|c|}{ Inner Circle Size } & \multicolumn{1}{c|}{ Middle Circle Size } \\
\hline Hazard & \# of events & $\begin{array}{c}\text { Avg fatalities per } \\
\text { event }\end{array}$ & Total Consequence & \multicolumn{1}{|c|}{ Total Consq Max } & Total Consq Top 5\% \\
\hline Coast & 417 & 1.06 & $\$ 52,733,193,430$ & $\$ 47,712,000,000$ & $\$ 51,025,207,881$ \\
\hline Eqke & 2 & 0.00 & $\$ 2,650,261$ & $\$ 2,650,000$ & $\$ 2,650,000$ \\
\hline Flood & 2518 & 0.44 & $\$ 28,750,107,823$ & $\$ 2,252,970,095$ & $\$ 23,817,374,479$ \\
\hline Hail & 2512 & 0.10 & $\$ 6,316,010,461$ & $\$ 683,588,243$ & $\$ 4,957,600,864$ \\
\hline Heat & 253 & 4.11 & $\$ 8,547,841,166$ & $\$ 2,000,500,001$ & $\$ 6,710,715,393$ \\
\hline Hurr & 242 & 2.09 & $\$ 149,929,385,734$ & $\$ 27,105,904,000$ & $\$ 113,740,820,097$ \\
\hline Lndsd & 29 & 6.30 & $\$ 1,039,396,389$ & $\$ 599,840,000$ & $\$ 794,059,470$ \\
\hline Light & 4295 & 0.38 & $\$ 10,513,852,852$ & $\$ 300,104,250$ & $\$ 3,326,700,989$ \\
\hline Storm & 4930 & 0.19 & $\$ 20,473,142,065$ & $\$ 3,576,585,870$ & $\$ 16,207,144,059$ \\
\hline Tornd & 3195 & 0.68 & $\$ 39,615,609,830$ & $\$ 3,693,959,087$ & $\$ 30,571,014,557$ \\
\hline Wldfr & 114 & 0.02 & $\$ 1,080,680,279$ & $\$ 548,200,000$ & $\$ 985,548,654$ \\
\hline Wind & 5756 & 0.19 & $\$ 21,891,561,180$ & $\$ 2,214,315,610$ & $\$ 16,628,084,552$ \\
\hline Wintr & 686 & 1.66 & $\$ 15,677,868,954$ & $\$ 1,093,316,001$ & $\$ 10,144,843,014$ \\
\hline
\end{tabular}

\begin{tabular}{|c|r|r|r|r|r|}
\cline { 3 - 6 } \multicolumn{2}{c|}{} & \multicolumn{4}{c|}{ Contributions to the Total Consequence amount } \\
\hline Hazard & Total Consequence & \multicolumn{1}{|c|}{ Injuries } & \multicolumn{1}{c|}{ Fatalities } & Property Loss & \multicolumn{1}{c|}{ Crop Loss } \\
\hline Coast & $\mathbf{\$ 2 , 7 3 3 , 1 9 3 , 4 3 0}$ & $\$ 225,084,000$ & $\$ 1,763,280,000$ & $\$ 50,703,409,749$ & $\$ 41,419,681$ \\
\hline Eqke & $\mathbf{\$ 2 , 6 5 0 , 2 6 1}$ & $\$ 0$ & $\$ 0$ & $\$ 2,650,261$ & $\$ 0$ \\
\hline Flood & $\mathbf{\$ 2 8 , 7 5 0 , 1 0 7 , 8 2 3}$ & $\$ 1,001,112,000$ & $\$ 4,440,600,000$ & $\$ 19,399,582,928$ & $\$ 3,908,812,895$ \\
\hline Hail & $\mathbf{\$ 6 , 3 1 6 , 0 1 0 , 4 6 1}$ & $\$ 1,535,592,000$ & $\$ 976,000,000$ & $\$ 2,571,245,522$ & $\$ 1,233,172,939$ \\
\hline Heat & $\mathbf{\$ 8 , 5 4 7 , 8 4 1 , 1 6 6}$ & $\$ 461,052,000$ & $\$ 4,161,120,000$ & $\$ 1,066,103,161$ & $\$ 2,859,566,006$ \\
\hline Hurr & $\mathbf{\$ 1 4 9 , 9 2 9 , 3 8 5 , 7 3 4}$ & $\$ 20,042,160,000$ & $\$ 2,021,240,000$ & $\$ 114,524,504,667$ & $\$ 13,341,481,067$ \\
\hline Lndsd & $\mathbf{\$ 1 , 0 3 9 , 3 9 6 , 3 8 9}$ & $\$ 63,000,000$ & $\$ 731,040,000$ & $\$ 227,356,389$ & $\$ 18,000,000$ \\
\hline Light & $\mathbf{\$ 1 0 , 5 1 3 , 8 5 2 , 8 5 2}$ & $\$ 2,932,752,000$ & $\$ 6,605,120,000$ & $\$ 807,988,027$ & $\$ 167,992,826$ \\
\hline Storm & $\mathbf{\$ 2 0 , 4 7 3 , 1 4 2 , 0 6 5}$ & $\$ 2,790,348,000$ & $\$ 3,688,400,000$ & $\$ 11,861,271,120$ & $\$ 2,133,122,945$ \\
\hline Tornd & $\mathbf{\$ 3 9 , 6 1 5 , 6 0 9 , 8 3 0}$ & $\$ 20,216,442,000$ & $\$ 8,667,160,000$ & $\$ 10,567,447,166$ & $\$ 164,560,664$ \\
\hline Wldfr & $\mathbf{\$ 1 , 0 8 0 , 6 8 0 , 2 7 9}$ & $\$ 167,268,000$ & $\$ 8,000,000$ & $\$ 868,528,778$ & $\$ 36,883,501$ \\
\hline Wind & $\mathbf{\$ 2 1 , 8 9 1 , 5 6 1 , 1 8 0}$ & $\$ 5,144,208,000$ & $\$ 4,445,360,000$ & $\$ 10,290,406,217$ & $\$ 2,011,586,963$ \\
\hline Wintr & $\mathbf{\$ 1 5 , 6 7 7 , 8 6 8 , 9 5 4}$ & $\$ 2,161,140,000$ & $\$ 4,560,040,000$ & $\$ 5,563,551,758$ & $\$ 3,393,137,196$ \\
\hline
\end{tabular}

\begin{tabular}{|c|c|c|c|c|c|}
\hline FATALITIES & & & & & \\
\hline Hazard & Total fatalities & \# of events & Max fatalities in one & Total minus max & \% of total \\
\hline Coast & 441 & 417 & 47 & 394 & $11 \%$ \\
\hline Eqke & 0 & 2 & 0 & 0 & $0 \%$ \\
\hline Flood & 1110 & 2518 & 109 & 1001 & $10 \%$ \\
\hline Hail & 244 & 2512 & 47 & 197 & $19 \%$ \\
\hline Heat & 1040 & 253 & 269 & 771 & $26 \%$ \\
\hline Hurr & 505 & 242 & 138 & 368 & $27 \%$ \\
\hline Lndsd & 183 & 29 & 150 & 33 & $82 \%$ \\
\hline Light & 1651 & 4295 & 8 & 1643 & $0 \%$ \\
\hline Storm & 922 & 4930 & 111 & 811 & $12 \%$ \\
\hline Tornd & 2167 & 3195 & 300 & 1867 & $14 \%$ \\
\hline Wldfr & 2 & 114 & 1 & 1 & $50 \%$ \\
\hline Wind & 1111 & 5756 & 107 & 1004 & $10 \%$ \\
\hline Wintr & 1140 & 686 & 79 & 1061 & $7 \%$ \\
\hline
\end{tabular}

Table 11-2: Southeast region fatality consequence tables 

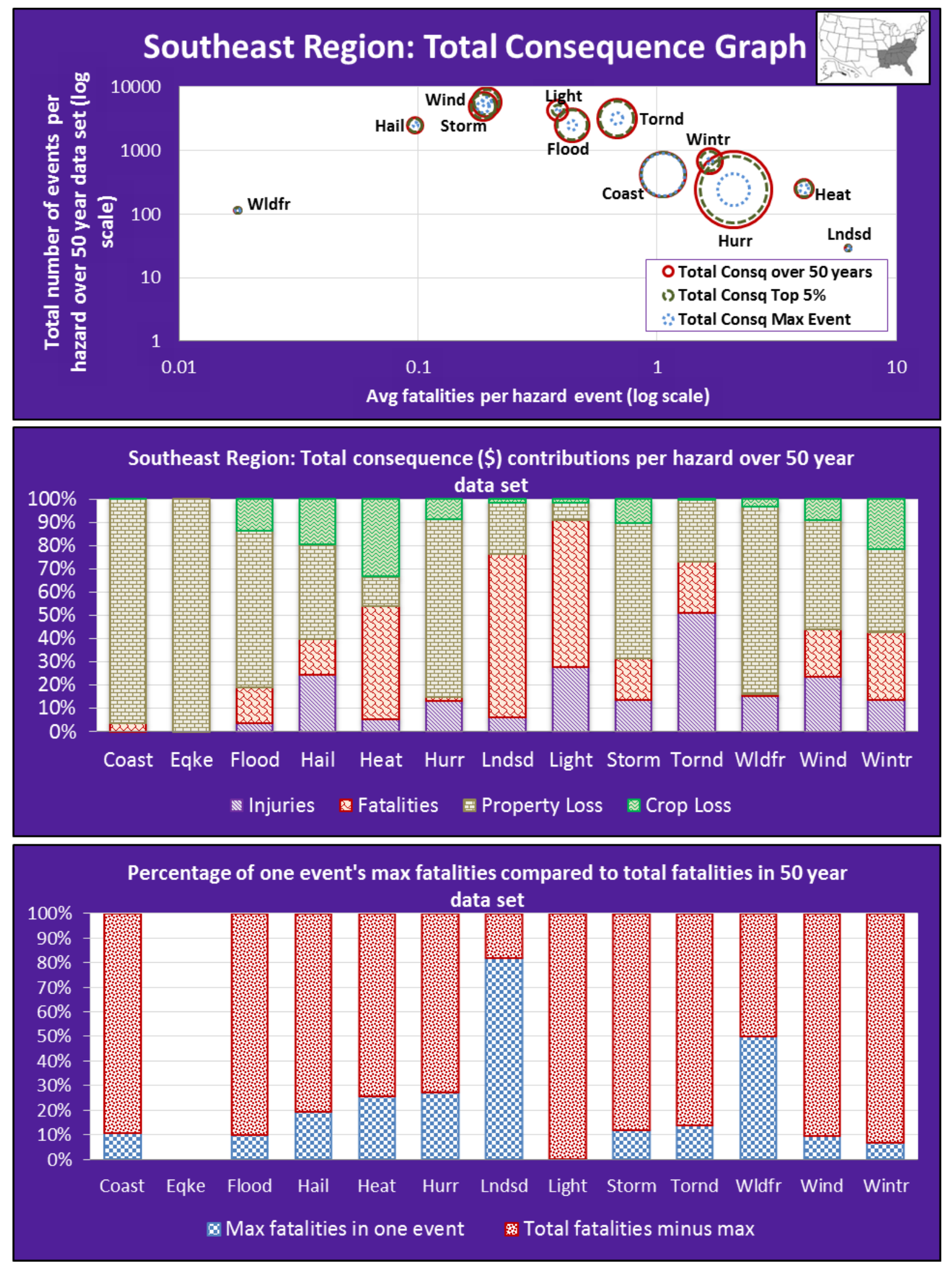

Figure 11-2: Southeast region fatality consequence graphics 


\begin{tabular}{|c|c|r|r|r|r|}
\hline DAMAGES & Y-axis & \multicolumn{1}{|c|}{ X-axis } & Outside Circle Size & \multicolumn{1}{|c|}{ Inner Circle Size } & Middle Circle Size \\
\hline Hazard & \# of events & $\begin{array}{c}\text { Avg damages per } \\
\text { event }\end{array}$ & Total Consequence & \multicolumn{1}{|c|}{ Total Consq Max } & Total Consq Top 5\% \\
\hline Coast & 417 & $\$ 121,690,238$ & $\$ 52,733,193,430$ & $\$ 47,712,000,000$ & $\$ 51,025,207,881$ \\
\hline Eqke & 2 & $\$ 1,325,130$ & $\$ 2,650,261$ & $\$ 2,650,000$ & $\$ 2,650,000$ \\
\hline Flood & 2518 & $\$ 9,256,710$ & $\$ 28,750,107,823$ & $\$ 2,252,970,095$ & $\$ 23,817,374,479$ \\
\hline Hail & 2512 & $\$ 1,514,498$ & $\$ 6,316,010,461$ & $\$ 683,588,243$ & $\$ 4,957,600,864$ \\
\hline Heat & 253 & $\$ 15,516,479$ & $\$ 8,547,841,166$ & $\$ 2,000,500,001$ & $\$ 6,710,715,393$ \\
\hline Hurr & 242 & $\$ 528,371,842$ & $\$ 149,929,385,734$ & $\$ 27,105,904,000$ & $\$ 113,740,820,097$ \\
\hline Lndsd & 29 & $\$ 8,460,565$ & $\$ 1,039,396,389$ & $\$ 599,840,000$ & $\$ 794,059,470$ \\
\hline Light & 4295 & $\$ 227,237$ & $\$ 10,513,852,852$ & $\$ 300,104,250$ & $\$ 3,326,700,989$ \\
\hline Storm & 4930 & $\$ 2,838,619$ & $\$ 20,473,142,065$ & $\$ 3,576,585,870$ & $\$ 16,207,144,059$ \\
\hline Tornd & 3195 & $\$ 3,359,001$ & $\$ 39,615,609,830$ & $\$ 3,693,959,087$ & $\$ 30,571,014,557$ \\
\hline Wldfr & 114 & $\$ 7,942,213$ & $\$ 1,080,680,279$ & $\$ 548,200,000$ & $\$ 985,548,654$ \\
\hline Wind & 5756 & $\$ 2,137,247$ & $\$ 21,891,561,180$ & $\$ 2,214,315,610$ & $\$ 16,628,084,552$ \\
\hline Wintr & 686 & $\$ 13,056,398$ & $\$ 15,677,868,954$ & $\$ 1,093,316,001$ & $\$ 10,144,843,014$ \\
\hline
\end{tabular}

\begin{tabular}{|c|c|c|c|c|c|}
\hline \multirow[b]{2}{*}{ Hazard } & \multirow[b]{2}{*}{ Total Consequence } & \multicolumn{4}{|c|}{ Contributions to the Total Consequence amount } \\
\hline & & Injuries & Fatalities & Property Loss & Crop Loss \\
\hline Coast & $\$ 52,733,193,430$ & $\$ 225,084,000$ & $\$ 1,763,280,000$ & $\$ 50,703,409,749$ & $\$ 41,419,681$ \\
\hline Eqke & $\$ 2,650,261$ & $\$ 0$ & $\$ 0$ & $\$ 2,650,261$ & $\$ 0$ \\
\hline Flood & $\$ 28,750,107,823$ & $\$ 1,001,112,000$ & $\$ 4,440,600,000$ & $\$ 19,399,582,928$ & $\$ 3,908,812,895$ \\
\hline Hail & $\$ 6,316,010,461$ & $\$ 1,535,592,000$ & $\$ 976,000,000$ & $\$ 2,571,245,522$ & $\$ 1,233,172,939$ \\
\hline Heat & $\$ 8,547,841,166$ & $\$ 461,052,000$ & $\$ 4,161,120,000$ & $\$ 1,066,103,161$ & $\$ 2,859,566,006$ \\
\hline Hurr & $\$ 149,929,385,734$ & $\$ 20,042,160,000$ & $\$ 2,021,240,000$ & $\$ 114,524,504,667$ & $\$ 13,341,481,067$ \\
\hline Lndsd & $\$ 1,039,396,389$ & $\$ 63,000,000$ & $\$ 731,040,000$ & $\$ 227,356,389$ & $\$ 18,000,000$ \\
\hline Light & $\$ 10,513,852,852$ & $\$ 2,932,752,000$ & $\$ 6,605,120,000$ & $\$ 807,988,027$ & $\$ 167,992,826$ \\
\hline Storm & $\$ 20,473,142,065$ & $\$ 2,790,348,000$ & $\$ 3,688,400,000$ & $\$ 11,861,271,120$ & $\$ 2,133,122,945$ \\
\hline Tornd & $\$ 39,615,609,830$ & $\$ 20,216,442,000$ & $\$ 8,667,160,000$ & $\$ 10,567,447,166$ & $\$ 164,560,664$ \\
\hline Wldfr & $\$ 1,080,680,279$ & $\$ 167,268,000$ & $\$ 8,000,000$ & $\$ 868,528,778$ & $\$ 36,883,501$ \\
\hline Wind & $\$ 21,891,561,180$ & $\$ 5,144,208,000$ & $\$ 4,445,360,000$ & $\$ 10,290,406,217$ & $\$ 2,011,586,963$ \\
\hline Wintr & $\$ 15,677,868,954$ & $\$ 2,161,140,000$ & $\$ 4,560,040,000$ & $\$ 5,563,551,758$ & $\$ 3,393,137,196$ \\
\hline
\end{tabular}

\begin{tabular}{|c|r|r|r|r|r|}
\hline DAMAGES & & & & & \\
\hline Hazard & \multicolumn{1}{|c|}{ Total damages } & \# of events & Max damages in one & \multicolumn{1}{|c|}{ Total minus max } & $\%$ of total \\
\hline Coast & $\$ 50,744,829,430$ & 417 & $\$ 47,712,000,000$ & $\$ 3,032,829,430$ & $94 \%$ \\
\hline Eqke & $\$ 2,650,261$ & 2 & $\$ 2,650,000$ & $\$ 261$ & $100 \%$ \\
\hline Flood & $\$ 23,308,395,823$ & 2518 & $\$ 2,244,970,095$ & $\$ 21,063,425,728$ & $10 \%$ \\
\hline Hail & $\$ 3,804,418,461$ & 2512 & $\$ 683,588,243$ & $\$ 3,120,830,218$ & $18 \%$ \\
\hline Heat & $\$ 3,925,669,166$ & 253 & $\$ 1,457,500,001$ & $\$ 2,468,169,165$ & $37 \%$ \\
\hline Hurr & $\$ 127,865,985,734$ & 242 & $\$ 27,105,904,000$ & $\$ 100,760,081,735$ & $21 \%$ \\
\hline Lndsd & $\$ 245,356,389$ & 29 & $\$ 167,019,470$ & $\$ 78,336,919$ & $68 \%$ \\
\hline Light & $\$ 975,980,852$ & 4295 & $\$ 35,023,548$ & $\$ 940,957,304$ & $4 \%$ \\
\hline Storm & $\$ 13,994,394,065$ & 4930 & $\$ 3,576,585,870$ & $\$ 10,417,808,195$ & $26 \%$ \\
\hline Tornd & $\$ 10,732,007,830$ & 3195 & $\$ 419,085,000$ & $\$ 10,312,922,830$ & $4 \%$ \\
\hline Wldfr & $\$ 905,412,279$ & 114 & $\$ 509,200,000$ & $\$ 396,212,279$ & $56 \%$ \\
\hline Wind & $\$ 12,301,993,180$ & 5756 & $\$ 2,212,521,610$ & $\$ 10,089,471,570$ & $18 \%$ \\
\hline Wintr & $\$ 8,956,688,954$ & 686 & $\$ 882,000,000$ & $\$ 8,074,688,954$ & $10 \%$ \\
\hline
\end{tabular}

Table 11-3: Southeast region damage consequence tables 

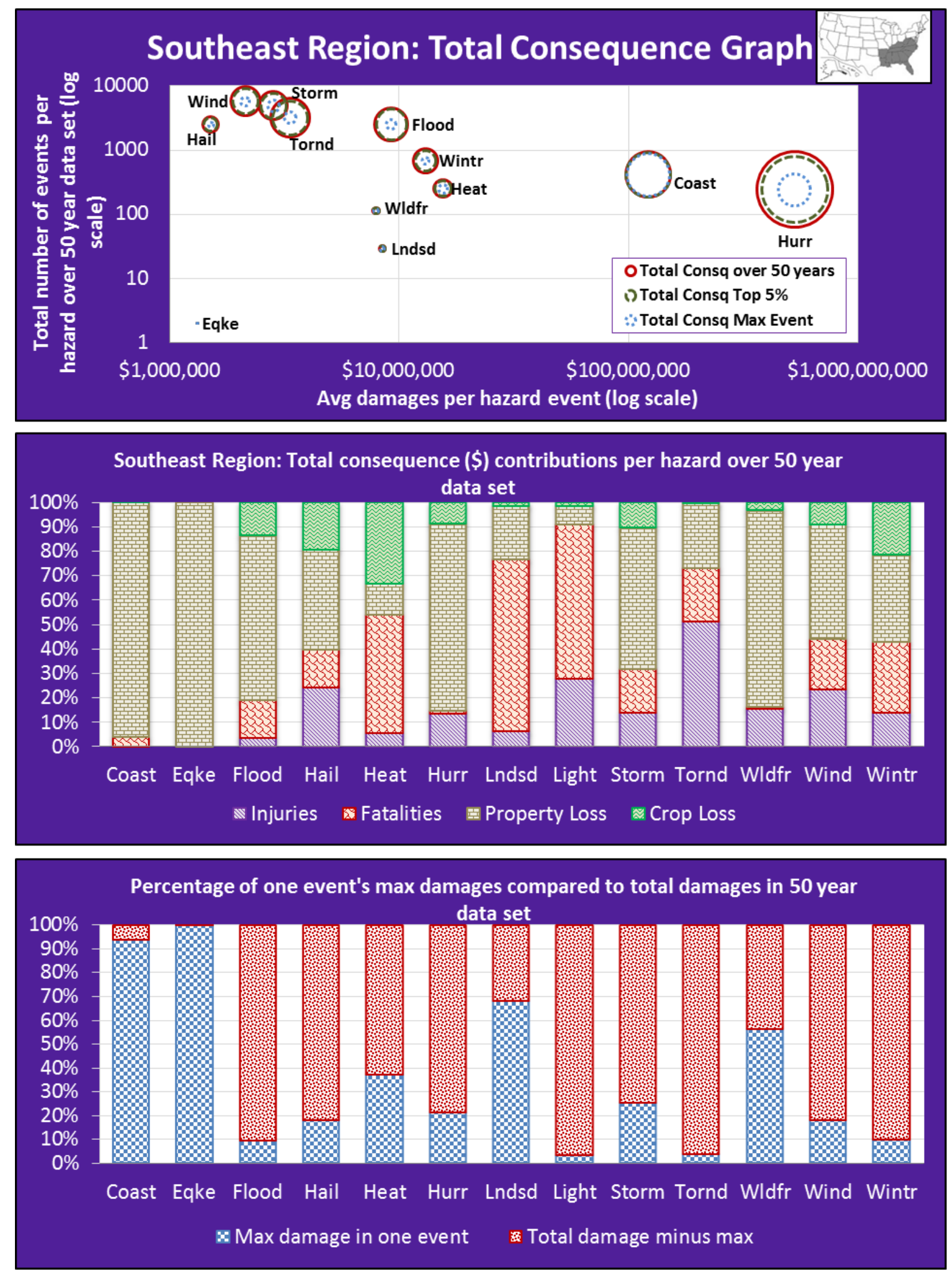

Figure 11-3: Southeast region damage consequence graphics 


\subsection{REGION CONSEQUENCE RANKINGS}

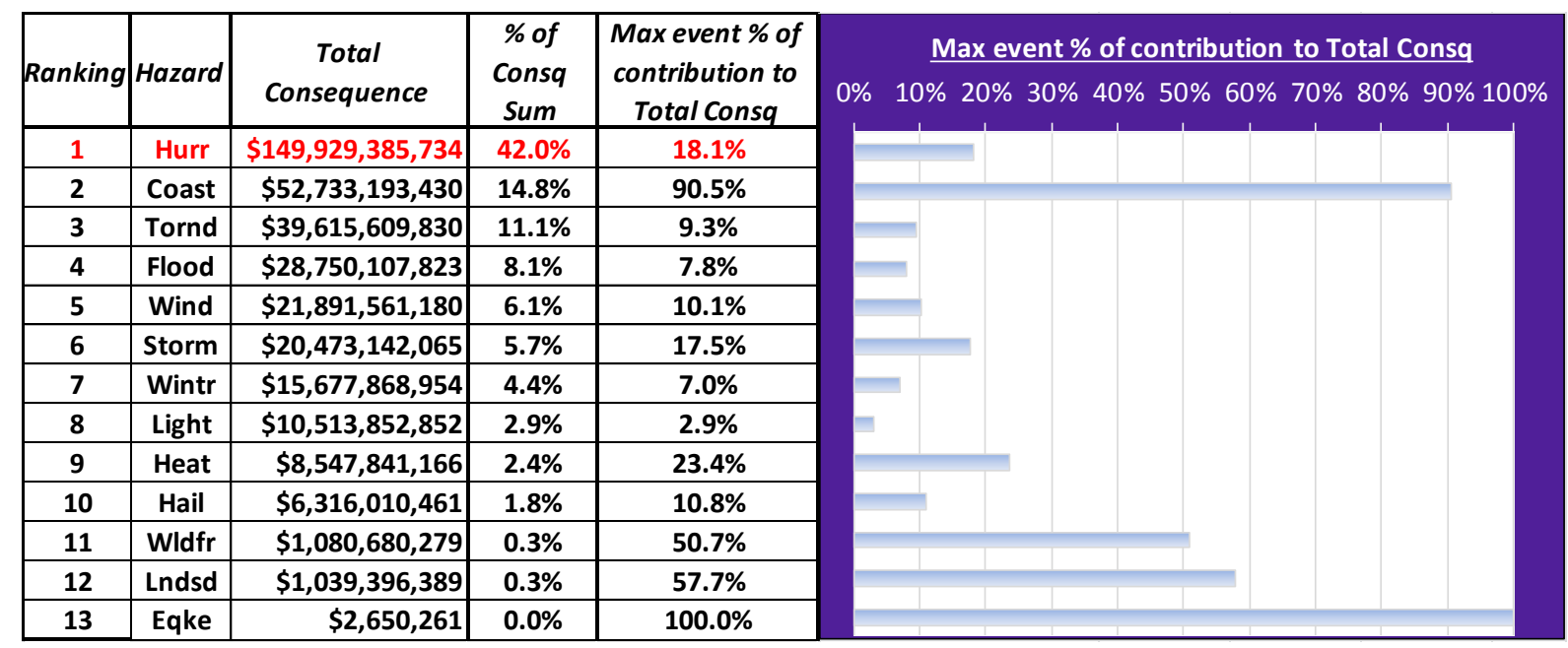

INJURIES

\begin{tabular}{|c|c|}
\hline Hazard & Avg injuries/event \\
\hline Hurr & 138.03 \\
\hline Tornd & 10.55 \\
\hline Wintr & 5.25 \\
\hline Lndsd & 3.62 \\
\hline Heat & 3.04 \\
\hline Wldfr & 2.45 \\
\hline Wind & 1.49 \\
\hline Light & 1.14 \\
\hline Hail & 1.02 \\
\hline Storm & 0.94 \\
\hline Coast & 0.90 \\
\hline Flood & 0.66 \\
\hline Eqke & 0.00 \\
\hline Hazard & Total injuries \\
\hline Tornd & 33694 \\
\hline Hurr & 33404 \\
\hline Wind & 8574 \\
\hline Light & 4888 \\
\hline Storm & 4651 \\
\hline Wintr & 3602 \\
\hline Hail & 2559 \\
\hline Flood & 1669 \\
\hline Heat & 768 \\
\hline Coast & 375 \\
\hline Wldfr & 279 \\
\hline Lndsd & 105 \\
\hline Eqke & 0 \\
\hline
\end{tabular}

FATALITIES

\begin{tabular}{|c|c|}
\hline Hazard & Avg fatalities/event \\
\hline Lndsd & 6.30 \\
\hline Heat & 4.11 \\
\hline Hurr & 2.09 \\
\hline Wintr & 1.66 \\
\hline Coast & 1.06 \\
\hline Tornd & 0.68 \\
\hline Flood & 0.44 \\
\hline Light & 0.38 \\
\hline Wind & 0.19 \\
\hline Storm & 0.19 \\
\hline Hail & 0.10 \\
\hline Wldfr & 0.02 \\
\hline Eqke & 0.00 \\
\hline
\end{tabular}

\begin{tabular}{|c|c|}
\hline \hline Hazard & Total fatalities \\
\hline Tornd & 2167 \\
\hline Light & 1651 \\
\hline Wintr & 1140 \\
\hline Wind & 1111 \\
\hline Flood & 1110 \\
\hline Heat & 1040 \\
\hline Storm & 922 \\
\hline Hurr & 505 \\
\hline Coast & 441 \\
\hline Hail & 244 \\
\hline Lndsd & 183 \\
\hline Wldfr & 2 \\
\hline Eqke & 0 \\
\hline
\end{tabular}

DAMAGES

\begin{tabular}{|c|c|}
\hline Hazard & Avg damage/event \\
\hline Hurr & $\$ 528,371,842$ \\
\hline Coast & $\$ 121,690,238$ \\
\hline Heat & $\$ 15,516,479$ \\
\hline Wintr & $\$ 13,056,398$ \\
\hline Flood & $\$ 9,256,710$ \\
\hline Lndsd & $\$ 8,460,565$ \\
\hline Wldfr & $\$ 7,942,213$ \\
\hline Tornd & $\$ 3,359,001$ \\
\hline Storm & $\$ 2,838,619$ \\
\hline Wind & $\$ 2,137,247$ \\
\hline Hail & $\$ 1,514,498$ \\
\hline Eqke & $\$ 1,325,130$ \\
\hline Light & $\$ 227,237$ \\
\hline Hazard & Total damage \\
\hline Hurr & $\$ 127,865,985,734$ \\
\hline Coast & $\$ 50,744,829,430$ \\
\hline Flood & $\$ 23,308,395,823$ \\
\hline Storm & $\$ 13,994,394,065$ \\
\hline Wind & $\$ 12,301,993,180$ \\
\hline Tornd & $\$ 10,732,007,830$ \\
\hline Wintr & $\$ 8,956,688,954$ \\
\hline Heat & $\$ 3,925,669,166$ \\
\hline Hail & $\$ 3,804,418,461$ \\
\hline Light & $\$ 975,980,852$ \\
\hline Wldfr & $\$ 905,412,279$ \\
\hline Lndsd & $\$ 245,356,389$ \\
\hline Eqke & $\$ 2,650,261$ \\
\hline
\end{tabular}

Table 11-4: Southeast region consequence rankings 


\subsection{REGIONAL SUMMARY}

The Southeast region of the US is comprised of the largest number of states and accounts for $25 \%$ of the total population as of 2010 totaling 78 million people (US Census Bureau 2011). There are large portions of populations that lie along the coast and several major cities that are spread out within the interior states. Additionally, this region also has seen the largest portion of total consequences in the entire nation, making up forty percent, and amounting to $\$ 300$ billion since 1960. The graphs and numerical figures above show that hurricane hazards have contributed to nearly half of that amount.

While hurricanes cause great losses; storms, flooding, and tornadoes have caused $\$ 90$ billion of losses in the region. Tornado hazards top the ranking charts with injuries upward of 34,000 and fatalities totaling 2,200.

The largest difference between hurricane hazards and the others are when looking at the overall damages caused by the events. Hurricane damage was calculated to be $\$ 128$ billion and tornadoes amounted to $\$ 10$ billion. Other observations can be made between some of the other hazards that are of greatest concern of this region, but hurricanes result in over $\$ 500$ million dollars per event on average, making this of utmost concern to create preventative measures.

Hurricanes are devastating to this region and nation because of the widespread, long-term impacts. Holistic mitigation plans need to be developed by stakeholders and government officials to lessen devastation that these storms bring. This has wide implications on society's quality of life as well as its immense influence in the financial markets and economy. 


\subsection{LAYOUT}

Chapter 12 contains the natural hazard risk assessment and analysis for the Mid-Atlantic region, which consists of the following five states and district: Pennsylvania, New York, New Jersey, Delaware, Maryland, and Washington D.C. Figures included in this chapter are:

- Mid-Atlantic region consequence tables for injuries, fatalities, and damages

Table 12-1, Table 12-2, and Table 12-3, respectively

- Mid-Atlantic region consequence graphics for injuries, fatalities, and damages

$>$ Figure 12-1, Figure 12-2, and Figure 12-3, respectively

- Mid-Atlantic region consequence rankings (Table 12-4)

$>$ Total consequence and overall percentage

$>$ Average loss per event: injuries, fatalities, damages

$>$ Total losses: injuries, fatalities, damages

The following hazard events have not been recorded by SHELDUS and will not appear in the graphical or chart displays for this region.

- Earthquake 


\subsection{REGION CONSEQUENCE DISPLAYS}

\begin{tabular}{|c|c|c|c|c|c|}
\hline INJURIES & Y-axis & $\mathrm{X}$-axis & Outside Circle Size & Inner Circle Size & Middle Circle Size \\
\hline Hazard & \# of events & $\begin{array}{c}\text { Avg injuries per } \\
\text { event }\end{array}$ & Total Consequence & Total Consq Max & Total Consq Top 5\% \\
\hline Coast & 123 & 3.39 & $\$ 1,440,798,249$ & $\$ 387,835,085$ & $\$ 873,334,384$ \\
\hline Eqke & 0 & 0.00 & $\$ 0$ & $\$ 0$ & $\$ 0$ \\
\hline Flood & 951 & 0.91 & $\$ \$ 16,624,881,373$ & $\$ 3,452,349,002$ & $\$ 14,703,623,767$ \\
\hline Hail & 572 & 1.27 & $\$ 1,446,045,554$ & $\$ 198,561,650$ & $\$ 1,062,875,398$ \\
\hline Heat & 111 & 15.84 & $\$ 5,877,016,266$ & $\$ 1,075,800,000$ & $\$ 3,473,449,250$ \\
\hline Hurr & 23 & 4.51 & $\$ 900,227,445$ & $\$ 284,558,000$ & $\$ 451,798,258$ \\
\hline Lndsd & 11 & 0.00 & $\$ 2,654,595$ & $\$ 1,230,000$ & $\$ 1,230,000$ \\
\hline Light & 1384 & 1.20 & $\$ 3,626,990,126$ & $\$ 327,565,000$ & $\$ 1,730,161,510$ \\
\hline Storm & 2011 & 1.30 & $\$ 14,341,153,052$ & $\$ 3,452,349,002$ & $\$ 11,497,190,377$ \\
\hline Tornd & 525 & 3.61 & $\$ 3,023,738,084$ & $\$ 669,248,650$ & $\$ 2,464,733,779$ \\
\hline Wldfr & 25 & 2.24 & $\$ 138,253,893$ & $\$ 28,610,002$ & $\$ 56,730,002$ \\
\hline Wind & 2285 & 1.28 & $\$ 9,276,065,414$ & $\$ 1,130,000,000$ & $\$ 6,430,542,689$ \\
\hline \multirow[t]{2}{*}{ Wintr } & 1139 & 5.47 & $\$ 12,154,011,780$ & $\$ 1,120,992,000$ & $\$ 7,838,598,442$ \\
\hline & & \multicolumn{4}{|c|}{ Contributions to the Total Consequence amount } \\
\hline Hazard & Total Consequence & Injuries & Fatalities & Property Loss & Crop Loss \\
\hline Coast & $\$ 1,440,798,249$ & $\$ 250,428,000$ & $\$ 467,720,000$ & $\$ 715,406,082$ & $\$ 7,244,167$ \\
\hline Eqke & $\$ 0$ & $\$ 0$ & \$O & $\$ 0$ & $\$ 0$ \\
\hline Flood & $\$ 16,624,881,373$ & $\$ 522,084,000$ & $\$ 1,517,400,000$ & $\$ 14,019,641,130$ & $\$ 565,756,243$ \\
\hline Hail & $\$ 1,446,045,554$ & $\$ 436,320,000$ & $\$ 307,000,000$ & $\$ 532,831,129$ & $\$ 169,894,425$ \\
\hline Heat & $\$ 5,877,016,266$ & $\$ 1,054,782,000$ & $\$ 4,808,160,000$ & $\$ 7,174,501$ & $\$ 6,899,765$ \\
\hline Hurr & $\$ 900,227,445$ & $\$ 62,196,000$ & $\$ 147,440,000$ & $\$ 621,457,476$ & $\$ 69,133,969$ \\
\hline Lndsd & $\$ 2,654,595$ & $\$ 0$ & $\$ 0$ & $\$ 2,653,600$ & $\$ 995$ \\
\hline Light & $\$ 3,626,990,126$ & $\$ 999,636,000$ & $\$ 2,034,360,000$ & $\$ 572,654,335$ & $\$ 20,339,790$ \\
\hline Storm & $\$ 14,341,153,052$ & $\$ 1,571,544,000$ & $\$ 2,960,600,000$ & $\$ 8,947,041,469$ & $\$ 861,967,584$ \\
\hline Tornd & $\$ 3,023,738,084$ & $\$ 1,137,594,000$ & $\$ 507,640,000$ & $\$ 1,358,547,672$ & $\$ 19,956,411$ \\
\hline Wldfr & $\$ 138,253,893$ & $\$ 33,672,000$ & $\$ 27,760,000$ & $\$ 76,067,303$ & $\$ 754,591$ \\
\hline Wind & $\$ 9,276,065,414$ & $\$ 1,753,764,000$ & $\$ 2,999,600,000$ & $\$ 4,410,581,230$ & $\$ 112,120,184$ \\
\hline Wintr & $\$ 12,154,011,780$ & $\$ 3,739,620,000$ & $\$ 4,229,720,000$ & $\$ 4,062,914,593$ & $\$ 121,757,186$ \\
\hline
\end{tabular}

\begin{tabular}{|c|c|c|c|c|c|}
\hline INJURIES & & & & & \\
\hline Hazard & Total injuries & \# of events & Max injuries in one & Total minus max & \% of total \\
\hline Coast & 417 & 123 & 100 & 317 & $24 \%$ \\
\hline Eqke & 0 & 0 & 0 & 0 & $0 \%$ \\
\hline Flood & 870 & 951 & 241 & 629 & $28 \%$ \\
\hline Hail & 727 & 572 & 180 & 547 & $25 \%$ \\
\hline Heat & 1758 & 111 & 696 & 1062 & $\mathbf{4 0 \%}$ \\
\hline Hurr & 104 & 23 & 65 & 39 & $\mathbf{6 2 \%}$ \\
\hline Lndsd & 0 & 11 & 0 & 0 & $2 \%$ \\
\hline Light & 1666 & 1384 & 41 & 1625 & $3 \%$ \\
\hline Storm & 2619 & 2011 & 74 & 2545 & $\mathbf{3 0 \%}$ \\
\hline Tornd & 1896 & 525 & 567 & 1329 & $\mathbf{2} \%$ \\
\hline Wldfr & 56 & 25 & 35 & 21 & $\mathbf{3} \%$ \\
\hline Wind & 2923 & 2285 & 88 & 2835 & $12 \%$ \\
\hline Wintr & 6233 & 1139 & 729 & 5503 & \\
\hline
\end{tabular}

Table 12-1: Mid-Atlantic region injury consequence tables 

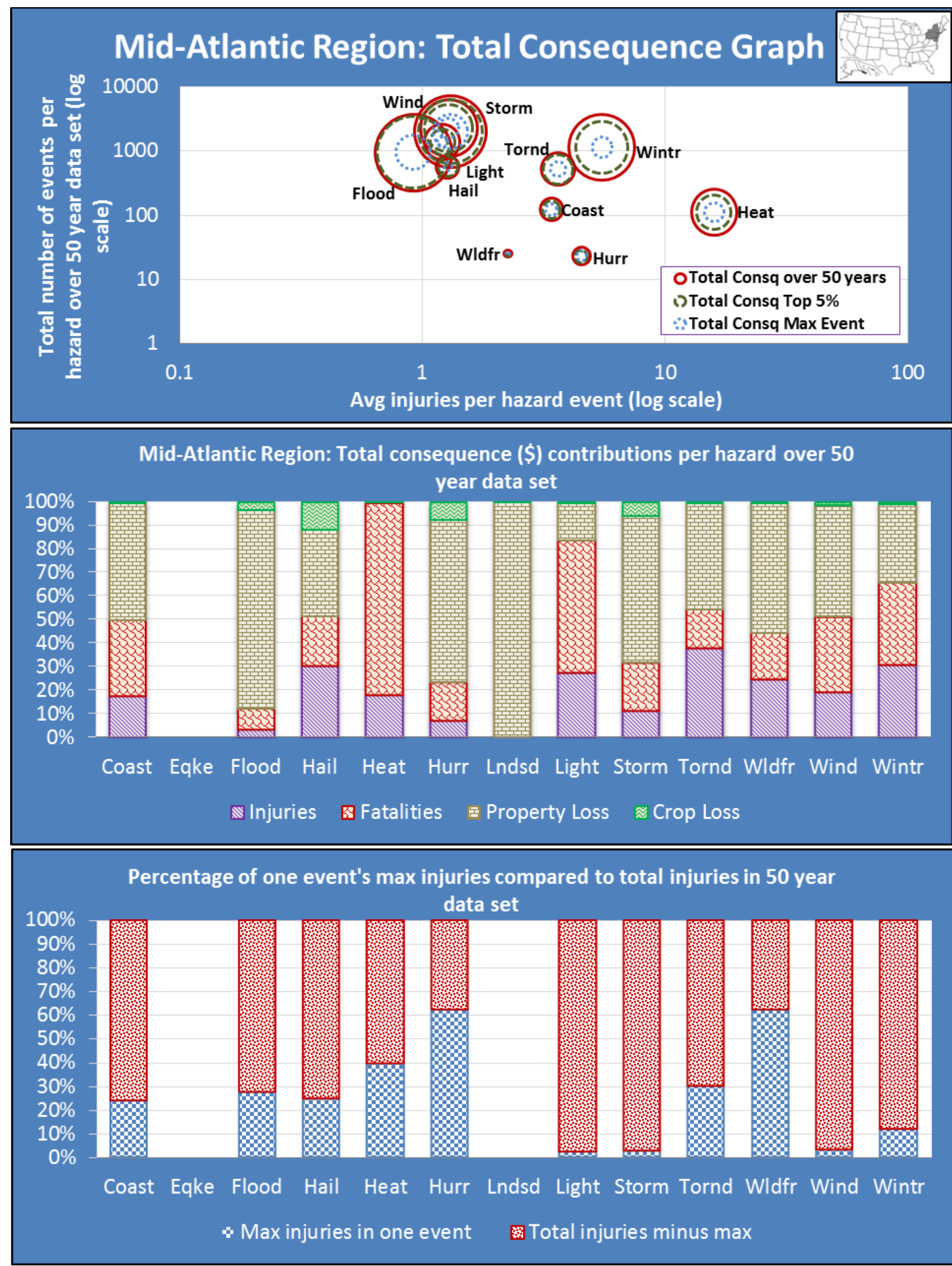

Figure 12-1: Mid-Atlantic region injury consequence graphics 


\begin{tabular}{|c|c|c|r|r|r|}
\hline FATALITIES & Y-axis & X-axis & Outside Circle Size & Inner Circle Size & Middle Circle Size \\
\hline Hazard & \# of events & $\begin{array}{c}\text { Avg fatalities per } \\
\text { event }\end{array}$ & Total Consequence & Total Consq Max & Total Consq Top 5\% \\
\hline Coast & 123 & 0.95 & $\$ 1,440,798,249$ & $\$ 387,835,085$ & $\$ 873,334,384$ \\
\hline Eqke & 0 & 0.00 & $\$ 0$ & $\$ 0$ & $\$ 0$ \\
\hline Flood & 951 & 0.40 & $\$ 16,624,881,373$ & $\$ 3,452,349,002$ & $\$ 14,703,623,767$ \\
\hline Hail & 572 & 0.13 & $\$ 1,446,045,554$ & $\$ 198,561,650$ & $\$ 1,062,875,398$ \\
\hline Heat & 111 & 10.83 & $\$ 5,877,016,266$ & $\$ 1,075,800,000$ & $\$ 3,473,449,250$ \\
\hline Hurr & 23 & 1.60 & $\$ 900,227,445$ & $\$ 284,558,000$ & $\$ 451,798,258$ \\
\hline Lndsd & 11 & 0.00 & $\$ 2,654,595$ & $\$ 1,230,000$ & $\$ 1,230,000$ \\
\hline Light & 1384 & 0.37 & $\$ 3,626,990,126$ & $\$ 327,565,000$ & $\$ 1,730,161,510$ \\
\hline Storm & 2011 & 0.37 & $\$ 14,341,153,052$ & $\$ 3,452,349,002$ & $\$ 11,497,190,377$ \\
\hline Tornd & 525 & 0.24 & $\$ 3,023,738,084$ & $\$ 669,248,650$ & $\$ 2,464,733,779$ \\
\hline Wldfr & 25 & 0.28 & $\$ 138,253,893$ & $\$ 28,610,002$ & $\$ 56,730,002$ \\
\hline Wind & 2285 & 0.33 & $\$ 9,276,065,414$ & $\$ 1,130,000,000$ & $\$ 6,430,542,689$ \\
\hline Wintr & 1139 & 0.93 & $\$ 12,154,011,780$ & $\$ 1,120,992,000$ & $\$ 7,838,598,442$ \\
\hline
\end{tabular}

\begin{tabular}{|c|r|r|r|r|r|}
\cline { 3 - 6 } \multicolumn{2}{c|}{} & \multicolumn{4}{c|}{ Contributions to the Total Consequence amount } \\
\hline Hazard & Total Consequence & \multicolumn{1}{c|}{ Injuries } & \multicolumn{1}{c|}{ Fatalities } & Property Loss & \multicolumn{1}{c|}{ Crop Loss } \\
\hline Coast & $\mathbf{\$ 1 , 4 4 0 , 7 9 8 , 2 4 9}$ & $\$ 250,428,000$ & $\$ 467,720,000$ & $\$ 715,406,082$ & $\$ 7,244,167$ \\
\hline Eqke & $\mathbf{\$ 0}$ & $\$ 0$ & $\$ 0$ & $\$ 0$ & $\$ 0$ \\
\hline Flood & $\mathbf{\$ 1 6 , 6 2 4 , 8 8 1 , 3 7 3}$ & $\$ 522,084,000$ & $\$ 1,517,400,000$ & $\$ 14,019,641,130$ & $\$ 565,756,243$ \\
\hline Hail & $\mathbf{\$ 1 , 4 4 6 , 0 4 5 , 5 5 4}$ & $\$ 436,320,000$ & $\$ 307,000,000$ & $\$ 532,831,129$ & $\$ 169,894,425$ \\
\hline Heat & $\mathbf{\$ 5 , 8 7 7 , 0 1 6 , 2 6 6}$ & $\$ 1,054,782,000$ & $\$ 4,808,160,000$ & $\$ 7,174,501$ & $\$ 6,899,765$ \\
\hline Hurr & $\mathbf{\$ 9 0 0 , 2 2 7 , 4 4 5}$ & $\$ 62,196,000$ & $\$ 147,440,000$ & $\$ 621,457,476$ & $\$ 69,133,969$ \\
\hline Lndsd & $\mathbf{\$ 2 , 6 5 4 , 5 9 5}$ & $\$ 0$ & $\$ 0$ & $\$ 2,653,600$ & $\$ 995$ \\
\hline Light & $\mathbf{\$ 3 , 6 2 6 , 9 9 0 , 1 2 6}$ & $\$ 999,636,000$ & $\$ 2,034,360,000$ & $\$ 572,654,335$ & $\$ 20,339,790$ \\
\hline Storm & $\mathbf{\$ 1 4 , 3 4 1 , 1 5 3 , 0 5 2}$ & $\$ 1,571,544,000$ & $\$ 2,960,600,000$ & $\$ 8,947,041,469$ & $\$ 861,967,584$ \\
\hline Tornd & $\mathbf{\$ 3 , 0 2 3 , 7 3 8 , 0 8 4}$ & $\$ 1,137,594,000$ & $\$ 507,640,000$ & $\$ 1,358,547,672$ & $\$ 19,956,411$ \\
\hline Wldfr & $\mathbf{\$ 1 3 8 , 2 5 3 , 8 9 3}$ & $\$ 33,672,000$ & $\$ 27,760,000$ & $\$ 76,067,303$ & $\$ 754,591$ \\
\hline Wind & $\mathbf{\$ 9 , 2 7 6 , 0 6 5 , 4 1 4}$ & $\$ 1,753,764,000$ & $\$ 2,999,600,000$ & $\$ 4,410,581,230$ & $\$ 112,120,184$ \\
\hline Wintr & $\mathbf{\$ 1 2 , 1 5 4 , 0 1 1 , 7 8 0}$ & $\$ 3,739,620,000$ & $\$ 4,229,720,000$ & $\$ 4,062,914,593$ & $\$ 121,757,186$ \\
\hline
\end{tabular}

\begin{tabular}{|c|c|c|c|c|c|}
\hline FATALITIES & & & & & \\
\hline Hazard & Total fatalities & \# of events & Max fatalities in one & Total minus max & $\%$ of total \\
\hline Coast & 117 & 123 & 16 & 101 & $14 \%$ \\
\hline Eqke & 0 & 0 & 0 & 0 & $0 \%$ \\
\hline Flood & 379 & 951 & 70 & 309 & $18 \%$ \\
\hline Hail & 77 & 572 & 15 & 62 & $20 \%$ \\
\hline Heat & 1202 & 111 & 269 & 933 & $22 \%$ \\
\hline Hurr & 37 & 23 & 11 & 26 & $30 \%$ \\
\hline Lndsd & 0 & 11 & 0 & 0 & $0 \%$ \\
\hline Light & 509 & 1384 & 81 & 428 & $16 \%$ \\
\hline Storm & 740 & 2011 & 78 & 662 & $11 \%$ \\
\hline Tornd & 127 & 525 & 69 & 58 & $54 \%$ \\
\hline Wldfr & 7 & 25 & 2 & 5 & $29 \%$ \\
\hline Wind & 750 & 2285 & 53 & 697 & $7 \%$ \\
\hline Wintr & 1057 & 1139 & 67 & 990 & $6 \%$ \\
\hline
\end{tabular}

Table 12-2: Mid-Atlantic region fatality consequence tables 

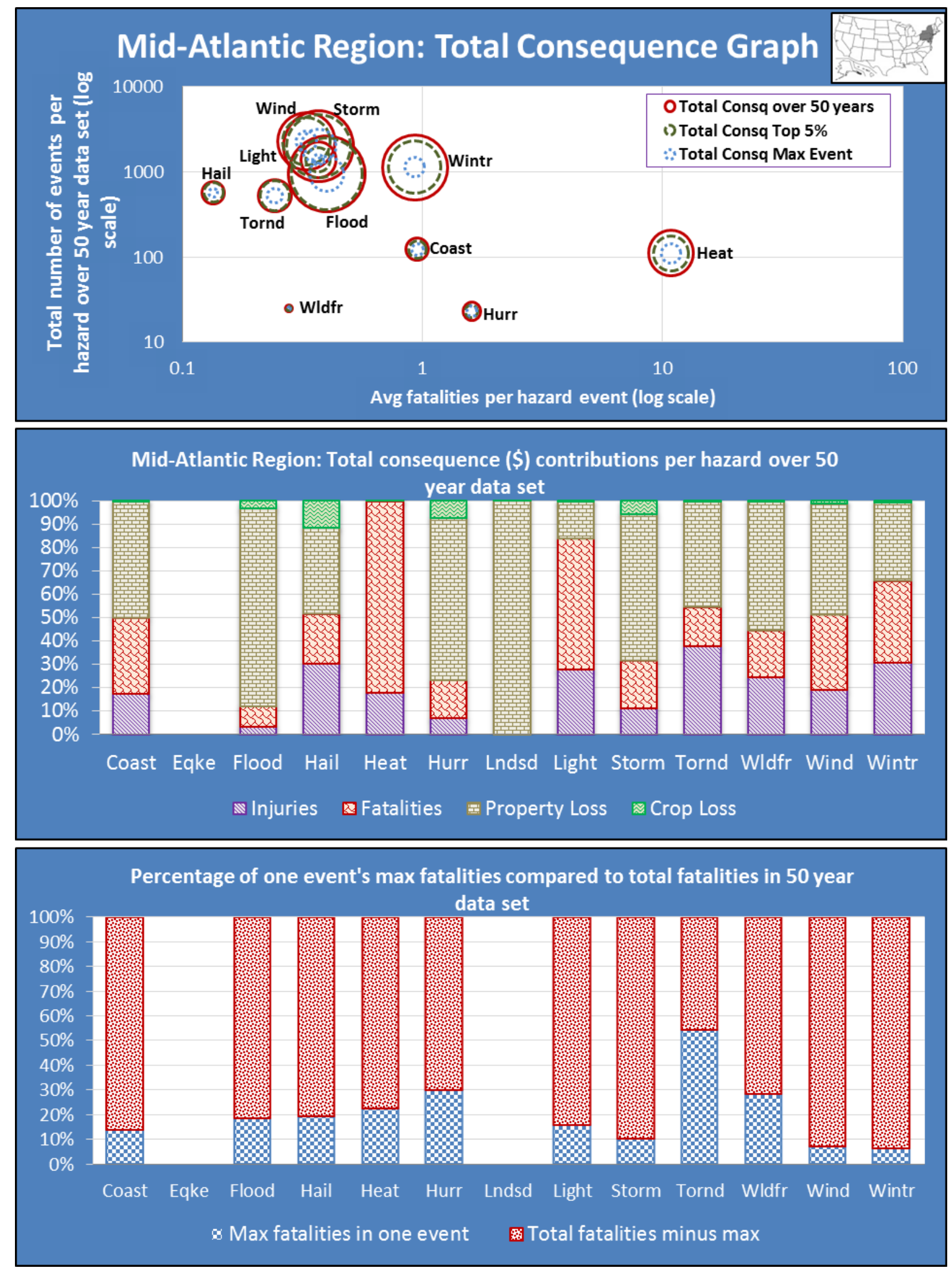

Figure 12-2: Mid-Atlantic region fatality consequence graphics 


\begin{tabular}{|c|c|r|r|r|r|}
\hline DAMAGES & Y-axis & \multicolumn{1}{|c|}{ X-axis } & Outside Circle Size & Inner Circle Size & Middle Circle Size \\
\hline Hazard & \# of events & $\begin{array}{c}\text { Avg damages per } \\
\text { event }\end{array}$ & Total Consequence & Total Consq Max & Total Consq Top 5\% \\
\hline Coast & 123 & $\$ 5,875,205$ & $\$ 1,440,798,249$ & $\$ 387,835,085$ & $\$ 873,334,384$ \\
\hline Eqke & 0 & $\$ 0$ & $\$ 0$ & $\$ 0$ & $\$ 0$ \\
\hline Flood & 951 & $\$ 15,336,906$ & $\$ 16,624,881,373$ & $\$ 3,452,349,002$ & $\$ 14,703,623,767$ \\
\hline Hail & 572 & $\$ 1,228,541$ & $\$ 1,446,045,554$ & $\$ 198,561,650$ & $\$ 1,062,875,398$ \\
\hline Heat & 111 & $\$ 126,795$ & $\$ 5,877,016,266$ & $\$ 1,075,800,000$ & $\$ 3,473,449,250$ \\
\hline Hurr & 23 & $\$ 30,025,715$ & $\$ 900,227,445$ & $\$ 284,558,000$ & $\$ 451,798,258$ \\
\hline Lndsd & 11 & $\$ 241,327$ & $\$ 2,654,595$ & $\$ 1,230,000$ & $\$ 1,230,000$ \\
\hline Light & 1384 & $\$ 428,464$ & $\$ 3,626,990,126$ & $\$ 327,565,000$ & $\$ 1,730,161,510$ \\
\hline Storm & 2011 & $\$ 4,877,677$ & $\$ 14,341,153,052$ & $\$ 3,452,349,002$ & $\$ 11,497,190,377$ \\
\hline Tornd & 525 & $\$ 2,625,722$ & $\$ 3,023,738,084$ & $\$ 669,248,650$ & $\$ 2,464,733,779$ \\
\hline Wldfr & 25 & $\$ 3,072,876$ & $\$ 138,253,893$ & $\$ 28,610,002$ & $\$ 56,730,002$ \\
\hline Wind & 2285 & $\$ 1,979,300$ & $\$ 9,276,065,414$ & $\$ 1,130,000,000$ & $\$ 6,430,542,689$ \\
\hline Wintr & 1139 & $\$ 3,673,988$ & $\$ 12,154,011,780$ & $\$ 1,120,992,000$ & $\$ 7,838,598,442$ \\
\hline
\end{tabular}

\begin{tabular}{|c|r|r|r|r|r|}
\cline { 3 - 6 } \multicolumn{2}{c|}{} & \multicolumn{4}{c|}{ Contributions to the Total Consequence amount } \\
\hline Hazard & Total Consequence & \multicolumn{1}{c|}{ Injuries } & \multicolumn{1}{c|}{ Fatalities } & Property Loss & \multicolumn{1}{c|}{ Crop Loss } \\
\hline Coast & $\mathbf{\$ 1 , 4 4 0 , 7 9 8 , 2 4 9}$ & $\$ 250,428,000$ & $\$ 467,720,000$ & $\$ 715,406,082$ & $\$ 7,244,167$ \\
\hline Eqke & $\mathbf{\$ 0}$ & $\$ 0$ & $\$ 0$ & $\$ 0$ & $\$ 0$ \\
\hline Flood & $\mathbf{\$ 1 6 , 6 2 4 , 8 8 1 , 3 7 3}$ & $\$ 522,084,000$ & $\$ 1,517,400,000$ & $\$ 14,019,641,130$ & $\$ 565,756,243$ \\
\hline Hail & $\mathbf{\$ 1 , 4 4 6 , 0 4 5 , 5 5 4}$ & $\$ 436,320,000$ & $\$ 307,000,000$ & $\$ 532,831,129$ & $\$ 169,894,425$ \\
\hline Heat & $\mathbf{\$ 5 , 8 7 7 , 0 1 6 , 2 6 6}$ & $\$ 1,054,782,000$ & $\$ 4,808,160,000$ & $\$ 7,174,501$ & $\$ 6,899,765$ \\
\hline Hurr & $\mathbf{\$ 9 0 0 , 2 2 7 , 4 4 5}$ & $\$ 62,196,000$ & $\$ 147,440,000$ & $\$ 621,457,476$ & $\$ 69,133,969$ \\
\hline Lndsd & $\mathbf{\$ 2 , 6 5 4 , 5 9 5}$ & $\$ 0$ & $\$ 0$ & $\$ 2,653,600$ & $\$ 995$ \\
\hline Light & $\mathbf{\$ 3 , 6 2 6 , 9 9 0 , 1 2 6}$ & $\$ 999,636,000$ & $\$ 2,034,360,000$ & $\$ 572,654,335$ & $\$ 20,339,790$ \\
\hline Storm & $\mathbf{\$ 1 4 , 3 4 1 , 1 5 3 , 0 5 2}$ & $\$ 1,571,544,000$ & $\$ 2,960,600,000$ & $\$ 8,947,041,469$ & $\$ 861,967,584$ \\
\hline Tornd & $\mathbf{\$ 3 , 0 2 3 , 7 3 8 , 0 8 4}$ & $\$ 1,137,594,000$ & $\$ 507,640,000$ & $\$ 1,358,547,672$ & $\$ 19,956,411$ \\
\hline Wldfr & $\mathbf{\$ 1 3 8 , 2 5 3 , 8 9 3}$ & $\$ 33,672,000$ & $\$ 27,760,000$ & $\$ 76,067,303$ & $\$ 754,591$ \\
\hline Wind & $\mathbf{\$ 9 , 2 7 6 , 0 6 5 , 4 1 4}$ & $\$ 1,753,764,000$ & $\$ 2,999,600,000$ & $\$ 4,410,581,230$ & $\$ 112,120,184$ \\
\hline Wintr & $\mathbf{\$ 1 2 , 1 5 4 , 0 1 1 , 7 8 0}$ & $\$ 3,739,620,000$ & $\$ 4,229,720,000$ & $\$ 4,062,914,593$ & $\$ 121,757,186$ \\
\hline
\end{tabular}

\begin{tabular}{|c|r|c|r|r|r|}
\hline DAMAGES & & & & & \\
\hline Hazard & Total damages & \# of events & Max damages in one & Total minus max & $\%$ of total \\
\hline Coast & $\$ 722,650,249$ & 123 & $\$ 313,795,085$ & $\$ 408,855,164$ & $43 \%$ \\
\hline Eqke & $\$ 0$ & 0 & $\$ 0$ & $\$ 0$ & $0 \%$ \\
\hline Flood & $\$ 14,585,397,373$ & 951 & $\$ 3,137,481,002$ & $\$ 11,447,916,371$ & $22 \%$ \\
\hline Hail & $\$ 702,725,554$ & 572 & $\$ 133,826,377$ & $\$ 568,899,177$ & $19 \%$ \\
\hline Heat & $\$ 14,074,266$ & 111 & $\$ 6,763,900$ & $\$ 7,310,366$ & $48 \%$ \\
\hline Hurr & $\$ 690,591,445$ & 23 & $\$ 272,228,000$ & $\$ 418,363,445$ & $39 \%$ \\
\hline Lndsd & $\$ 2,654,595$ & 11 & $\$ 1,230,000$ & $\$ 1,424,595$ & $46 \%$ \\
\hline Light & $\$ 592,994,126$ & 1384 & $\$ 133,826,377$ & $\$ 459,167,748$ & $23 \%$ \\
\hline Storm & $\$ 9,809,009,052$ & 2011 & $\$ 3,137,481,002$ & $\$ 6,671,528,051$ & $32 \%$ \\
\hline Tornd & $\$ 1,378,504,084$ & 525 & $\$ 156,180,750$ & $\$ 1,222,323,334$ & $11 \%$ \\
\hline Wldfr & $\$ 76,821,893$ & 25 & $\$ 28,120,000$ & $\$ 48,701,893$ & $37 \%$ \\
\hline Wind & $\$ 4,522,701,414$ & 2285 & $\$ 1,130,000,000$ & $\$ 3,392,701,414$ & $25 \%$ \\
\hline Wintr & $\$ 4,184,671,780$ & 1139 & $\$ 1,095,000,000$ & $\$ 3,089,671,780$ & $26 \%$ \\
\hline
\end{tabular}

Table 12-3: Mid-Atlantic region damage consequence tables 

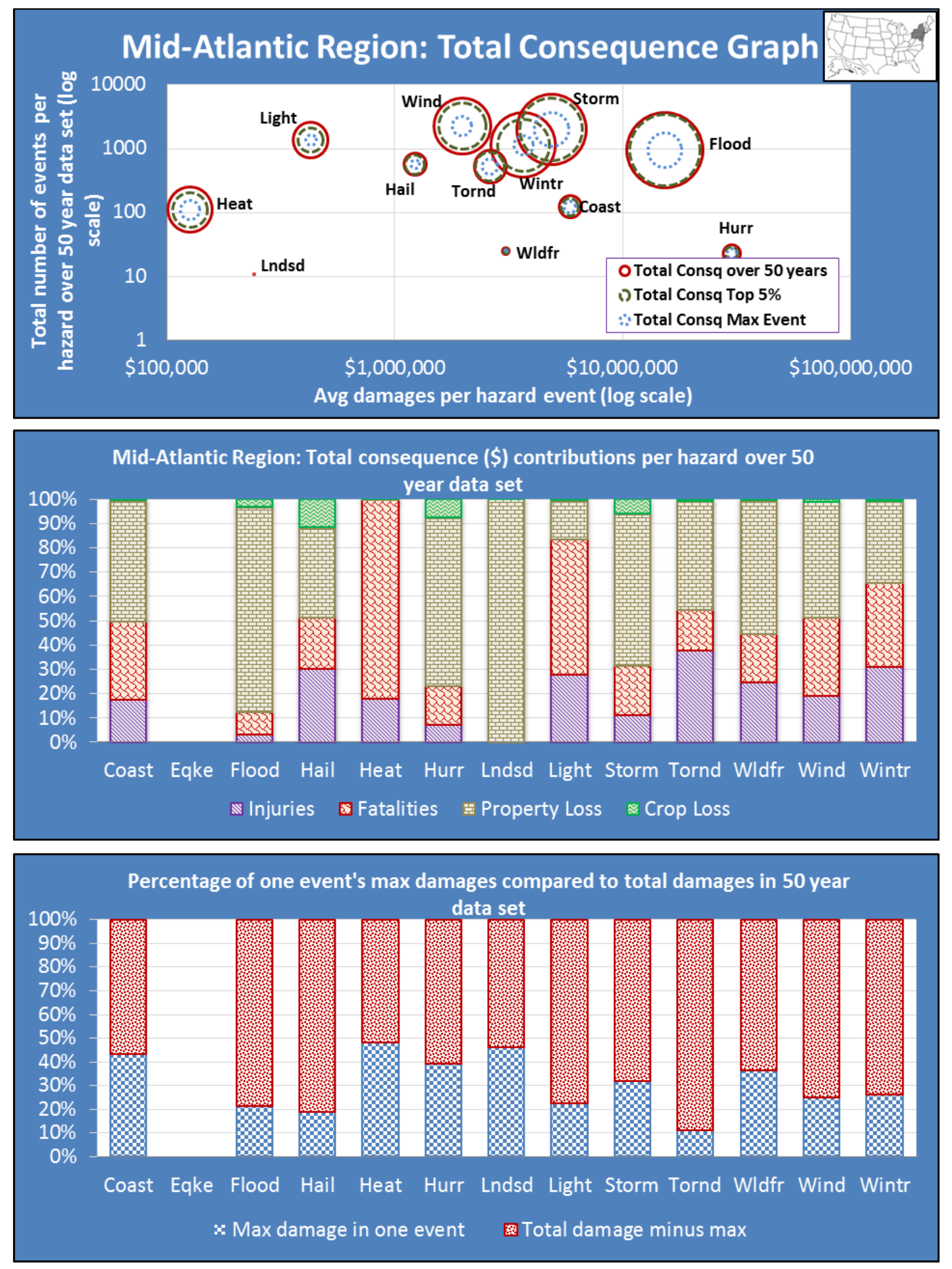

Figure 12-3: Mid-Atlantic region damage consequence graphics 


\subsection{REGION CONSEQUENCE RANKINGS}

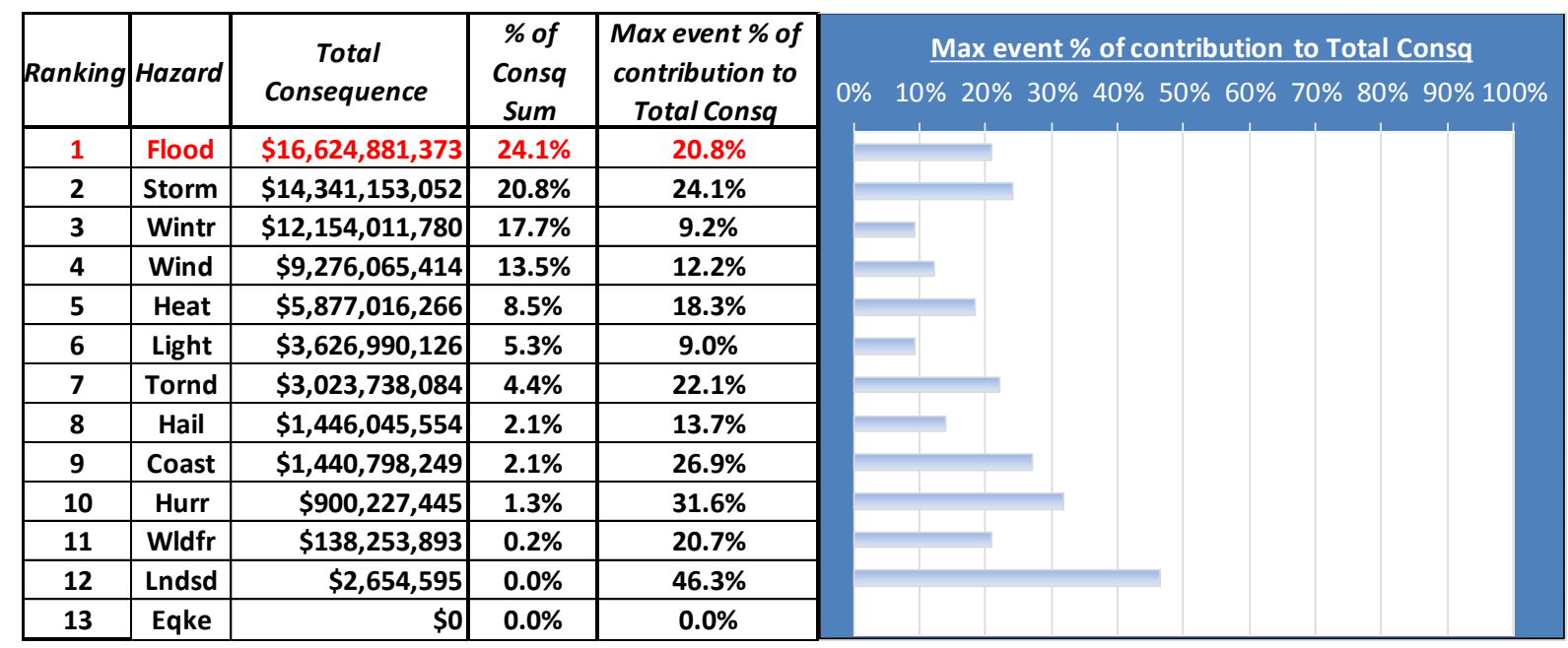

INJURIES

\begin{tabular}{|c|c|}
\hline Hazard & Avg injuries/event \\
\hline Heat & 15.84 \\
\hline Wintr & 5.47 \\
\hline Hurr & 4.51 \\
\hline Tornd & 3.61 \\
\hline Coast & 3.39 \\
\hline Wldfr & 2.24 \\
\hline Storm & 1.30 \\
\hline Wind & 1.28 \\
\hline Hail & 1.27 \\
\hline Light & 1.20 \\
\hline Flood & 0.91 \\
\hline Eqke & 0.00 \\
\hline Lndsd & 0.00 \\
\hline Hazard & Total injuries \\
\hline Wintr & 6233 \\
\hline Wind & 2923 \\
\hline Storm & 2619 \\
\hline Tornd & 1896 \\
\hline Heat & 1758 \\
\hline Light & 1666 \\
\hline Flood & 870 \\
\hline Hail & 727 \\
\hline Coast & 417 \\
\hline Hurr & 104 \\
\hline Wldfr & 56 \\
\hline Eqke & 0 \\
\hline Lndsd & 0 \\
\hline
\end{tabular}

FATALITIES

\begin{tabular}{|c|c|}
\hline Hazard & Avg fatalities/event \\
\hline Heat & 10.83 \\
\hline Hurr & 1.60 \\
\hline Coast & 0.95 \\
\hline Wintr & 0.93 \\
\hline Flood & 0.40 \\
\hline Storm & 0.37 \\
\hline Light & 0.37 \\
\hline Wind & 0.33 \\
\hline Wldfr & 0.28 \\
\hline Tornd & 0.24 \\
\hline Hail & 0.13 \\
\hline Eqke & 0.00 \\
\hline Lndsd & 0.00 \\
\hline \hline Hazard & Total fatalities \\
\hline Heat & 1202 \\
\hline Wintr & 1057 \\
\hline Wind & 750 \\
\hline Storm & 740 \\
\hline Light & 509 \\
\hline Flood & 379 \\
\hline Tornd & 127 \\
\hline Coast & 117 \\
\hline Hail & 77 \\
\hline Hurr & 37 \\
\hline Wldfr & 7 \\
\hline Eqke & 0 \\
\hline Lndsd & 0 \\
\hline & \\
\hline & 0 \\
\hline
\end{tabular}

DAMAGES

\begin{tabular}{|c|r|}
\hline Hazard & Avg damage/event \\
\hline Hurr & $\mathbf{\$ 3 0 , 0 2 5 , 7 1 5}$ \\
\hline Flood & $\mathbf{\$ 1 5 , 3 3 6 , 9 0 6}$ \\
\hline Coast & $\mathbf{\$ 5 , 8 7 5 , 2 0 5}$ \\
\hline Storm & $\mathbf{\$ 4 , 8 7 7 , 6 7 7}$ \\
\hline Wintr & $\mathbf{\$ 3 , 6 7 3 , 9 8 8}$ \\
\hline Wldfr & $\mathbf{\$ 3 , 0 7 2 , 8 7 6}$ \\
\hline Tornd & $\mathbf{\$ 2 , 6 2 5 , 7 2 2}$ \\
\hline Wind & $\mathbf{\$ 1 , 9 7 9 , 3 0 0}$ \\
\hline Hail & $\mathbf{\$ 1 , 2 2 8 , 5 4 1}$ \\
\hline Light & $\mathbf{\$ 4 2 8 , 4 6 4}$ \\
\hline Lndsd & $\mathbf{\$ 2 4 1 , 3 2 7}$ \\
\hline Heat & $\mathbf{\$ 1 2 6 , 7 9 5}$ \\
\hline Eqke & $\mathbf{\$ 0}$ \\
\hline \hline Hazard & Total damage \\
\hline Flood & $\mathbf{\$ 1 4 , 5 8 5 , 3 9 7 , 3 7 3}$ \\
\hline Storm & $\mathbf{\$ 9 , 8 0 9 , 0 0 9 , 0 5 2}$ \\
\hline Wind & $\mathbf{\$ 4 , 5 2 2 , 7 0 1 , 4 1 4}$ \\
\hline Wintr & $\mathbf{\$ 4 , 1 8 4 , 6 7 1 , 7 8 0}$ \\
\hline Tornd & $\mathbf{\$ 1 , 3 7 8 , 5 0 4 , 0 8 4}$ \\
\hline Coast & $\mathbf{\$ 7 2 2 , 6 5 0 , 2 4 9}$ \\
\hline Hail & $\mathbf{\$ 7 0 2 , 7 2 5 , 5 5 4}$ \\
\hline Hurr & $\mathbf{\$ 6 9 0 , 5 9 1 , 4 4 5}$ \\
\hline Light & $\mathbf{\$ 5 9 2 , 9 9 4 , 1 2 6}$ \\
\hline Wldfr & $\mathbf{\$ 7 6 , 8 2 1 , 8 9 3}$ \\
\hline Heat & $\mathbf{\$ 1 4 , 0 7 4 , 2 6 6}$ \\
\hline Lndsd & $\mathbf{\$ 2 , 6 5 4 , 5 9 5}$ \\
\hline Eqke & $\mathbf{\$} 0$ \\
\hline &
\end{tabular}

Table 12-4: Mid-Atlantic region consequence rankings 


\subsection{REGIONAL SUMMARY}

The Mid-Atlantic region has a relatively small land mass area compared to other regions, but still has $\$ 70$ billion in total consequences, with half of the losses from property damage. There are 48 million people living in this region in high concentrations along the Atlantic coastline. The density along the coast is 300 persons or more per square mile and is consistent throughout. As previously stated in chapter 2, some of the largest populated areas have densities in the thousands of persons per square mile.

Analysis of this region and others often show differences between the largest consequence rankings and the averages and total losses in each category. This is typically due to the fact that the hazard that has the highest consequence ranking usually only has high losses in one of the three risk metrics. For instance, flooding has a high damage amount at $\$ 15$ billion, but other hazards are more dominant in terms of injury and fatality losses. Heat hazards have caused a substantial amount of fatalities in the region and have an equally high average amount. Each hazard needs to be treated separately when assessing the optimum mitigation strategy. For example, heat hazards require one response, while flooding or storm hazards will need different mitigation measures put into effect. The frequencies of events also need to be taken into consideration. The heat hazard events thus far total 111 in the 50 year dataset, but the winter storms, severe storms, and wind have thousands of events to account for when creating mitigation plans.

In the midst of this study, Super Storm Sandy caused major losses with tens of billions of dollars in damages in many states of this region in late 2012. It should be noted that these preliminary estimates by various agencies have not been incorporated in this paper. 


\section{New England Regional Analysis}

\subsection{LAYOUT}

Chapter 13 contains the natural hazard risk assessment and analysis for the New England region, which consists of the following six states: Connecticut, Rhode Island, Massachusetts, Vermont, New Hampshire, and Maine. Figures included in this chapter are:

- New England region consequence tables for injuries, fatalities, and damages

Table 13-1, Table 13-2, and Table 13-3, respectively

- New England region consequence graphics for injuries, fatalities, and damages

Pigure 13-1, Figure 13-2, and Figure 13-3, respectively

- New England region consequence rankings (Table 13-4)

$>$ Total consequence and overall percentage

$>$ Average loss per event: injuries, fatalities, damages

$>$ Total losses: injuries, fatalities, damages

The following hazard events have not been recorded by SHELDUS and will not appear in the graphical or chart displays for this region.

- Earthquake 


\subsection{REGION CONSEQUENCE DISPLAYS}

\begin{tabular}{|c|c|c|r|r|r|}
\hline INJURIES & Y-axis & X-axis & Outside Circle Size & Inner Circle Size & Middle Circle Size \\
\hline Hazard & \# of events & $\begin{array}{c}\text { Avg injuries per } \\
\text { event }\end{array}$ & Total Consequence & Total Consq Max & Total Consq Top 5\% \\
\hline Coast & 97 & 0.59 & $\$ 606,498,133$ & $\$ 907,188,000$ & $\$ 332,604,321$ \\
\hline Eqke & 0 & 0.00 & $\$ 0$ & $\$ 0$ \\
\hline Flood & 401 & 0.72 & $\$ 2,801,025,684$ & $\$ 776,607,500$ & $\$ 2,265,471,749$ \\
\hline Hail & 252 & 2.75 & $\$ 624,215,105$ & $\$ 304,075,893$ & $\$ 517,931,295$ \\
\hline Heat & 3 & 0.00 & $\$ 20,000,000$ & $\$ 8,000,000$ & $\$ 0$ \\
\hline Hurr & 26 & 3.54 & $\$ 583,778,854$ & $\$ 268,097,000$ & $\$ 470,057,000$ \\
\hline Lndsd & 4 & 0.00 & $\$ 1,899,800$ & $\$ 920,000$ & $\$ 920,000$ \\
\hline Light & 864 & 1.44 & $\$ 1,336,005,663$ & $\$ 304,110,492$ & $\$ 712,546,709$ \\
\hline Storm & 909 & 1.29 & $\$ 2,493,467,726$ & $\$ 348,329,850$ & $\$ 1,762,411,927$ \\
\hline Tornd & 195 & 5.04 & $\$ 1,046,159,030$ & $\$ 477,000,000$ & $\$ 905,218,340$ \\
\hline Wldfr & 1 & 11.00 & $\$ 6,926,500$ & $\$ 6,926,500$ & $\$ 0$ \\
\hline Wind & 1241 & 1.17 & $\$ 3,283,900,493$ & $\$ 498,120,000$ & $\$ 2,414,585,161$ \\
\hline Wintr & 779 & 1.23 & $\$ 3,787,596,590$ & $\$ 498,120,000$ & $\$ 2,623,631,262$ \\
\hline
\end{tabular}

\begin{tabular}{|c|r|r|r|r|r|}
\cline { 3 - 6 } \multicolumn{2}{c|}{} & \multicolumn{4}{c|}{ Contributions to the Total Consequence amount } \\
\hline Hazard & Total Consequence & \multicolumn{1}{c|}{ Injuries } & Fatalities & Property Loss & \multicolumn{1}{l|}{ Crop Loss } \\
\hline Coast & $\mathbf{\$ 6 0 6 , 4 9 8 , 1 3 3}$ & $\$ 34,128,000$ & $\$ 203,760,000$ & $\$ 368,160,762$ & $\$ 449,371$ \\
\hline Eqke & $\mathbf{\$ 0}$ & $\$ 0$ & $\$ 0$ & $\$ 0$ & $\$ 0$ \\
\hline Flood & $\mathbf{\$ 2 , 8 0 1 , 0 2 5 , 6 8 4}$ & $\$ 172,776,000$ & $\$ 212,000,000$ & $\$ 2,367,424,313$ & $\$ 48,825,370$ \\
\hline Hail & $\mathbf{\$ 6 2 4 , 2 1 5 , 1 0 5}$ & $\$ 416,424,000$ & $\$ 71,920,000$ & $\$ 124,521,291$ & $\$ 11,349,814$ \\
\hline Heat & $\mathbf{\$ 2 0 , 0 0 0 , 0 0 0}$ & $\$ 0$ & $\$ 20,000,000$ & $\$ 0$ & $\$ 0$ \\
\hline Hurr & $\mathbf{\$ 5 8 3 , 7 7 8 , 8 5 4}$ & $\$ 55,284,000$ & $\$ 60,080,000$ & $\$ 435,803,259$ & $\$ 32,611,595$ \\
\hline Lndsd & $\mathbf{\$ 1 , 8 9 9 , 8 0 0}$ & $\$ 0$ & $\$ 0$ & $\$ 1,899,800$ & $\$ 0$ \\
\hline Light & $\mathbf{\$ 1 , 3 3 6 , 0 0 5 , 6 6 3}$ & $\$ 745,470,000$ & $\$ 411,720,000$ & $\$ 173,489,272$ & $\$ 5,326,391$ \\
\hline Storm & $\mathbf{\$ 2 , 4 9 3 , 4 6 7 , 7 2 6}$ & $\$ 701,268,000$ & $\$ 577,240,000$ & $\$ 1,160,029,760$ & $\$ 54,929,965$ \\
\hline Tornd & $\mathbf{\$ 1 , 0 4 6 , 1 5 9 , 0 3 0}$ & $\$ 589,764,000$ & $\$ 80,080,000$ & $\$ 355,849,043$ & $\$ 20,465,987$ \\
\hline Wldfr & $\mathbf{\$ 6 , 9 2 6 , 5 0 0}$ & $\$ 6,600,000$ & $\$ 0$ & $\$ 326,500$ & $\$ 0$ \\
\hline Wind & $\mathbf{\$ 3 , 2 8 3 , 9 0 0 , 4 9 3}$ & $\$ 869,958,000$ & $\$ 963,240,000$ & $\$ 1,429,880,972$ & $\$ 20,821,521$ \\
\hline Wintr & $\mathbf{\$ 3 , 7 8 7 , 5 9 6 , 5 9 0}$ & $\$ 576,894,000$ & $\$ 1,180,160,000$ & $\$ 2,016,754,791$ & $\$ 13,787,799$ \\
\hline
\end{tabular}

\begin{tabular}{|c|c|c|c|c|c|}
\hline INJURIES & & & & & \\
\hline Hazard & Total injuries & \# of events & Max injuries in one & Total minus max & $\%$ of total \\
\hline Coast & 57 & 97 & 16 & 41 & $28 \%$ \\
\hline Eqke & 0 & 0 & 0 & 0 & $0 \%$ \\
\hline Flood & 288 & 401 & 209 & 79 & $73 \%$ \\
\hline Hail & 694 & 252 & 500 & 194 & $72 \%$ \\
\hline Heat & 0 & 3 & 0 & 0 & $0 \%$ \\
\hline Hurr & 92 & 26 & 53 & 39 & $57 \%$ \\
\hline Lndsd & 0 & 4 & 0 & 0 & $0 \%$ \\
\hline Light & 1242 & 864 & 500 & 742 & $40 \%$ \\
\hline Storm & 1169 & 909 & 500 & 669 & $43 \%$ \\
\hline Tornd & 983 & 195 & 500 & 483 & $51 \%$ \\
\hline Wldfr & 11 & 1 & 11 & 0 & $100 \%$ \\
\hline Wind & 1450 & 1241 & 500 & 950 & $34 \%$ \\
\hline Wintr & 961 & 779 & 77 & 885 & $8 \%$ \\
\hline
\end{tabular}

Table 13-1: New England region injury consequence tables 

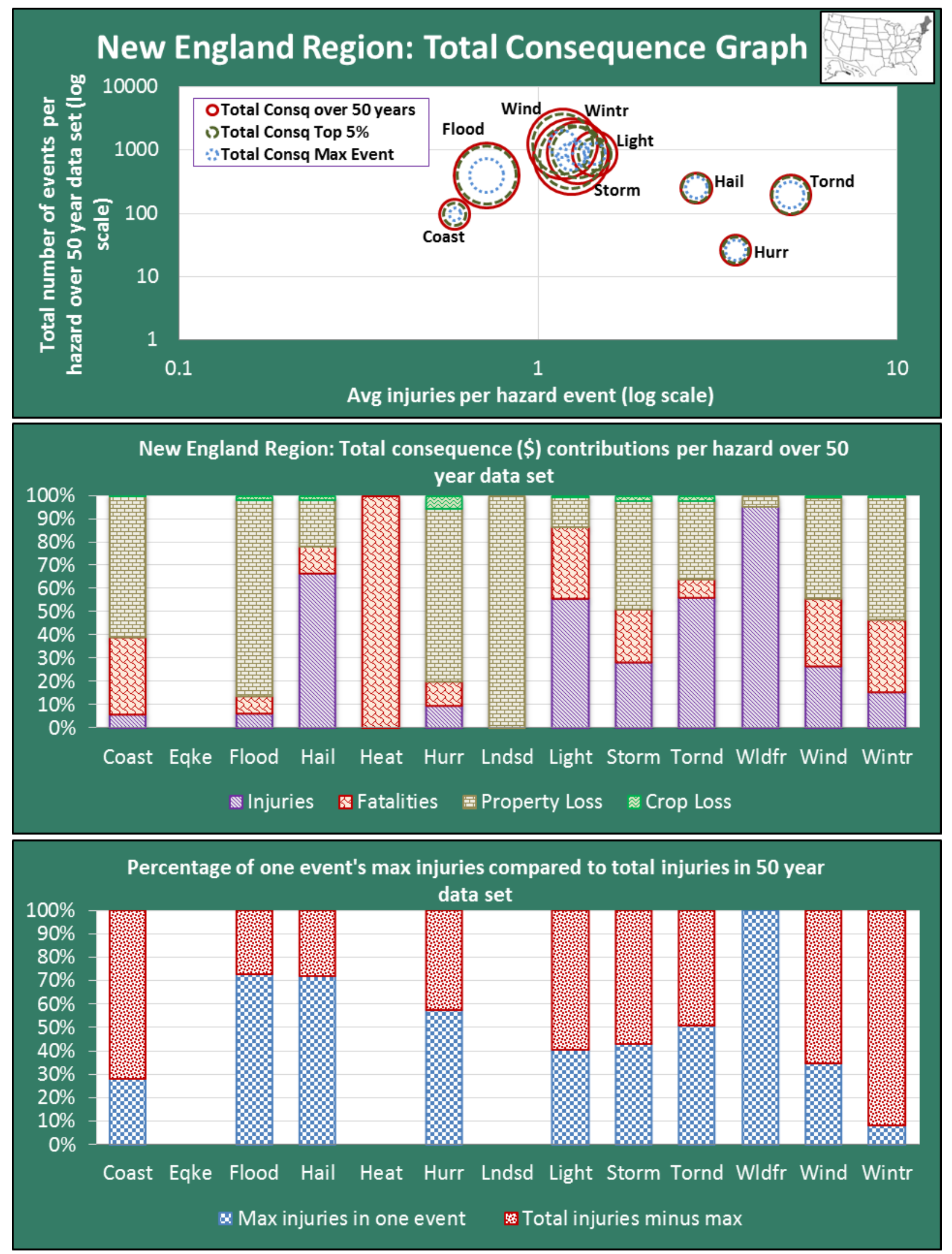

Figure 13-1: New England region injury consequence graphics 


\begin{tabular}{|c|c|c|r|r|r|}
\hline FATALITIES & Y-axis & \multicolumn{1}{|c|}{ X-axis } & Outside Circle Size & \multicolumn{1}{|c|}{ Inner Circle Size } & Middle Circle Size \\
\hline Hazard & \# of events & $\begin{array}{c}\text { Avg fatalities per } \\
\text { event }\end{array}$ & Total Consequence & Total Consq Max & Total Consq Top 5\% \\
\hline Coast & 97 & 0.53 & $\$ 606,498,133$ & $\$ 97,188,000$ & $\$ 332,604,321$ \\
\hline Eqke & 0 & 0.00 & $\$ 0$ & $\$ 0$ & $\$ 0$ \\
\hline Flood & 401 & 0.13 & $\$ 2,801,025,684$ & $\$ 776,607,500$ & $\$ 2,265,471,749$ \\
\hline Hail & 252 & 0.07 & $\$ 624,215,105$ & $\$ 304,075,893$ & $\$ 517,931,295$ \\
\hline Heat & 3 & 1.67 & $\$ 20,000,000$ & $\$ 8,000,000$ & $\$ 0$ \\
\hline Hurr & 26 & 0.58 & $\$ 583,778,854$ & $\$ 268,097,000$ & $\$ 470,057,000$ \\
\hline Lndsd & 4 & 0.00 & $\$ 1,899,800$ & $\$ 920,000$ & $\$ 920,000$ \\
\hline Light & 864 & 0.12 & $\$ 1,336,005,663$ & $\$ 304,110,492$ & $\$ 712,546,709$ \\
\hline Storm & 909 & 0.16 & $\$ 2,493,467,726$ & $\$ 348,329,850$ & $\$ 1,762,411,927$ \\
\hline Tornd & 195 & 0.10 & $\$ 1,046,159,030$ & $\$ 477,000,000$ & $\$ 905,218,340$ \\
\hline Wldfr & 1 & 0.00 & $\$ 6,926,500$ & $\$ 6,926,500$ & $\$$ \\
\hline Wind & 1241 & 0.19 & $\$ 3,283,900,493$ & $\$ 498,120,000$ & $\$ 2,414,585,161$ \\
\hline Wintr & 779 & 0.38 & $\$ 3,787,596,590$ & $\$ 498,120,000$ & $\$ 2,623,631,262$ \\
\hline
\end{tabular}

\begin{tabular}{|c|c|c|c|c|c|}
\hline \multirow[b]{2}{*}{ Hazard } & \multirow[b]{2}{*}{ Total Consequence } & \multicolumn{4}{|c|}{ Contributions to the Total Consequence amount } \\
\hline & & Injuries & Fatalities & Property Loss & Crop Loss \\
\hline Coast & $\$ 606,498,133$ & $\$ 34,128,000$ & $\$ 203,760,000$ & $\$ 368,160,762$ & $\$ 449,371$ \\
\hline Eqke & $\$ 0$ & $\$ 0$ & $\$ 0$ & $\$ 0$ & $\$ 0$ \\
\hline Flood & $\$ 2,801,025,684$ & $\$ 172,776,000$ & $\$ 212,000,000$ & $\$ 2,367,424,313$ & $\$ 48,825,370$ \\
\hline Hail & $\$ 624,215,105$ & $\$ 416,424,000$ & $\$ 71,920,000$ & $\$ 124,521,291$ & $\$ 11,349,814$ \\
\hline Heat & $\$ 20,000,000$ & $\$ 0$ & $\$ 20,000,000$ & $\$ 0$ & \$O \\
\hline Hurr & $\$ 583,778,854$ & $\$ 55,284,000$ & $\$ 60,080,000$ & $\$ 435,803,259$ & $\$ 32,611,595$ \\
\hline Lndsd & $\$ 1,899,800$ & $\$ 0$ & $\$ 0$ & $\$ 1,899,800$ & $\$ 0$ \\
\hline Light & $\$ 1,336,005,663$ & $\$ 745,470,000$ & $\$ 411,720,000$ & $\$ 173,489,272$ & $\$ 5,326,391$ \\
\hline Storm & $\$ 2,493,467,726$ & $\$ 701,268,000$ & $\$ 577,240,000$ & $\$ 1,160,029,760$ & $\$ 54,929,965$ \\
\hline Tornd & $\$ 1,046,159,030$ & $\$ 589,764,000$ & $\$ 80,080,000$ & $\$ 355,849,043$ & $\$ 20,465,987$ \\
\hline Wldfr & $\$ 6,926,500$ & $\$ 6,600,000$ & $\$ 0$ & $\$ 326,500$ & $\$ 0$ \\
\hline Wind & $\$ 3,283,900,493$ & $\$ 869,958,000$ & $\$ 963,240,000$ & $\$ 1,429,880,972$ & $\$ 20,821,521$ \\
\hline Wintr & $\$ 3,787,596,590$ & $\$ 576,894,000$ & $\$ 1,180,160,000$ & $\$ 2,016,754,791$ & $\$ 13,787,799$ \\
\hline
\end{tabular}

\begin{tabular}{|c|c|c|c|c|c|}
\hline \multicolumn{6}{|c|}{ FATALITIES } \\
\hline Hazard & Total fatalities & \# of events & Max fatalities in one & Total minus max & $\%$ of total \\
\hline Coast & 51 & 97 & 11 & 40 & $22 \%$ \\
\hline Eqke & 0 & 0 & 0 & 0 & $0 \%$ \\
\hline Flood & 53 & 401 & 5 & 48 & $9 \%$ \\
\hline Hail & 18 & 252 & 3 & 15 & $17 \%$ \\
\hline Heat & 5 & 3 & 2 & 3 & $40 \%$ \\
\hline Hurr & 15 & 26 & 6 & 9 & $40 \%$ \\
\hline Lndsd & 0 & 4 & 0 & 0 & $0 \%$ \\
\hline Light & 103 & 864 & 4 & 99 & $4 \%$ \\
\hline Storm & 144 & 909 & 6 & 138 & $4 \%$ \\
\hline Tornd & 20 & 195 & 4 & 16 & $20 \%$ \\
\hline Wldfr & 0 & 1 & 0 & 0 & $0 \%$ \\
\hline Wind & 241 & 1241 & 27 & 214 & $11 \%$ \\
\hline Wintr & 295 & 779 & 35 & 260 & $12 \%$ \\
\hline
\end{tabular}

Table 13-2: New England region fatality consequence tables 

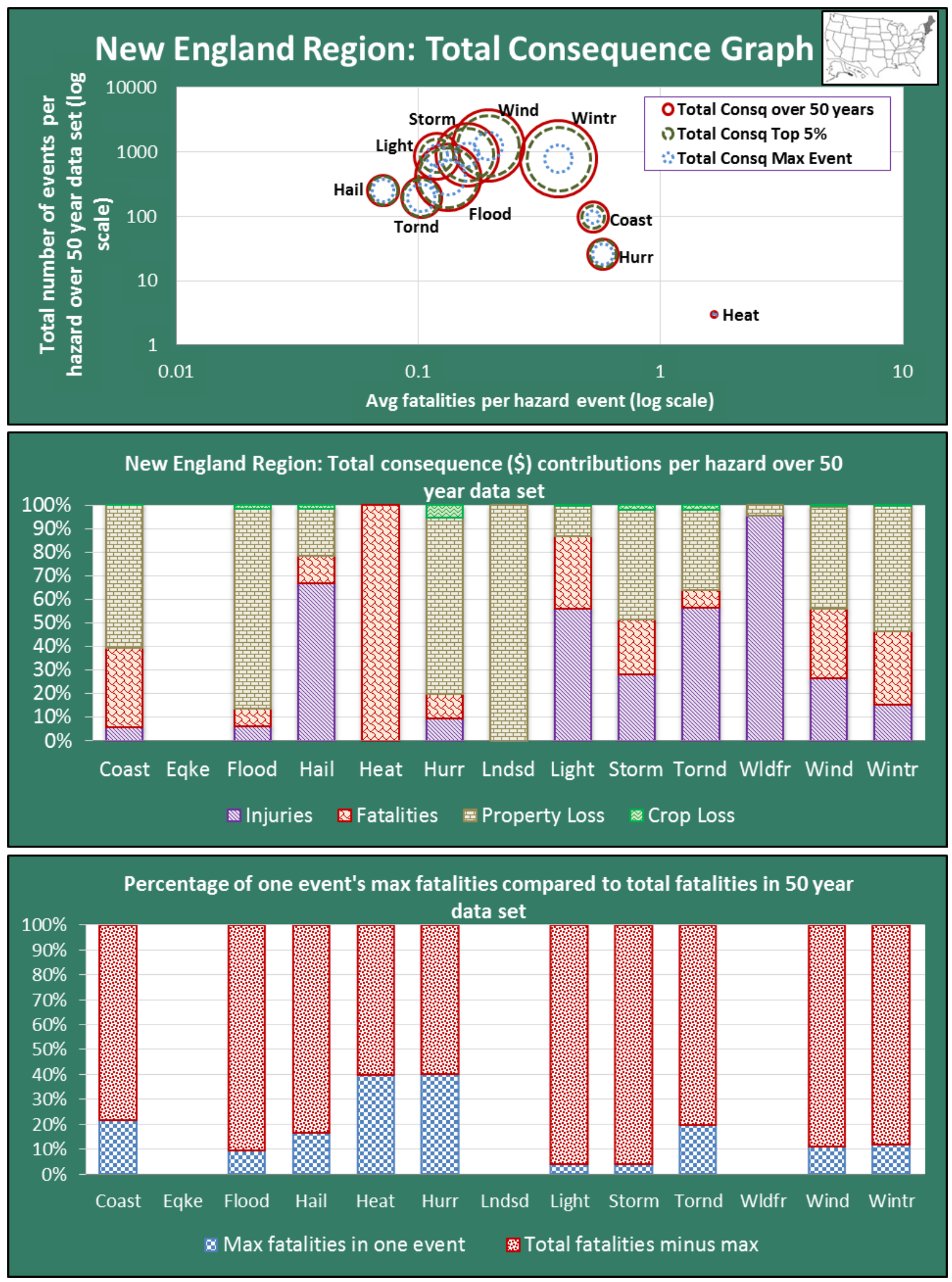

Figure 13-2: New England region fatality consequence graphics 


\begin{tabular}{|c|c|r|r|r|r|}
\hline DAMAGES & Y-axis & \multicolumn{1}{|c|}{ X-axis } & Outside Circle Size & Inner Circle Size & Middle Circle Size \\
\hline Hazard & \# of events & $\begin{array}{c}\text { Avg damages per } \\
\text { event }\end{array}$ & Total Consequence & Total Consq Max & Total Consq Top 5\% \\
\hline Coast & 97 & $\$ 3,800,104$ & $\$ 606,498,133$ & $\$ 97,188,000$ & $\$ 332,604,321$ \\
\hline Eqke & 0 & $\$ 0$ & $\$ 0$ & $\$ 0$ & $\$ 0$ \\
\hline Flood & 401 & $\$ 6,025,560$ & $\$ 2,801,025,684$ & $\$ 776,607,500$ & $\$ 2,265,471,749$ \\
\hline Hail & 252 & $\$ 539,171$ & $\$ 624,215,105$ & $\$ 304,075,893$ & $\$ 517,931,295$ \\
\hline Heat & 3 & $\$ 0$ & $\$ 20,000,000$ & $\$ 8,000,000$ & $\$ 0$ \\
\hline Hurr & 26 & $\$ 18,015,956$ & $\$ 583,778,854$ & $\$ 268,097,000$ & $\$ 470,057,000$ \\
\hline Lndsd & 4 & $\$ 474,950$ & $\$ 1,899,800$ & $\$ 920,000$ & $\$ 920,000$ \\
\hline Light & 864 & $\$ 206,963$ & $\$ 1,336,005,663$ & $\$ 304,110,492$ & $\$ 712,546,709$ \\
\hline Storm & 909 & $\$ 1,336,589$ & $\$ 2,493,467,726$ & $\$ 348,329,850$ & $\$ 1,762,411,927$ \\
\hline Tornd & 195 & $\$ 1,929,821$ & $\$ 1,046,159,030$ & $\$ 477,000,000$ & $\$ 905,218,340$ \\
\hline Wldfr & 1 & $\$ 326,500$ & $\$ 6,926,500$ & $\$ 6,926,500$ & $\$ 0$ \\
\hline Wind & 1241 & $\$ 1,168,979$ & $\$ 3,283,900,493$ & $\$ 498,120,000$ & $\$ 2,414,585,161$ \\
\hline Wintr & 779 & $\$ 2,606,602$ & $\$ 3,787,596,590$ & $\$ 498,120,000$ & $\$ 2,623,631,262$ \\
\hline
\end{tabular}

\begin{tabular}{|c|r|r|r|r|r|}
\cline { 3 - 6 } \multicolumn{2}{c|}{} & \multicolumn{4}{c|}{ Contributions to the Total Consequence amount } \\
\hline Hazard & Total Consequence & \multicolumn{1}{c|}{ Injuries } & Fatalities & Property Loss & \multicolumn{1}{c|}{ Crop Loss } \\
\hline Coast & $\mathbf{\$ 6 0 6 , 4 9 8 , 1 3 3}$ & $\$ 34,128,000$ & $\$ 203,760,000$ & $\$ 368,160,762$ & $\$ 449,371$ \\
\hline Eqke & $\mathbf{\$ 0}$ & $\$ 0$ & $\$ 0$ & $\$ 0$ & $\$ 0$ \\
\hline Flood & $\mathbf{\$ 2 , 8 0 1 , 0 2 5 , 6 8 4}$ & $\$ 172,776,000$ & $\$ 212,000,000$ & $\$ 2,367,424,313$ & $\$ 48,825,370$ \\
\hline Hail & $\mathbf{\$ 6 2 4 , 2 1 5 , 1 0 5}$ & $\$ 416,424,000$ & $\$ 71,920,000$ & $\$ 124,521,291$ & $\$ 11,349,814$ \\
\hline Heat & $\mathbf{\$ 2 0 , 0 0 0 , 0 0 0}$ & $\$ 0$ & $\$ 20,000,000$ & $\$ 0$ & $\$ 0$ \\
\hline Hurr & $\mathbf{\$ 5 8 3 , 7 7 8 , 8 5 4}$ & $\$ 55,284,000$ & $\$ 60,080,000$ & $\$ 435,803,259$ & $\$ 32,611,595$ \\
\hline Lndsd & $\mathbf{\$ 1 , 8 9 9 , 8 0 0}$ & $\$ 0$ & $\$ 0$ & $\$ 1,899,800$ & $\$ 0$ \\
\hline Light & $\mathbf{\$ 1 , 3 3 6 , 0 0 5 , 6 6 3}$ & $\$ 745,470,000$ & $\$ 411,720,000$ & $\$ 173,489,272$ & $\$ 5,326,391$ \\
\hline Storm & $\mathbf{\$ 2 , 4 9 3 , 4 6 7 , 7 2 6}$ & $\$ 701,268,000$ & $\$ 577,240,000$ & $\$ 1,160,029,760$ & $\$ 54,929,965$ \\
\hline Tornd & $\mathbf{\$ 1 , 0 4 6 , 1 5 9 , 0 3 0}$ & $\$ 589,764,000$ & $\$ 80,080,000$ & $\$ 355,849,043$ & $\$ 20,465,987$ \\
\hline Wldfr & $\mathbf{\$ 6 , 9 2 6 , 5 0 0}$ & $\$ 6,600,000$ & $\$ 0$ & $\$ 326,500$ & $\$ 0$ \\
\hline Wind & $\mathbf{\$ 3 , 2 8 3 , 9 0 0 , 4 9 3}$ & $\$ 869,958,000$ & $\$ 963,240,000$ & $\$ 1,429,880,972$ & $\$ 20,821,521$ \\
\hline Wintr & $\mathbf{\$ 3 , 7 8 7 , 5 9 6 , 5 9 0}$ & $\$ 576,894,000$ & $\$ 1,180,160,000$ & $\$ 2,016,754,791$ & $\$ 13,787,799$ \\
\hline
\end{tabular}

\begin{tabular}{|c|r|c|r|r|c|}
\hline DAMAGES & & & & & \\
\hline Hazard & Total damages & \# of events & Max damages in one & Total minus max & $\%$ of total \\
\hline Coast & $\$ 368,610,133$ & 97 & $\$ 96,000,000$ & $\$ 272,610,133$ & $26 \%$ \\
\hline Eqke & $\$ 0$ & 0 & $\$ 0$ & $\$ 0$ & $0 \%$ \\
\hline Flood & $\$ 2,416,249,684$ & 401 & $\$ 776,007,500$ & $\$ 1,640,242,184$ & $32 \%$ \\
\hline Hail & $\$ 135,871,105$ & 252 & $\$ 88,000,000$ & $\$ 47,871,105$ & $65 \%$ \\
\hline Heat & $\$ 0$ & 3 & $\$ 0$ & $\$ 0$ & $0 \%$ \\
\hline Hurr & $\$ 468,414,854$ & 26 & $\$ 238,525,000$ & $\$ 229,889,854$ & $51 \%$ \\
\hline Lndsd & $\$ 1,899,800$ & 4 & $\$ 920,000$ & $\$ 979,800$ & $48 \%$ \\
\hline Light & $\$ 178,815,663$ & 864 & $\$ 15,315,000$ & $\$ 163,500,663$ & $9 \%$ \\
\hline Storm & $\$ 1,214,959,726$ & 909 & $\$ 348,329,850$ & $\$ 866,629,876$ & $29 \%$ \\
\hline Tornd & $\$ 376,315,030$ & 195 & $\$ 165,000,000$ & $\$ 211,315,030$ & $44 \%$ \\
\hline Wldfr & $\$ 326,500$ & 1 & $\$ 326,500$ & & $\$ 0$ \\
\hline Wind & $\$ 1,450,702,493$ & 1241 & $\$ 384,100,000$ & $\$ 1,066,602,493$ & $100 \%$ \\
\hline Wintr & $\$ 2,030,542,590$ & 779 & $\$ 416,740,000$ & $\$ 1,613,802,590$ & $26 \%$ \\
\hline
\end{tabular}

Table 13-3: New England region damage consequence tables 

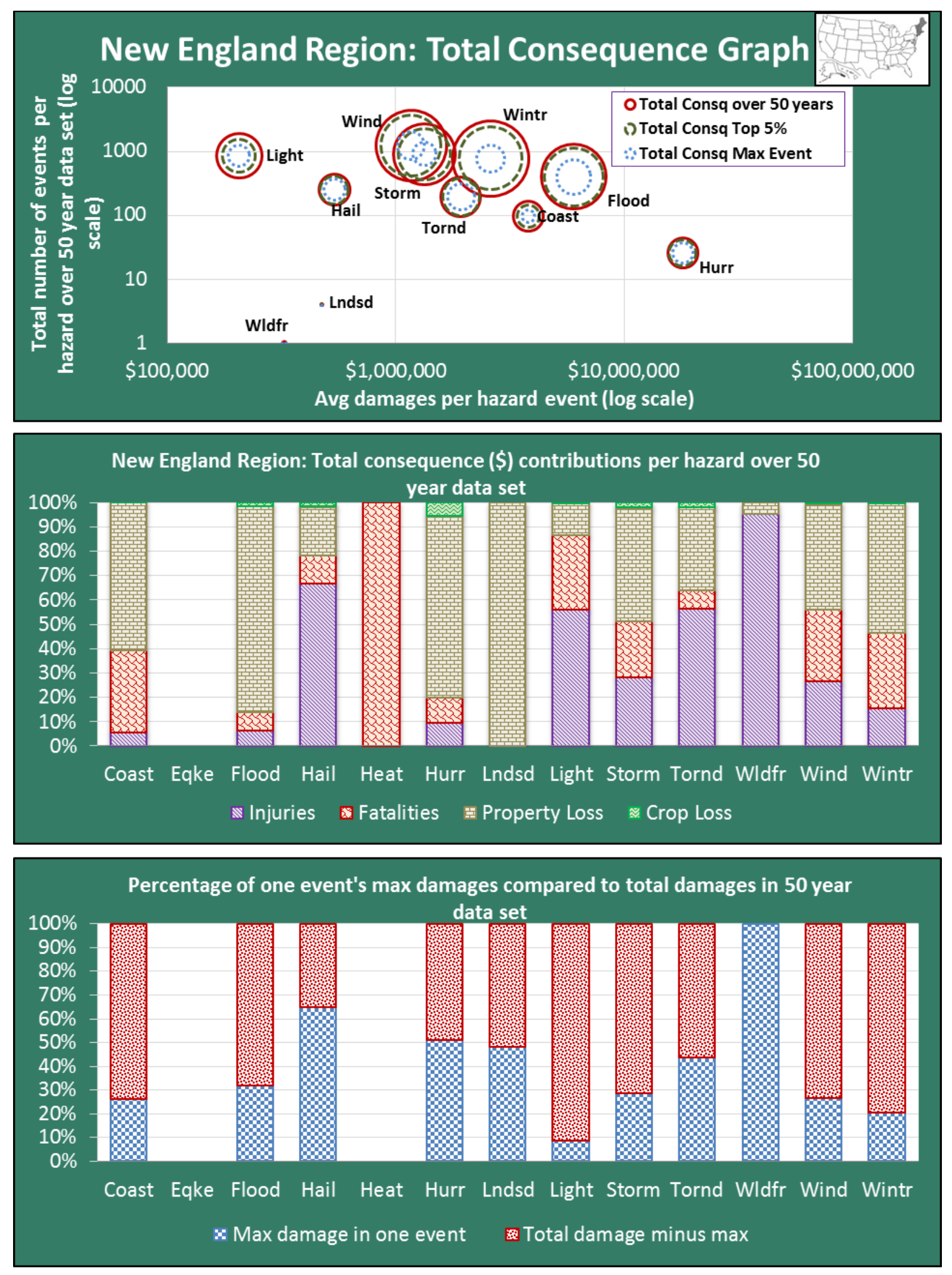

Figure 13-3: New England region damage consequence graphics 


\subsection{REGION CONSEQUENCE RANKINGS}

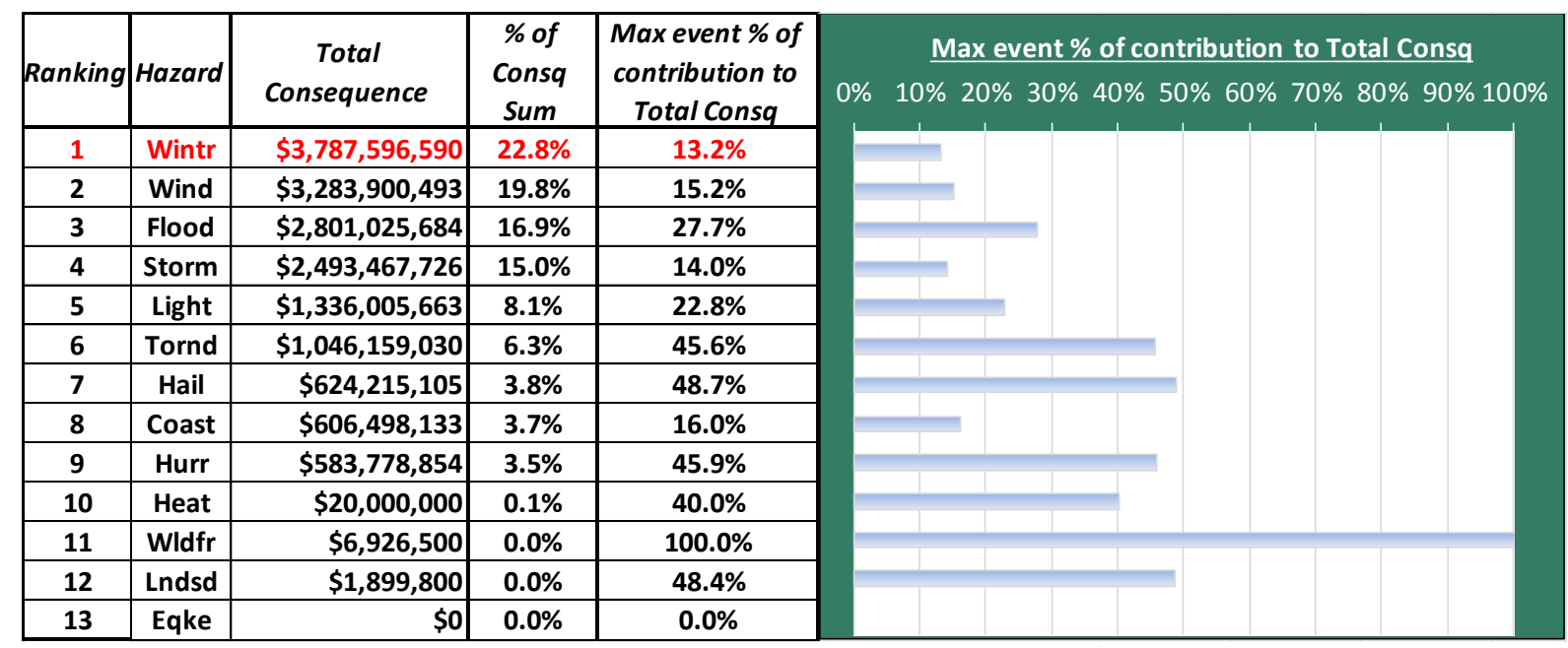

INJURIES

\begin{tabular}{|c|c|}
\hline Hazard & Avg injuries/event \\
\hline Wldfr & 11.00 \\
\hline Tornd & 5.04 \\
\hline Hurr & 3.54 \\
\hline Hail & 2.75 \\
\hline Light & 1.44 \\
\hline Storm & 1.29 \\
\hline Wintr & 1.23 \\
\hline Wind & 1.17 \\
\hline Flood & 0.72 \\
\hline Coast & 0.59 \\
\hline Eqke & 0.00 \\
\hline Heat & 0.00 \\
\hline Lndsd & 0.00 \\
\hline Hazard & Total injuries \\
\hline Wind & 1450 \\
\hline Light & 1242 \\
\hline Storm & 1169 \\
\hline Tornd & 983 \\
\hline Wintr & 961 \\
\hline Hail & 694 \\
\hline Flood & 288 \\
\hline Hurr & 92 \\
\hline Coast & 57 \\
\hline Wldfr & 11 \\
\hline Eqke & 0 \\
\hline Heat & 0 \\
\hline Lndsd & 0 \\
\hline
\end{tabular}

FATALITIES

\begin{tabular}{|c|c|}
\hline Hazard & Avg fatalities/event \\
\hline Heat & 1.67 \\
\hline Hurr & 0.58 \\
\hline Coast & 0.53 \\
\hline Wintr & 0.38 \\
\hline Wind & 0.19 \\
\hline Storm & 0.16 \\
\hline Flood & 0.13 \\
\hline Light & 0.12 \\
\hline Tornd & 0.10 \\
\hline Hail & 0.07 \\
\hline Eqke & 0.00 \\
\hline Lndsd & 0.00 \\
\hline Wldfr & 0.00 \\
\hline \hline Hazard & Total fatalities \\
\hline Wintr & 295 \\
\hline Wind & 241 \\
\hline Storm & 144 \\
\hline Light & 103 \\
\hline Flood & 53 \\
\hline Coast & 51 \\
\hline Tornd & 20 \\
\hline Hail & 18 \\
\hline Hurr & 15 \\
\hline Heat & 5 \\
\hline Eqke & 0 \\
\hline Lndsd & 0 \\
\hline Wldfr & 0 \\
\hline & \\
\hline & 0 \\
\hline
\end{tabular}

DAMAGES

\begin{tabular}{|c|r|}
\hline Hazard & Avg damage/event \\
\hline Hurr & $\mathbf{\$ 1 8 , 0 1 5 , 9 5 6}$ \\
\hline Flood & $\mathbf{\$ 6 , 0 2 5 , 5 6 0}$ \\
\hline Coast & $\mathbf{\$ 3 , 8 0 0 , 1 0 4}$ \\
\hline Wintr & $\mathbf{\$ 2 , 6 0 6 , 6 0 2}$ \\
\hline Tornd & $\mathbf{\$ 1 , 9 2 9 , 8 2 1}$ \\
\hline Storm & $\mathbf{\$ 1 , 3 3 6 , 5 8 9}$ \\
\hline Wind & $\mathbf{\$ 1 , 1 6 8 , 9 7 9}$ \\
\hline Hail & $\mathbf{\$ 5 3 9 , 1 7 1}$ \\
\hline Lndsd & $\mathbf{\$ 4 7 4 , 9 5 0}$ \\
\hline Wldfr & $\mathbf{\$ 3 2 6 , 5 0 0}$ \\
\hline Light & $\mathbf{\$ 2 0 6 , 9 6 3}$ \\
\hline Eqke & $\mathbf{\$ 0}$ \\
\hline Heat & $\mathbf{5}$ \\
\hline \hline Hazard & Total damage \\
\hline Flood & $\mathbf{\$ 2 , 4 1 6 , 2 4 9 , 6 8 4}$ \\
\hline Wintr & $\mathbf{\$ 2 , 0 3 0 , 5 4 2 , 5 9 0}$ \\
\hline Wind & $\mathbf{\$ 1 , 4 5 0 , 7 0 2 , 4 9 3}$ \\
\hline Storm & $\mathbf{\$ 1 , 2 1 4 , 9 5 9 , 7 2 6}$ \\
\hline Hurr & $\mathbf{\$ 4 6 8 , 4 1 4 , 8 5 4}$ \\
\hline Tornd & $\mathbf{\$ 3 7 6 , 3 1 5 , 0 3 0}$ \\
\hline Coast & $\mathbf{\$ 3 6 8 , 6 1 0 , 1 3 3}$ \\
\hline Light & $\mathbf{\$ 1 7 8 , 8 1 5 , 6 6 3}$ \\
\hline Hail & $\mathbf{\$ 1 3 5 , 8 7 1 , 1 0 5}$ \\
\hline Lndsd & $\mathbf{\$ 1 , 8 9 9 , 8 0 0}$ \\
\hline Wldfr & $\mathbf{\$ 3 2 6 , 5 0 0}$ \\
\hline Eqke & $\mathbf{\$} 0$ \\
\hline Heat & $\mathbf{\$} 0$ \\
\hline &
\end{tabular}

Table 13-4: New England region consequence rankings 


\subsection{REGIONAL SUMMARY}

The New England region experienced the smallest amount of total consequences and number of hazard events in all of the US. The region's losses amounted to $\$ 17$ billion and makes up $2 \%$ of the overall total throughout the regions. The largest consequences come from winter, wind, flooding, and severe storm hazard, accounting for $75 \%$. The combinations of these storm categories also cause the largest amount of injuries and fatalities. Half of the losses in this region come from property damage caused by these hazards. Similar to the Mid-Atlantic region, the population has heavy concentrations along the coastlines, generally with 300 persons or more per square mile. The land mass is also about the same as that of the Mid-Atlantic, but has far less consequences and about a third of the population size totaling 15 million people.

It is important to incorporate the number of people as well as where the densities of people are located when creating hazard policies. How society perceives risk is not only based on the number of events and total losses over time, but also related to catastrophic losses of specific events (Slovic and Weber 2002). The northeast region (Mid-Atlantic and New England) of the US is a prime example. If one low probability, extreme natural hazard occurs in the region, the damages and other losses are likely to be much higher than one that occurs in the Mountain region. People and infrastructure are concentrated into a much smaller space, creating the potential for large losses. The Southeast region has seen this effect immensely along its coasts and heavily populated areas, and this could also happen to dense areas in the northeast. While the northeast hasn't seen as many consequences over the past 60 years, its susceptibility is high because of the large number of people living along coastlines. 


\section{US Natural Hazard Conclusions}

\subsection{DISCUSSION}

As discussed in the regional summaries, there are many ways that the natural hazard risk assessment graphs and charts can be used for analysis. These summary displays provide a means to help stakeholders make effective decisions about future mitigation action and funding based on a hazard's range of consequences. Rather than only providing the expected value metric to communicate risk, emphasis is also given to the extreme values for each type of hazard. There are several instances in each of the regions where the largest $5 \%$ of events make up the majority of the consequences over the 50 year time frame. For example, in the Pacific region, an average of $75 \%$ of the consequences is made up of the largest $5 \%$ of events for each hazard. In some cases, the maximum event has caused over $50 \%$ of the consequences. These low probability, high consequence events require long-term mitigation plans in order to reduce the impending devastation from a disaster. These types of events and their consequences are difficult to comprehend beforehand, but improving communication of the risk will lead to better public preparation.

It should also be noted that in some cases average values are seen as an adequate measure of risk for some types of hazards that have relatively large sample sizes over the 50 year period, such as wind, flooding, and severe storms. The events documented often number in the thousands and one occurrence does not influence the average as much as the types of hazards that are relatively infrequent. Most of the hazard types analyzed with large sample sizes are observed to have $20 \%$ or more of the events with values ranging around the calculated average 
and often $70 \%$ of the occurrences have losses below the average. For example, when analyzing wind hazards in the Plain region, the average total consequence is $\$ 3.5$ million per event with nearly 4,000 documented occurrences, and more than $90 \%$ of the events have losses that are below $\$ 10$ million. Another case is observed when analyzing the losses from flooding events in the Southwest region which has an average consequence of $\$ 9$ million per event. There were nearly 2,000 flooding occurrences recorded and $85 \%$ of the events have losses that are below $\$ 10$ million. The hazards with large amount of occurrences for each of the regions tend to have a more stable expected value and are a good representation of the hazard risk. Another observation of the hazards with large sample sizes is that they have the greatest difference between the average losses and the event with the maximum losses. For instance, the wind hazard listed above has a maximum event that is over 200 times the average and the flooding hazard maximum event is over 400 times the average. Similar cases are seen throughout all of the regions and need to be accounted for when developing long-term strategies.

This movement to develop and implement long-term mitigation for catastrophic events has been gaining momentum in recent years. One prime example of this is the effort being made by the collaborators of the California Shake Out exercise (CalShakeOut 2008). In this earthquake simulation, a realistic depiction of the consequences from a 7.8 magnitude earthquake is shown along a southern portion of the San Andreas Fault near heavy populated areas of Los Angeles. The public awareness campaign provides preparation and safety information to citizens and also sponsors an annual safety drill to practice for this scenario. This campaign has been successful in educating the public and making them more aware of their earthquake risk. In California there are now over a million participants taking part in the annual safety drill, and this movement has spread throughout the last couple years to include many other states and regions throughout the 
world (CalShakeOut 2008). Better planning and implementation of mitigation measures and awareness campaigns like this are necessary for reducing losses from future natural hazard events.

Another conclusion from the analysis of natural hazards throughout the eight regions is that there is a need to distinguish which hazards have the greatest impact in a particular area. It is suggested that this should be done through the use of GIS mapping and the creation of new regions based on the natural hazards themselves. This idea of creating 'hazard regions' is expanded further by the concept of incorporating them into multi-hazard maps. This combines the consequences from natural hazards with metrics such as the social vulnerability index and population density to provide stakeholders with a way to determine where mitigation efforts need to take place in order to reduce damages. These concepts are further explained in Chapter 15, where a background is given in addition to the methodology for creating these maps. 


\section{Natural Hazard Regions}

\subsection{OVERVIEW}

This chapter presents a new method for analyzing natural hazard risk in the United States by creating regions boundaries based on each type of hazard. These will distinguish consequences by type of hazard and enable stakeholders to visualize the hazards of most concern in their area. The creation of these regions will lead to the development of multi-hazard vulnerability risk assessment maps that aid mitigation planners in making decisions for future projects and natural hazard policy.

\subsection{DEVELOPMENT OF HAZARD REGIONS}

Currently in the United States, government agencies divide the country into regions differently according to the organization's structure and purpose. Parameters that are taken into consideration include geographical landscape, climatology, politics, and several other methodologies. The eight regions that were used in this paper were formed by the Bureau of Economic Analysis (BEA) and are based on a variety of social and economic factors in different sections of the country (Wilson and Brown 2012). The philosophy for development of the regions being that as a larger entity is reduced in size it will result in better homogeneity and provide similar characteristics in regard to trade and industry. Another example to show how the country is divided into regions can be seen by looking at FEMA's structure. In order to respond to natural disasters, FEMA has divided the country into ten regions that are based on the distribution of population, and not the hazard risks that the regions face (NPRG 2001). Since regions established are not standardized across agencies, interpreting SHELDUS data is 
challenging because the specific areas that need natural hazard mitigation and the degree of impact that the hazards have on those areas within the region cannot be identified. Presently, the graphs and charts created for this study have shown how natural hazards affect each region holistically, displaying the broad implications of natural hazard losses. It is helpful to use graphs, charts, and tables to get an overall sense of the damages caused by natural hazards in the US, but it lacks the necessary details for communities to begin planning and strategizing for mitigation purposes. Since this presents a limitation for analyzing data on a local level, it is prudent to customize the regions by the hazard consequences that are impacting local communities within the US.

In order to facilitate a detailed examination, the research in this study proposes a new method of analysis for natural hazard losses by creating regions with respect to the natural hazards themselves. Rather than displaying natural hazard information through regions created by BEA, the newly established boundaries will be determined by the particular type of natural hazard. These regions, termed 'hazard regions', provide a practical approach for analyzing specific natural hazard risks by explicitly showing the total consequences over a time period for a geospatial location. For example, if all of the hurricane consequence data from SHELDUS is shown by county on a GIS map, a boundary line will be configured to establish a hurricane hazard region for the United States. This will better emphasize which hazard is the largest source of consequences over time and will show the user the exact locations of their past occurrences.

The need for hazard-based regions can be demonstrated by examining the Southwest region's consequences. Recall that the majority of the natural hazard events and respective losses throughout the region primarily come from the states of Texas and Oklahoma. More than half of the region's consequences over the past 50 years come from only three types of natural hazards: 
hurricanes, tornadoes, and flooding. Comparatively, the region's other two states - Arizona and New Mexico - contribute little to the overall consequences within the region. One of the contributing factors to this disparity is due to the distribution of the population and infrastructure throughout the region. The state of Texas total population as of 2010 is 25 million people and makes up two-thirds of the region's inhabitants. When combining this total with Oklahoma's population, it amounts to $80 \%$ of the entire region. Taking this information into account makes it much clearer to understand why there is such an inequality of natural hazard consequences throughout the region. When local governments within Arizona and New Mexico begin to update natural hazard mitigation measures, the generated consequence graphs and charts are not sufficient enough to begin planning for hazards in their states. The stakeholders strategizing to reduce natural hazard losses in the future need to know the specific hazards that are causing the damages, the total amount of damages, where these hazards are impacting the state, and information on the population and infrastructure that have incurred losses.

The Southwest is not the only region in which reported hazard consequences do not accurately align with mitigation needs for every part of the region. For instance, earthquakes make up half of all the consequences in the Pacific region, but the natural hazard characteristics in the state of Nevada are far different than those in the region's other states such as California. Another case in point can be observed by comparing the inland states to the coastal states in the Southeast region. Hurricanes and coastal hazards make up over $60 \%$ of the total consequences over the data range. The population in this region totals 80 million people, three-quarters of whom live in the coastal states where these losses primarily occur. The inland states natural hazard concerns are much different than those along the coastlines. In order to get a better 
depiction of the hazards that result in the largest consequences for the inland states, another method of analysis needs to be implemented to give precise information to mitigation planners.

The objective of this research is to inform the public/policymakers of natural hazard risk in a concise, meaningful way that promotes effective mitigation planning. Defining a region constructed by the type of natural hazard is the level of detail needed to begin creating natural hazard mitigation plans for local and state governments. These newly created 'hazard regions' will provide a means to see natural hazard impacts in their exact locations and distinguish among the hazards the have caused the majority of the losses. This will help stakeholders focus their efforts by prioritizing hazard mitigation funding and facilitating effective long-term land use and infrastructure decisions.

\subsubsection{GIS MAPS}

In order to accomplish the goal of presenting natural hazard consequences over time for exact locations within country, it is necessary to build GIS maps for each of the 13 types of natural hazards in this study. The hazard specific regions being generated will be based on a hazard type's primary exposure area, where exposure is defined as the severity, frequency, and areal extent for the type of hazard (Emrich and Cutter 2011). The advent of Geographic Information System (GIS) technology has been a vital component in deducing interrelationships between pieces of data that are tied to geographical locations. The technology is primarily used to visualize the distribution of information in a geospatial context and has a multitude of applications that include scientific inquiry, resource management, and infrastructure planning (USGS 2007).

In regard to natural hazard research and creation of mitigation policies, GIS maps are being developed and used by a variety of municipalities to understand their risks (Tate, Cutter 
and Berry 2010). In fact, between 2000 and 2010, FEMA sponsored and successfully passed legislation that require the development of GIS maps to identify and quantify hazard impacts in order to create natural hazard policies (FEMA 592; DMA 2000). In several research studies by the University of South Carolina, natural hazard information from SHELDUS is used in combination with other metrics such as social vulnerability to enable stakeholders to envision impacts from local to state level. This information is broken down into discrete county and census block levels in order to get precise assessments of an area's characteristics and features that are affected by natural hazards (Tate, Cutter and Berry 2010). There will be further discussion of the development of these maps in section 15.4 on multi-hazard mapping.

This present study suggests that using GIS maps with regions based on natural hazard types as a supplementary layering tool is beneficial for creating natural hazard policies. The total consequence data that are incorporated into these maps contain all losses transformed into a single monetary value. The established total consequence value is made up of direct financial damage, fatalities, and injuries from natural hazard occurrences. These assessment factors are a necessity for creating maps that stakeholders use to determine local and state risk. Visually presenting natural hazard consequences to decision makers in this way provides a tool to distinguish between natural hazard types and the allocation of mitigation funding that should be given to each. Additionally, if these localized hazard maps are combined with graphical displays and charts, a user will be able to recognize trends over a given time period to see if implemented mitigation measures have achieved their goals in reducing losses. 


\subsubsection{MAP CREATION}

To begin developing hazard region GIS maps, a specific hazard type is downloaded from SHELDUS that contains loss data for every occurrence in the US over the past 50 years for that particular natural hazard. Before downloading the information from the website, the financial damages from hazard events are adjusted for inflation and put in terms of 2009 dollars. These hazard losses are then added to a spreadsheet and categorized by column. Each data entry generated by SHELDUS contains a date of occurrence and location by county in which the losses occurred. Each of the counties listed has a corresponding FIPS code that is needed to detect the location upon importing the data into GIS software. The FIPS code is a unique identifier for each county and is an essential piece for the GIS program. The FIPS code enables the software to relate the numbered item in the spreadsheet to a set boundary line and creates a polygon layer on top of the previously fixed county outline. Once all the FIPS codes are checked for location accuracy, the data are ready to be uploaded for the production of a GIS map.

There are several different desktop applications and web-based mapping tools available to generate GIS maps. For this study, the web-based platform called "Geocommons" was employed to create samples of two types of hazard region maps. The two hazard maps created as examples are specific to: earthquakes and hurricanes. These were chosen to illustrate hazard regions because they exhibit relatively large losses in the US and both of them primarily occur in distinct sections of the country.

For presentation purposes, the style editor is used to show the range of total consequences for each type of hazard on a color ranking scale. The two example maps created - earthquakes and hurricane hazard regions - are shown and described in the following section. 


\subsection{HAZARD REGION EXAMPLES}

\subsubsection{EARTHQUAKE HAZARD CONSEQUENCE: SAMPLE MAP}

The first sample GIS map shown in Figure 15-1 displays the total consequences due to earthquakes in states along the Pacific coast including: California, Oregon, and Washington. Each county has an associated range of consequences and is a sum of all earthquake losses recorded over a 50 year period (1960-2009). Counties with higher losses are shown in a dark red color and those counties with low consequences are a pale yellow. Counties in this region that do not have any color attributes do not have any recorded losses in the SHELDUS database. It should be noted that these counties without color should not be interpreted as being any safer than those with color. These maps should only be used to examine hazard occurrences, losses, trends, and address vulnerabilities within the built environment. Showing these locations by county enables mitigation planners to see the level of detail needed to understand the amount of impact that a particular hazard can have. When this information is incorporated into multi-hazard maps (discussed in section 15.4) and combined with population density and the social vulnerability index, it can help focus mitigation efforts in the areas with the most need. 


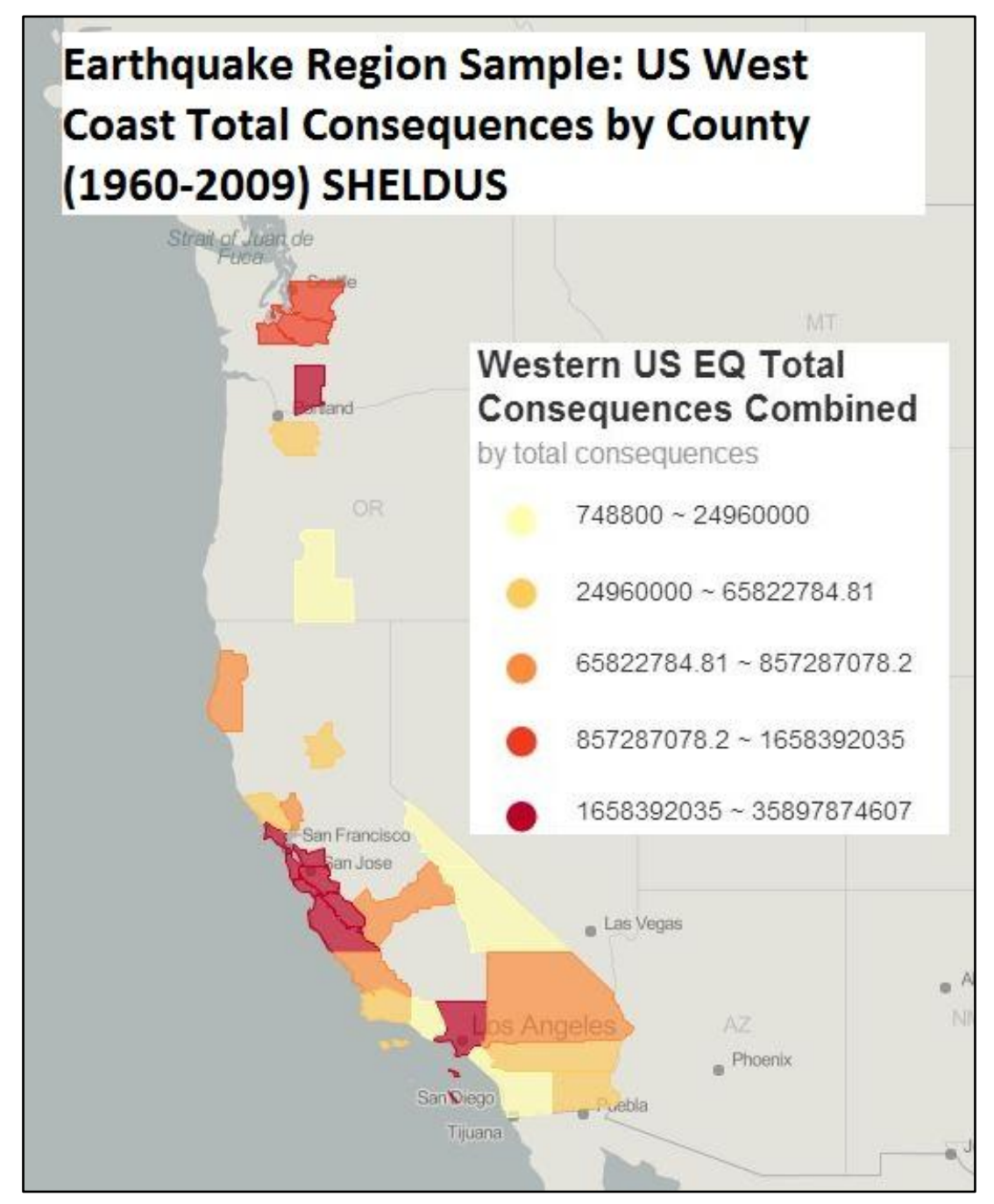

Figure 15-1: Earthquake Region Sample (GIS map)

\subsubsection{HURRICANE HAZARD CONSEQUENCES: SAMPLE MAP}

Similar to earthquake losses shown by county in the previous section, a sample map (in Figure 15-2) was created to show the distribution of losses from hurricanes in the state of South Carolina. This shows that the counties along the coastlines and with the highest populations have the largest total consequences over a 50 year time frame. This type of mapping should also be completed for all states along the Atlantic and Gulf coasts to see the extent of damages and trends of hurricane damage. These maps can also be used interactively to discover if mitigation 
efforts have helped reduce damages in storms over time, or see areas that continually have more damages than other counties with comparable infrastructure and population densities.

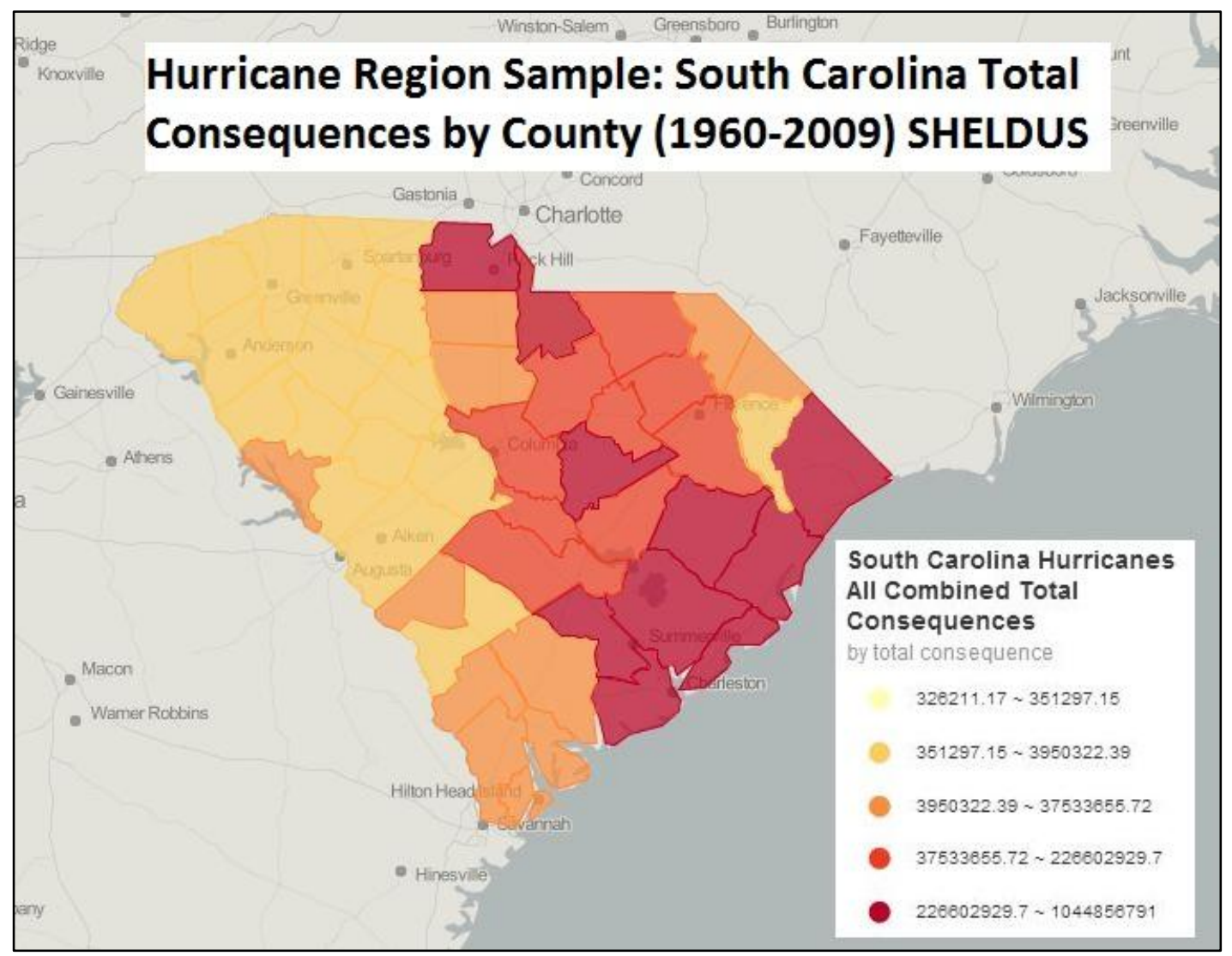

Figure 15-2: Hurricane Region Sample (GIS map)

\subsection{MULTI-HAZARD MAPS}

Once GIS maps are created for all 13 natural hazards, the concept for using these maps can be advanced further by overlapping all of the hazard region layers into what is termed 'multihazard' maps. These overlays contain the total consequences for every county in the US and can be summed together using the union operator function within GIS software. Aggregating these separate layers provides an additional tool for hazard mitigation planners. The planners can now show the consequences over time and create charts that present the percentage contribution of each hazard to the overall combined total. The user can examine separate layers to discover 
correlations and associations between different types of hazards. Furthermore, supplementary data layers such as population density and social vulnerability can be added to examine how their relationships influence the overall natural hazard consequences. The interactive display available on GIS mapping software permits the user to draw conclusions about various connections in a geospatial context, which would be difficult otherwise (USGS 2007). In the case of the earthquake hazard map presented, a comparison can be made between uniform design spectra maps created by USGS to the total consequences from previous documented earthquakes in the past 50 years. Did the previous earthquake magnitude and location conform to the range presented on the spectra maps? This question can be evaluated by comparing the two layers. Other comparisons can also be completed to see how the size and demographics of population in those areas contribute to those consequences. If a timing component utilized, then trends can be observed that gives a hazard manager a means to communicate to the public about potential future consequences, perhaps deterring development in higher risk areas and promoting more stringent infrastructure regulations.

The main motivation behind the creation multi-hazard maps comes from federal legislation passed in the year 2000. The US Disaster Mitigation Act (DMA), spearheaded by FEMA, amended the Stafford Act of 1988 in order to take a proactive approach to reducing damages, fatalities, and injuries by creating a program for pre-disaster mitigation (DMA 2000). The legislation requires communities to produce hazard-mitigation plans that incorporate multihazard maps. This includes completing hazard and vulnerability assessments so that prioritized mitigation funding can be dispersed to the areas that have the greatest vulnerabilities (Tate, Cutter and Berry 2010). 
Since this initial regulation passed in 2000 , there have been numerous research efforts in creating methodologies for assessing vulnerability through the creation of multi-hazard maps. Many of these include various metrics and factor analyses when generating GIS maps used for mitigation planning (Tate, Cutter and Berry 2010). The variety of strategies chosen by researchers and government personnel are due to the fact that the legislation does not provide any guidance on what the necessary procedures or standards are needed to be included in the assessments. This has caused many types of methodologies to be produced, and currently there still is not a consensus on an optimum approach to multi-hazard assessments (Simpson and Human 2008). A few illustrations on the differences between analyses are given to get a better understanding of the differences and commonalties.

Recently, in 2007, a statewide multi-hazard assessment was completed for Kentucky that had a mapping structure using a hazard vulnerability score system that incorporated exposure to hazards as well as frequency and area affected by the hazards. The exposure score given to hazards combined metrics such as population density, property values and social vulnerability indexing, while the hazard score relied on SHELDUS data to apply occurrence rankings to the natural hazards in the state (Simpson and Human 2008). Another study by Emrich and Cutter (2011) took separate natural hazard exposure data for the southeastern US and combined it with social vulnerability indexing factors to determine the overall vulnerability to the counties via creation of regional bivariate maps. Alternatively to these two previous methods, a study by Tate et al (2010) focused on one particular county in South Carolina to present an assessment methodology that included creating a list of the hazards that affect the area, incorporating the extent of damage that would be caused by each, and associating social vulnerability to the areas of exposure. 
Using many of the examples presented in studies such as these, this research proposes constructing a vulnerability assessment tool by creating a multi-hazard map that encapsulates the entire country. As previously stated in the opening paragraph of this section, this map will overlap the hazard layers and sum the total consequences by each of the counties in the US. After this is completed, the social vulnerability index available at HVRI will be supplemented in order for mitigation planners to see the susceptibility of populations have to natural hazards. These two elements of total consequences and vulnerability are to be combined into a bivariate map that provides a matrix color coded scale to measure where most of natural hazards consequences exist and compare that to the location of the most vulnerable populations.

\subsubsection{SOCIAL VULNERABILITY INDEX}

One of the common features that appear in many of the studies when creating multihazard maps is the empirically based social vulnerability index (SoVI). The intended use of SoVI is for the evaluation of environmental hazards in the US by incorporating the data into multihazard maps as a comparative metric (HVRI 2012). This index is utilized to convey the graphical variation of social vulnerabilities among counties in the US. It also demonstrates irregularities between population socioeconomic and demographic factors and relates them to their capacity to "prepare for, respond to and recover from hazards" (HVRI 2012). This is a powerful tool because it allows a user to compare and form causal relationships between population demographics and consequences from past hazard events. Displaying this information on a GIS map provides readily available information to make effective decisions on mitigation policies and helps communicate to the public why actions are being taken to reduce future losses.

The index contains 30 different socioeconomic and demographic factors that previous research suggests are measures of one's inability to resist and cope with natural hazard impacts 
(HVRI 2012). It also incorporates variables to relate to the built environment within counties. These factors are synthesized into a quantitative measurement by principal component analysis to gauge the social vulnerability in discrete areas of the US (HVRI 2012). The values that SoVI generates are typically displayed at the county level, but can also be reduced to census block areas for a refined level of detail. This is very beneficial to stakeholders and planners because they are able to see in advance which areas are most likely going to sustain the largest losses within a county before the next hazard occurrence and can prepare for them ahead of time. Once these areas are located, political measures can be introduced to provide funding to increase awareness of hazard consequences, plan safety and escape routes for citizens, or establish longterm mitigation plans for communities.

\subsection{DISCUSSION}

The generation of 'hazard regions' and their implementation into multi-hazard vulnerability assessments allows people to visually see calculated natural hazard risks in a meaningful way by displaying them in a geospatial context. Identifying vulnerable populations that are at risk to natural hazards provides a method for effective decision making and enables society to respond to future hazard situations and disasters (Emrich and Cutter 2011). By demonstrating areas where hazards have caused and have the potential for major losses, multihazard maps should be used to deter communities from building in high risk areas or motivate rehabilitation efforts for existing infrastructure at high risk.

Currently, there are already many states and jurisdictions that are becoming more aware of the natural hazard risks and are creating incentive programs to encourage mitigation practices. For instance, Berkeley, California was one of the first cities to create tax incentives for citizens 
that seismically retrofit buildings within the city (Chakos, Schulz and Tobin 2002). Collaboration between the municipal government and UC Berkeley developed building rehabilitation policies in order to reduce collective community risk to earthquakes by introducing a systematic approach for completing continual structural improvements to gradually eliminate all hazardous buildings in the city. This has been quite successful because there was significant community involvement and voters approved almost $\$ 400$ million in taxes to fund earthquake mitigation projects.

There are also other cases where natural hazard risks are being estimated dependent on descriptions of the building stock and the demographics of populations. For example, the state of South Carolina requires that all county and state mitigation plans incorporate components of the types of building construction and demographics into mitigation plans they approve (Tate, Cutter and Berry 2010). Additionally, many states that are beginning to create mitigation plans are basing their loss estimations on SHELDUS data to calculate the risks within their communities. Although SHELDUS data only displays direct losses from hazards, it gives the planners a tool to approximate future consequences. Some examples of government entities that are using hazard mapping and SHELDUS data are Sacramento County, CA; Shelby County, AL; and the State of Texas (HVRI 2012).

Additional considerations to improve mitigation plan methodologies can be gained by normalizing natural hazard loss data by the state or county population. Showing losses per capita enables them to be compared with other communities (Gall, Borden and Emrich 2011). Research by Gall et al (2011) evaluated the entire US utilizing this method and discovered trends by analyzing losses by decade. Final calculations from the study found that the average normalized 
losses per capita decreased for three decades between the 1960 s and 1980 s from $\$ 51$ to $\$ 43$. Then in the 1990 s and 2000s the figure increased dramatically to $\$ 82$ per capita.

The methods for analyzing natural hazard losses throughout the US are continuously evolving to better inform and educate communities about their risks. They are being displayed in graphs, charts and by the use of GIS technology in order to visually represent the data and provide a communication and analytical tool for mitigation planners. The multi-hazard vulnerability assessment map proposed in this study is just one of many ways to begin taking important steps forward in reducing the significant losses from natural hazard events. Once society comprehends the scope and locations of infrastructure vulnerabilities, communities can start the process of long-term mitigation projects that will slow the pace of natural hazard destruction and save many lives in the future. 


\subsection{CONCLUDING REMARKS}

This research demonstrates a new method of assessing natural hazard risk that provides a way to analyze data more comprehensively than current practices and promotes more informed mitigation decisions. Elements of risk perception are combined with objective risk for eight regions of the US to improve mitigation plans. Higher levels of risk perception are influenced by dread and familiarity and are related to the extreme events and number of occurrences displayed in the graphs. The more losses incurred and amount of people that are affected by extreme events lead to a greater distortion of risk. Consequently, funding and mitigation are often diverted to causes that are not necessarily the highest actual risk, but those that are perceived to be larger. While perceptions are important to take into consideration during decision-making processes, these perceived risks need to be set in a context that give a holistic view of natural hazard risk. The graphs recognize this aspect of risk perception in the size of the rings for each of the hazards and then a comparison is made between each of the natural hazard types to better communicate each hazard's actual risks. Seeing the risks in a graphical format such as this makes it easier to compare which hazards have higher risks relative to one another by compiling thousands of pieces of data into one display. These graphs and supplemental charts provide a way to put risks into perspective so that better mitigation strategies can be made and to allocate funding with respect to a hazard's impact on society in the long-term. Additionally, these graphs and charts aid stakeholder decision-making and provide a communication tool to inform the public about risks. The summary displays used to present the conclusions of this risk analysis create a way to 
visualize which hazards have the most negative consequences. Risk perception metrics are incorporated into analysis because they have an enormous influence on societal investments and the summary displays help align societal risk perceptions with objective risk. The inclusion of both quantitative measures and risk perception metrics allows prioritization of mitigation efforts specific to the region rather than just by subjective measures such as dread and familiarity.

A primary conclusion of the data analysis in this report is that separate mitigation plans need to be made for different types of hazard events. For example, low probability high consequence events need different mitigation plans than more frequent small loss events. By accounting for different types of hazard events, stakeholders will be able to develop long-term measures to improve building codes, construction quality, and land use decisions. These measures also should create awareness campaigns to motivate public preparation for potential devastating events. The data presented in the graphs and charts increase communication about the differences in expected losses and extreme losses and will help reduce misrepresentations of these risks. In order to create better long-term mitigation policies, society needs to recognize that cognitive processes are subjective, and through the use scientific tools, one can objectively analyze and effectively communicate risk.

In addition to the risk analyses performed, this study suggests developing hazard regions that focus and prioritize mitigation efforts in areas with the most need. Furthermore, GIS maps created for each type of hazard should be utilized to generate multi-hazard maps. Combining natural hazard consequence with social vulnerability locations has the potential to reduce future losses by revealing trends and populations susceptible to environmental hazards. Once these locations are recognized, focused mitigation efforts can begin reducing long-term risk for communities within the US. 


\subsection{FUTURE RESEARCH}

There are numerous ways to extend the research presented in this paper. For instance, the limitations on the damage estimates from natural hazard databases do not entirely reflect societal risk because they only represent direct damages from events. To better refine risk assessment, research should be completed to determine the extent of indirect losses after a natural disaster occurs and identify the main components that contribute to these losses. This will require an extensive case study from recent history that focuses on the secondary ripple effects that result from a particular disaster. This should involve factors such as population displacement, the amount of time businesses are closed, and lost wages due to injuries sustained from natural hazards. If case studies are completed for several disasters, then it might be possible to produce a scale of indirect loss totals and apply a scaling factor to the estimated direct losses in order to provide a better depiction of risk. This can have a profound effect for estimating future natural hazard risks and enable local and state preparation for future natural disasters.

Further explorations should incorporate risk perception as a metric when creating multihazard maps. Currently, a social vulnerability layer is added to these maps to see locations that are most affected by natural hazards. Supplementing these maps with an additional layer representing risk perception can determine if areas with higher risk perceptions are better prepared for natural disasters than those with lower risk perceptions. That is, do the areas with higher risk perceptions tend to have smaller overall losses than those that do not? This builds upon a previous study completed by Hurley (2013) that represented risk perception by dread and familiarity measurements. If the risk perception measurement is graphed within a geospatial 
context, then the social-psychological dimension can be visually analyzed alongside with vulnerabilities and previous natural hazard consequences. 


\section{Bibliography}

Applebaum, Binyamin. "A Life's Value? It May Depend on the Agency - Dollar Figure is Rising, to Varying Degrees." New York Times 17 February 2011.

Berke, Philip and Gavin Smith. "Hazard Mitigation, Planning, and Disaster." Paleo, Fra. Building Safer Communities: Risk Governance, Spatial Planning and Responses to Natural Hazards . Amsterdam: IOS Press, 2009. 1-20.

Blake, Eric and Ethan Gibney. THE DEADLIEST, COSTLIEST, AND MOST INTENSE UNITED. Technical Memorandom. Miami: NOAA, 2011.

Bureau of Economic Analysis. 19 December 2012. 10 February 2013 <http://www.bea.gov/regional/index.htm>.

Bureau, US Census. US Census Bureau. April 2011. 11 March 2013 <http://www.census.gov/>.

Center, Southern California Earthquake. The Great California Shake Out. 2013. 28 March 2013 $<$ http://www.shakeout.org/california/>.

Chakos, Arrietta, Paula Schulz and Thomas Tobin. "Making It Work in Berkeley: Investing in Community Sustainability." ASCE Natural Hazards Review 3.2 (2002): 55-67.

Cleary, Sean. "Cognitive constraints and behavior biases." Kunreauther, Howards and Michael Useem. Learning from catastrophies. Upple Saddle River: Wharton School Publishing, 2010. 74-75.

Coakley, Caitlin E, Daniel A Reed and Shane T Taylor. "Gross Domestic Product by State." Annual Bureau of Economic Analysis GDP Report. 2009.

Cutter, Susan, et al. "The U.S. Hurricane Coasts: Increasingly Vulnerable?" Environment: Science and Policy for Sustainable Development 49.7 (2007): 8-21.

Cutter, Susan, Jerry Mitchell and Michael Scott. "Revealing the Vulnerability of People and Places: A Case Study of Georgetown County, South Carolina." Annals of the Association of American Geographers 90.4 (2000): 713-737.

"DMA 2000." Disaster Mitigation Act of 2000. Washington D.C.: 106th Congress, 30102000.

DOE. Wikipedia. 24 July 2009. 6 February 2013

<http://en.wikipedia.org/wiki/File:US_DOE_Rgns.png>.

Drabek, Thomas. The Human Side of Disaster. Boca Raton: The Human Side of Disaster Book, 2009.

Emrich, Chris and Susan Cutter. "Social Vulnerability to Climate-Sensitive Hazards in the Southern United States." Weather, Climate, and Society 3.3 (2011): 193-208. 
FEMA 592. "Robert T. Stafford Disaster Relief \& Emergency Assistance Act, as amended, and Related Authorities." Government. 2007.

FEMA. "A guide to the disaster declaration process and federal disaster assistance." n.d. Federal Emergency Management Agency. 9 February 2013 <http://www.fema.gov/pdf/rebuild/recover/dec_proc.pdf>.

-. FEMA Enterprise GIS Services. 30 April 2010. 8 February 2013 <http://gis.fema.gov/>.

—. "Mitigation Value to Society." Mitigation Value to Society: Fact Sheet. Washington D.C.: FEMA, May 2007.

Fischhoff, Barauch and John D Kadvany. Risk: A very short introduction. Oxford: 2011, 2011.

Gall, Melanie, et al. "The Unsustainable Trend of Natural Hazard Losses in the United States." Sustainability 3.11 (2011): 2157-2181.

Haimes, Yacov Y. Risk Modeling, Assessment, and Management. New York: John Wiley \& Sons, Inc., 1998.

Hurley, Maura and Ross Corotis. "Perception of Risk of Natural Hazards: A Hazard Mitigation Plan Framework." International Journal of Risk Assessment and management (2013): In Print.

HVRI. SHELDUS: Selected Applications of the Usage of SHELDUS. 4 September 2012. 15 March $2013<$ http://webra.cas.sc.edu/hvri/products/sheldusapps.aspx>.

- The Spatial Hazard Events and Losses Database for the United States, Version 7.0 [Online Database]. 2009. July-March 2012-2013 <Available from http://www.sheldus.org>.

Jones, J.M. and R.B. Corotis. "The Regional Consequences of Individual Natural Hazard Events." International Journal of Risk Assessment and Management 16.1 (2012): 78-111.

Kahneman, D. and A. Tversky. Editors, Choices, Values, and Frames. Cambridge: Cambridge University Press, 2000.

Keller, C., M. Siegrist and H. Gutscher. "The Role of the Affect and Availability Hueristics in Risk Communication." Risk Analysis, 26(3) (2006): 631-639.

Kellogg, Becky. The Weather Channel: 2012 Natural Disasters Spur \$160 Billion Price Tag. 3 January 2013. 22 January $2013<$ http://www.weather.com/news/costly-disasters20130103>.

Kerjan, M. and P. Slovic. The Irrational Economist. New York: Public Affairs, 2010.

Kluger, Jeffrey. "Why we worry about the things we shouldn't... ...And ignore the things we should." Time 26 November 2006: 64-71.

Kunreuther, H and E. Michel-Kerjan. "Overcoming Myopia." The Milken Institute (2010). 
Kunreuther, Howard and Michael Useem. "Principles and Challenges for Reducing Risks from Disasters." Kunreuther, Howard and Michael Useem. Learning from Catastrophes: Strategies for Reaction and Response. Upper Saddle River: Whaton School Publishing, 2009. 1-13.

Lerner, J.S., et al. "Effects of fear and anger on perceived risks of terrorism: A national field experiment." Psychological Science (2003): 144-150.

Locsin, Aurelio. USA Today. n.d. 28 January $2013<$ http://traveltips.usatoday.com/air-travelsafer-car-travel-1581.html>.

Mileti, Dennis. Disasters by Design: A Reassessment of Natural Hazards in the United States. Washington, D.C.: Joseph Henry Press, 1999.

Nafday, Avinash M. "Strategies for Managing the Consequences of Black Swan Events." Leadership and Management in Engineering (2009): 197-197.

Niedek, Inge. "The Role of Media in Public Communication of Early Warning Systems." Zschau, Jochen and Andreas Kuppers. Early Warning Systems for Natural Disaster Reduction. Berlin: Springer, 2003. 74.

NOAA. Extreme Weather 2011. 19 January 2012. 12 March 2013 <http://www.noaa.gov/extreme2011/index.html>.

-. National Coastal Population Report: Population Trends from 1970 to 2020. 26 March 2013. 28 March $2013<$ http://oceanservice.noaa.gov/facts/population.html>.

-. National Oceanic And Atmospheric Administration:News. 17 August 2011. 22 January 2013 <http://www.noaanews.noaa.gov/stories2011/20110817_weatherready.html>.

NPRG. National Partnership for Reinventing Government Library. 20 January 2001. 21 March 2013 <http://govinfo.library.unt.edu/npr/library/index.html>.

Ripley, Amanda. The Unthinkable: Who survives when disaster strikes and why. New York: Crown, 2008.

Rose, Adam, et al. "Benefit-Cost Analysis of FEMA Hazard Mitigation Grants." 6 December 2006. 11 March 2013 <http://bechtel.colorado.edu/ porterka/Rose-et-al-2007-NHRBCA.pdf>.

Simpson, David and Josh Human. "Large-scale vulnerability assessments for natural hazards." Natural Hazards 47.2 (2008): 143-155.

Slovic, P., et al. "Risk as Analysis and Risk as Feelings: Some thoughts about Affect, Reason, Risk, and Rationality." Risk Analysis 24(2) (2004): 311-322.

Slovic, Paul and Elke U. Weber. "Perception of Risk Posed by Extreme Events." Risk Management Strategies in an Uncertain World. Palisades, 2002. 1-21. 
Slovic, Paul and Ellen Peters. "Risk Perception and Affect." Current Directions in Psychological Science (2006): 322-325.

Slovic, Paul. The Perception of Risk. London: Earthscan Publications Ltd, 2000.

Smith, Gavin. "Hurricane Sandy makes an entrance." Natural Hazards Observer January 2013: 115.

Tate, Eric, Susan Cutter and Melissa Berry. "Integrated multihazard mapping." Environmental and Planning B: Planning and Design 37.4 (2010): 646-663.

Tierney, Kathleen J, Michael K Lindell and Ronald W Perry. Facing the unexpected: Disaster Preparedness and Response in the United States. Washington, DC: Joseph Henry Press, 2001.

US Census Bureau. Population Density for Counties and Puerto Rico Municipios. 1 July 2011.6 February $2013<\mathrm{http}: / /$ www.census.gov/popest/data/maps/2011/County-Density11.html>.

USGS. Geographic Information Systems. 2007 February 2007. 2 March 2013 <http://egsc.usgs.gov/isb/pubs/gis_poster/>.

Viscusi, W Kip. "The Value of Life: Estimates with Risks by Occupation and Industry." Economic Inquiry 42.1 (2007): 29-48.

Vrijling, J.K., W. Van Hengel and Houben R.J. "Acceptable risk as a basis for design." Reliability Engineering \& System Safety 59.1 (1998): 141-150.

Wilson, Ronald and Timothy Brown. "The Use of Bureau of Economic Analysis (BEA) Areas and Regions for Representing Geographic Variation." Paper. 2012. 